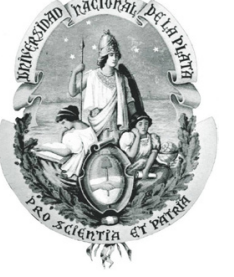

Universidad Nacional de La Plata Facultad de Ciencias Naturales y Museo

\title{
Estudio de LA Diversidad FÚngICA EN TURBERAS COMPACTAS del Sur de TierRa del Fuego
}

Tesis presentada para optar al Título de Doctor de la Universidad Nacional de La Plata en el Área de Ciencias Naturales

\section{Noelia Ivana Paredes}

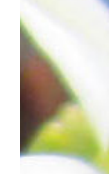

Director De Tesis: Dr. Marcelo Barrera

Codirectora: Dra. Verónica A. Pancotto

Lugar De Trabajo: Laboratorio De Ecología Terrestre,

Centro Austral De Investigaciones Científicas (Cadic-Conicet)

La Plata, 2015 
'And / think my spaceship knows which way to go'.

(Space Oddity de David Bowie) 


\section{ESTUDIO DE LA DIVERSIDAD FÚNGICA EN TURBERAS COMPACTAS DEL SUR}

\section{DE TIERRA DEL FUEGO}

Las turberas fueguinas representan la concentración más austral de turberas en el mundo y se caracterizan por albergar comunidades de gran valor ecológico, como resultado de las condiciones climáticas y biogeográficas en las que se desarrollan. El conocimiento de la diversidad microfúngica en estos ambientes es escaso. Por lo tanto, la presente Tesis Doctoral tiene como objetivo principal caracterizar y analizar la composición y la diversidad de la comunidad de hongos microscópicos presentes en turberas compactas de Astelia-Donatia en situaciones geográficas disímiles, su vinculación con las variables ambientales, la profundidad y su importancia en la descomposición de la materia orgánica. Se determinaron y compararon rasgos físico-químicos de dichas turberas y se observó que los mismos resultaron similares. Ambas turberas están sometidas a las mismas condiciones de $\mathrm{pH}$ muy ácido (aprox. 4), bajas temperaturas $\left(2-5^{\circ} \mathrm{C}\right)$ y acumulan turba con altos contenido hídrico y de carbono (más del $90 \%$ ) y bajo contenido de nitrógeno (menos del $4 \%$ ). Previo al abordaje de la diversidad, se evaluó la eficacia de tres metodologías clásicas de cultivo y aislamiento fúngico. Es así que la técnica de lavado de partículas de suelo mostró ser la más eficiente y adecuada para aislar microhongos presentes en muestras de turba. A partir de 80 muestras de turba, se obtuvieron 3.255 aislamientos fúngicos que correspondieron a 9 géneros (Aureobasidium, Beauveria, Botryosporum, Cladosporium, Mortierella, Mucor, Parasterinella, Penicillium, Trichoderma) y 19 especies de Hyphomycetes, representados principalmente por las Subdivisiones Ascomycotina y Zygomycotina; siendo mayor el número de Ascomycetes. Las especies más frecuentes fueron Aurebasidium pullulans, Beauveria bassiana, Mortierella alpina, Penicillium frequentans y Trichoderma viride. Con la implementación de metodologías moleculares se identificaron 30 micelios estériles que correspondieron a las especies Tolypocladium cylindrosporum, T. inflatum, Fusarium culmorum y un hongo perteneciente a la clase Leotiomycetes (ectomicorriza no

cultivable), que al presentar requerimientos de cultivo diferentes no habían sido aisladas con las metodologías clásicas. La mayoría de las especies presentan una distribución geográfica muy amplia y corresponden a la microcarga normal de turberas y conforman una comunidad cuya 
estructura (riqueza) es simple, con una diversidad de nivel medio y presentan cierta homogeneidad con respecto su distribución. Es decir, que el número, tipo y frecuencia de especies no varió con respecto al tipo de sustrato, la profundidad de muestreo y la ubicación geográfica. Por otra parte, las muestras no presentaron un ordenamiento acorde a la composición de especies, discriminando según los tipos de sustrato y la temporada de muestreo. Sin embargo, los hongos microscópicos se organizan y responden a las variables ambientales, y si éstas se mantienen homogéneas y estables resulta probable que sus microorganismos asociados sigan la misma tendencia. Finalmente, se evaluó la habilidad degradativa de 4 microhongos más frecuentemente aislados y la influencia de la temperatura y el tipo de sustrato sobre esta actividad. Los resultados mostraron que las 4 cepas presentan una mayor habilidad para descomponer turba de Sphagnum con respecto a Astelia y esta actividad se incrementa con el aumento de la temperatura de incubación. Los resultados expuestos en este trabajo representan una gran base de información de los hongos microscópicos de turberas compactas de Astelia-Donatia, y además, generan nuevas posibilidades de investigación vinculadas con su funcionalidad en estos ambientes.

Palabras clave: turberas, turbera compacta deAstelia-Donatia, diversidad fúngica, hongos microscópicos, decomposición in vitro. 


\section{FUNGAL DIVERSITY STUDY FROM CUSHION PEATLANDS IN THE SOUTHERN}

\section{PART OF TIERRA DEL FUEGO}

Peatlands of Tierra del Fuego represent the southernmost concentration of peatlands in the world. They host communities with high ecological value as a result of climatic and biogeographical conditions in which they develop. The knowledge about the diversity of microscopic fungi in these environments is scarce. Therefore, the main objective of this $\mathrm{PhD}$ thesis is to characterize and analyze the composition and diversity of the community of microscopic fungi present in AsteliaDonatia cushion bog with dissimilar geographical locations, its relations with environmental variables, depth and its importance in the decomposition of organic matter. Physicochemichal features were registered in both peatlands. The results showed that both studied peatlands are subjectedt to the same environmental conditions such as very acidic $\mathrm{pH}$ (approximately 4 ), low temperature $\left(2-5^{\circ} \mathrm{C}\right)$ and high carbon and water content (over than $90 \%$ ) and low nitrogen concentration (less than $4 \%$ ). In order to address the composition of the community, the efficiency of three classic methods of fungal cultivation and isolation was evaluated. Washing soil particles method resulted the most efficient and suitable technique for the isolation of microfungi on peat samples. From 80 peat samples, 3.255 fungal isolates were obtained and corresponded to 9 genera (Aureobasidium, Beauveria, Botryosporum, Cladosporium, Mortierella, Mucor, Parasterinella, Penicillium and Trichoderma) and 19 species of Hyphomycetes, which were mainly represented by Ascomycotina and Zygomycotina Subdivisions. The number of Ascomycetes was greater than Zygomycetes. Aureobasidium pullulans, Beauveria bassiana, Mortierella alpina, Penicillium frequentans and Trichoderma viride were the most common species. Thirty sterile mycelia were identified using molecular approaches, as they need special requirements for cultivation using classic methodology. These mycelia correspond to Tolypocladium cylindrosporum, T. inflatum, Fusarium culmorum and a fungus belonging to Loetiomycetes Class (uncultured ecotmychorrhiza). The isolated species have a very wide distribution, they are commonly found in peat microfungi community, which has a simple structure (richness) with a medium diversity and homogeneous distribution. Hence, the number, type and frequency of species were not influenced by type of substrate, sampling depth and geographic location. Moreover, there was not a clearly arrangement between samples according to species composition, or by discriminating type of substrate and sampling season. However, microfungi organize and respond to environmental 
variables, and if the environment remain stable it is likely that their associated microorganisms follow the same trend. Finally, the degradative ability of the 4 most frequently isolated microfungi and the influence of temperature and substrate type on this activity was evaluated. The results showed that the 4 strains decompose Sphagnum more efficiently than Astelia peat, and this activity increase with temperature of incubation near $20^{\circ} \mathrm{C}$. The results presented in this study are part of a starting point of information about microscopic fungi from Astelia-Donatia cushion peatlads, and also generate new researching possibilities related to its functionality in these environments.

Key words: peatlands, Astelia-Donatia cushion bogs, fungal diversity, microscopic fungi, decomposition in vitro. 


\section{AGRADECIMIENTOS}

Al terminar de escribir la tesis y siendo consciente de que falta un solo mínimo paso para recibir el título de Doc, seguramente el primer pensamiento de todo becario es 'se cierra una etapa'. Pero... ¡yo no lo pienso y tampoco lo siento así!... No me sale decir que terminó 'algo'. ¡Todo lo contrario! Me brota sonreír y decir que caminé un montón (porque esto arranca desde el día en que me fui a vivir a Mardel a estudiar para la Lic.), que volví a la isla que guarda mi casa pero no para cerrar una etapa, sino para seguir descubriendo la misma: la de ser bióloga. Podrá tener nuevos recovecos o nuevos caminos que seguramente me van a llevar a aprender y saber mucho más, pero lo más importante es que no se cierra.

La tarea de ser cada día un poquito mejor biólogo, ipor suerte!, no se aprende solo, y la tarea de ser cada día un mejor humano, jtampoco! Siempre digo y defiendo que son dos tareas que van hermanadas y que tienen que crecer en conjunto para poder llegar siempre a buenos lugares y que todo marche bien. Tengo la suerte de haber conocido y de haber recibido el cariño, la compañía, las sapiencias (académicas y humanas), el aguante, la solidaridad, la amistad de muchas personas que en distintos momentos me brindaron su estar y su ayuda desinteresada para que yo pudiera lograr todo lo que me propuse (iy aun más!). Porque lo repito otra vez, pero de otra manera... ¡Uno no llega adonde llega, ni es lo que es, solo! Sino con la ayuda de un montón de personas que con mucho o poco te motivan, te acompañan, te toleran, te esperan, te empujan... Esas personas son las que hoy se merecen un GRACIAS enorme con todo mi corazón y están en la lista que sigue a continuación.

A mi directora y mamá científica, la Dra. Angélica Arambarri: Vasca, que me recibió con una sonrisa desde que estaba terminando la licenciatura y porque aún me sigue guiando con su luz. Sus risas, su compañía, sus abrazos, su cariño, sus consejos, su ayuda desinteresada y su estar tan incondicional siguen y seguirán vivos y presentes en mí siempre.

A mi codirectora por segunda vez, la Dra. Verónica Pancotto por aceptar ser parte de este nuevo escalón en mi camino como bióloga, por su tolerancia y su paciencia para guiarme en mi trabajo, por todos los consejos y el tiempo que le dedicó a mi aprendizaje y por sobre todo por aceptar que aprendamos juntas un poco más del ambiente que tanto nos gusta a ambas.

A mi directora, la Dra. Fabiana Consolo, por estar nuevamente como una de mis guías principales en mi formación como bióloga, porque todo mi aprendizaje de laboratorio y el toque 
artesanal de este trabajo lo aprendí de sus manos y su paciencia, por contagiarme la curiosidad y el interés para redescubrir siempre el mundo fúngico, por sus consejos y por todo el cariño que siempre recibí.

A mi director, el Dr. Marcelo Barrera, por abrir sus brazos y su corazón en el momento más difícil de este doctorado, por aceptarme, por brindarme siempre su apoyo desinteresado, por compartir tan didáctica y pacientemente sus saberes, por tener siempre las palabras analgésicas justas y por sobre todo por tener siempre la sonrisa y el consejo pronto para motivarme a seguir siempre adelante y sin bajar los brazos.

A mi humano preferido, mi mamá, por la vida, por darme la libertad y el apoyo incondicional de elegir mi camino, por enseñarme la primera tarea de mi vida: ser una buena persona, por su amor, por sus mimos a tiempo, por su presencia en todos y cada uno de los momentos de mi vida.

A mi gota de agua, mi hermano Tavo, por acompañarme y contenerme a la distancia, por abrazarme siempre el corazón, por toda la motivación, y por todos los “iRompela, Mister!" que siempre me animaron a tener las ramas bien arriba.

A mis hermanos del Spegazzini Ana, Mario, Marta, Lore, Sil, Ceci, Clara, Seba, Mónica, Agos, Romi, por recordarme siempre que "somos hermanos de la misma mamá: Vasca" y hacerlo presente en cada una de las ayudas que recibí en todo momento, por enseñarme, guiarme y compartir sin condiciones todo lo que saben, porque a pesar de los kilómetros que nos separan su cariño y su estar incondicional estuvieron siempre prontos para hacer que mis brazos se mantengan bien arriba y con una sonrisa, porque realmente los siento mis hermanos en la ciencia.

Al Dr. Cristian Fritz, por acompañarme en mis primeros pasos, por compartir siempre todo su trabajo, por sus consejos, por el ánimo y la motivación que recibí de su parte, aun estando a un océano de distancia, por poner fichas en mí, por toda su cordialidad y sobre todo por ser un alemán muy buena onda y compañero.

A mi familia platense Gri, Loba, Leah, Toto y Naty por abrir las puertas de sus corazones para recibirme y acompañarme en los momentos de más trabajo, por brindarme sus abrazos familieros, por las charlas, las comilonas, las salidas, los llantos, las risas y por sobre todo, por el amor que sentí siempre mientras estuve lejos de mi hogar. 
A mi amiga Mariela (Gremlin), por hacerme siempre un lugarcito en sus días plantenses, por todas las horas que pasamos acomodando el mundo en charlas y risas, por ser siempre verdadera y tan buen amiga.

A Lucha, Noe y Peyton que fueron las primeras en brindarme el calor de su hogar, su amistad y me apoyaron en mis primeras idas a La Plata y porque lo compartieron todo conmigo durante mi primer etapa de trabajo.

A mi querido Polillo platense por hacerme un huequito en su hogar y en su vida, por haberme hecho sonreir en los momentos más extraños, y por sobre todo por ser uno de los humanos más cope y divertidos conmigo a pesar de tener siempre presente mis estados de locura.

A mi compañero de camino y gira en esta vida Rockanruler (Nahuel) por la incondicionalidad en todo, por las palabras cacheteadoras a tiempo, por bancarse mis pedidos a distancia, por compartir su nicho (incluye casa, gustos musicales, hábitos, comidas, salidas), por ser uno de mis biólogos preferidos y porque en los momentos más complicados siempre recibí el pogo mental necesario para mirar las cosas de otra manera y seguir.

A Lagarten (Gabi), por todo el amor, la tolerancia y la espera; por enseñarme a ser fuerte, a quitarme las estructuras que no llevan a ningún lado y a escalar y esquivar todos los muros que se presentaron en mi camino; por enseñarme a ver y disfrutar mi lado artístico y divertido; por las palabras suaves y de aliento siempre a tiempo, por darme todas las herramientas que pusieron en marcha mi nave para viajar y soñar, por animarme a buscar lo que me hace feliz, por ayudarme a no tener miedo y por sobre todo por enseñarme todos los días a ser un mejor humano.

A mis concubinos de oficina: Leo, Erika, Princess, Sole, Seba, Diego, Pau y Lucho, por hacerme reír mucho en los descansitos oficinísticos; por compartir sapiencias, juntadas, consejos; pero por sobre todo por la paciencia y bancarme mi poca simpatía en los momentos más tensos y de nervios.

A mis compañeros de trabajo y de Lab: Alicia, Julio, Jaz, Caro, Vero, Romi, Sole, Luciano, Naty, por hacerme un lugar en el laboratorio, por confiar en mí, por la ayuda y el interés en mis progresos, por los consejos, por hacer amenas y productivas las salidas de campo, por estar siempre a mi lado en todo lo que necesité. 
A los micólogos de los que aprendí nuevas cosas y compartí mucho más que saberes fungísticos: Luchi Silvestro, Vale de los palos (Vale Silva), Virginia Moreno, Silvana Velázquez, Mario Saparrat, Marta Cabello, Lorena Elíades; porque dieron siempre lo mejor de sí para ayudarme en todo lo que necesité.

A mis amigas y hermanitas mayores, las doctoras Solecín y Chakis, por sus palabras, por sus consejos, por las mechoneadas de cabello necesarias, por compartir más que el trabajo, porque siempre estuvieron con la oreja y los brazos dispuestos cada vez que lo necesité, por aceptarme así con mis locuras y mis rayes y hacerme siempre el aguante y quererme mucho.

A mi amiga y compañera de Rocky-ada fueguina, Colombian-Falcao (Eri), por enseñarme y brindarme siempre la calidez de su corazón colombiano, por compartir mucho más que la ofi, por ser mi humano gasolero de risa preferido, por las orejas, los llantos, las risas, los aguantes mutuos que compartimos sobre todo este último año tan difícil para las dos.

Al Dr. "Niño.que.lo.sabe.todo" (Leo-Rockola) por lo verdadero y puro de su amistad, por tener la cachetada acomodadora de ideas lista para ponerme en rumbo, por brindarme siempre su "amor amiguil" cada vez que lo necesité, por hacerme reír con cada una de sus ocurrencias y por ser un humano tan sincero, aniñado y genial.

A mi amigo el Dr. Joan (Juan Negro), por todas las charlas y terapias que hicimos juntos caminando y merendando, por todo su apoyo incondicional, por ser un amigo empático, sensible y siempre dispuesto a brindarlo todo.

A mi amiga y compañera de ruta, Ratón2 (Ceci), por acompañarme y defenderme con tus "yo te banco por la ecología de poblaciones", por ser parte de la gente linda que camina a mi lado en mi vida de bióloga, por compartir actividades y diversiones extra trabajo y por compartir golpes, rodadas y risas en la pista.

A mi amiga y jefa de la Antártida (Euge), por los almuerzos compartidos, por los abrazos en el momento justo, por escuchar, por el aguante aun cuando estuve de un humor tremendo, y por estar siempre dispuesta a ayudar.

A mi hermanita de camino, Lau Villarreal, por la gran empatía que sentimos siempre la una con la otra, por abrazar mi corazón cuando lo necesité, por sus palabras animadoras y dulces y por estar presente desde los detalles más pequeños y necesarios. 
A mis compañeros de ruta, los Comarqueños: Pao, Pili, Merri, Darío, Pablito, Ari, Celi, Cholo, Clarits, Luis, por compartir muchas horas de risa, por la empatía y el aguante mutuo en todo.

A la Universidad Nacional de La Plata por darme la oportunidad de educarme y formarme como bióloga de una manera libre y gratuita.

Al Centro Austral de Investigaciones Científicas y al CONICET por recibirme y brindarme el apoyo, la infraestructura y el financiamiento para poder hacer mi doctorado.

A todas aquellas personas con las que me crucé en este caminar y que desde distintos lugares y situaciones me brindaron su apoyo en detalles y cosas pequeñas que también fueron sumando muchísimo para que yo llegue hasta acá. 
A mi humano preferido en el mundo: MI MAMÁ.

A mi tierna y dulce madre científica: VASCA. 
La finalidad de la presente tesis es aumentar el conocimiento del ensamble fúngico de las turberas compactas de Astelia-Donatia de Tierra del Fuego, evaluando su distribución y funcionalidad en estos ecosistemas. Dicha información se expone en 5 capítulos, que serán descriptos a continuación.

En el primer capítulo se presenta el marco teórico de este trabajo y también, información general sobre las turberas fueguinas con especial interés en las turberas que han sido elegidas como áreas de estudio (turberas compactas de Astelia-Donatia).

Las temáticas abordadas en los capítulos segundo, tercero y cuarto involucran la utilización de metodologías propias y presentan implicancias particulares, por lo tanto el contenido de ambos se presenta en capítulos separados, incluyendo cada uno su introducción, metodología, resultados y discusión.

El segundo capítulo presenta las características físico-químicas principales de las turberas compactas elegidas para la realización de esta tesis. Por lo tanto, se registraron y compararon estas variables en dos turberas compactas con situaciones geográficas diferenciales (una turbera cercana a la costa y otra, en zona montañosa) y en presencia de dos tipos de cobertura vegetal (Astelia y Sphagnum).

En el tercer capítulo se exploró la distribución de los Hyphomycetes presentes en turberas compactas fueguinas, evaluando al mismo tiempo distintas metodologías clásicas de aislamiento y cultivo. Además se analizaron y compararon la composición y la diversidad de la comunidad fúngica en las turberas en estudio y teniendo en cuenta la profundidad de muestreo y la cobertura vegetal. También se analizó la respuesta temporal y espacial de los hongos a diferentes variables ambientales, relacionando las mismas con la frecuencia de las especies

Los resultados obtenidos en el capítulo anterior sirvieron de base para realizar un experimento de descomposición utilizando las cuatro especies fúngicas aisladas con mayor frecuencia de las turberas compactas fueguinas. Por lo tanto en el cuarto capítulo se exhiben los resultados obtenidos a partir de evaluar y comparar la descomposición in vitro de cuatro especies fúngicas microscópicas nativas de turberas compactas. 
En el quinto capítulo se presenta una síntesis de los diversos conocimientos obtenidos, se discuten los resultados globales más relevantes, y, por último, se resaltan las posibilidades de investigaciones futuras que se derivan de toda la información expuesta en esta tesis.

Finalmente se cita la bibliografía consultada y analizada en la tesis. 
CONTENIDOS

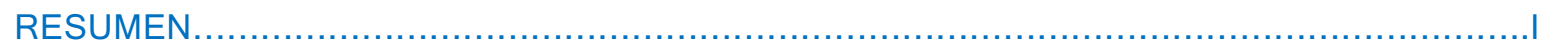

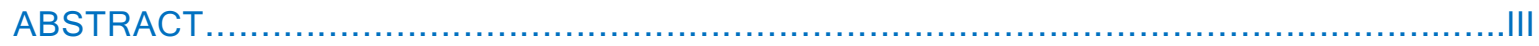

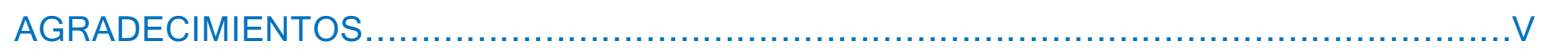

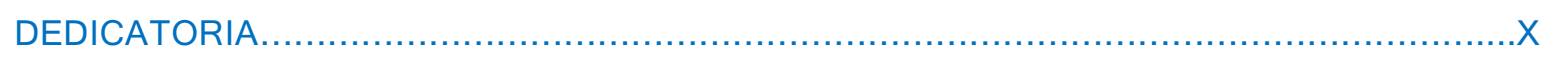

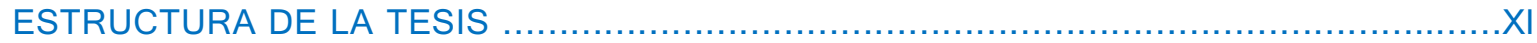

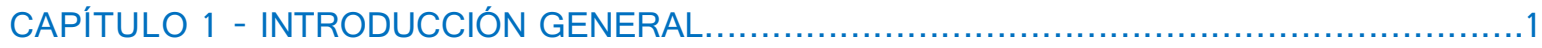

CAPÍTULO 2 - DESCRIPCIÓN DEL ÁREA Y CARACTERIZACIÓN DE LAS TURBERAS EN

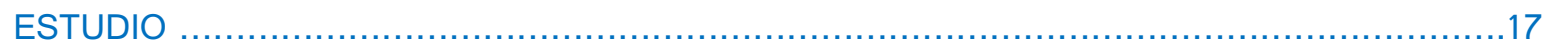

CAPÍTULO 3 - MICROHONGOS DE TURBERAS COMPACTAS EN TIERRA DEL

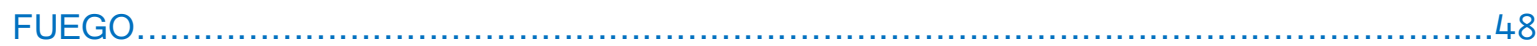

CAPÍTULO 4-MICROCOSMOS: DESCOMPOSICIÓN IN VITRODE TURBA POR MICROHONGOS NATIVOS DE TURBERAS COMPACTAS FUEGUINAS .........................114

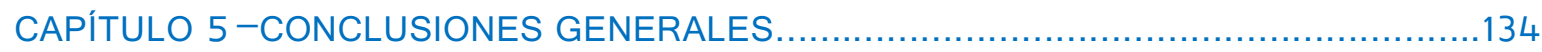

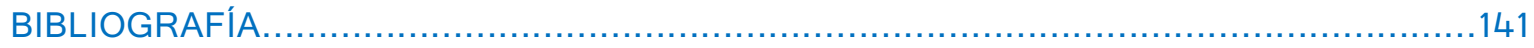

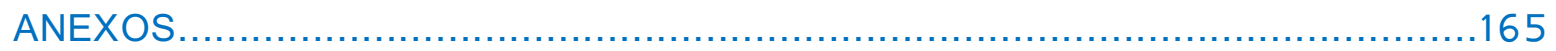




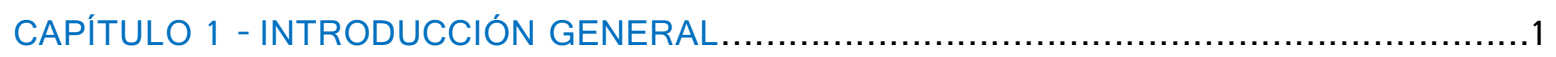

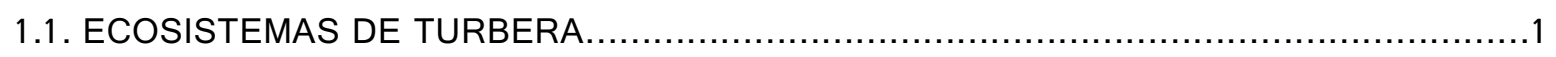

1.1.1. Clasificación de las turberas............................................

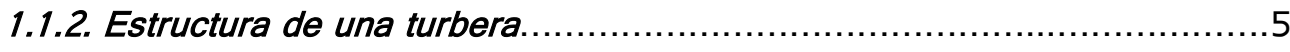

1.1.3. Importancia de las turberas...............................................6

1.2. DESCOMPOSICIÓN Y CICLO DEL CARBONO EN TURBERAS ...............................

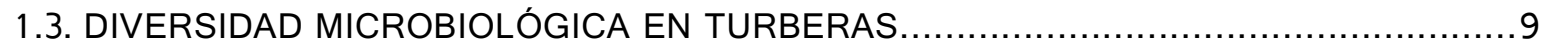

1.4. ESTUDIO DE HONGOS MICROSCÓPICOS EN TURBERAS ....................................11

1.5. ANTECEDENTES ED ESTUDIOS MICROBIOLÓGICOS Y FÚNGICOS

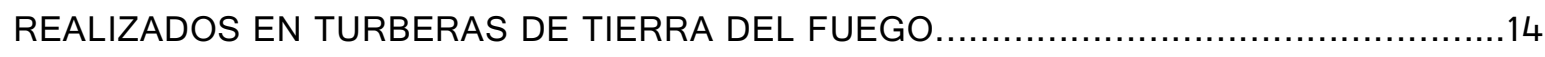

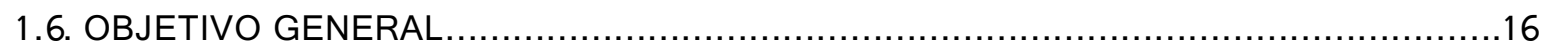

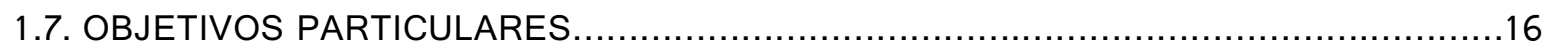

CAPÍTULO 2 -DESCRIPCIÓN DEL ÁREA \& CARACTERIZACIÓN DE LAS TURBERAS EN

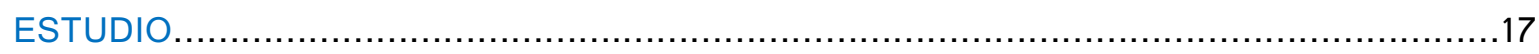

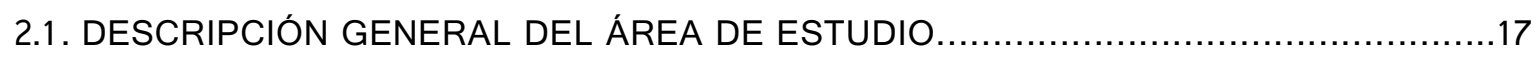

2.1.1. Situación geográfica........................................................17

2.1.2. Geomorfología...........................................................17

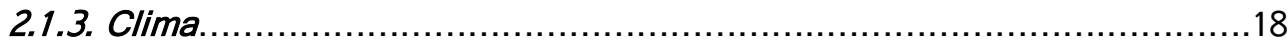

2.1.4. Vegetación ..................................................................... 20

2.1.5. Características y particularidades de Astelia pumila........................22

2.1.6. Turberas de Astelia con agua..............................................24

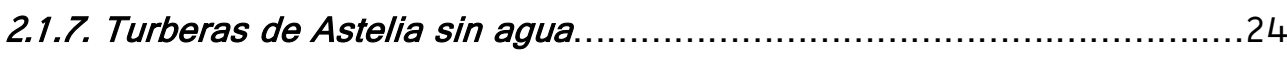

2.1.8. Sitios de estudio....................................................... 25

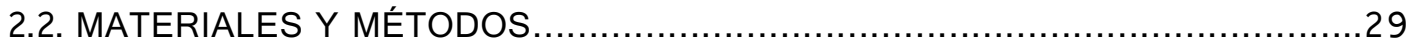

2.2.1. Recolección de muestras y conservación del

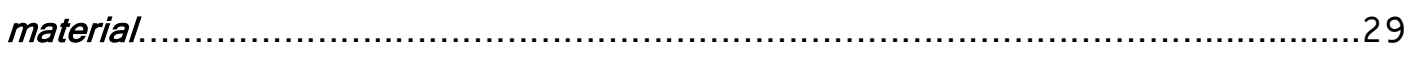

2.2.2. Procesamiento y fraccionamiento de muestras.............................31 
2.2.3. Determinación de las variables físico-químicas.

a) Caracterización florística.................................................33

b) Caracterización hidrológica................................................33

c) $\mathrm{pH}$ y temperatura.................................................. 33

d) Contenido hídrico de las muestras.......................................33

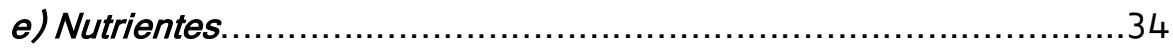

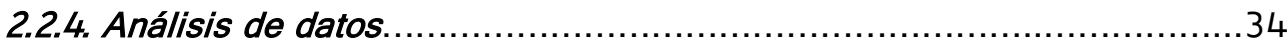

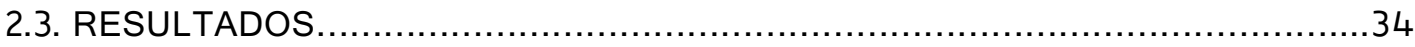

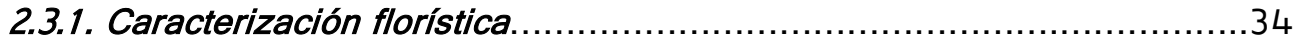

2.3.2. Caracterización hidrológica.................................................. 36

2.3.3. $\mathrm{pH}$ y Temperatura de las turberas en estudio.................................38

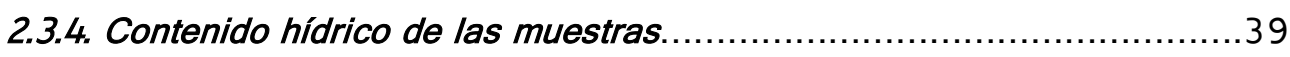

2.3.5. Contenido de materia orgánica...........................................4 4

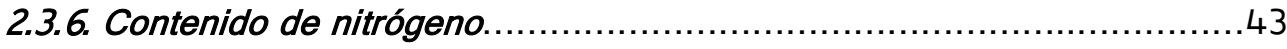

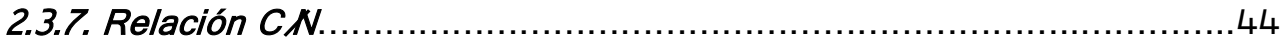

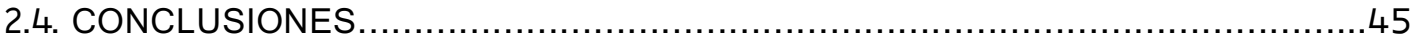

\section{CAPÍTULO 3 -MICROHONGOS DE TURBERAS COMPACTAS EN TIERRA DEL FUEGO}

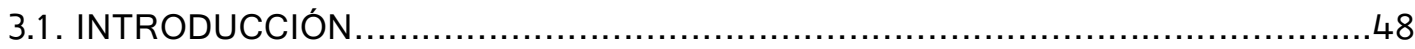

3.1.1. Comunidad microbiana y

diversidad. .48

3.1.2. Estudio de hongos presentes en turberas................................49

3.1.3. Diversidad fúngica en turberas fúngicas....................................51

3.1.4. Objetivos particulares del capítulo........................................53

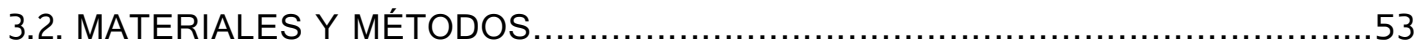

3.2.1. RECOLECCIÓN DE MUESTRAS Y CONSERVACIÓN DEL MATERIAL

3.2.2. AISLAMIENTO Y CARACTERIZACIÓN TAXONÓMICA DE MICROHONGOS POR METODOLOGÍAS CLÁSICAS ....................................54

a) Aislamiento de cepas fúngicas......................................54

b) Identificación de especies fúngicas....................................56 


\subsubsection{IDENTIDAD DE MICELIOS ESTÉRILES POR METODOLOGÍAS}

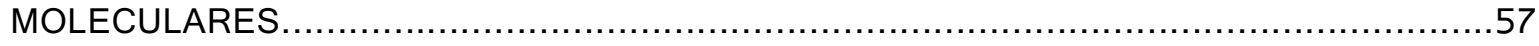

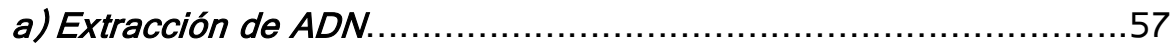

b) Amplificación de ADN fúngico mediante PCR..........................59

c) Purificación de productos de PCR .....................................60

d) Secuenciación y análisis de los fragmentos de ADN

clonados.....................................................................60

3.2.4. ANÁLISIS DE DATOS...................................................... 61

a) Evaluación de las metodologías de cultivo.............................61

b) Cálculo de frecuencias....................................................61

c) Análisis de la diversidad...............................................62

e) Análisis estadístico.....................................................63

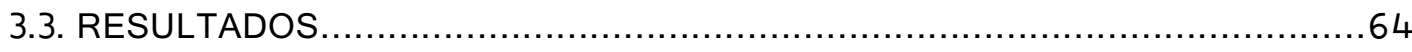

3.3.1. AISLAMIENTO Y CARACTERIZACIÓN TAXONÓMICA DE MICROHONGOS POR METODOLOGÍAS

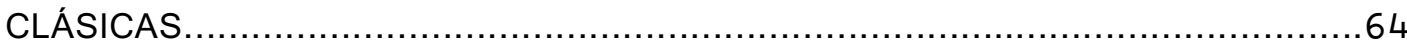

a) Evaluación de metodologías clásicas de estudio........................64

b) Incidencia de microhongos en turberas compactas

fueguinas.

c) Microhongos de turberas fueguinas y compactas de Astelia-

Donatia.

d) Análisis de la composición especifica y abundancia según cobertura vegetal': Astelia vs Sphagnum............................................ 74

e) Análisis de la composición específica y abundancia según 'sitio': Moat vs Garibaldi...... .77

f) Análisis de la composición específica y abundancia según 'profundidad de muestreo': profundidad $A$ vs profundidad $B$ 80

g) Análisis de la diversidad fúngica. 82

h) Análisis de la composición fúngica y su relación con las variables abióticas. 
3.3.2. AMPLIFICACIÓN Y SECUENCIACIÓN DE ADN A PARTIR DE

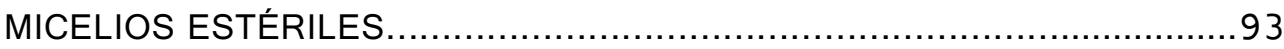

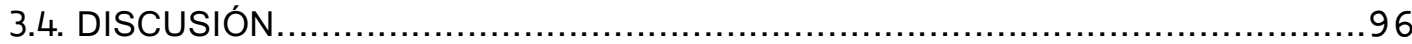

a) Métodos de aislamiento de Hyphomycetes.......................................96

b) Hyphomycetes en turberas compactas.....................................101

c) Abundancia, composición \& diversidad de la comunidad fúngica en turberas compactas. 106

3.5. CONCLUSIONES. 113

\section{CAPÍTULO 4-MICROCOSMOS: DESCOMPOSICIÓN IN VITRO DE TURBA POR} MICROHONGOS NATIVOS DE TURBERAS COMPACTAS FUEGUINAS

4.1. INTRODUCCIÓN .114

OBEJTIVOS PARTICULARES..................................................... 117

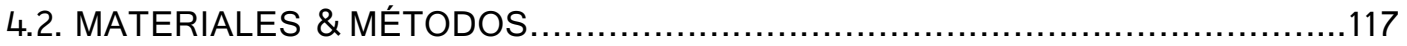

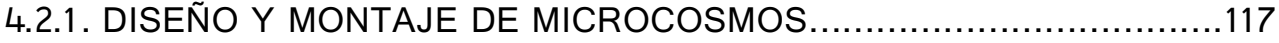

a) Recolección de muestras y conservación del

material.

b) Elección y acondicionamiento de las cepas

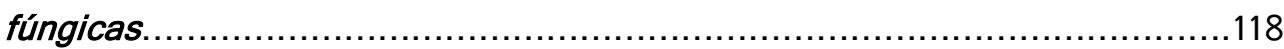

c) Preparación de bolsas de descomposición.............................118

d) Ensayos de microcosmos............................................118

4.2.2. ANÁLISIS DE DATOS .....................................................

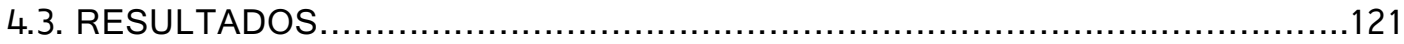

4.3.1. Descomposición con cepas fúngicas vs controles..........................121

4.3.2. Influencia de la temperatura y el sustrato sobre la descomposición fúngica.

4.3.3. Análisis de la descomposición entre cepas fúngicas.......................123

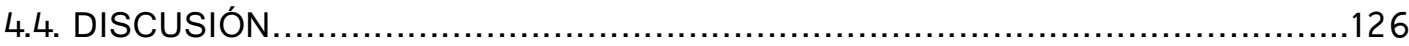

a) Descomposición \& sustrato...................................................127

b) Influencia de la temperatura sobre la descomposición.........................128

c) Descomposición \& cepas............................................................131

d) Consideraciones finales.......................................................... 132 


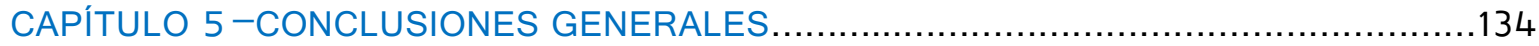

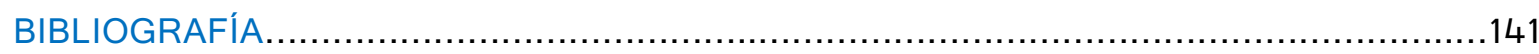

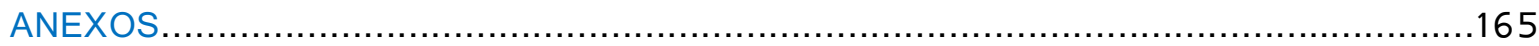




\section{LISTA DE FIGURAS \& TABLAS}

\section{FIGURAS}

Figura 1. Estructura de una turbera.

Figura 2. Componentes que intervienen en la formación de turba y principales rutas del carbono en una turbera.

Figura 3. Situación geográfica de la Isla Grande de Tierra del Fuego.

Figura 4. Regiones naturales del sector argentino de la Isla Grande de Tierra del Fuego.

Figura 5. A. Astelia pumila. B. Donatia fascicularis. C. Porción de turba con raíces expuestas de Astelia pumila.

Figura 6. Ubicación geográfica de los sitios de muestreo.

Figura 7. Turbera compacta de Astelia-Donatia en Moat, Tierra del Fuego.

Figura 8. Turbera compacta de Astelia pumila próxima al Paso Garibaldi, Tierra del Fuego.

Figura 9. Parcela de muestreo. A. Astelia pumila. B. Sphagnum magellanicum.

Figura 10. Recolección de muestras de turba con barreno (A) y cuchillo dentado (B) en una turbera compacta de Astelia en Tierra del Fuego.

Figura 11. Esquema del fraccionamiento de muestras de turba de Astelia y Sphagnum.

Figura 12. Porcentajes de superficie cubierta por Astelia pumila y Sphagnum magellanicum en las parcelas muestreadas de las turberas en estudio, situadas en Moat (M) y Garibaldi (G).

Figura 13. Géneros vegetales registrados en las parcelas de muestreo de dos turberas compactas (Moat y Garibaldi).

Figura 14. Valores (en centímetros) de la distancia media al agua que presentaron los sitios de muestreo de dos turberas compactas (Moat y Garibaldi), durante dos temporadas de muestreo 
(Febrero 2012 y Octubre 2012) y en presencia de dos tipos de cobertura vegetal (Ast: Astelia pumila y Sph: Sphagnum magellanicum).Los valores negativos corresponden a sitios de muestreo sumergidos.

Figura 15. Contenido de carbono orgánico medio, expresado en proporción al peso seco (\%), de las muestras de turba tomadas durante dos temporadas de muestreo (febrero y noviembre 2012), en dos turberas compactas (Moat \& Garibaldi), a dos profundidades $(A=3-10 \mathrm{~cm}$ y $B=10$ a 20 $\mathrm{cm}$ ) y en presencia de dos tipos de cubierta vegetal (Astelia y Sphagnum).

Figura 16. Contenido medio de nitrógeno medio, expresado en porcentaje (\%) presente en las muestras de turba tomadas durante dos temporadas de muestreo (febrero y noviembre 2012), en dos turberas compactas (Moat \& Garibaldi) y en presencia de dos tipos de cubierta vegetal (Astelia y Sphagnum).

Figura 17. Cuadro comparativo con características principales de las turberas situadas en Moat y Garibaldi.

Figura 18. Cámara húmeda realizada con 5 porciones de turba fueguina de Sphagnum.

Figura 19. Esquema de la organización de los genes ribosomales en hongos. Se muestran los cebadores utilizados ITS5 e ITS4 y la región que amplifican.

Figura 20. Frecuencia de ocurrencia de microhongos aislados por lavado a partir de 80 muestras de turba tomadas en febrero de 2012, en dos turberas compactas de Tierra del Fuego.

Figura 21. Valores de índice de diversidad de Shannon-Weaner (A), Equidad (B) y Riqueza específica (C) calculados para muestras de turba provenientes de dos turberas compactas en Tierra del Fuego (M: Moat; G:Garibaldi), colectadas en febrero de 2012, a dos profundidades diferentes (A: 3-10 cm.; B: 10-20 cm.) y en presencia de dos tipos de cobertura vegetal (Ast: Astelia pumila y Sph: Sphagnum magellanicum.

Figura 22. Valores de índice de diversidad de Shannon-Weaner (A), Equidad (B) y Riqueza específica (C) calculados para muestras de turba provenientes de dos turberas compactas en 
Tierra del Fuego (M: Moat; G: Garibaldi), colectadas en noviembre de 2012, a dos profundidades diferentes (A: 3-10 cm.; B: $10-20 \mathrm{~cm}$.) y en presencia de dos tipos de cobertura vegetal (Ast: Astelia pumila y Sph: Sphagnum magellanicum).

Figura 23. Análisis de componentes principales (ACP) de las muestras basado en la abundancia de las especies fúngicas de Moat y Garibaldi para febrero 2012. Las muestras corresponden a cubiertas con Astelia (Ast). Se representan los vectores de las espcies de mayor contribución a cada eje. Apull: Aureobasidium pullulans; lev: levaduras; Malp: Mortierella alpina; Pfrq: Penicillium frequentans; Tpol: Trichoderma polysporum.

Figura 24. Análisis de componentes principales (ACP) de las muestras basado en la abundancia de las especies fúngicas de Moat y Garibaldi para noviembre 2012. Las muestras corresponden a cubiertas con Astelia (Ast). Se representan los vectores de las espcies de mayor contribución a cada eje. Apull: Aureobasidium pullulans; Bbass: Beauveria bassiana; Pfrq: Penicillium frequentans; Tvir: Trichoderma viridae.

Figura 25. Análisis de componentes principales (ACP) de las muestras basado en la abundancia de las especies fúngicas de Moat y Garibaldi para febrero 2012. Las muestras corresponden a cubiertas con Sphagnum (Sph). Se representan los vectores de las espcies de mayor contribución a cada eje. Apull: Aureobasidium pullulans; lev: levaduras; Malp: Mortierella alpina; Pfrq: Penicillium frequentans; Tpol: Trichoderma polysporum.

Figura 26. Análisis de componentes principales (ACP) de las muestras basado en la abundancia de las especies fúngicas de Moat y Garibaldi para noviembre 2012. Las muestras corresponden a cubiertas con Sphagnum (Sph). Se representan los vectores de las espcies de mayor contribución a cada eje. Apull: Aureobasidium pullulans; Bbass: Beauveria bassiana; lev: levaduras; Thar: Trichoderma harzianum.

Figura 27. Productos de amplificación obtenidos utilizando cebadores ITS5 e ITS4 a partir del ADN genómico total de 30 micelios estériles, separados por electroforesis en gel de agarosa al 1\% y teñidos con Gel Red (10 mg/l). Calle M: marcador de peso molecular escala de 100 pb (Life 
Techonology); calles 1-5: muestras de micelio estéril. La flecha señala la posición del producto de amplificación esperado para la región ITS e las especies fúngicas.

Figura 28. Unidad experimental utilizada en el ensayo de microcosmos para evaluar la descomposición de distintos tipos de turba incubada con especies de hongos nativos de turberas compactas de Tierra del Fuego.

Figura 29. Masa remanente (\%) luego de 6 meses de incubación de un ensayo de descomposición en microcosmos con microhongos nativos de turberas compactas. Las unidades experimentales fueron incubadas con diferentes tratamientos: bolsa con Astelia a $7^{\circ} \mathrm{C}\left(\mathrm{Ast}+7^{\circ} \mathrm{C}\right)$, bolsa con Sphagnum a $7^{\circ} \mathrm{C}\left(\mathrm{Sph}+7^{\circ} \mathrm{C}\right)$, bolsa con Astelia a temperatura ambiente (Ast $\left.+20^{\circ} \mathrm{C}\right)$ y bolsa con Sphagnum a temperatura ambiente $\left(\mathrm{Sph}+20^{\circ} \mathrm{C}\right)$.

Figura 30. Masa remanente media luego de 6 meses de incubación de un ensayo de microcosmos para testear la habilidad de descomposición de 4 cepas microfúngicas aislados de turberas compactas de Astelia-Donatia.

Figura 31. Masa remanente (\%) de turba luego de un ensayo de microcosmos para testear la habilidad de descomposición para cuatro microhongos nativos de turberas compactas. A. Aureobasidium pullulans. B. Beauveria bassiana. C. Penicillium frequentans. D. Trichoderma viride. Los tratamientos fueron: Astelia a $7^{\circ} \mathrm{C}\left(\right.$ Ast $\left.+7^{\circ} \mathrm{C}\right)$, Sphagnum a $7^{\circ} \mathrm{C}\left(\mathrm{Sph}+7^{\circ} \mathrm{C}\right)$, Astelia a temperatura ambiente $\left(\right.$ Ast $\left.+20^{\circ} \mathrm{C}\right)$ y Sphagnum a temperatura ambiente $\left(\mathrm{Sph}+20^{\circ} \mathrm{C}\right)$.

\section{TABLAS}

Tabla 1. Valores medios de temperatura $\left({ }^{\circ} \mathrm{C}\right)$ registrados para las turberas situadas en Moat y Garibaldi durante dos temporadas de muestreo (Febrero y Noviembre de 2012) y en presencia de las especies vegetales Astelia pumila y Sphagnum magellanicum. 
Tabla 2. Contenido hídrico medio (\%) en muestras de turba colectadas en dos turberas compactas (G: Garibaldi; M: Moat) de Tierra del Fuego, en presencia de dos tipos de cobertura vegetal (Ast: Astelia; Sph: Sphagnum), a dos profundidades (A: $3-10 \mathrm{~cm} ; \mathrm{B}=10-20 \mathrm{~cm}$ ) y en dos temporadas de muestreo (febrero y noviembre de 2012).

Tabla 3. Relación Carbono:Nitrógeno $(\mathrm{C}: \mathrm{N})$ presente en las muestras de turba tomadas durante dos temporadas de muestreo (febrero y noviembre 2012), en dos turberas compactas (Moat \& Garibaldi) y en presencia de dos tipos de cubierta vegetal (Astelia y Sphagnum).

Tabla 4. Comparación de los resultados obtenidos por la implementación de tres metodologías de cultivo clásicas (SD: siembra directa, $\mathrm{CH}$ : siembra en cámaras húmedas y L: lavado de partículas de suelo) en el aislamiento de especies fúngicas, a partir de muestras tomadas en febrero del 2012 en turberas compactas de Astelia-Donatia (Tierra del Fuego).

Tabla 5. Número de partículas sembradas y número de aislamientos fúngicos obtenidos de 80 muestras de turba recolectadas en dos turberas compactas de Tierra del Fuego a partir de dos muestreos (febrero y noviembre de 2012) y utilizando diferentes metodologías clásicas de cultivo fúngico (siembra directa de suelo, lavado de partículas de suelo, cámaras húmedas).

Tabla 6. Lista de microhongos aislados a partir de 80 muestras de turba, obtenidas de dos turberas compactas (Astelia-Donatia) de Tierra del Fuego durante dos temporadas de muestreo en el período febrero-noviembre 2012.

Tabla 7. Frecuencias relativas de hongos microscópicos aislados a partir de muestras de turba recolectadas de parcelas con diferentes coberturas vegetales (Astelia pumila y Sphagnum magellanicum) durante dos campañas de muestreo ( $\mathrm{F}$ : febrero y $\mathrm{N}$ : noviembre) en turberas compactas de Astelia-Donatia en Tierra del Fuego.

Tabla 8. Frecuencias relativas de hongos microscópicos aislados a partir de muestras de turba recolectadas de parcelas ubicadas en dos turberas compactas de Astelia en Tierra del Fuego y en zonas geográficas disímiles (Moat: turbera con fuerte influencia marítima; Garibaldi: turbera ubicada en zona montañosa). 
Tabla 9. Frecuencias relativas de hongos microscópicos aislados a partir de muestras de turba recolectadas a dos profundidades diferentes $(A: 3-10 \mathrm{~cm}$ y $B: 10-20 \mathrm{~cm}$ ) de parcelas ubicadas en dos turberas compactas de Astelia en Tierra del Fuego.

Tabla 10. Matriz de correlación entre las variables ambientales y la posición de las muestras sobre los ejes I y II para Astelia (A) y Sphagnum (B). (En rojo se muestran los valores significativos).

Tabla 11. Análisis de 30 productos de PCR obtenidos a partir de la amplificación de ADN de micelios fúngicos estériles según el análisis de las secuencias nucleotídicas obtenidas según el análisis de BLAST. 


\section{Capítulo 1}

\section{InTRODUcción GenERAL}

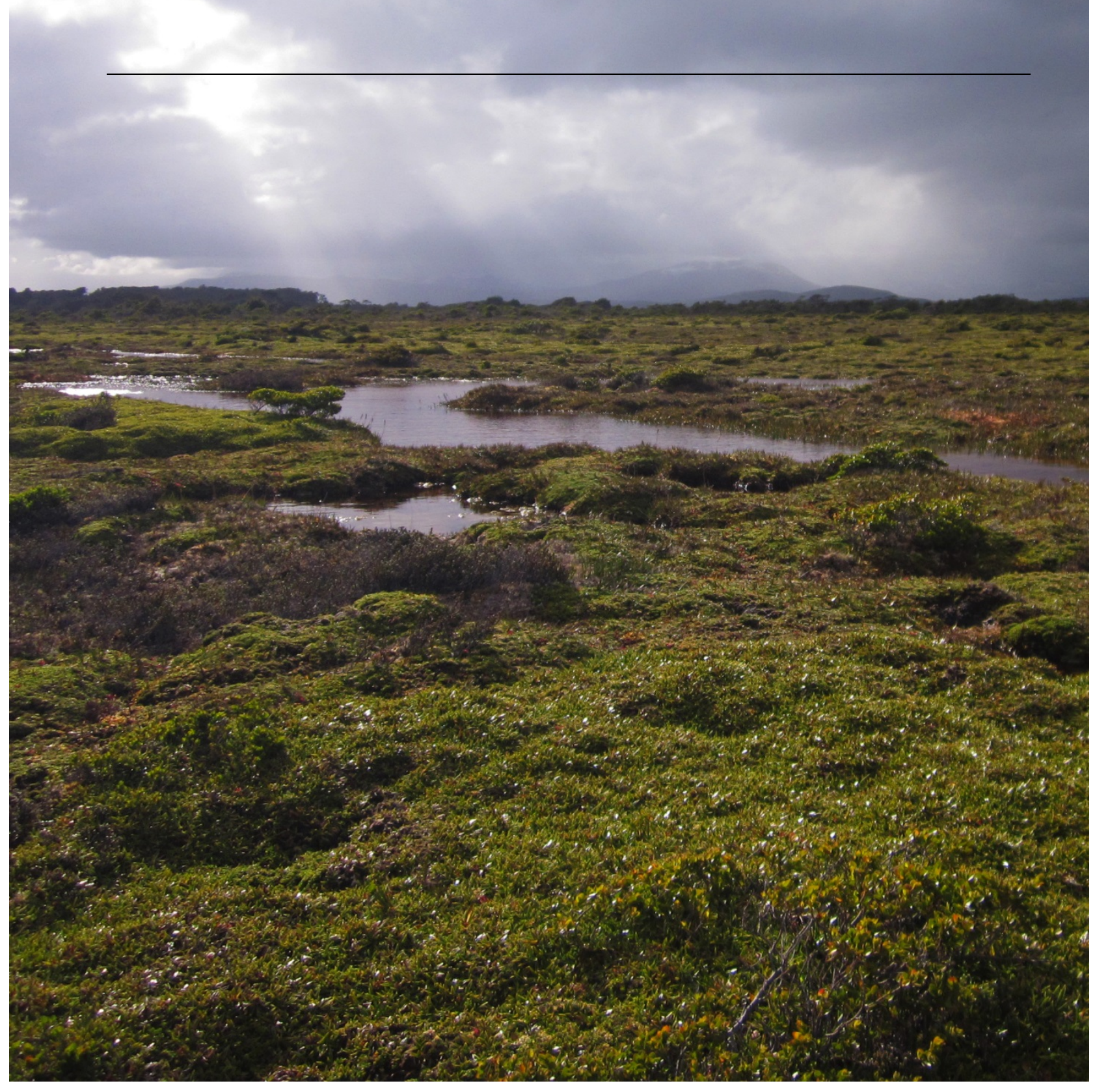




\subsection{ECOSISTEMAS DE TURBERA}

Las turberas forman un grupo diverso de ecosistemas de humedal que se caracterizan principalmente por presentar grandes depósitos de materia vegetal en distintos estados de degradación anaeróbica (Schlatter y Schlatter, 2004). La gran acumulación de materia orgánica ocurre cuando las condiciones ambientales limitan la descomposición de la materia orgánica en combinación con una alta producción primaria neta, provocando así, un desbalance entre producción y descomposición, que resulta en la acumulación de material vegetal parcialmente degradado (Moore y col., 2007). Este desbalance, debido principalmente a la baja descomposición, es generado por la presencia de niveles de agua permanentemente altos (anegamiento), resultando en condiciones anóxicas que inhiben la actividad de los microorganismos descomponedores y llevan a la formación de un suelo compuesto por materia orgánica, denominada 'turba' (Glaser y Janssens, 1986).

Son ambientes característicos de zonas que presentan condiciones climáticas particulares, con bajas temperaturas, alta humedad, bajas tasas de evaporación y altas precipitaciones regularmente distribuidas (Lindsay y col., 1988), que promueven la formación de turba. Por lo tanto, las turberas representan ecosistemas complejos y frágiles con interacciones muy estrechas entre la vegetación, la turba, el agua y los distintos factores involucrados en su formación (clima, topografía, morfología, etc.), que, gracias a sus mecanismos de autorregulación, han permanecido, bajo diferentes condiciones climáticas, por miles de años (Pontevedra Pombal y Martínez Cortizas, 2004).

En diversos estudios (Crum, 1988; Gorham, 1991; Joosten y Clarke, 2002) se ha utilizado como criterio para definir a un ambiente como turbera a la profundidad alcanzada por 
la turba que la está formando. Por lo tanto, se considera que una turbera, para ser definida como tal, debe poseer una capa de turba de al menos 30 centímetros de espesor, pudiendo alcanzar varios metros de profundidad. Otros autores (Martínez Cortizas y col., 2009) ponen énfasis en que las turberas deben poseer una vegetación actual formadora de turba; esto las diferenciaría de otros tipos de hábitat en los cuales puede haber vegetación potencialmente formadora de turba pero que no vive sobre un sustrato exclusiva o casi exclusivamente orgánico. Entonces, podría decirse que en términos botánicos, las turberas son definidas como sitios que soportan una comunidad vegetal formadora de turba; mientras que ecológicamente son definidas como ecosistemas con altos niveles de agua en los que, debido a las condiciones anóxicas, se acumula materia orgánica parcialmente descompuesta en forma de turba (Laine y Vasander, 1996).

El alto nivel del agua es el factor principal en la ecología funcional de una turbera, ya que la variación en el nivel y calidad de agua regulan la estructura de las comunidades descomponedoras, las vías de descomposición, el transporte de los productos de descomposición y la concentración de nutrientes solubles en agua (Päivänen y Vasander, 1994).

Con respecto a la disponibilidad de nutrientes, el nitrógeno se encuentra inmovilizado principalmente a los compuestos orgánicos y, por lo tanto, no se encuentra disponible para ser tomado por las plantas. También es relativamente frecuente que exista una insuficiencia de potasio y fósforo en estos ambientes (Potila, 2008).

Las turberas están conformadas por asociaciones de especies entre las que predominan las plantas hidrófilas, con gran capacidad de retener humedad y que además están adaptadas 
a vivir en condiciones de contenido de oxígeno reducido y disponibilidad escasa de nutrientes (Blanco y de la Balze, 2004). Las turberas de Sphagnum, a diferencia de otras turberas conformadas, por ejemplo, de plantas en cojín, ciperáceas y juncáceas, son dominadas por el musgo Sphagnum magellanicum, el que modifica física y químicamente su medio ambiente, a tal punto que impide el desarrollo de los procesos de descomposición (Clymo, 1987).

La descomposición incompleta del material vegetal es lo que constituye el suelo en estos ecosistemas (Page y col., 2012). El suelo orgánico de las turberas, como consecuencia de la relación ente la vegetación y el agua, al permanecer por debajo del nivel de agua, es anóxico, frecuentemente ácido (Gorham, 1991; Munson y Gherini, 1993) y del tipo histosol. El material vegetal se acumula estratigráficamente y los restos constituyentes reflejan las condiciones climáticas locales y regionales, capacidad nutritiva, humedad (Nicholson y Vitt, 1990) y, muy especialmente, la naturaleza del agua presente durante su formación (Hulme y col., 1980). Esto es fruto de una fuerte interacción entre el agua que fluye por el depósito, el sustrato geológico y la materia orgánica (Pontevedra Pombal y Martínez Cortizas, 2004).

\subsubsection{Clasificación de las turberas}

Se han distinguido muchos tipos de turberas basados en características como su vegetación, geomorfología, hidrología, química, estratigrafía, y turba, resultando en extensos sistemas de clasificación (Mitsch y Gosselink, 2000; Succow y Joosten, 2001). Sin embargo, es importante conocer y utilizar algunas de estas clasificaciones. 
Los dos tipos principales de turberas, que difieren en su hidrología y su estado mineral, son las turberas alimentadas por precipitación, denominadas ombrotróficas, y las turberas alimentadas de aguas subterráneas, llamadas minerotróficas. La superficie de las turberas ombotróficas (término en inglés: bogs) está aislada del flujo de escorrentía y las aguas subterráneas de la zona de captación; por lo tanto, reciben el agua y elementos químicos únicamente a partir de la deposición atmosférica (Golovchenko y col., 2007). Además, están formadas por encima de la tierra circundante y las capas de turba pueden tener más de 20 metros de profundidad (Whitmore, 1984; Whitten y col., 1987). La turba y el agua de drenaje es muy pobre en nutrientes, porque no hay modo que ingresen nutrientes al sistema a partir del suelo mineral o el agua subterránea. Por ello, la vegetación existe únicamente con los nutrientes que obtiene a partir de la biomasa viva, turba o a partir del agua de lluvia. Los musgos formadores de turba del género Sphagnum se encuentran típicamente en turberas ombrotróficas, que liberan protones $\left(\mathrm{H}^{+}\right)$, creando, por lo tanto, un ambiente ácido $(\mathrm{pH}<5)$ (Wheeler y Proctor, 2000). En contraste, las turberas minerotróficas (término en inglés: fens) se forman en depresiones topográficas, y las plantas reciben los nutrientes a partir del suelo mineral y las aguas subterráneas, además de los residuos vegetales y el agua de lluvia. Las turberas minerotróficas reciben nutrientes a partir de la entrada de agua que drena cerca de los suelos minerales (Ingram, 1992) y son ricas en cationes $\mathrm{Mg}^{2+}, \mathrm{K}^{+}, \mathrm{y} \mathrm{Ca}^{+2}$ (Malmer y col., 1992). Por lo tanto, los niveles de nutrientes en las turberas minerotróficas van desde oligotróficos a eutróficos, pero son típicamente mesotróficos. El pH del suelo (usualmente de 4 a 9 ) puede ser más alto que el presentado por la turba ombrogénica y es menos favorable para los microorganismos del suelo, que no están involucrados en la mineralización de la materia orgánica del suelo. Se caracterizan 
típicamente por la presencia de especies herbáceas y pastos cuyos tejidos aerenquimáticos les permiten vivir en condiciones de anegamiento (Golovchenko y col., 2007). Muchas especies vegetales son capaces de alcanzar el limo y la arcilla mineral debajo de la turba y, por lo tanto, no dependen enteramente del agua de lluvia para nutrirse. Sin embargo, la mayoría de la vegetación poco productiva y limitada nutricionalmente, como ciperáceas y briófitas, son características de estas turberas (Hajek y col., 2006). El desarrollo de la turba en ellas, es más lento que en su contraparte (bogs), y, usualmente, no se forma turba a grandes profundidades (Whitten y col., 1987).

\subsubsection{Estructura de una turbera}

Una turbera evoluciona de forma continua entre procesos de acumulación y descomposición, reemplazando los niveles de turba más antiguos por niveles más recientes (Blanco y de la Balze, 2004). Sin embargo, las turberas son consideradas tradicionalmente como sistemas estructurados verticalmente, y en base a criterios hidrológicos, se han propuesto los términos acrotelmo (capa superior) y catotelmo (capa profunda o inferior) para diferenciar esta estructura vertical de un modo generalizado (Ingram, 1978).

El acrotelmo es un estrato oxigenado, poroso, generalmente con un espesor de 0.4-0.5 metros (Ingram, 1978; Clymo, 1984) y es considerado hidrológicamente activo, porque en él ocurren las fluctuaciones del nivel de agua que generan la aireación periódica de la turba (Belyea y Malmer, 2004; Clymo, 1984). Además, esta capa superficial es considerada como biológicamente activa, conformada por asociaciones de especies, entre las que predominan plantas hidrófilas con gran capacidad de retener humedad. Prácticamente toda la actividad 
biológica, los procesos de acumulación y descomposición de la materia orgánica y la mayor parte de los movimientos de agua ocurren en el acrotelmo (Iturraspe y Roig, 2000).

El catotelmo es el sustrato anóxico, está permanentemente saturado de agua y puede llegar a medir varios metros (Ingram, 1978; Clymo, 1984). En este estrato, sólo ocurre una lenta descomposición de la materia orgánica y un lentísimo movimiento de agua (Malmer y Mailén, 1993).

Este criterio hidrológico está ampliamente aceptado como una distinción útil para analizar la descomposición y acumulación de turba (Belyea y Malmer, 2004; Clymo, 1984).

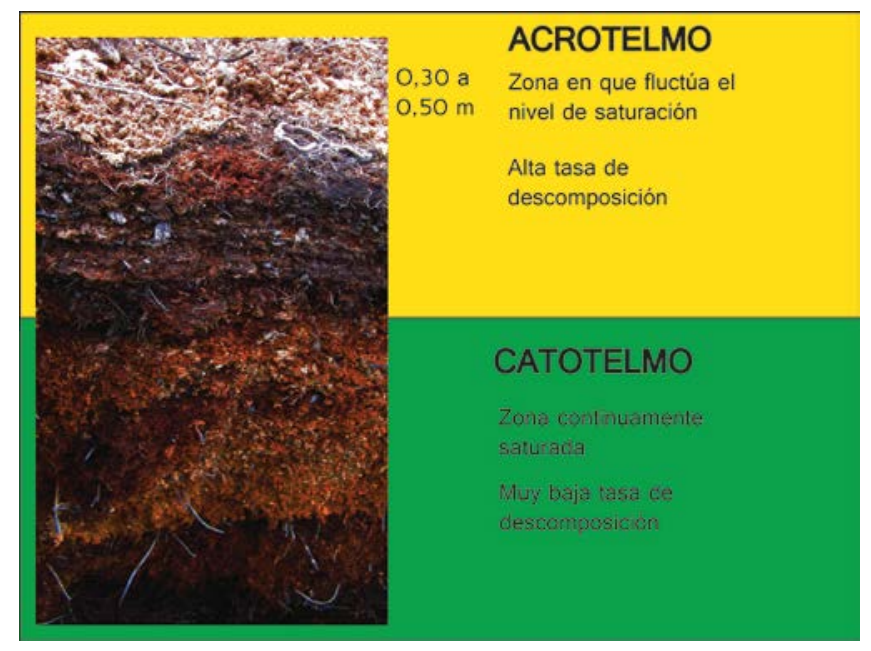

Figura 1. Estructura de una turbera.

\subsubsection{Importancia de las turberas.}

Las turberas almacenan carbono e historia. El material vegetal preservado en las turberas comprende un archivo de la historia ambiental (Charman, 2002), debido a que funcionan como verdaderos banco de datos, acumulan sedimentos en sus capas y registran información vinculada con las condiciones ambientales, ecológicas y climáticas circundantes. Su 
depositación continua permite obtener un registro paleoambiental ininterrumpido que puede ser datado con gran precisión y confiabilidad por carbono 14 (Rabassa, 2000). Así, la turba, a partir de diferentes estudios y análisis radioquímicos, isotópicos y de polen, ha contribuido significativamente al análisis de los climas y civilizaciones pasadas.

También se ha reconocido su inmensa capacidad de retener grandes cantidades de agua. Este aspecto hace que las turberas tengan una influencia significativa en la hidrología y el clima de las áreas donde ellas se extienden (Blanco y de la Balze, 2004). Las turberas cumplen importantes funciones ecológicas en la prevención de inundaciones y condicionan las características de drenaje en las cuencas hídricas en las que se encuentran, pues absorben la precipitación y la escorrentía directamente. Por otra parte, protegen la calidad del agua interceptando y filtrando la escorrentía y proveen de hábitats críticos a comunidades únicas de plantas y animales (Díaz y col., 2005).

Principalmente, las turberas son consideradas importantes en el ciclo del carbono global contemporáneo, porque fijan carbono desde la atmósfera y lo secuestran como turba (Turunen y col., 2002; Vasander y Kettunen, 2006), siendo reconocidas internacionalmente como uno de los mayores almacenamientos de carbono en el mundo, superando al de los bosques (RAMSAR, 2002). Se cree que contienen cerca de un tercio de todo el carbono que se encuentra en el suelo, a pesar que sólo cubren del 4 al $5 \%$ de la superficie terrestre (Waddington y col., 2003). 


\subsection{DESCOMPOSICIÓN Y CICLO DEL CARBONO EN TURBERAS}

Las turberas constituyen un claro ejemplo de ecosistemas en los que el ciclo de carbono está desbalanceado, porque la tasa de entrada de carbono en el ecosistema esencialmente a través de la fijación de $\mathrm{CO}_{2}$ por la vegetación, es mayor que la del carbono que sale del sistema en forma de $\mathrm{CO}_{2}, \mathrm{CH}_{4} \mathrm{O}$ carbono orgánico particulado y disuelto, luego de la descomposición (Wieder y Vitt, 2006). Si bien las estimaciones varían, la mayor parte del material vegetal original $(>80 \%)$ se 'pierde' y solo la fracción restante es acumulada como turba. Por lo tanto, la formación y acumulación de turba requiere de largos períodos de tiempo (décadas, siglos o milenios), y el carbono almacenado a nivel mundial es el resultado de un proceso iniciado mayoritariamente desde el último período glacial, hace aproximadamente 10.000 a 20.000 años, dependiendo de la región del planeta (Yu y col., 2010).

En la figura 2 se puede apreciar de un modo simplificado cuáles son las principales rutas del carbono involucradas en una turbera; donde el carbono fijado fotosintéticamente se acumula anualmente en el acrotelmo (el horizonte oxigenado de la turba), luego de la abscisión de las hojas, la caída de los tallos y raíces y el crecimiento vertical de briofitas (producción de hojarasca o material vegetal senescente). Las tasas más altas de descomposición, llevadas a cabo por los hongos y bacterias, ocurren en el acrotelmo, liberando $\mathrm{CO}_{2}$ a la atmósfera; sin embargo, la mayor parte de la materia orgánica producida está parcialmente descompuesta y es tapada por el material producido en los años subsiguientes, formando parte del catotelmo (horizonte anaeróbico). En este horizonte tiene lugar la descomposición llevada a cabo por bacterias anaeróbicas (Clymo, 1984), lo que resulta en la producción de metano, que subsecuentemente es emitido a la atmósfera o es 
oxidado por bacterias anaeróbicas metanotróficas y difunde verticalmente a través del acrotelmo (Dedysh, 2002; Wartiainen y col., 2003).

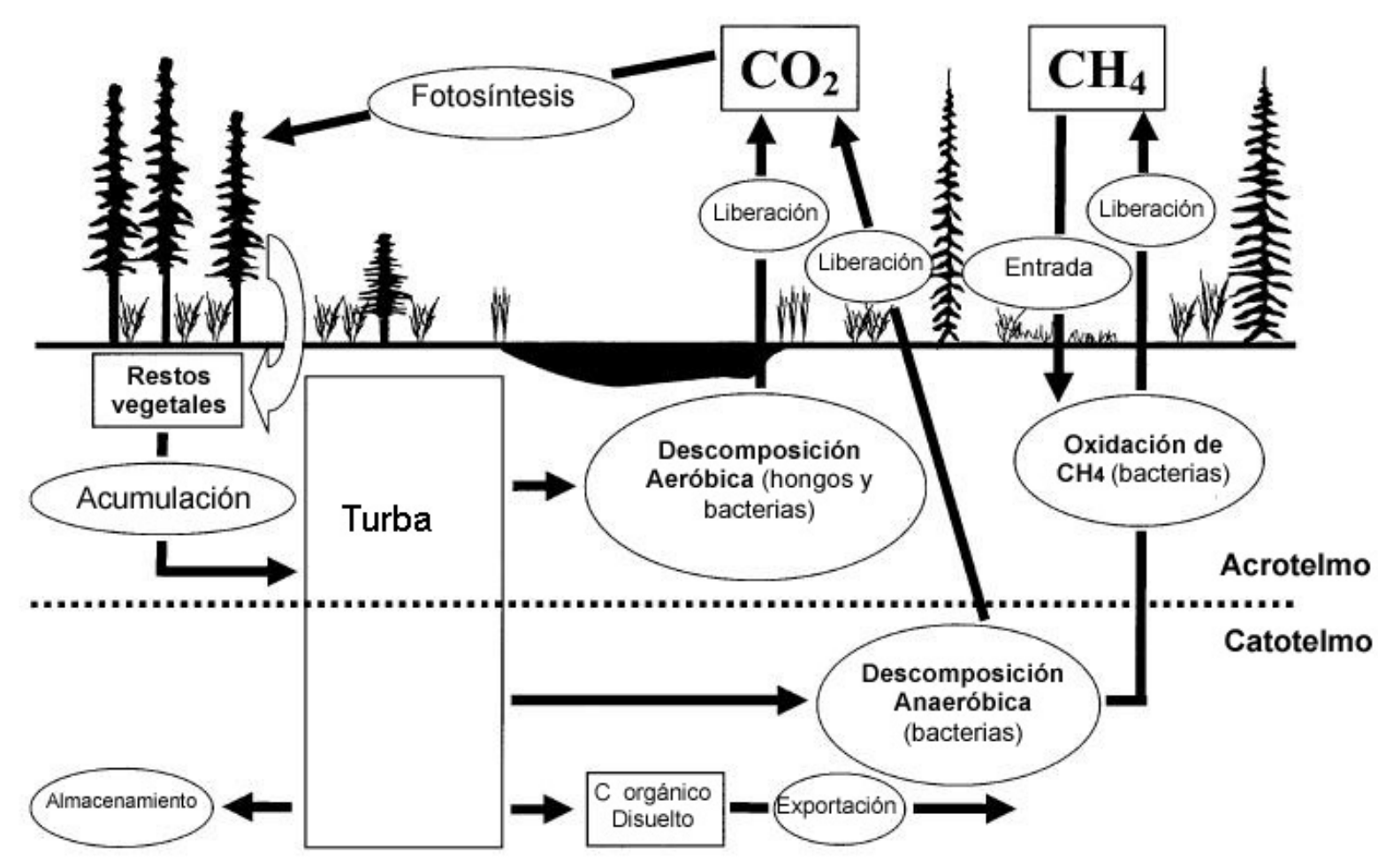

Figura 2. Componentes que intervienen en la formación de turba y principales rutas del carbono en una turbera (Thornmann, 2005).

\section{3. DIVERSIDAD MICROBIOLÓGICA EN TURBERAS}

Las turberas albergan una gran diversidad de microorganismos con diferentes funciones metabólicas. La microflora en estos ecosistemas consiste de procariotas (bacterias y Archaea) y hongos (Kamal y Varma, 2008). Estos microorganismos descomponedores resultan de particular interés debido a que están involucrados en la descomposición de los tejidos vegetales, produciendo tanto la acumulación de turba como la liberación de $\mathrm{CO}_{2}$ y $\mathrm{CH}_{4}$ 
(Moore y Basiliko, 2006). Todos estos organismos juegan un papel importante en el ciclo del carbono, interactúan con las plantas a través del intercambio de compuestos orgánicos e inorgánicos, y también pueden alterar el entorno físico-químico de los demás organismos con los que se interrelacionan (Kamal y Varma, 2008). En muchos estudios se ha demostrado que la biomasa microbiana disminuye con la profundidad, y esto se explicaría por la presencia de materia orgánica más lábil y los mayores estados rédox encontrados cerca de la superficie en los perfiles de turba (Blodau y col., 2004; Basiliko y col., 2007).

Si bien los estudios acerca de los microorganismos de turberas comenzaron entre los años 1920 (Begak, 1926) y 1930 (Waksman y Purvis, 1932), existen pocos estudios que detallen su comunidad microbiana. La mayoría de los estudios se focalizan en grupos individuales como los organismos metanogénicos (Basiliko y col., 2003; Sizova y col., 2003; Cadillo-Quiróz y col., 2008), metanótrofos (Chen y col., 2008; Kip y col., 2012; Gupta y col., 2012) y reductores de sulfuro (Pester y col., 2010). Estos estudios basados en metodologías de cultivo clásicas, han identificado una amplia variedad de bacterias, tales como Bacillus, Pseudomonas, Achromobacter, Cytophaga, Micrococcus, Chromobacterium, Clostridium, Streptomyces, Actinomyces, Mycobacterium, Micromonospora y Nocardia; así como también hongos de los géneros Penicillium, Cladosporium, Trichoderrna, Mucor, Mortierella, Cephalosporium, Geotrichium (Williams y Crawford 1983).

Esta rica diversidad microbiológica dentro de las turberas sugiere una compleja red ecológica con muchos nichos especializados (Preston Michael 2013 tesis). Por otra parte, los hongos tienen un papel fundamental en los procesos de descomposición de la materia 
orgánica en todos los ecosistemas y, desde una perspectiva funcional, son tal vez más importantes que las bacterias (Kox, 1954; Latter y col., 1967; Williams y Crawford, 1983).

\subsection{ESTUDIO DE HONGOS MICROSCÓPICOS EN TURBERAS}

Los hongos están involucrados en las transformaciones del carbono y los nutrientes del suelo (Lindahl y col., 2002) y, por lo tanto, poseen un papel crucial en el funcionamiento de los ecosistemas. Son descomponedores ubicuos que embeben sus cuerpos somáticos dentro de la fuente de alimento, formando extensas redes miceliares; y además, son los responsables de la descomposición de la materia orgánica muerta (detritos), que reintroducen al ambiente a través de la mineralización de varios elementos esenciales, como carbono, nitrógeno y fósforo (Herbert y col., 2003). Para ello, producen una amplia gama de enzimas que degradan polímeros complejos, tales como el almidón, celulosa, proteínas, quitina, queratina, e incluso los materiales lignificados más complejos como la madera (Christensen 1989). Es así que representan uno de los grupos funcionales de microorganismos del suelo más importantes y son críticos para el ciclado de nutrientes, transporte de nutrientes a las plantas, crecimiento de las plantas y la supresión de enfermedades (Christensen, 1989; Thorn, 1997).

La mayoría de los grupos fúngicos son encontrados en los suelos; especialmente prevaleciendo como las formas filamentosas de los Saprolegniales, Pythiales, Mucorales, Eurotiales, Microascales, Hypocreales, Sordariales, Onugenales, Leotiales, Pezizales, y una gran cantidad de hongos mitospóricos, que son casi exclusivamente anamorfos de especies 
de asocmicetos o basidiomicetos. Muchos hongos del suelo son saprófitos y se encuentran en el material orgánico, en diferentes etapas de deterioro y, con algunas excepciones, son fácilmente cultivables (Bills y col., 2004).

Muchos estudios han demostrado que la biomasa y producción fúngica dominan sobre las bacterias en ecosistemas ácidos como las turberas, y que esto se debe a sus altos niveles de tolerancia a la acidez (Latter y col., 1967; Williams y Crawford, 1983; Williams \& Crawford; Frostergård y Bååth, 1996; Andersen y col., 2006). Además, se ha reportado que los hongos degradadores de celulosa son más abundantes en las turberas que sus contrapartes bacterianas (Hiroki y Watanabe, 1996) y, actualmente, son considerados los principales descomponedores aeróbicos en estos hábitats (Thornmann, 2006a, 2006b).

Se ha aislado un gran número de especies microfúngicas a partir de muestras de Sphagnum fuscum vivo y descompuesto, y está bien descripta su habilidad para descomponer varios compuestos orgánicos, como, por ejemplo, ácidos tánicos, celulosa y pectina (Thornmann y col., 2001, 2002). Desde un punto de vista taxonómico, los anamorfos de ascomicetes formaron el grupo más grande $(62 \%)$ en estos estudios, y los géneros Penicillium y Acremonium fueron los grupos dominantes en los estudios relacionados con aislamientos de hongos (Thornmann, 2006a).

Por otro lado, los tres phyla dominantes, Ascomycota, Basidiomycota y Zygomycota, son encontrados de modo consistente en varios estudios sobre turberas (Artz y col., 2007; Lin y col., 2012; Peltonimi y col. 2012). Generalmente, tanto los hongos Ascomycota como los Basidiomycota son observados dentro de las capas superficiales y son degradadores de celulosa y compuestos fenólicos en estudios de laboratorio (Lynd y col., 2002; Thornmann, 
2006), mientras que los Zygomycota han sido observados en profundidad y no está claro si están activos o latentes debido a las condiciones anóxicas (Lin y col., 2012). No obstante, los Zygomycota son relativamente pobres degradadores de compuestos carbonados vegetales y Lin y col. (2012) sugieren que estos organismos podrían estar involucrados en la degradación de sustratos carbonados animales y vegetales.

Con respecto a los factores que determinarían la presencia de las especies fúngicas, diversos autores han descripto que la composición de la comunidad fúngica puede variar bajo diferentes tipos de vegetación de turbera (Artz y col., 2007; Trinder y col., 2008). En otros estudios, se han observado diversas comunidades de hongos debajo de las coberturas de Sphagnum y en asociación cercana con arbustos ericáceos (Thormann, 2006; Artz y col., 2007). Sin embargo, el pH parece ser el factor menos importante en la estructuración de la comunidad fúngica en comparación con las bacterias, ya que, como se mencionó anteriormente, los hongos parecen ser más ácido-tolerantes (Thornmann, 2006).

Las últimas revisiones realizadas acerca de la diversidad fúngica y basadas en varios estudios llevados a cabo en turberas de Europa, Norteamérica y Sudamérica (Thormann, 2006; Thormann y Rice, 2007), reportan, a nivel mundial, la identificación de 601 especies de hongos; siendo los Ascomicetes el grupo más numeroso (con 276 especies identificadas, representando el $40 \%$ de total de hongos reportados), seguido de los Zigomicetes (55 especies, 9\%) y los Chitridiomicetes (26 especies, 4\%).

Si bien existen varios estudios acerca de las comunidades fúngicas, hasta la fecha, las turberas no han sido investigadas de manera intensiva con respecto a esta temática. Los estudios que incluyen el cultivo de hongos aislados o la identificación directa por microscopía, 
se realizaron hace varias décadas (Dooley y Dickinson, 1970). Otros estudios se han centrado en las especies de plantas particulares o la descomposición de residuos vegetales frescos en laboratorio (Thornmann y col., 2003; 2004; Thornmann, 2006). También se han identificado diferencias en la estructura de la comunidad microbiana entre distintos tipos de turbera (e.g. bogs y fens) así como entre las profundidades que conforman un perfil de turba (Jaatinen y col., 2007; Peltoniemi y col., 2009; Preston y col., 2012). Otros estudios de turberas boreales (Jaatinen y col., 2008) se han enfatizado en el rol de los hongos micorrícicos en los ciclos biogeoquímicos (Lindahl y col. 2002; Lindahl y col., 2007).

Es así que la mayor parte de los trabajos publicados sobre diversidad en ambientes de turbera, a nivel mundial, brindan información taxonómica, constituyendo aproximaciones cualitativas acerca de la diversidad fúngica presente, sin definir parámetros que permitan comprender la estructura y dinámica de la comunidad, ni incluir los factores que probablemente están determinando la distribución de las diferentes especies fúngicas (Rydin y Jeglum, 2006).

\subsection{ANTECEDENTES DE ESTUdIOS MICROBIOLÓGICOS Y FÚNGICOS REALIZADOS EN TURBERAS DE TIERRA DEL FUEGO}

Si bien en el hemisferio sur, y principalmente en Tierra del Fuego, se han realizado diversos estudios relacionados con la micología, es reducida la información acerca de la comunidad fúngica presente en ambientes de turbera.

En la Patagonia fueguina, los primeros trabajos florístico-taxonómicos sobre hongos y ascomicetes liquenizados, fueron realizados a fines del siglo XIX y comienzos del siglo XX. 
Desde entonces, determinados grupos y ambientes han sido más considerados que otros, disponiendo de un valioso relevamiento de la región avalado por numerosas publicaciones científicas. En un artículo publicado por Gamundí y Amos (2007) se resume la información acerca de las exploraciones micológicas en Tierra del Fuego durante los últimos siglos basada en diferentes trabajos, y se realiza una evaluación del conocimiento de la diversidad fúngica para el mismo período (lapso) de tiempo y del estado de conservación actual de algunas especies fúngicas. La mencionada publicación se basa en datos extraídos de las citas de material micológico contenidas en los trabajos de la Flora Criptogámica de Tierra del Fuego (Guarrera y col., 1975-2002), Singer (1952-1953, 1969), y Spegazzini (1887, $1896,1923,1924,1926)$ entre otros.

Se han realizado algunos estudios en turberas de Tierra del Fuego acerca de la comunidad microbiana (Searles, 2001) y fúngica (Robson y col., 2004) en ecosistemas de turberas del Hemisferio Sur, describiendo los cambios que se producen por reducción (filtración) de la radiación solar UV-B en las mencionadas comunidades presentes solo en turberas de Sphagnum. Más recientemente, Paredes y col. (2014) realizaron un estudio en el que describen la composición de hongos filamentosos presentes en una turbera compacta de Astelia (Asteliaceae) y Donatia (Donatiaceae) en la región fueguina de Moat. Sin embargo, aún resulta escasa la información sobre la diversidad y los roles de la comunidad de hongos microscópicos de turberas y su relación específica en el proceso de descomposición en estos ambientes.

El motivo principal para la realización de esta tesis, es completar y profundizar sobre la información de las comunidades de hongos microscópicos (Hyphomycetes) presentes en 
turberas compactas de Tierra del Fuego, así como la necesidad de definir cuáles son las variables que determinan su distribución.

\subsection{OBJETIVO GENERAL}

Analizar la composición, la diversidad, la dinámica y el rol de la comunidad de microhongos en turberas compactas de Tierra del Fuego y las variables que determinan las características de esta comunidad.

\subsection{OBJETIVOS PARTICULARES}

Aislar, identificar y caracterizar las especies de microhongos asociados a dos turberas compactas en Tierra del Fuego mediante metodologías clásicas de aislamiento y cultivo y metodologías moleculares.

$\checkmark \quad$ Evaluar la riqueza y diversidad de la comunidad fúngica en turberas compactas de Tierra del Fuego dominadas por Astelia sp. y Donatia sp.

$\checkmark \quad$ Analizar y relacionar algunas características físico-químicas de con la distribución de especies.

$\checkmark \quad$ Definir los roles potenciales que tendrían los microhongos en las turberas compactas en los procesos de descomposición de la materia orgánica. 


\section{CApítulo 2}

\section{DESCRIPCIÓN DEL ÁREA \&}

\section{CARACTERIZACIÓN DE LAS}

\section{TURBERAS DE ESTUDIO}




\subsection{DESCRIPCIÓN GENERAL DEL ÁREA DE ESTUDIO}

2.1.1. Situación geográfica. El sector argentino de la Isla Grande de Tierra del Fuego se encuentra entre los $52^{\circ}$ y $56^{\circ}$ de latitud sur, y los $63^{\circ}$ y $75^{\circ}$ de longitud oeste, con una superficie de $20.180 \mathrm{~km}^{2}$ (Figura 3). Limita al norte con el Estrecho de Magallanes, al sur con el Canal Beagle, al este con el océano Atlántico y al oeste con el sector chileno de la Isla, siendo el límite establecido el meridiano de 68³6' (Allué y col., 2010).

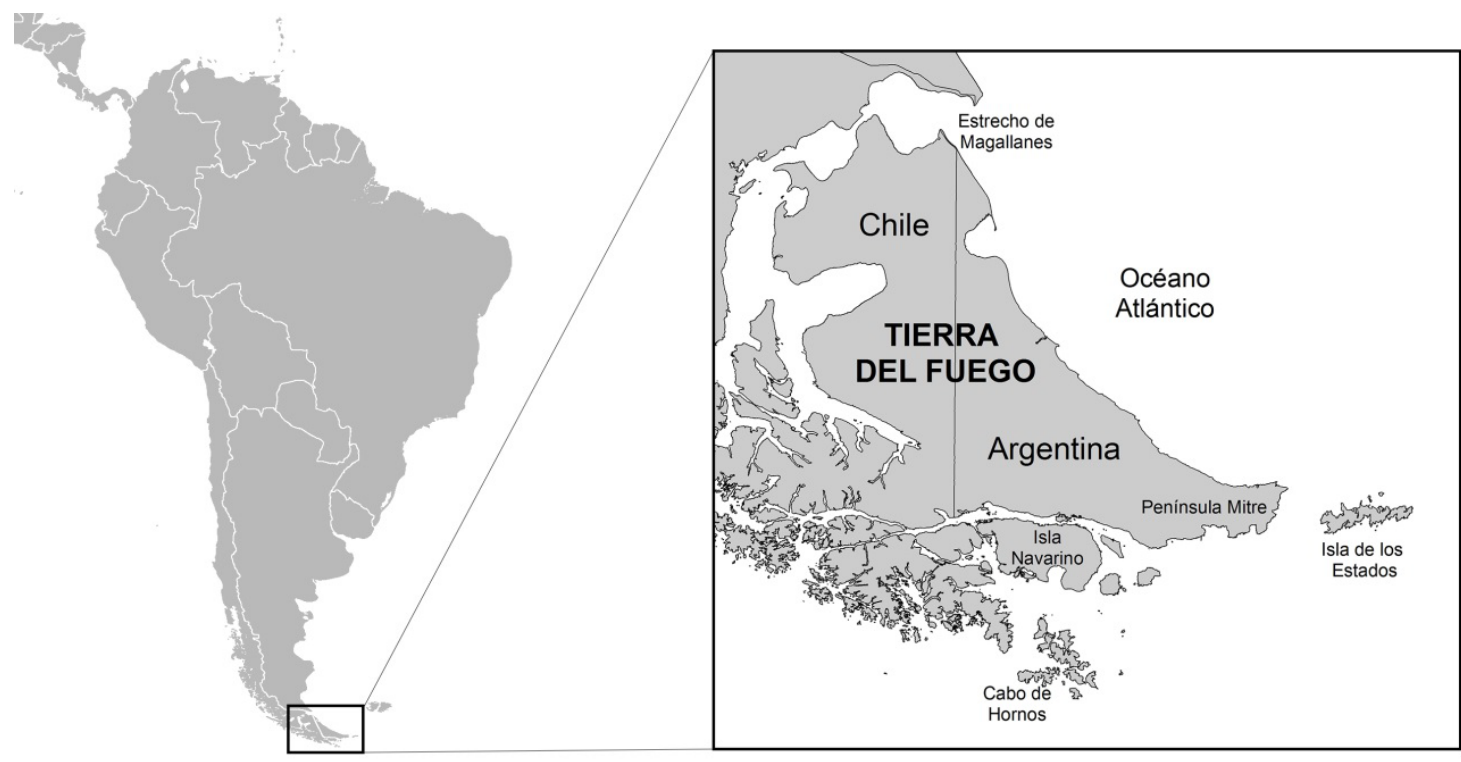

Figura 3. Situación geográfica de la Isla Grande Tierra del Fuego.

2.1.2. Geomorfología. En la Isla Grande de Tierra del Fuego existen dos grandes áreas topográficas: el área andina y el área extra andina. 
El área andina abarca el sur de la isla y los archipiélagos situados al sur y al oeste de la misma. La Cordillera de los Andes se sitúa en esta región, discurriendo de este a oeste, junto con diversos cordones montañosos. Se caracteriza por la presencia de glaciares y nieves permanentes en los picos más elevados. En los valles más profundos se sitúan lagos y se encuentran grandes extensiones ocupadas por turberas. Los valles poseen un característico relieve formado por la erosión glaciar; también existen otros valles con fondos abruptos con relieves modelados por los ríos (Bava, 1998).

El área extra andina comprende el norte de la isla, donde se extiende la prolongación de la meseta patagónica, con relieves llanos, lomas bajas y redondeadas desprovistas de vegetación arbórea y donde las sierras alcanzan una altura máxima de 500 metros. Además, la parte central actúa como zona de transición entre la estepa y el bosque y se caracteriza por presentar suaves ondulaciones y valles anchos poco profundos y alargados (Borelli y Oliva, 2001).

2.1.3. Clima. Las particularidades climáticas de Tierra del Fuego están relacionadas con las características de circulación de la atmósfera y las corrientes oceánicas a las latitudes involucradas, la influencia de la masa de hielo antártico, la naturaleza insular del territorio y la localización de la cordillera de los Andes (Frangi y col., 2004).

La isla recibe la influencia de los océanos Pacífico y Atlántico y la cercanía a la Antártida (aprox. $1.000 \mathrm{~km}$ ). Es así que los océanos moderan el enfriamiento invernal, lo que se manifiesta con temperaturas medias en las costas de Tierra del Fuego por encima del punto de 
congelación (Tuhkanen y col., 1990). Este efecto moderador se acentúa en invierno sobre la costa pacífica por acción de la corriente de aire proveniente del oeste. En la costa atlántica la corriente de agua fría proveniente de las Islas Malvinas produce un enfriamiento de las temperaturas invernales debajo de los $0^{\circ} \mathrm{C}$ (Carabelli, 2000).

La influencia anual ciclónica O-SO se relaciona con la dirección dominante de los vientos (Tuhkanen, 1992). En invierno Tierra del Fuego se halla al paso del viento antártico que provoca condiciones secas y ventosas. Sobre la superficie relativamente cálida de las aguas oceánicas este viento frío se calienta rápidamente y se humidifica en su marcha con rumbo norte hacia Tierra del Fuego (Carabelli, 2000)

Con este patrón de vientos dominantes y las condiciones de relieve de la cadena montañosa de los Andes se genera un acentuado gradiente de precipitación que influye en la distribución de la vegetación. Las nubes húmedas que transportan los vientos provenientes del Pacífico descargan en las laderas oeste de los Andes chilenos. Continuando en dirección E favorecen como vientos secos la extensión de la estepa fueguina en el sector noreste de la isla (Carabelli, 2000).

Por último, en general las condiciones climáticas de Tierra del Fuego son notablemente oceánicas (Tuhkanen, 1992), con lluvias frecuentes todo el año y régimen térmico de moderada amplitud: la temperatura media anual en Ushuaia (a nivel del mar) es de $5.5^{\circ} \mathrm{C}$; el promedio de enero -el mes más cálido- de $9.4^{\circ} \mathrm{C}$ y de julio -el más frio- de $1^{\circ} \mathrm{C}$. La precipitación anual a 
nivel del mar es de $530 \mathrm{~mm}$ (registros de Ushuaia), pero este valor se duplica en el ambiente de montaña (Iturraspe y col., 2007).

2.1.4. Vegetación. Tierra del Fuego posee particularidades climáticas y de su geomorfología que se reflejan en su fisonomía vegetal, generando ambientes naturales muy bien diferenciados (Pisano, 1981, 1997; Frangi y Richter, 1992; Burkart et al., 1999). Según Moore (1983) es posible definir en la región cuatro tipos principales de vegetación: la estepa patagónica, los bosques deciduos, los bosques siempreverdes, y la vegetación de alta montaña en los sistemas de mayor altitud. Por otro lado, Collado (2007) divide el territorio en cuatro regiones naturales: La zona norte o estepa magallánica, una zona central de ecotono estepa-bosque y el sur, compartido por dos zonas, de cordillera al oeste y de turbales al este (Figura 4) (Allué y col., 2010). 


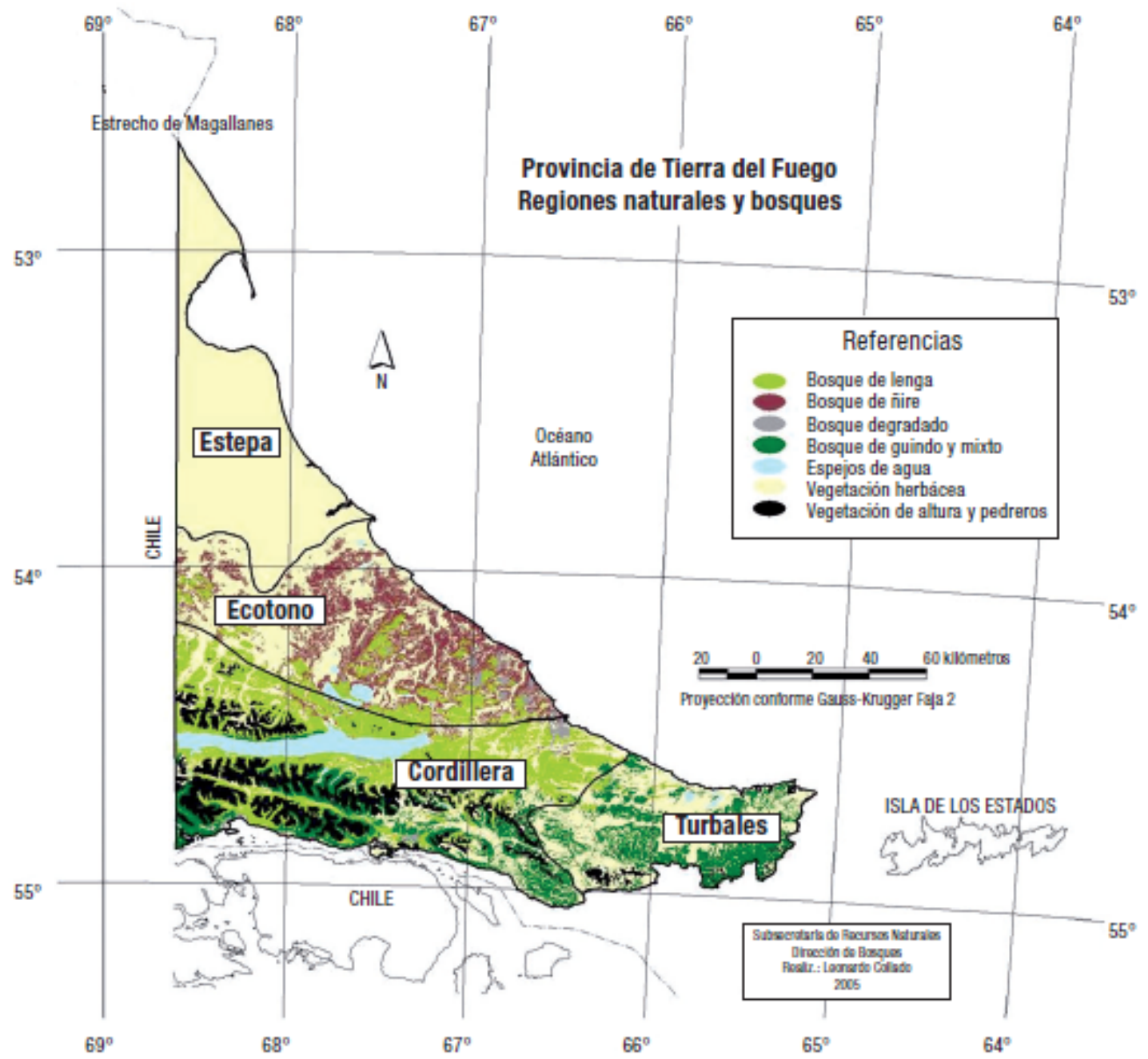

Figura 4. Regiones naturales del sector argentino de la Isla Grande de Tierra del Fuego (Collado, 2007).

De estas regiones naturales, las turberas fueguinas conforman componentes ambientales en diversas variedades, estados de desarrollo y extensión, presentes en casi todas las zonas de la Isla, dado que en la estepa, si bien son reducidos los turbales activos, se los encuentra con frecuencia en estado fósil (Bonarelli, 1917). 
Existen diferentes tipos de turberas en Tierra del Fuego y están determinados por los constituyentes botánicos que las componen. Sin embargo, en esta descripción general, sólo se enfatizará en las turberas compactas formadas y/o dominadas por la planta en cojín Astelia pumila.

2.1.5. Características y particularidades de Astelia pumila. Es una de las plantas más singulares en algunas turberas del Sur de la Patagonia y Tierra del Fuego (Figura 5A). Se caracteriza por presentar raíces largas y una relativamente pequeña cantidad de biomasa por encima del suelo. La presencia de esta especie formando turberas compactas o en cojín sólo ocurre en el Hemisferio Sur. En Tierra del Fuego, Astelia pumila crece, junto a Donatia fascicularis (Figura 5B), en Moat y Península Mitre y es dominante en turberas que están próximas al mar; mientras que en los valles más internos del Sur patagónico y Tierra del Fuego, Sphagnum magellanicum es la especie dominante en las turberas (Keizer y Hermen, 2008). 

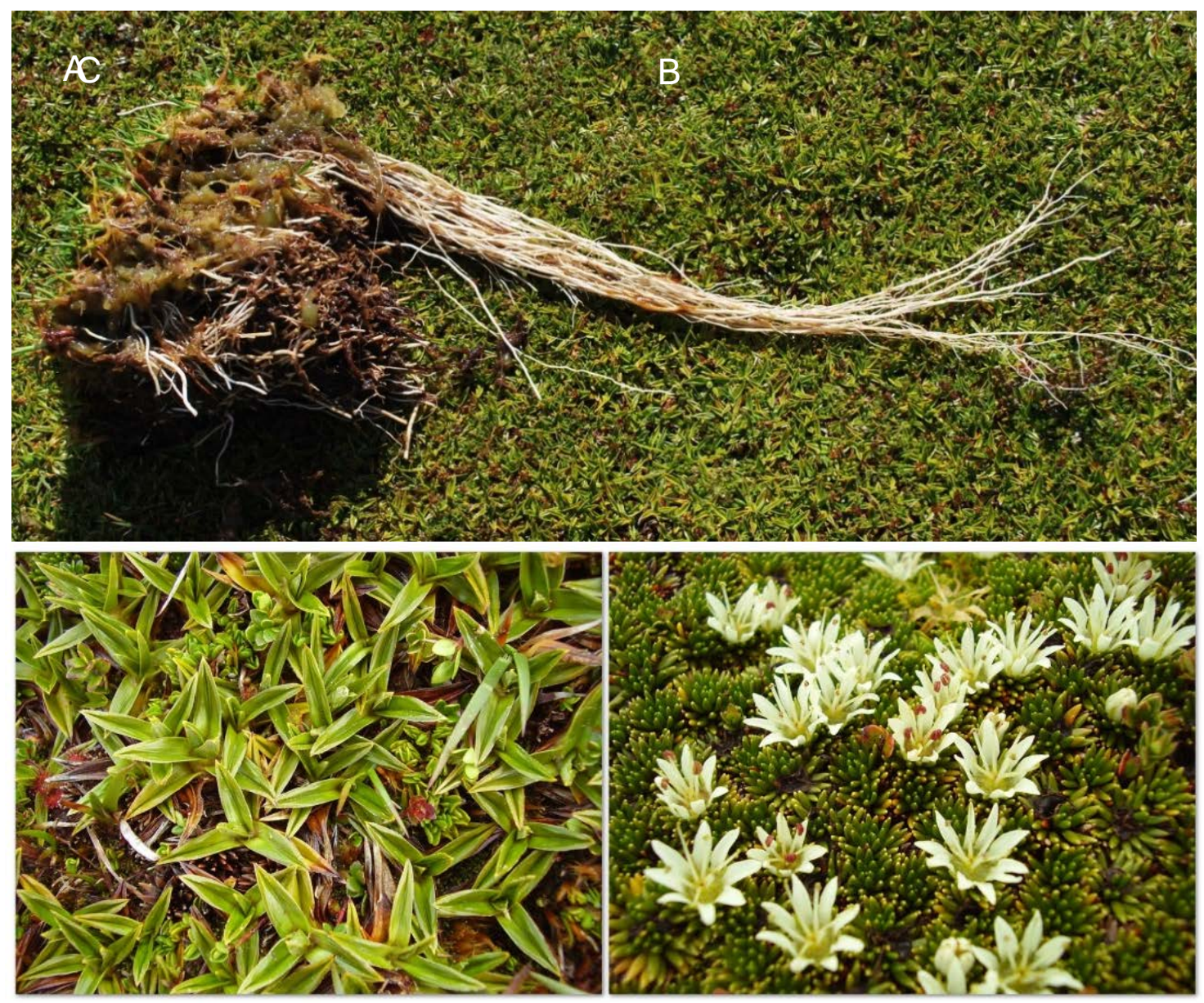

Figura 5. A. Astelia pumila. B. Donatia fascicularis. C. Porción de turba con raíces expuestas de Astelia pumila.

La carpeta de Astelia se satura y retiene el agua de lluvia que no es acumulada en los tejidos, sino en la densa masa de hojas y tallos muertos de Astelia y otras especies vegetales acompañantes. Suele ser rica en Marsipospermum y Empetrum rubrum, En el continente puede ingresar en ella Nothofagus betuloides con plantas normalmente poco desarrolladas. Este tipo de turbera adquiere particular importancia no solo en Tierra del Fuego, sino también en las islas del 
sur, en Cabo de Hornos y luego en Malvinas, aunque no llega a las Georgias (Blanco y de la Balze, 2004).

\subsubsection{Turberas de Astelia con agua. Son turberas planas o en planos levemente} inclinados formando carpetas duras, con charcas elongadas y con una profundidad de hasta un metro. Las charcas cubren más del $30 \%$ de la superficie. Por lo general, se encuentran en las zonas topográficamente más bajas, como el fondo de valle. La profundidad de la acumulación de turba es superior al metro. La especie dominante es Astelia pumila, con túmulos poco prominentes y amplios. La acompañan Donatia fascicularis, que se mezcla con la anterior pero en una proporción varias veces menor. También están presentes Empetrum rubrum y Caltha dioneifolia. En los bordes de las charcas y dentro de las mismas encontramos Tetroncium magellanicum, a veces muy abundante, y Sphagnum magellanicum. Elementos aún menos frecuentes de esta formación vegetal son Nothotfagus betuloides de formas enanas y poco desarrolladas, Nanodea muscosa, Myrteola nummularia, Marsipospermum grandiflorum, Rotskovia magellanica, Pernettya pumila y líquenes de los géneros Cladina y Cladonia (Martínez Carretero, 2004).

2.1.7. Turberas de Astelia sin agua. Son turberas que forman carpetas duras, sobre topografías planas u onduladas, sin presencia de ojos de agua o con presencia ocasional y de pequeñas dimensiones. Estas turberas se presentan generalmente en posiciones de borde 
respecto del bosque, ejerciendo una transición entre éste y las turberas de Astelia con ojos de agua, donde éstas existen, o bien se encuentran sin estas últimas en ubicaciones topográficas más elevadas que aquellas, pero en el relieve general ocupan el fondo de valle. La profundidad de la acumulación de turba es siempre superior a un metro de longitud. La especie dominante es Astelia pumila, con coberturas superiores al $50 \%$, formando túmulos poco prominentes y amplios. La especie codominante en esta asociación es Nothofagus betuloides, que se presenta en forma dispersa, con individuos que no superan los $2 \mathrm{~m}$ y coberturas del orden del $15-30 \%$. Son comunes en menores porcentajes Donatia fascicularis, Empetrum rubrum, Caltha dioneifolia y Rotskovia magellanica. Representantes menos abundantes son Tetroncium magellanicum, Oreobolus obtusangulus, Myrteola nummularia, Marsipospermum grandiflorum y líquenes de los géneros Cladina y Cladonia. Asociadas a Nothofagus betuloides y bajo su dosel, encontramos a Gunnera magellanica, Chilliotrichum diffusum, Senecio sp. y Luzuriaga marginata (Martínez Carretero, 2004).

2.1.8. Sitios de estudio. Este trabajo se llevó a cabo en sitios de muestreo seleccionados en dos turberas compactas ubicadas en la zona sur de Tierra del Fuego. Una turbera está situada en cercanías al río Moat ( $54^{\circ} 58^{\prime} 28 S, 66^{\circ} 43^{\prime} 540$ ) (Figuras 6 y 7 ) y otra, próxima a la zona del

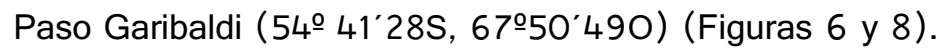

La vegetación típica de las turberas seleccionadas está representada por especies que constituyen carpetas densas, verde intensa, ricas en especies que presentan una intrincada trama 
radicular en suelo orgánico, negruzco y húmedo. En general, estuvieron dominadas por la presencia de Astelia pumila (G. Forst.) Gaudich., y se encontraron algunas especies de ciperáceas, juncáceas, briófitas, líquenes y ejemplares de Nothofagus sp. enanos y achaparrados.

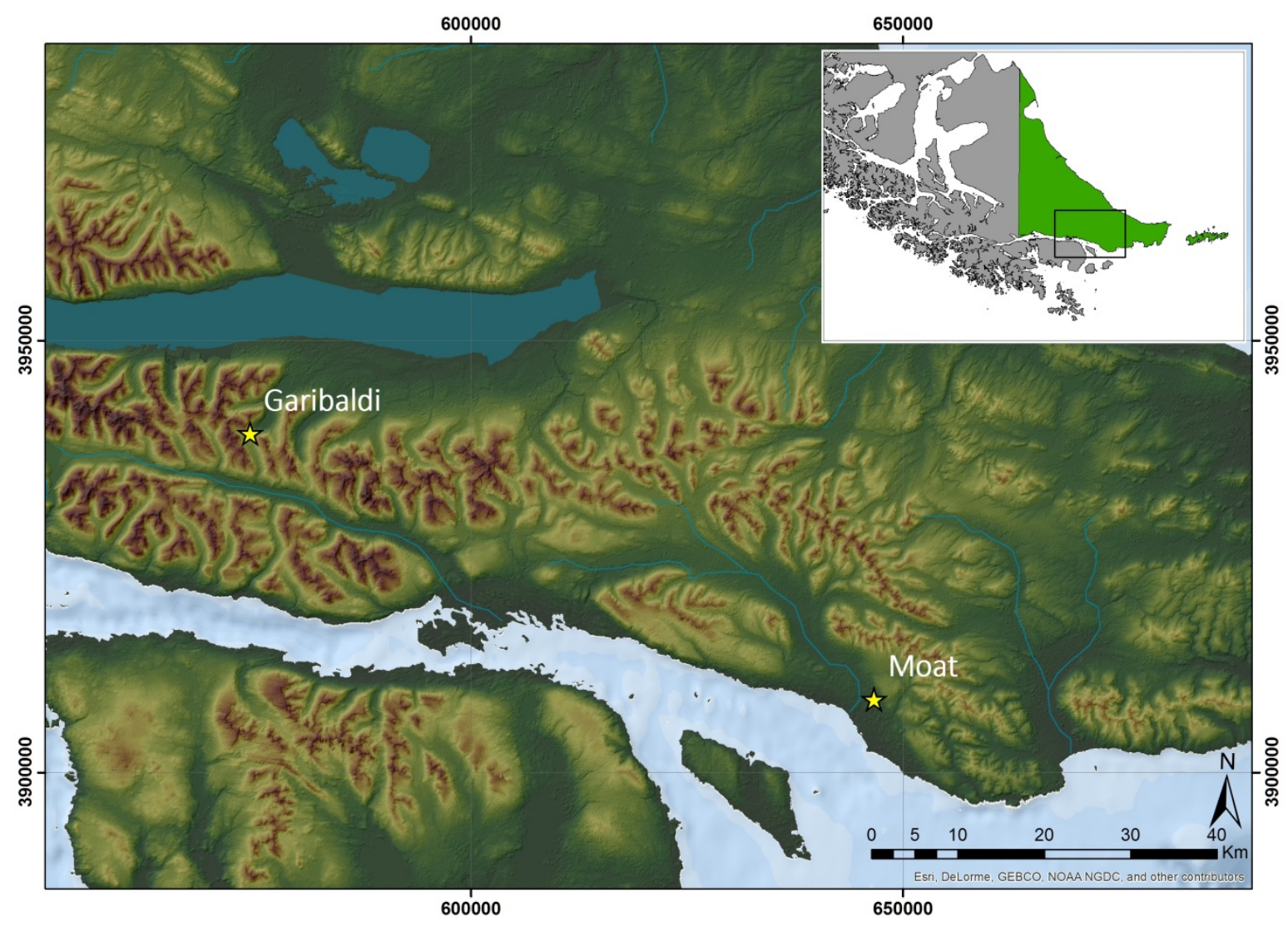

Figura 6. Ubicación geográfica de los sitios de muestreo.

La selección de estas turberas se realizó considerando que dichas áreas están situadas en condiciones geográficas contrastantes. Ambas turberas están dominadas por plantas perennes en cojín entremezcladas con parches (pocos metros cuadrados) cubiertos por Sphagnum magellanicum. 
La turbera de la región Moat se encuentra localizada al Este de la ciudad de Ushuaia, ocupando un lugar costero, donde la precipitación es mayor a los $2.000 \mathrm{~mm}$ anuales, con alta influencia marina, vientos fuertes y deposición de sales marinas. Además se desarrolla en sitios planos formando un patrón de carpetas duras intercaladas con charcas (pools). Las plantas en cojín que dominan el área son Astelia pumila y Donatia fascicularis, cubriendo más del $70 \%$ de la superficie. También se encuentran otras especies vegetales de turbera, como Tetroncium magellanicum, Caltha dioneifolia, Drosera uniflora y algunos individuos de Nothofagus betuloides poco desarrollados.

Por otro lado, la turbera cercana al Paso Garibaldi se sitúa al noroeste de Ushuaia, en una zona de mayor altura y de paisaje y/o relieve montañoso, protegida de los vientos. No presenta charcas, ocupa una menor extensión con respecto a la turbera de Moat y la comunidad vegetal que la acompaña también es diferente. 


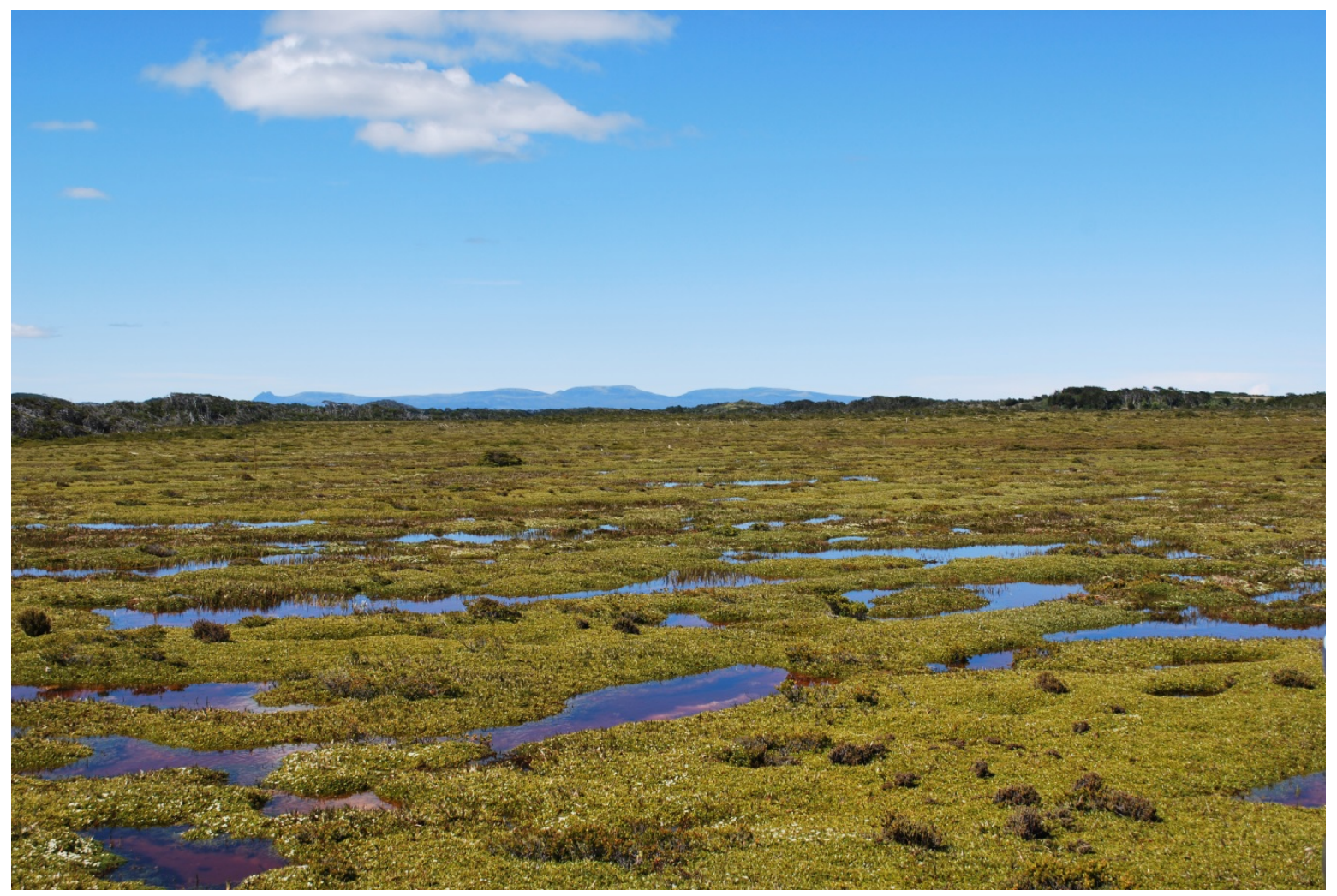

Figura 7. Turbera compacta de Astelia-Donatia en Moat, Tierra del Fuego. 


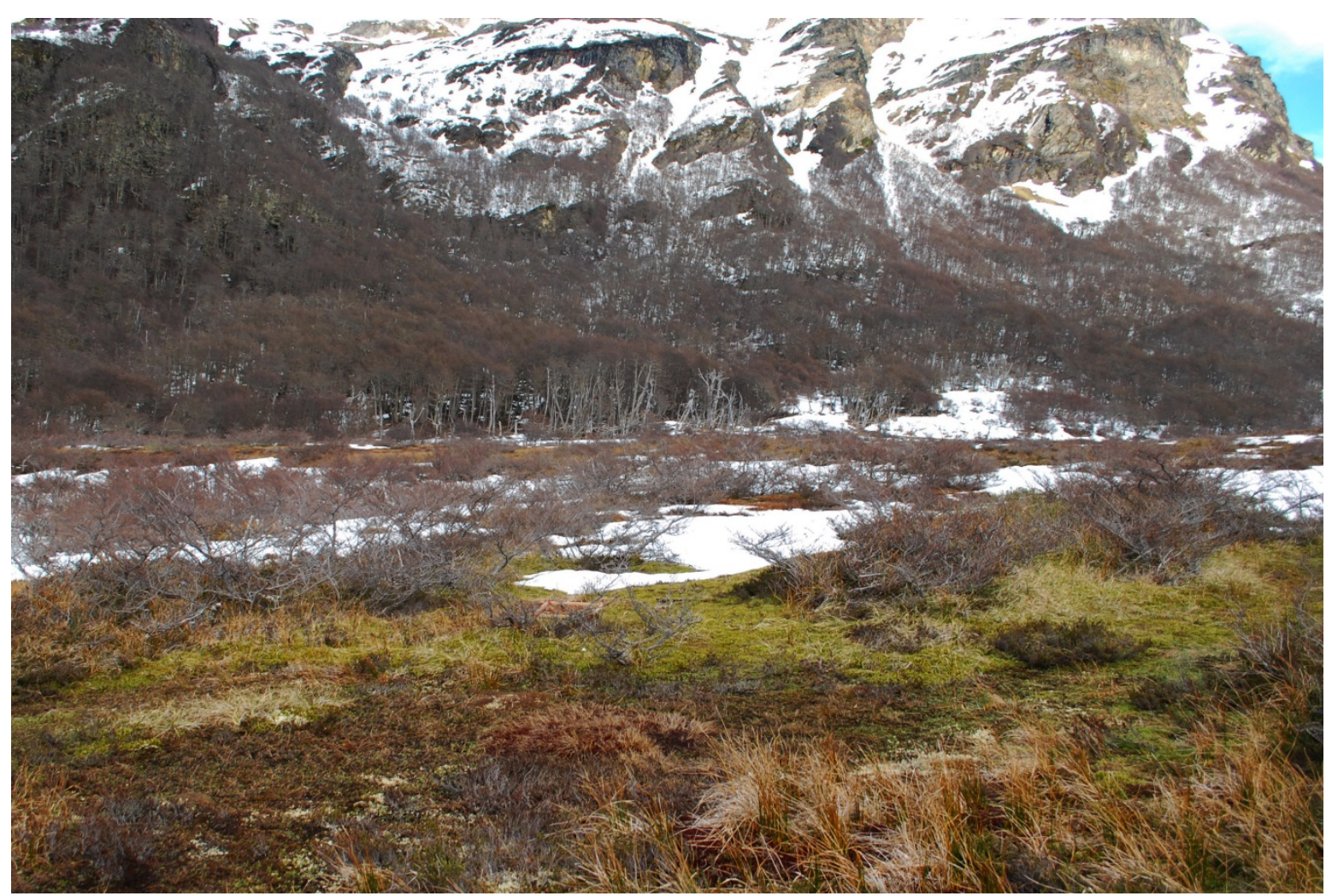

Figura 8. Turbera compacta de Astelia pumila próxima al Paso Garibaldi, Tierra del Fuego.

\subsection{MATERIALES \& MÉTODOS}

2.2.1. Recolección de muestras y conservación del material. En las turberas descriptas

previamente se llevaron a cabo dos campañas de relevamiento de datos y toma de muestras, durante los meses de febrero y noviembre de 2012, trabajando en los puntos seleccionados durante un muestreo piloto (realizado en el año 2011). 
Las muestras de turba fueron tomadas a partir de la instalación de parcelas de $50 \times 50 \mathrm{~cm}$ en 20 puntos de muestreo ubicados en las dos turberas en estudio ( 10 parcelas en Garibaldi; 10 parcelas en Moat; Figura 6). Las parcelas se situaron de modo que aproximadamente la mitad de la superficie a muestrear estuvo cubierta por Sphagnum magellanicum y la otra mitad por Astelia pumila (Figura 9).

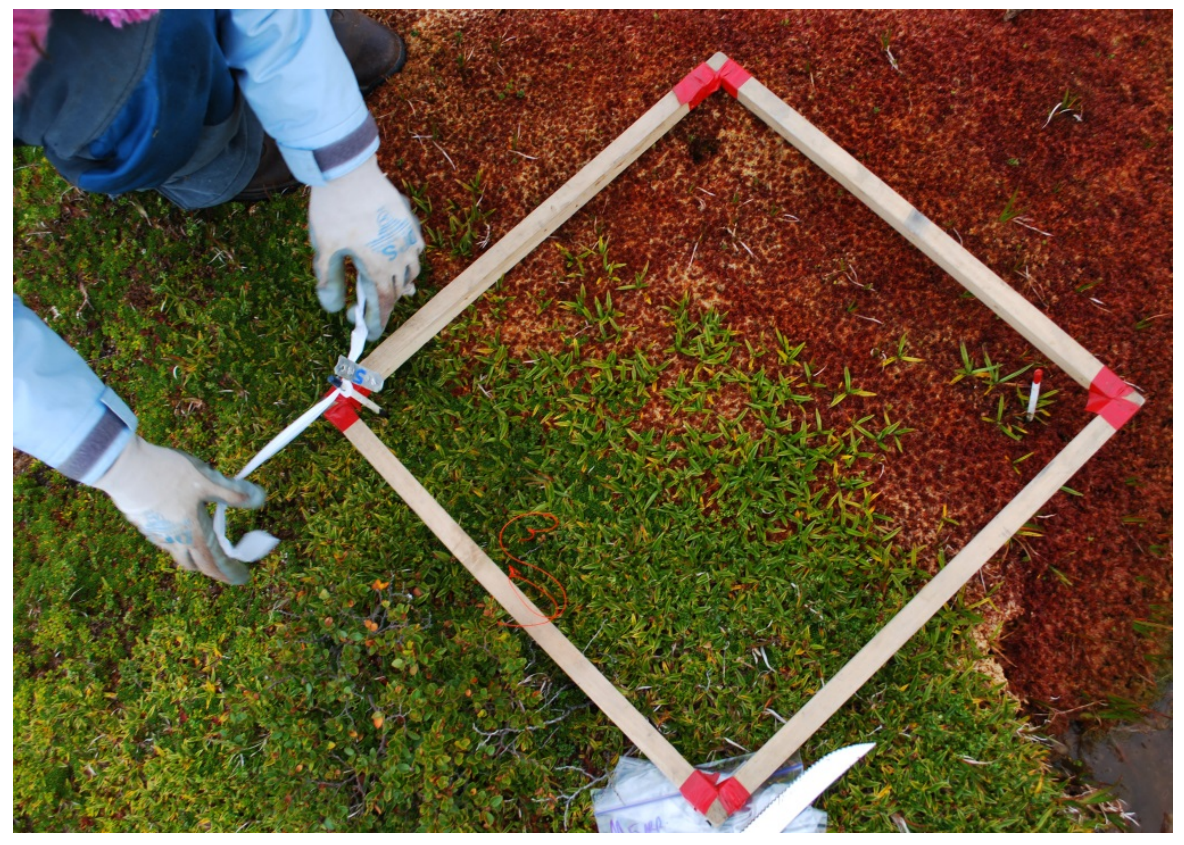

Figura 9. Parcela de muestreo. A. Astelia pumila. B. Sphagnum magellanicum.

En cada parcela se tomó una muestra de turba de Sphagnum y una muestra de turba de Astelia, de los primeros 20 centímetros de profundidad. Se colectaron un total de 40 muestras por campaña, resultando en un total de 80 muestras analizadas para el estudio completo (Figura 10). 

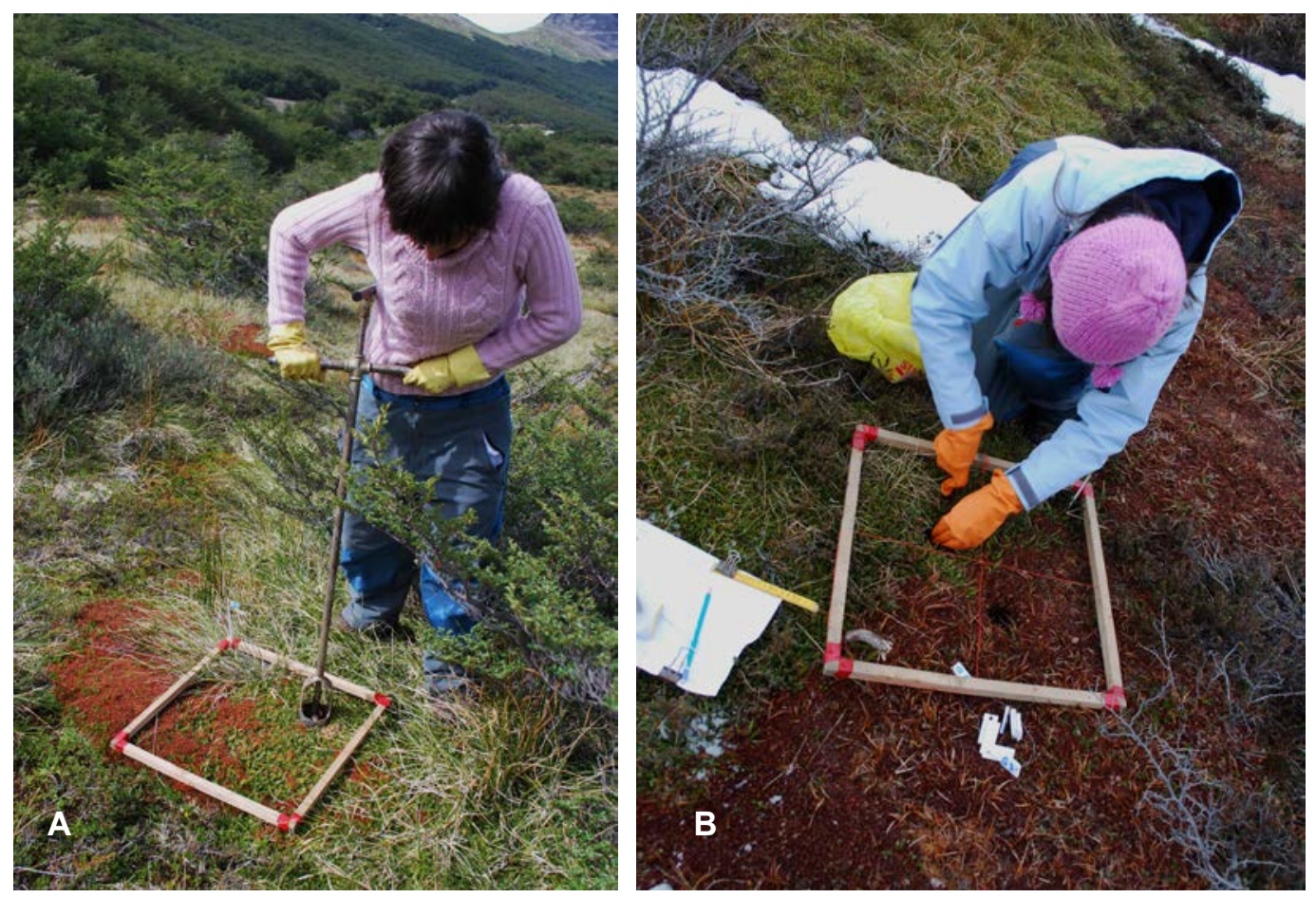

Figura 10. Recolección de muestras de turba con barreno (A) y cuchillo dentado (B) en una turbera compacta de Astelia en Tierra del Fuego.

Las muestras fueron conservadas en bolsas de plástico estériles con cierre hermético y se mantuvieron a $4^{\circ} \mathrm{C}$ en el Centro Austral de Investigaciones Científicas (CADIC-CONICET) de la ciudad de Ushuaia, hasta su posterior procesamiento, fraccionamiento y análisis en el Laboratorio de Ecología Terrestre.

2.2.2. Procesamiento y fraccionamiento de muestras. El procesamiento de las muestras consistió en la remoción de los $3 \mathrm{~cm}$ superficiales, porción aérea viva, de cada muestra de turba 
recolectado. El bloque de turba resultante fue fraccionado en sub-muestras de dos profundidades (A: 3-10 cm; B: 10-20 cm, Figura 11). De esta forma, a partir de las 40 muestras tomadas por campaña se obtuvieron un total de 80 sub-muestras, resultando en 160 sub-muestras totales analizadas para el estudio completo. De cada sub-muestra, se removieron los restos y se conservó la turba para posteriores análisis.

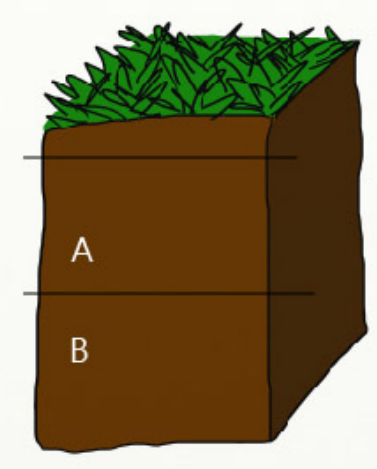

Astelia pumila

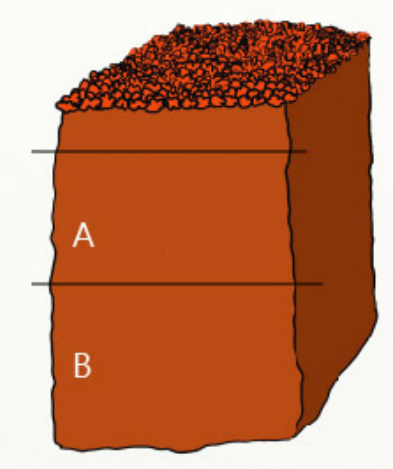

Sphagnum magellanicum

Figura 11. Esquema del fraccionamiento de muestras de turba de Astelia pumila y Sphagnum magellanicum $(A=3-10 \mathrm{~cm} ; B=10-20 \mathrm{~cm})$.

Parte del material fraccionado fue trasladado a los laboratorios del Instituto de Botánica Carlos Spegazzini (Facultad de Ciencias Naturales y Museo - UNLP) de la ciudad de La Plata para realizar el aislamiento e identificación de hongos microscópicos (CAP. 3).

2.2.3. Determinación de las variables físico-químicas. En cada punto de muestreo de las turberas en estudio, se registró información relacionada con la caracterización florística e hidrológica, el pH y la temperatura. En el Laboratorio de Ecología Terrestre (CADIC-CONICET), 
luego del fraccionamiento de las muestras de turba recolectadas, se determinó el contenido hídrico y de nutrientes (carbono y nitrógeno) de las muestras de turba recolectadas.

a) Caracterización florística. Se registraron las especies de plantas vasculares, y la presencia de musgos, hepáticas y líquenes acompañantes.

b) Caracterización hidrológica. La altura del agua se registró con un metro, considerando la distancia desde la superficie del punto de muestreo hasta el agua.

c) $\mathrm{pH}$ y temperatura. Durante los muestreos se registró la temperatura con data logger, así como el pH a campo, utilizando un peachímetro. En los casos en que estos parámetros no pudieron ser determinados en campo, se realizó la determinación en el laboratorio.

d) Contenido hídrico de las muestras. El contenido hídrico de las muestras se determinó por la diferencia de pesos entre el peso de las muestras de turba frescas (húmedas) y el peso de las muestras secas (secado en estufa a $60^{\circ} \mathrm{C}$ ). Siendo la pérdida de peso (\%) el contenido hídrico presente en la muestra. 
e) Nutrientes. Se determinó el contenido de carbono total y nitrógeno total. El contenido de carbono para cada muestra de turba se estimó como el $50 \%$ de la materia orgánica de la muestra, luego de su incineración a $500^{\circ} \mathrm{C}$, dado que los valores de carbono en las plantas oscilan entre el 48 y el $52 \%$ de la materia orgánica (Gallardo y Merino, 1993). Para determinar el contenido de nitrógeno total de las muestras, se siguió el procedimiento estándar de digestión ácida de Kjedahl (Bremmer y Mulvaney, 1982).

2.2.4. Análisis de datos. A través de análisis de varianza (ANOVA) se determinó la influencia de los factores 'profundidad" $(A=3-10 \mathrm{~cm} ; B=10-20 \mathrm{~cm})$, 'cobertura' (Astelia pumila; Sphagnum magellanicum) y 'sitio' (turbera Moat; turbera Garibaldi) sobre las variables 'nivel de agua', 'contenido hídrico', 'contenido de materia orgánica' y ‘contenido de nitrógeno’.

\subsection{RESULTADOS}

2.3.1. Caracterización florística. La cubierta vegetal de las turberas compactas seleccionadas en este estudio forma una carpeta vegetal dura compuesta por grandes parches de Astelia pumila y algunos parches de Sphagnum magellanicum que cubren una menor superficie. En la figura 12 se pueden observar los porcentajes de superficie cubierta por Astelia pumila y 
Sphagnum magellanicum en cada una de las parcelas muestreadas para la realización de este estudio.

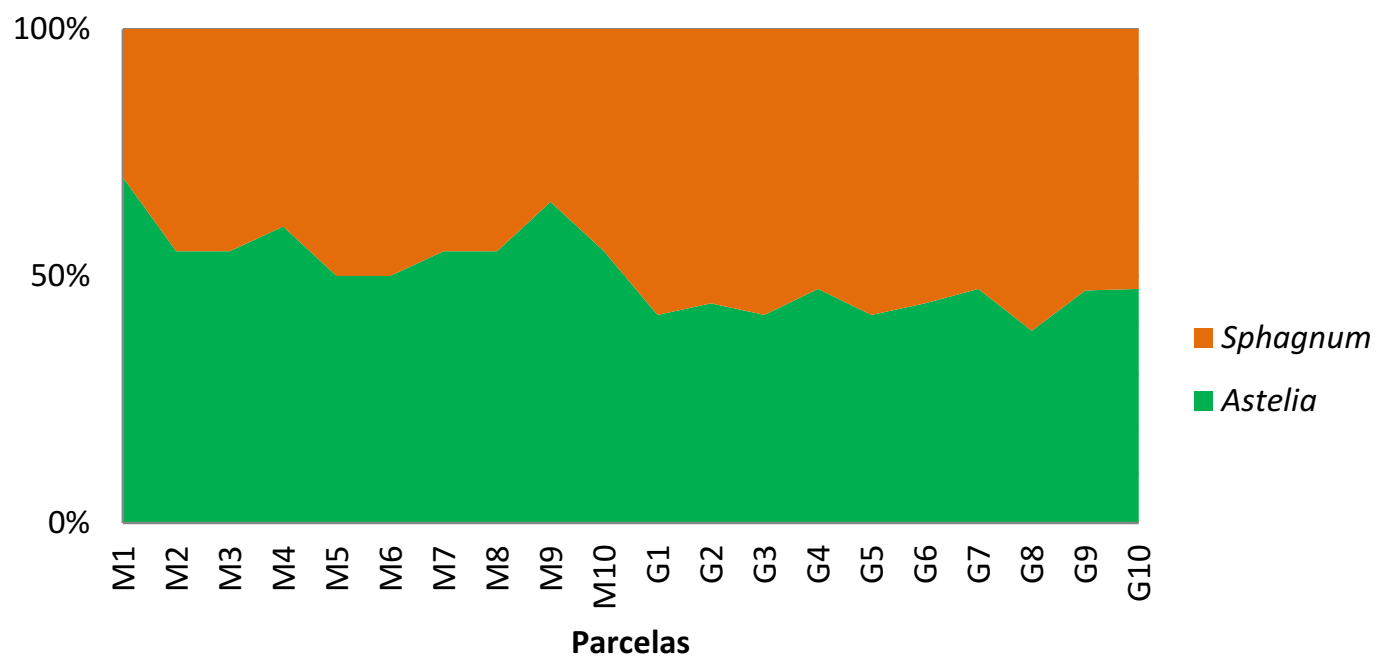

Figura 12. Porcentajes de superficie cubierta por Astelia pumila y Sphagnum magellanicum en las parcelas muestreadas de las turberas en estudio, situadas en Moat (M) y Garibaldi (G).

La composición específica varió en los sitios muestreados, las parcelas ubicadas en la turbera situada en Moat se registraron Donatia, Drossera, Nanodea; mientras que en parcelas de Garibaldi, se encontró: Carex, Chilliotrichum, Nothofagus, Gunnera, Juncus y Marsipospermum. Ambas turberas compartieron sólo la presencia de los géneros Caltha, Pernettya y Tetroncium (Figura 13). 


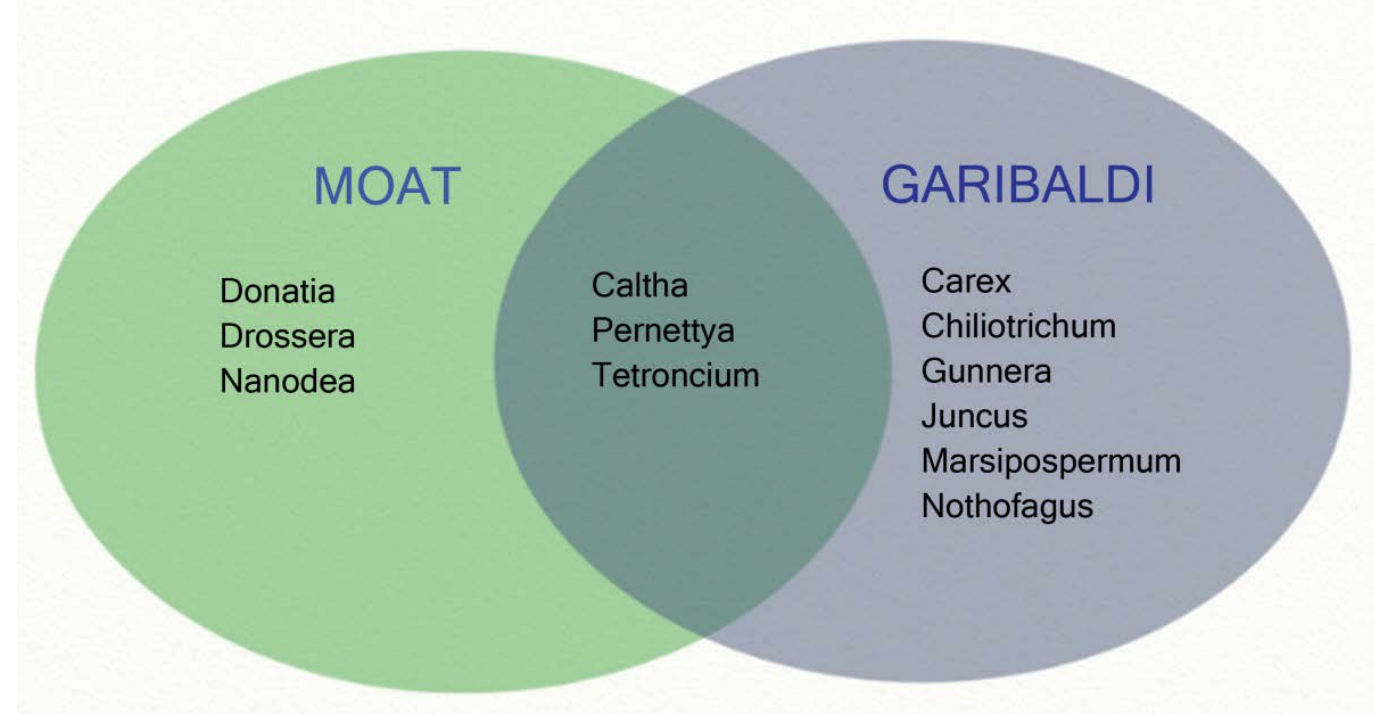

Figura 13. Géneros vegetales registrados en las parcelas de muestreo de dos turberas compactas (Moat y Garibaldi).

2.3.2. Caracterización hidrológica. La distancia al agua en los distintos puntos de muestreo de las turberas en estudio osciló entre los 0,40 y $13,50 \mathrm{~cm}$ para el sitio Moat y 6 y 17 cm para el sitio Garibaldi (Figura 14).

La distancia a la napa freática fue mayor en el sitio de Garibaldi, respecto de Moat. Este patrón fue común tanto en febrero (ANOVA: ANEXO 1) como en noviembre (ANOVA: ANEXO 2), siendo mayor la distancia al agua en las parcelas cubiertas por Astelia con respecto a las cubiertas por Sphagnum (Figura 14). En febrero se registró una mayor distancia al agua en las parcelas cubiertas por Astelia. Sin embargo, se observó que para los valores registrados para la temporada de noviembre la cobertura vegetal no tuvo un efecto significativo sobre el nivel de agua (ANOVA: ANEXO 2- Tabla B). 
Con respecto al factor 'sitio', al analizar los datos de la temporada de febrero, se observó que éste tuvo un efecto significativo sobre la distancia al agua solo en aquellas parcelas cubiertas por Sphagnum (ANOVA: ver ANEXO 1-Tabla C), siendo mayor la distancia al agua de las muestras tomadas en Garibaldi, tanto a la profundidad A $(3-10 \mathrm{~cm})$ como $B(10-20 \mathrm{~cm})$ con respecto a las muestras tomadas en Moat (Figura 14). Por otro lado, en noviembre el factor 'sitio' influyó significativamente en todas las muestras, presentando mayores distancias las parcelas ubicadas en la turbera Garibaldi; excepto, cuando se compararon las muestras tomadas de parcelas con Sphagnum y a la profundidad (A), no hubo diferencias significativas (ANOVA: ver ANEXO 2-Tabla C).

En general, las turberas en estudio difirieron significativamente con respecto al nivel de agua, siendo mayor la distancia al agua registrada para los puntos de muestreo ubicados en la turbera de Garibaldi. Además, durante el muestreo realizado en primavera (noviembre) la distancia fue menor, es decir, el nivel de la freática se elevó en ambas turberas, lo que podría ser consecuencia del proceso de deshielo. 


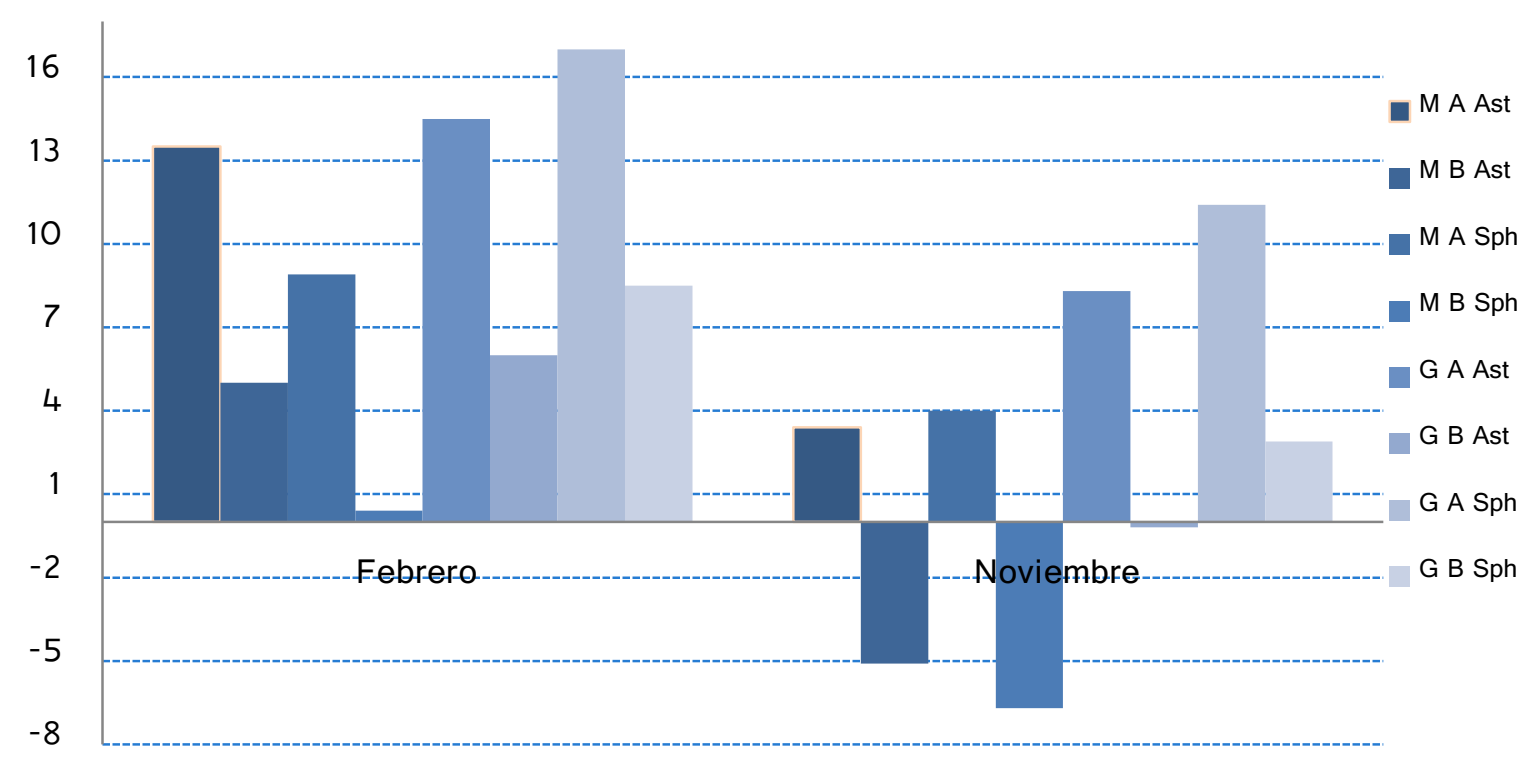

Figura 14. Distancia media (centímetros) al agua que presentaron los sitios de muestreo de dos turberas compactas (Moat y Garibaldi), durante dos temporadas de muestreo (Febrero 2012 y Octubre 2012) y en presencia de dos tipos de cobertura vegetal (Ast: Astelia pumila y Sph: Sphagnum magellanicum).Los valores negativos corresponden a sitios de muestreo sumergidos.

\subsection{3. $\mathrm{pH}$ y Temperatura de las turberas en estudio. Las turberas en estudio} presentaron un $\mathrm{pH}$ de carácter fuertemente ácido, oscilando los valores medios entre 3,63 y 4,39. Para ambas turberas, en el muestreo realizado en febrero los valores de $\mathrm{pH}$ registrados fueron levemente superiores en las muestras de turba tomadas de las parcelas cubiertas por Astelia con respecto a los valores registrados para las de Sphagnum (datos no mostrados). Los valores medios de $\mathrm{pH}$ para la turbera situada en Moat fueron de 4,02 en el muestreo de febrero y 3,68 en el de noviembre; mientras que los valores para la turbera en Garibaldi, fueron de 4,43 y 3,97 para enero y febrero respectivamente. 
En la tabla 1 se presentan los valores medios de temperatura registrados durante las dos temporadas de muestreo en las turberas de estudio. En general, se observa que durante la temporada de muestreo de febrero, tanto para Moat como para Garibaldi, los valores de temperatura promedio fueron muy similares y bajos $\left(4,04-5,95^{\circ} \mathrm{C}\right)$, a pesar de corresponder con el período de verano. En la temporada de noviembre el data logger instalado en la turbera Moat no registró datos.

Tabla 1. Valores medios de temperatura $\left({ }^{\circ} \mathrm{C}\right)$ registrados para las turberas situadas en Moat y Garibaldi durante dos temporadas de muestreo (Febrero y Noviembre de 2012) y en presencia de las especies vegetales Astelia pumila y Sphagnum magellanicum.

\begin{tabular}{ccc}
\multicolumn{3}{c}{ TEMPERATURA } \\
SITIO \& COBERTURA & FEBRERO & NOVIEMBRE \\
\hline MOAT ASTELIA & 5,41 & - \\
\hline MOAT SPHAGNUM & 5,95 & - \\
\hline GARIBALDI ASTELIA & 4,04 & 3,42 \\
\hline GARIBALDI SPHAGNUM & 5,73 & 2,61 \\
\hline
\end{tabular}

2.3.4. Contenido hídrico de las muestras. Las muestras de turba presentaron un contenido hídrico cuyos valores oscilaron entre el 66,09 y el 93,49\% (Tabla 2).

El contenido hídrico resultó similar en muestras tomadas a las profundidades $\mathrm{A}$ y $\mathrm{B}, \mathrm{y}$ este resultado se observó en ambos períodos de muestreo (Tabla 2; ANOVA: ANEXOS 3 y 4- 
Tablas A). Por otro lado, las muestras de Sphagnum presentaron un mayo contenido hídrico respecto de las de Astelia, independientemente de la profundidad (Tabla 2; ANOVA: ANEXOS 3 y 4-Tablas B).

Considerando el sitio de muestro, tanto en febrero como en noviembre el contenido hídrico fue mayor en las muestras tomadas en la turbera de Garibaldi (Tabla 2; ANOVA: ANEXOS 3 y 4 -Tablas C).

En general, el contenido hídrico de las muestras de turba analizadas superó el $50 \%$ de su peso húmedo. 
Tabla 2. Contenido hídrico medio (\%) en muestras de turba colectadas en dos turberas compactas (G: Garibaldi; M: Moat) de Tierra del Fuego, en presencia de dos tipos de cobertura vegetal (Ast: Astelia; Sph: Sphagnum), a dos profundidades (A: 3-10 cm; B $=10-20 \mathrm{~cm}$ ) y en dos temporadas de muestreo (febrero y noviembre de 2012).

\begin{tabular}{|c|c|c|c|}
\hline & Sitio \& Cobertura & Profundidad & $\mathrm{CH}(\%)$ \\
\hline \multirow{8}{*}{ 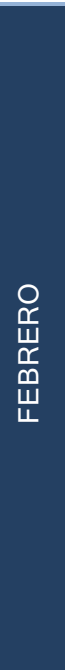 } & \multirow{2}{*}{ M Ast } & A & 87,84 \\
\hline & & B & 89,68 \\
\hline & \multirow{2}{*}{ M Sph } & A & 93,63 \\
\hline & & B & 93,88 \\
\hline & \multirow{2}{*}{ G Ast } & A & 90,07 \\
\hline & & B & 91,15 \\
\hline & \multirow{2}{*}{ G Sph } & A & 94,09 \\
\hline & & B & 93,49 \\
\hline \multirow{8}{*}{ 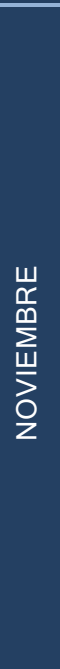 } & \multirow{2}{*}{ M Ast } & A & 66,09 \\
\hline & & B & 67,03 \\
\hline & \multirow{2}{*}{ M Sph } & A & 77,81 \\
\hline & & B & 74,77 \\
\hline & \multirow{2}{*}{ G Ast } & A & 74,65 \\
\hline & & B & 77,71 \\
\hline & \multirow{2}{*}{ G Sph } & A & 79,43 \\
\hline & & B & 78,61 \\
\hline
\end{tabular}

2.3.5. Contenido de materia orgánica. En general, las muestras de turba de las turberas en estudio presentaron un alto contenido de carbono (Figura 15), con valores mayores al $90 \%$. 
Tanto en la temporada de muestreo de febrero como en la temporada de noviembre, no hubieron diferencias significativas en el contenido de materia orgánica de entre las muestras de turba de Astelia y de Sphagnum (Figura 15; ANOVA: ANEXOS 5 y 6-Tablas A).

En ambas temporadas de muestreo el factor 'sitio' influyó significativamente en el contenido de materia orgánica presente en las muestras, siendo mayor en las muestras colectadas de la turbera situada en Moat (Figura 15; ANOVA: ver ANEXOS 5 y 6 - Tablas B).

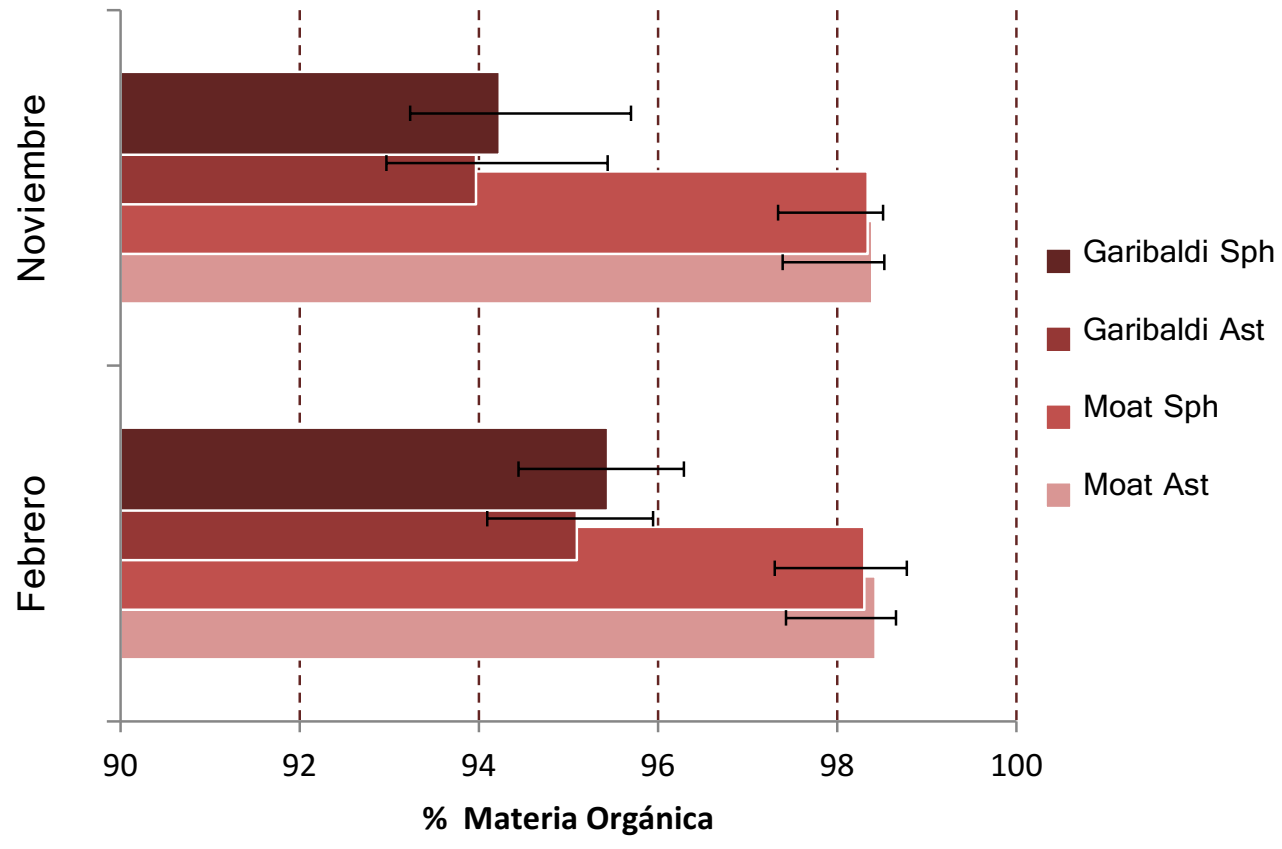

Figura 15. Contenido de carbono orgánico medio, expresado en proporción al peso seco (\%), de las muestras de turba tomadas durante dos temporadas de muestreo (febrero y noviembre 2012), en dos turberas compactas (Moat y Garibaldi) en presencia de dos tipos de cubierta vegetal (Astelia y Sphagnum). 
2.3.6. Contenido de nitrógeno. Las muestras presentaron un contenido de nitrógeno generalmente muy bajo y sus valores medios variaron de 0,44 a 3,26\% (Figura 16).

Por otro lado, tanto en febrero como en noviembre, no se registraron diferencias significativas en el contenido de carbono al comparar las profundidades de muestreo, excepto en la turbera de Garibaldi, donde se registró un mayor contenido de nitrógeno en las muestras tomadas a profundidad B (10-20 cm) (Figura 16; ANOVA: ver ANEXOS 7 y 8-Tablas A).

Con respecto a la cobertura vegetal, en las muestras tomadas en febrero existieron diferencias con respecto a los sitios de muestreo. Para la turbera de Moat se registró un mayor contenido de nitrógeno en las muestras tomadas de parcelas cubiertas por Astelia; mientras que en Garibaldi, en muestras de Sphagnum (Figura 16; ANOVA: ANEXO 7- Tabla B). Sin embargo, las muestras tomadas en noviembre presentaron un contenido de nitrógeno similar, excepto en Garibaldi, donde se determinaron valores altos para las muestras de Sphagnum (Figura 16; ANOVA: ANEXO 8-Tabla C).

Teniendo en cuenta el factor 'sitio', en general, para las dos temporadas de muestreo el contenido de nitrógeno fue mayor en las muestras provenientes de Garibaldi (Figura 16; ANOVA: ANEXOS 7 y 8 -Tabla C). 


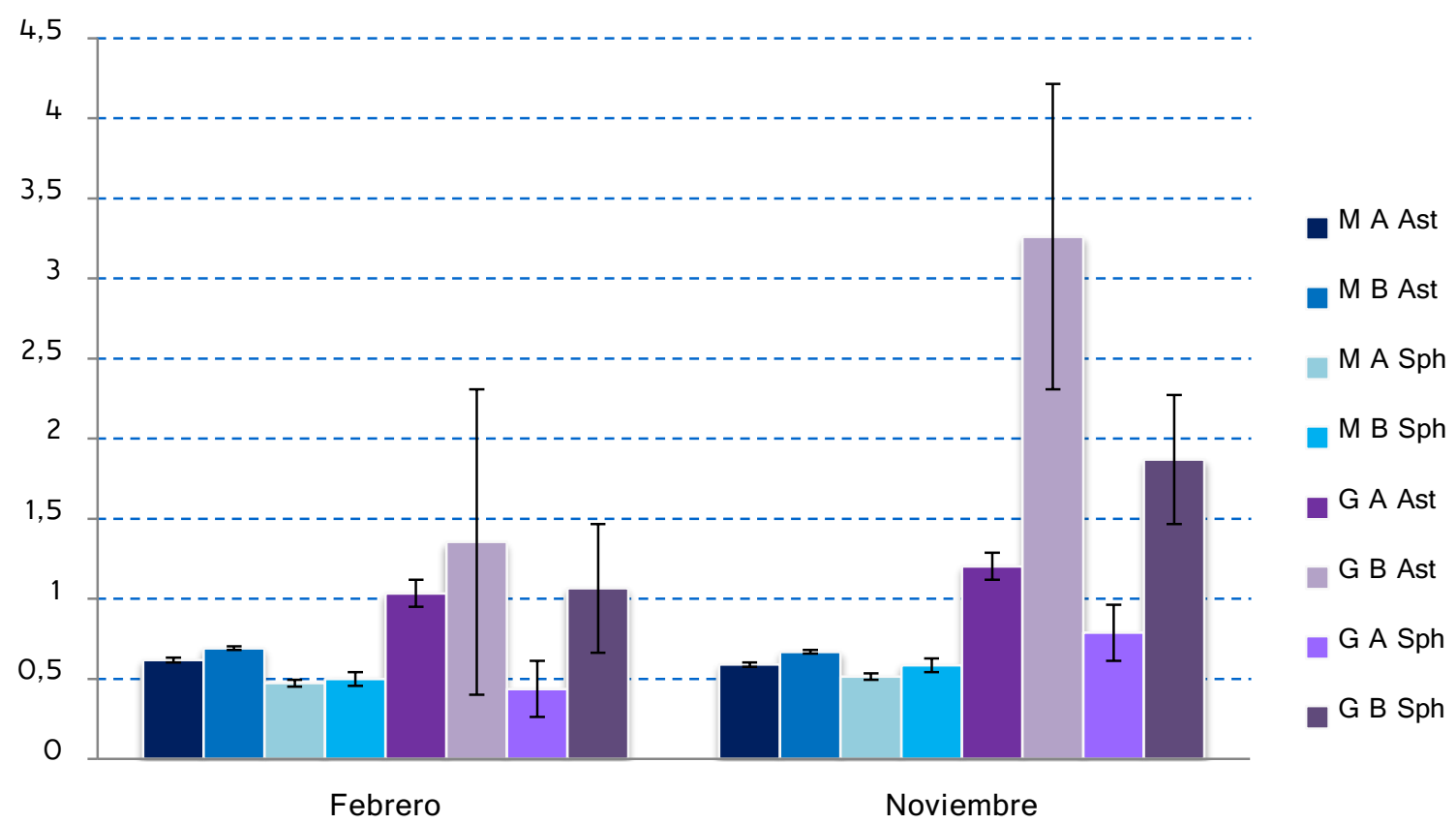

MUESTREOS

Figura 16. Contenido medio de nitrógeno medio, expresado en porcentaje (\%) presente en las muestras de turba tomadas durante dos temporadas de muestreo (febrero y noviembre 2012), en dos turberas compactas (Moat y Garibaldi) y en presencia de dos tipos de cubierta vegetal (Astelia y Sphagnum).

2.3.7. Relación Carbono:Nitrógeno (CN). En las dos temporadas de muestreo, la turba recolectada presentó una relación C:N fue muy alta (Tabla 3), como era esperable para estos ecosistemas que funcionan como sumideros de $\mathrm{C}$, con tasas de descomposición muy bajas y con retención del $\mathrm{N}$ en la biomasa microbiana (inmovilización biológica del $\mathrm{N}$ ). 
Tabla 3. Relación Carbono:Nitrógeno ( $\mathrm{C}: \mathrm{N})$ presente en las muestras de turba tomadas durante dos temporadas de muestreo (febrero y noviembre 2012), en dos turberas compactas (Moat \& Garibaldi) y en presencia de dos tipos de cubierta vegetal (Astelia y Sphagnum).

\begin{tabular}{ccc} 
& \multicolumn{3}{c}{ Relación C:N } \\
Muestra & Febrero & Noviembre \\
\hline M Ast A & $179 / 1$ & $170 / 1$ \\
\hline M Ast B & $148 / 1$ & $155 / 1$ \\
\hline M Sph A & $240 / 1$ & $201 / 1$ \\
\hline M Sph B & $221 / 1$ & $179 / 1$ \\
\hline G Ast A & $113 / 1$ & $86 / 1$ \\
\hline G Ast B & $143 / 1$ & $47 / 1$ \\
\hline G Sph A & $248 / 1$ & $134 / 1$ \\
\hline G Sph B & $114 / 1$ & $54 / 1$ \\
\hline
\end{tabular}

\subsection{CONCLUSIONES}

Se realizó una caracterización físico-química de los sitios y las muestras con el objetivo de tener información acerca de la heterogeneidad de las turberas elegidas para la realización de este trabajo. En ninguno de los casos se observaron diferencias significativas entre los valores de las variables registrados en febrero con los registrados en noviembre dado que se consideró que para evaluar el efecto de la 'estacionalidad' en las muestras deberían realizarse más campañas 
de muestreo y no fue el objeto de este estudio. Por este motivo, los valores fueron analizados de manera particular, por temporada.

En la figura 17 se presenta un cuadro general o resumen en el que se exponen las principales características de las turberas en estudio a partir de las muestras y datos tomados de ellas.

\begin{tabular}{|c|c|c|}
\hline & $\mathrm{MOAT}$ & G A R I B A L D I \\
\hline VEGETACIÓN & $\begin{array}{l}\text { Donatia, Drossera, Nanodea } \\
\text { Caltha, Pernettya, Tetroncium }\end{array}$ & $\begin{array}{c}\text { Carex, Chilliotrichum, Nothofagus, Gunnera, Juncus, } \\
\text { Marsipospermum, Caltha, Pernettya, Tetroncium }\end{array}$ \\
\hline \multirow{2}{*}{ NIVEL FREÁTICO } & Menor distancia a la napa freática & Mayor distancia a la napa freática \\
\hline & \multicolumn{2}{|c|}{ Las parcelas de Astelia fueron más distantes al agua y fue mayor el NF en primavera (deshielo). } \\
\hline \multirow{2}{*}{$\mathrm{PH}$} & $3.68-4.02$ & $3.97-4.43$ \\
\hline & \multicolumn{2}{|c|}{ Las turberas tienen un carácter fuertemente ácido. } \\
\hline \multirow{2}{*}{ TEMPERATURA } & $5.41-5.95^{\circ} \mathrm{C}$ & $2.61-4.43$ \\
\hline & \multicolumn{2}{|c|}{ Los valores de temperatura fueron muy bajos tanto en primavera como en verano. } \\
\hline \multirow{2}{*}{$\%$ HUMEDAD } & Muestras con menor \% & Muestras con mayor \% \\
\hline & \multicolumn{2}{|c|}{ Las muestras de ambas turberas presentaron un alto contenido de humedad que superó el $50 \%$ de su peso. } \\
\hline C & \multicolumn{2}{|c|}{ Las muestras de turba presentaron un contenido de carbono mayor al $90 \%$. } \\
\hline \multirow{2}{*}{$\mathrm{N}$} & Muestras con menor contenido de nitrógeno & Muestras con mayor contenido de nitrógeno \\
\hline & \multicolumn{2}{|c|}{ El contenido de nitrógeno en ambas turberas fue muy bajo $(0.44-3.26 \%)$} \\
\hline $\mathrm{C}: \mathrm{N}$ & \multicolumn{2}{|c|}{ La relación Carbono:Nitrógeno es muy alta $(47 / 1-248 / 1)$} \\
\hline
\end{tabular}

Figura 17. Cuadro comparativo con características principales de las turberas situadas en Moat y

Garibaldi. 
En general, las turberas, a pesar de tener situaciones geográficas muy disímiles (la turbera en Moat está próxima al mar; la turbera de Garibaldi se ubica en una zona montañosa), fueron similares en los rasgos que las definen y éstos fueron estrechamente homogéneos. Ambas, presentaron un carácter fuertemente ácido con valores de $\mathrm{pH}$ muy bajos (cercanos a 4), están expuestas a temperaturas muy bajas (aproximadamente $2-5^{\circ} \mathrm{C}$ ), poseen poca diversidad vegetal y acumulan turba con una carga hídrica muy alta, un elevado porcentaje de materia orgánica (más del 90\%) y un contenido de nitrógeno muy bajo (menos del $4 \%$ ).

Por lo tanto, estos sitios como otras turberas en el mundo, presentan condiciones que limitan la tasa de descomposición, siendo desfavorables para los microorganismos involucrados en la mineralización. 


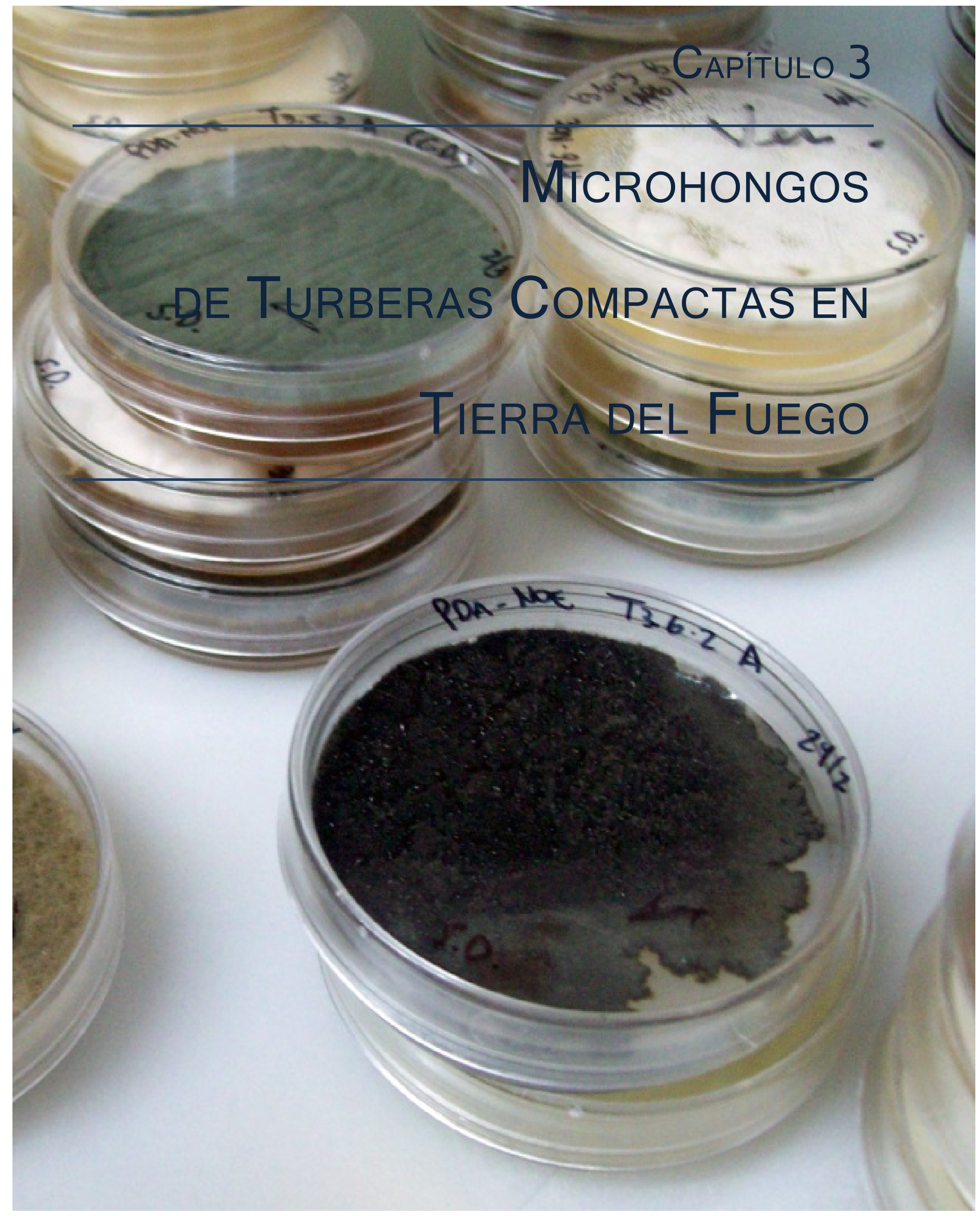




\subsection{INTRODUCCIÓN}

"I believe that mycelium is the neurological network of nature. Interlacing mosaics of mycelium infuse habitats with information-sharing membranes. These membranes are aware, react to change, and collectively have the long-term health of the host environment in mind. The mycelium stays in constant molecular communication with its environment, devising diverse enzymatic and chemical responses to complex challenges."

Paul Stamets, Mycelium Running: How Mushrooms Can Help Save the World

\subsubsection{Comunidad microbiana y diversidad}

La comunidad microbiana puede verse como un ensamblaje de poblaciones que interaccionan entre ellas y con el ambiente, espacial y temporalmente. Dichas interacciones dependen de las poblaciones que la conforman y la distribución de las mismas en el espacio, confiriéndole a la comunidad atributos mediante los que puede ser caracterizada: estructura y función (Begon y col., 2006). Así, la estructura de la comunidad puede ser medida y descripta en términos de composición de especies (diversidad), las cuales cumplen con roles especializados dentro del ecosistema. La diversidad es afectada por los cambios en el ambiente y estos patrones temporales pueden ser indicadores sensibles del funcionamiento del ecosistema, debido a que los cambios en las comunidades pueden ocurrir como respuesta a condiciones ambientales globales, dando lugar a procesos de cambio en la función de la comunidad (Atlas y Bartha, 2002). Por tal motivo, la mayoría de los estudios relacionados con la ecología microbiana están orientados a determinar cómo la diversidad de microorganismos influye en el 
funcionamiento de los ecosistemas y la relación existente entre diversidad-funcionamiento (Griffiths y col., 1997; Hooper y col., 2002).

Un entendimiento global y adecuado de la diversidad fúngica en un área puede ayudar a identificar problemas dentro del ecosistema (Letourneau, 2010). Sin embargo, los resultados obtenidos en un estudio de la comunidad fúngica del suelo dependen, principalmente, de los métodos utilizados. En general, cada método presenta ciertas preferencias a ciertos grupos específicos de hongos. Además, es necesario considerar que el suelo no es un sustrato sino un sistema compuesto por una mezcla de sustratos más diversos que incluyen partes de las plantas vivas y muertas, animales y otros microorganismos, junto con minerales y agua (Ludwig y Magalhães de Abreu, 2012).

\subsubsection{Estudio de hongos presentes en turberas}

Las comunidades de hongos de las turberas han sido estudiadas desde 1930. A comienzos del siglo XX, se pensaba que la turba era estéril. Desde entonces, Waksman y Purvis (1932) han demostrado que las comunidades fúngicas así como la viabilidad y la habilidad de los hongos para descomponer los constituyentes de la turba varían entre las diferentes capas. Así, por ejemplo el trabajo publicado por Christensen y Whittingham (1965) ha confirmado que las comunidades fúngicas difieren entre los suelos orgánico y mineral. Desde esta perspectiva funcional, se pensaba que el rol de los hongos en la descomposición de la materia orgánica era menos importante que el de las bacterias (Waksman y Purvis, 1932). Sin embargo, esta visión 
fue desplazada. Actualmente se ha demostrado que los hongos son más significativos entre las comunidades de descomponedores presentes en la turba, particularmente en el horizonte oxigenado, el acrotelmo (Thormann y Rice, 2007). Los hongos también están presentes en el horizonte anóxico de la turba, el catotelmo, pero crecen lentamente en él debido a la falta o a las bajas concentraciones de oxígeno (Golovchenko y Polyanskaya, 1999; Kurakov y col., 2008; Grum-Grzhimaylo, 2013). Consecuentemente, la mayor parte de la biomasa fúngica está presente en el acrotelmo. Esto se ha evaluado utilizando diferentes métodos, incluyendo microscopía de luminiscencia (Golovchenko y col., 1993; Golovchenko y col., 2002), el conteo de unidades formadoras de colonias (Zaguralskaya, 1967; Thormann y col., 2001) y midiendo la concentración de ácidos grasos fosfolipídicos (Sundh y col., 1997; Jaatinen y col., 2007; Andersen y col., 2010).

Se han aislado cerca de 600 taxa fúngicos en turberas, con una riqueza taxonómica similar en ascomicetes y basidiomicetes (Thormann y Rice, 2007). Los estudios más comunes en hongos de turbera se han llevado a cabo para macromicetes, y han contribuido en la mayor parte al conocimiento sobre los basidiomicetes de turberas (por ejemplo: Salo, 1979; Lange y Lange, 1982; Wurtzburger y col., 2004; Stasinska, 2011); mientras que los estudios sobre los ascomicetes provienen fundamentalmente de investigaciones basadas en cultivos (Thormann y col., 2001, 2003; Golovchenko y col., 2002; Kachalkin y col., 2005; Grum-Grzhimaylo, 2013).

La mayoría de los hongos encontrados en turberas son saprotrófos (Thormann, 2006; Thormann y Rice, 2007), por lo tanto, es importante entender sus impactos potenciales sobre las dinámicas del carbono en turberas, que forman componentes significativos del paisaje. Para ello 
es necesario estudiar y/o investigar la diversidad fúngica asociada con los restos vegetales en ambientes de turbera y cómo cambia a través del tiempo.

Durante las últimas décadas, se ha incrementado el interés sobre los hongos descomponedores presentes en estos ecosistemas y entre los estudios acerca de esta temática, se destacan las investigaciones realizadas por Thornmann y sus colaboradores (Thornmann y col. 2001; Thormann y col., 2003; Thornmann, 2006; Thormann y col., 2007; Thormann, 2011). Sin embargo, prácticamente no se han registrado taxas específicos de ambientes de turbera y la información acerca de estos organismos sigue siendo escasa.

\subsubsection{Diversidad fúngica en turberas fueguinas}

A pesar que se han realizado numerosas investigaciones en turberas fueguinas (por ejemplo: Searles y col., 2002; Pancotto y col., 2003; Iturraspe y Urciolo, 2004; Rabassa y col., 2004; Grootjans y col., 2010; Fritz y col., 2011; Grootjans y col., 2014), aún son escasas las investigaciones acerca de la diversidad de hongos de estos ambientes y, sobre todo, de turberas compactas formadas por Astelia pumila (G. Forst.) Gaudich. (Asteliaceae) y Donatia fascicularis J. R. Forst y G. Forst (Donatiaceae).

Existen varios estudios que describen expediciones y la diversidad fúngica de diferentes lugares de Tierra del Fuego, por ejemplo, algunos asociados a Gunnera magellanica Lam. (Pancotto y col., 2003) o Nothofagus (Gamundí y Amos, 2007; Godeas, 1983; Godeas y 
Arambarri, 2007). Otros trabajos han mostrado la influencia de radiación sola UV-B sobre la comunidad fúngica en turberas de Sphagnum (Searles y col., 2001; Robson y col., 2004).

Sin embargo, la mayoría de las investigaciones relacionadas con la diversidad fúngica en Tierra del Fuego, se han centrado en grupos específicos como Agaricales (Basidiomycota), considerado uno de los grupos más estudiados en la isla (Horak, 1980); por otra parte, los Aphyllophorales han sido documentados por Greslebin (2001), Greslebin y Rajchenberg (2003) y Rajchenberg (2006). Todos ellos representan investigaciones sobre hongos presentes principalmente en ambientes de bosques.

Asimismo, con respecto al conocimiento sobre los microhongos aislados de turberas en Tierra del Fuego, los registros se reducen a unos pocos trabajos (Godeas y col., 1977; Godeas y Arambarri, 1993). Más recientemente se conoce el trabajo de Paredes y col. (2014), que está relacionado específicamente con la comunidad de hongos presentes en una turbera compacta fueguina.

En general, la diversidad de hongos filamentosos de turberas fueguinas y compactas formadas por Astelia-Donatia ha sido poco estudiada en comparación con las turberas presentes en el Hemisferio Norte. Es por ello que los objetivos planteados en este estudio se basan en la descripción de la comunidad de Hyphomycetes presentes en dos turberas compactas dominadas por Astelia pumila y Donatia fascicularis y ubicadas en la zona sur de Tierra del Fuego. 


\subsubsection{Objetivos particulares}

$\checkmark$ Comparar diferentes metodologías clásicas para el cultivo y aislamiento de hongos filamentosos en turberas compactas de Astelia-Donatia.

$\checkmark$ Aislar, identificar y caracterizar las especies fúngicas asociadas a dos turberas compactas en Tierra del Fuego, mediante metodologías clásicas de aislamiento y cultivo y mediante técnicas moleculares.

$\checkmark \quad$ Analizar la composición y diversidad de las comunidades fúngicas presentes en turberas compactas de Astelia-Donatia.

$\checkmark$ Analizar la relación de las muestras la composición microfúngica en turberas compactas de Astelia-Donatia según el tipo de microambiente, el tipo de cobertura y la estación del año.

$\checkmark$ Analizar la relación de los parámetros ambientales en la distribución de microhongos en turberas compactas.

\subsection{MATERIALES \& MÉTODOS}

\subsubsection{RECOLECCIÓN DE MUESTRAS Y CONSERVACIÓN DEL MATERIAL}

Se ha descripto previamente en la sección 2.2 ('Materiales \& Métodos') del Capítulo 2 ('Descripción del área y caracterización de los sitios de estudio’). 


\subsubsection{AISLAMIENTO Y CARACTERIZACIÓN TAXONÓMICA DE MICROHONGOS}

POR METODOLOGÍAS CLÁSICAS

\section{a) Aislamiento de cepas fúngicas}

Luego de cada muestreo y, una vez procesadas y fraccionadas las muestras, se llevó a cabo el aislamiento de hongos microscópicos utilizando las siguientes metodologías de cultivo clásicas: cámaras húmedas, siembra directa de suelo y lavado de partículas de suelo.

Cámaras húmedas. Se colocó un papel de filtro, humedecido con agua estéril, en la base de placas de Petri estériles, sobre las que se depositaron 5 porciones de una muestra de turba (Figura 18). Las cámaras se mantuvieron a temperatura ambiente y fueron regadas con agua estéril, y observadas bajo lupa regularmente, hasta la aparición de crecimiento fúngico.

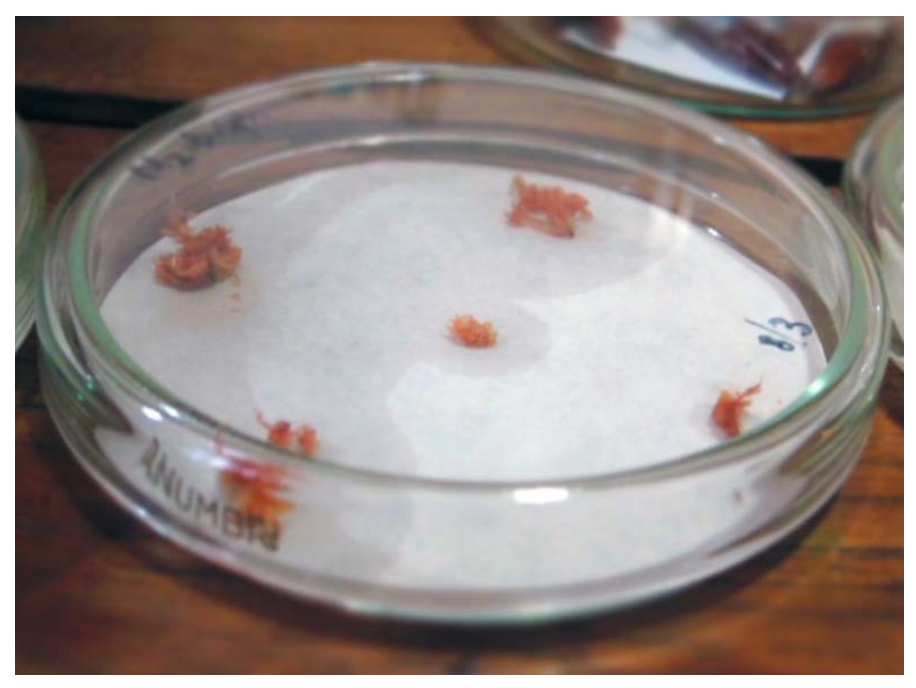

Figura 18. Cámara húmeda realizada con 5 porciones de turba fueguina de Sphagnum. 
Siembra directa de partículas de suelo. A partir de cada una de las sub-muestras, se fraccionó $1 \mathrm{~g}$ de turba, del que se tomaron 5 partículas que fueron colocadas directamente sobre placas de Petri conteniendo medio de cultivo sólido Agar Papa Glucosado (APG), con adición de cloranfenicol ( $1 \mathrm{~g} /$ litro $)$.

Lavado de partículas de suelo. Se fraccionaron $3 \mathrm{~g}$ de turba y se homogeneizaron pasándolos por una procesadora conteniendo $10 \mathrm{ml}$ de agua destilada estéril. Luego se procedió al lavado intenso de las muestras con agua destilada estéril. Se agitó y descartó el agua, y se conservó la fracción de turba del suelo con el fin de eliminar (lavar) las esporas y otras estructuras contaminantes, reteniendo únicamente las partículas de turba con micelio fúngico adherido. La suspensión resultante se pasó por un tamiz de 0,5 mm de malla, conservando las partículas retenidas por el mismo. Para eliminar el agua de lavado de las partículas, se filtró la suspensión a través de un disco de papel de flitro estéril utilizando una bomba de vacío. Bajo cámara de flujo laminar, el disco de papel conteniendo las partículas, se transfirió a una placa de Petri, conteniendo dos nuevos discos de papel de filtro estériles, que absorbieron los restos de humedad, y se dejó secar por 24 hs a temperatura ambiente (Parkinson y Williams, 1961). Las partículas fueron sembradas en placas conteniendo medio de cultivo CMYA (Corn Meal Yeast Agar), con el agregado de $0,5 \%$ de sulfato de estreptomicina y $0,25 \%$ de cloranfenicol. Esta técnica disminuye la incidencia de especies de rápido crecimiento y que inhibien la expresión de una mayor diversidad fúngica (Bills y col., 2004). Las placas se incubaron a $25^{\circ} \mathrm{C}$ y se observaron semanalmente bajo microscopio óptico. 
Con las muestras obtenidas en la primera campaña de muestreo (febrero 2012), se llevó a cabo el aislamiento de hongos microscópicos, a partir de la siembra de 200 partículas con cada una de las tres metodologías descriptas anteriormente (total de partículas sembradas: 600). Los resultados obtenidos por la implementación de las tres metodologías fueron analizados y comparados. Por lo tanto, en la segunda campaña (noviembre 2012), luego de observar los resultados obtenidos para el primer muestreo, se decidió incrementar el esfuerzo invertido en la utilización de una única metodología; en este caso, la técnica de lavado de suelo. Es así que se sembraron 50 partículas por sub-muestra, llevando a la siembra de un total de 4000 partículas en esta temporada ( 2 sitios de muestreo $\times 10$ puntos de muestreo $\times 2$ muestras de cada cobertura $\times 2$ sub-muestras de profundidades diferentes $\times 50$ partículas).

A partir de la observación bajo lupa de la presencia de colonias fúngicas, en las placas sembradas por las distintas metodologías descriptas, se tomó una porción de cada colonia y se sembró en una placa de Petri conteniendo medio de cultivo APG, con el fin de realizar los aislamientos o la obtención de cultivos axénicos.

Para la identificación de especies fúngicas, todas las cepas aisladas por las diferentes técnicas fueron conservadas bajo condiciones y métodos ya descriptos (Leung y Taga, 1988).

\section{b) Identificación de especies fúngicas}

Observación microscópica. Observando cada placa de aislamiento bajo una lupa, se tomó con una pinza una porción de la superficie de la colonia, que luego fue depositada sobre una 
gota de azul de lactofenol. Con la ayuda de una aguja se extendió el preparado y se cubrió con una lámina portaobjetos, para luego ser observada al microscopio con un aumento de 40x.

Uso de claves taxonómicas. Para la ubicación taxonómica de los hongos aislados, se utilizaron claves (Ramirez y Martínez, 1982; Domsch y col., 1980; Carmichael y col., 1980; Ellis, 1971; Ellis, 1976), teniendo en cuenta las características culturales y morfológicas de las colonias. Además se prepararon montajes en azul de lactofenol para definir las características de hifas, esporas y estructuras especializadas.

Conservación de aislamientos fúngicos. Un representante de cada una de las especies identificadas fue conservado en placas de Petri conteniendo medio de cultivo APG.

\subsubsection{IDENTIDAD DE MICELIOS ESTÉRILES POR METODOGÍAS MOLECULARES}

En el caso de las muestras que no pudieron ser identificadas por no haber presentado esporulación en los medios de cultivo utilizados, se extrajo el ADN a partir del micelio de esas colonias fúngicas aisladas con el fin de identificarlas por metodologías moleculares.

\section{a) Extracción de $A D N$}

Los micelios considerados como estériles fueron liofilizados y posteriormente molidos hasta obtener un polvo fino. Se extrajo el ADN total siguiendo el método de extracción de CTAB (bromuro de cetyltrimetilamonio). Se colocó el micelio molido en un tubo plástico de 1,5 ml, 
conteniendo, $750 \mu \mathrm{l}$ de buffer CTAB 2 X y $15 \mu \mathrm{l}$ de 2 -mercaptoetanol, de modo que la muestra de turba quedara resuspendida y con movilidad. Se mezcló suavemente mediante inversión. Se calentó a 30 min a $65^{\circ} \mathrm{C}$ y se homogeneizó durante la incubación cada 8 min invirtiendo los tubos. Se agregaron $300 \mu \mathrm{l}$ de tampón acetato de potasio $3 \mathrm{M}, \mathrm{pH} \mathrm{4,8} \mathrm{y} \mathrm{se} \mathrm{mezcló} \mathrm{suavemente}$ por inversión. Se incubó $15 \mathrm{~min}$ en hielo y luego se centrifugó durante 5 min a $17.300 \mathrm{~g}$ para separar las distintas fases. Se tomó la fase superior y se depositó en otro tubo de 1,5 $\mathrm{ml}$ al que se le agregaron $200 \mu \mathrm{l}$ de fenol y $200 \mu \mathrm{l}$ de cloroformo isoamílico (24:1). Se agitó suavemente y se centrifugó $5 \min$ a 17.300 g. Se separó la fase superior a la que se le agregó $250 \mu \mathrm{l}$ de cloroformo:alcohol isoamílico (24:1), se agitó suavemente y se centrifugó 5 min a $17.300 \mathrm{~g}$. Se tomaron $750 \mu \mathrm{l}$ de la fase superior, que fueron depositados en un tubo nuevo de $1,5 \mathrm{ml}$ y la precipitación del ADN se realizó agregando $750 \mu \mathrm{l}$ de isopropanol frío. Se dejaron los tubos durante $10 \mathrm{~min}$ en hielo y luego se centrifugaron a $5 \mathrm{~min}$ a $17.300 \mathrm{~g}$. Se descartó el isopropanol y se lavó 2 veces con $500 \mu$ de etanol $70 \%$ frío. Posteriormente se colocaron los tubos invertidos sobre papel de filtro durante $5 \mathrm{~min}$ y se dejaron secar a temperatura ambiente por 10 min. El ADN obtenido se resuspendió en 30 a $50 \mu \mathrm{l}$ de tampón TE (Tris- $\mathrm{HCl} 10$ mM, pH 8, EDTA 1mM) estéril.

La calidad del ADN fue determinada luego de la electroforesis en geles de agarosa al $1 \%$ (Sambrook y Rusell, 2001). 


\section{b) Amplificación de ADN fúngico mediante PCR}

Se llevó a cabo la amplificación de fragmentos del ADN de las muestras utilizando la reacción en cadena de la polimerasa (PCR), usando como templado ADN total. Se utilizaron cebadores reportados en la literatura los cuales permiten amplificar específicamente un amplio rango de especies fúngicas. Las regiones que amplifican comprenden a las regiones conservadas ITS1, ITS2, del gen codificante de la subunidad 5.8S del ADNr y a una región parcial del gen codificante de la subunidad 18S. Los cebadores utilizados fueron ITS5 como cebador directo (Gardes y Bruns, 1993) e ITS4 como cebador reverso (White et al., 1990) [Figura 19].

Las reacciones de PCR se llevaron a cabo en un ciclador térmico Bioer con gradiente de temperatura. Las condiciones de amplificación fueron: 2,5 min a $94^{\circ} \mathrm{C}$ seguido por 30 ciclos de $15 \mathrm{~s}$ a $94^{\circ} \mathrm{C}, 30 \mathrm{~s}$ a $53^{\circ} \mathrm{C}$ y $90 \mathrm{~s}$ a $72^{\circ} \mathrm{C}$, y un último paso de extensión de 5 min a $72^{\circ} \mathrm{C}$. Las reacciones de control negativo y positivo fueron realizadas en cada experimento. Como control negativo en cada reacción de PCR se utilizó $1 \mu l$ de agua bidestilada estéril y como control positivo se utilizó $1 \mu \mathrm{l}$ de ADN genómico del hongo Trichoderma harzianum.

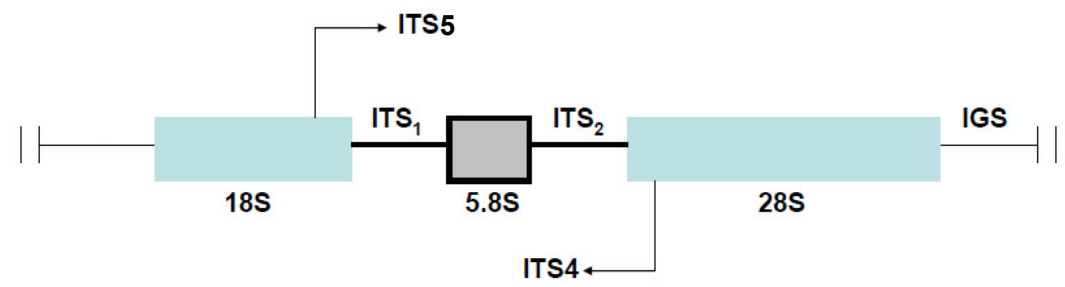

Figura 19. Esquema de la organización de los genes ribosomales en hongos. Se muestran los cebadores utilizados ITS5 e ITS4 y la región que amplifican, 


\section{c) Purificación de productos de PCR}

Los productos de PCR obtenidos a partir de la amplificación de los ADN de los treinta micelios estériles y fueron purificados utilizando el kit Pure Link PCR Purification kit (Invitrogen) siguiendo las recomendaciones del fabricante.

\section{d) Secuenciación y análisis de los fragmentos de ADN}

La secuenciación de todos los productos de amplificación obtenidos a partir de los hongos cultivables que presentaron micelio estéril se realizó mediante el servicio de Macrogen (Corea).

Se procedió luego al análisis de las secuencias obtenidas. Se identificó la homología de cada una de las secuencias de los fragmentos de ADN comparándolas con secuencias depositadas en la base de datos públicos Genbank (http//:www.ncbi.nlm.nih.gov/). Se realizó análisis de BLASTN para identificar secuencias de especies fúngicas en las muestras de turba o para identificar las de aquellas especies fúngicas aisladas que presentaron micelio estéril (Altschul, et al., 1997). Las secuencias obtenidas fueron ingresadas en el banco de EMBL. 


\subsubsection{ANÁLISIS DE DATOS}

\section{a) Evaluación de las metodologías de cultivo}

Se analizó y evaluó cuál de las tres metodologías de cultivo clásicas utilizadas luego de la primera campaña de muestreo (febrero 2012), resultó más adecuada para el aislamiento de hongos microscópicos a partir de muestras de turba. Para ello se compararon:

* Número de aislamientos (repeticiones) de la misma especie.

* Frecuencia de ocurrencia de cada especie en cada método

* Porcentaje de especies por método, calculado como el número de especies obtenido por método dividido por el número total de especies, multiplicado por $100 \%$.

\section{b) Cálculo de frecuencias}

Para las dos temporadas de muestreo, se calcularon las frecuencias totales de ocurrencia de las especies en base al número de aislamientos de cada especie dividido por el número total de aislamientos obtenidos para cada temporada.

Por otro lado, la diversidad se estimó únicamente en base a los resultados y/o datos obtenidos por la técnica de lavado de suelo en las temporadas de muestreo de febrero y noviembre de 2012. Por lo tanto, se realizó el cálculo de las frecuencias relativas para cada especie fúngica en base al número de partículas colonizadas por cada especie en cada muestra. 
De este modo, la frecuencia para cada especie en una muestra fue calculada en base al número total de partículas con crecimiento en todas las placas pertenecientes a esa muestra y no al número total de partículas que presentaron crecimiento fúngico en todas las muestras.

Luego, los datos de frecuencias relativas para cada hongo se utilizaron como base para la realización del cálculo y análisis de los parámetros de diversidad y los análisis de componentes principales.

\section{c) Análisis de la diversidad}

Las comunidades fúngicas de las dos temporadas de muestreo (febrero y noviembre de 2012) fueron descriptas en términos de su riqueza y abundancia específicas. Además, se calcularon los siguientes índices: diversidad de Shannon-Wiener $\left(H^{\prime}\right)$, y equitatividad (J), utilizando el programa MVSP 3.1 (Multi-Variate Statistical Package).

La riqueza de especies $(S)$ es comúnmente expresada como el número total de especies presentes en una comunidad (Wiensczky y col., 2002). La abundancia es el número de individuos en una determinada área. Se puede medir obteniendo las proporciones relativas de diferentes especies en la comunidad (frecuencias relativas) (Krebs, 1985).

La equitatividad ( $\mathrm{J}$ ') demuestra qué tan uniformemente están distribuidos los individuos entre las especies (Newman, 2003), es decir, se refiere a la abundancia proporcional de cada especie dentro de una comunidad, describiendo la igualdad de abundancia de especies en una 
comunidad (Pitkänen, 1998). Una equitatividad cercana a cero señala que una comunidad es dominada por una especie, un valor cercano a 1 señala que tienen un balance igual entre todas las especies (abundancias similares) (Clements y Newnman, 2002; Shaw, 2003).

El índice de Shannon-Wiener $\left(H^{\prime}\right)$ mide el grado promedio de incertidumbre en predecir a qué especie pertenecerá un individuo escogido al azar de una colección (Magurran, 1988; Baey y Peney, 1995). Es calculado a través de la ecuación $\mathrm{H}^{\prime}=-\sum \mathrm{pi}$ In pi, donde pi es la abundancia relativa de las i especies comparado con el total de especies identificadas en la muestra (Magurran, 1988). Este índice toma valores en el rango de 0 a 5. Expresa la uniformidad de los valores de importancia a través de todas las especies de la muestra y asume que los individuos son seleccionados al azar y que todas las especies están representadas en la muestra (Lindgren y Sullivan, 2001).

\section{d) Análisis estadístico}

La significancia de las diferencias entre la riqueza de especies (S) y diversidad $\left(H^{\prime}\right)$ se analizó por medio de un ANOVA, considerando como factores a la profundidad, sitio y cobertura.

Las muestras, según el tipo de sustrato (Astelia y Sphagnum) y temporada, fueron analizados de acuerdo a su composición de especies a través de un análisis de componentes principales (ACP; Digby y Kempton, 1987). Se analizaron cuatro situaciones: Astelia Febrero, Astelia-Noviembre, Sphagnum Febrero y Sphagnum-Noviembre. Debido a que en resultados anteriores (Paredes y col., 2014) se encontró que no había diferencias en la composición de 
acuerdo a la profundidad, los datos fueron reunidos para cada muestra. En los análisis no fueron incluídos los datos provenientes de micelios estériles ni de aquellas especies cuya frecuencia relativa fueran menores al $1 \%$. Este análisis multivariado permite realizar una representación de la variabilidad entre muestras a través de su ordenamiento sobre ejes sucesivos. El programa utilizado fue el MVSP 3.1 (Multi-Variate Statistical Package).

Con el fin de destacar si la posición de las muestras sobre los ejes en los ACP se asocia con las variables físico-químicas, se analizaron a través de un coeficiente de correlación de Pearson. Las variables incluidas en el análisis fueron contenido de nitrógeno (\%), contenido de materia orgánica $(\%)$, contenido hídrico $(\%)$, nivel freático $(\mathrm{cm})$ y relación carbono:nitrógeno.

\subsection{RESULTADOS}

\subsubsection{AISLAMIENTO Y CARACTERIZACIÓN TAXONÓMICA DE MICROHONGOS}

POR METODOLOGÍAS CLÁSICAS

\section{a) Evaluación de metodologías clásicas de cultivo}

Con las muestras obtenidas en la primera campaña de muestreo (febrero 2012), se realizó el aislamiento de hongos microscópicos, a partir del uso de las tres metodologías 
descriptas anteriormente. Por lo tanto, se realizó la comparación de metodologías y se sembraron 200 partículas para cada una de las mismas.

En la tabla 4 se presenta el número de aislamientos por especie fúngica y frecuencia para cada una de las metodologías evaluadas. Es así que, a partir de la implementación de los tres métodos de cultivo se aislaron 12 especies de hongos filamentosos. Tanto en siembra directa como en la siembra en cámaras húmedas, se aisló el menor número de especies ( 7 y 5 especies, respectivamente), mientras que por el método de lavado, se obtuvieron 10 especies, representativas del $61,65 \%$ del total registrado.

El mayor número de aislamientos se registró al utilizarse la técnica de lavado de suelo, con 164 aislamientos fúngicos. Por otro lado, para la técnica de siembra directa se registraron 87 aislamientos y a partir de la siembra en cámaras húmedas, se aisló la menor cantidad de hongos filamentosos (28 aislamientos) (Tabla 4).

Sin embargo, todas las especies aisladas por la siembra directa de partículas, estuvieron presentes en los aislamientos obtenidos por el método de lavado, excepto Penicillium citrinum. Por otra parte, la siembra en cámaras húmedas tuvo menos especies en común con las demás metodologías y se aislaron a partir de su implementación, dos especies, Botryosporum sp. y Parasterinella sp., que no estuvieron presentes en las partículas de siembra directa ni lavado (Tabla 4).

Realizando un análisis general de los resultados presentados en la tabla 6 , se observa que las especies fúngicas de mayor ocurrencia en las turberas compactas de Astelia 
corresponden a Penicillium frequentans, Mortierella alpina y Trichoderma viride. Estas especies resultaron más frecuentes en las metodologías de siembra directa y lavado de suelo; sin embargo, Parasterinella sp. fue la especie más frecuente para la siembra en cámaras húmedas. Por otro lado, tanto en la metodología de siembra directa como la de lavado de partículas se obtuvieron porcentajes muy altos de micelios estériles, 27,59 y 44,51\% respectivamente; mientras que con las cámaras húmedas no se observó crecimiento de micelios estériles. 
Tabla 4. Comparación de los resultados obtenidos por la implementación de tres metodologías de cultivo clásicas (SD: siembra directa, $\mathrm{CH}$ : siembra en cámaras húmedas y L: lavado de partículas de suelo) en el aislamiento de especies fúngicas, a partir de muestras tomadas en febrero del 2012 en turberas compactas de Astelia-Donatia (Tierra del Fuego). ( ${ }^{\circ} \mathrm{A}:$ número de aislamientos/repeticiones de la misma especie; F: frecuencia de ocurrencia de cada especie)

\begin{tabular}{|c|c|c|c|c|c|c|}
\hline \multirow{2}{*}{ ESPECIES FÚNGICAS } & \multicolumn{2}{|c|}{ SD } & \multicolumn{2}{|c|}{$\mathrm{CH}$} & \multicolumn{2}{|c|}{ L } \\
\hline & $\mathrm{N}^{\circ} \mathrm{A}$ & $\mathrm{F}$ & $\mathrm{N}^{\circ} \mathrm{A}$ & $\mathrm{F}$ & $\mathrm{N}^{\circ} \mathrm{A}$ & $\mathrm{F}$ \\
\hline Micelio estéril & 24 & 27,59 & --- & --- & 73 & 44,51 \\
\hline Penicillium frequentans & 20 & 22,99 & --- & --- & 16 & 9,76 \\
\hline Mortierella alpina & 13 & 14,94 & --- & --- & 18 & 10,98 \\
\hline Trichoderma viride & 17 & 19,54 & 1 & 6.67 & 11 & 6,71 \\
\hline T. polysporum & --- & --- & --- & --- & 17 & 10,37 \\
\hline Aureobasidium pullulans & --- & --- & --- & --- & 14 & 8,54 \\
\hline Levaduras & --- & --- & --- & --- & 9 & 5,49 \\
\hline Parasterinella sp. & --- & --- & 10 & 66.67 & 0 & 0,00 \\
\hline Cladosporium cladosporioides & 5 & 5,75 & --- & --- & 2 & 1,22 \\
\hline Penicillium canescens & 2 & 2,30 & 1 & 6.67 & 1 & 0,61 \\
\hline P. jensenii & 1 & 1,15 & 1 & 6.67 & 1 & 0,61 \\
\hline P. citrinum & 5 & 5,75 & 1 & 6.67 & --- & --- \\
\hline P. implicatum & --- & --- & --- & --- & 2 & 1,22 \\
\hline Botryosporum sp & --- & -- & 1 & 6.67 & --- & --- \\
\hline Total Aislamientos por Método & & & & & & \\
\hline$\%$ Aislamientos por método & & & & & & \\
\hline Total Especies por Método & & & & & & \\
\hline
\end{tabular}

(*)El número total de especie aislado por cada método fue calculado teniendo en cuenta solo los aislamientos de hongos filamentosos; se excluyeron las levaduras. 


\section{b) Incidencia de microhongos en turberas compactas fueguinas}

Luego de realizar el análisis de los resultados obtenidos para el primer muestreo, se decidió que en el muestreo posterior sólo se emplearía la técnica de lavado de suelo, debido a que con esta metodología se pudo obtener un mayor número de aislamientos y especies, y que las mismas fueron parte de los resultados obtenidos por las otras dos técnicas.

De las muestras de febrero se tomaron un total de 800 partículas para realizar la siembra; mientras que en noviembre se incrementó e invirtió un mayor esfuerzo en el número de partículas a sembrar. Finalmente se tomaron 50 partículas por sub-muestra de turba, llevando a la siembra de un total de 4.000 partículas ( 50 partículas $\times 10$ muestras $\times 2$ sub-muestras de 2 profundidades diferentes $\times 2$ tipos de cobertura $\times 2$ sitios de muestreo).

A continuación, tanto el análisis de la incidencia de los microhongos como los posteriores análisis de la comunidad (diversidad, análisis multivariado), se realizaron en base a los resultados obtenidos por la técnica de lavado de partículas de suelo en las dos temporadas de muestreo (febrero y noviembre de 2012).

En febrero se obtuvieron 658 aislamientos que correspondieron a 5 géneros (Aureobasidium, Cladosporium, Mortierella, Penicillium y Trichoderma) y 10 especies; entre las cuales, las especies Mortierella alpina, Aureobasidium pulullans y Trichoderma viride resultaron los más frecuentes y cuyas frecuencias de ocurrencia fueron $12,15,10,77$ y $10,77 \%$ respectivamente. Mientras que en noviembre, se registró un total de 2452 aislamientos, que se correspondieron con 6 géneros (Aureobasidium, Beauveria, Mortierella, Penicillium y 
Trichoderma) y 15 especies fúngicas (Fig. 19). Los géneros que estuvieron mejor representados en esta temporada fueron Penicillium, con 5 especies y un $16,6 \%$ en proporción al total de aislamientos, y Trichoderma, con 4 especies y una frecuencia de $11,01 \%$. Las especies más frecuentes fueron $A$. pullulans (29,04\%), Beauveria bassiana (18,35\%) y Penicillium frequentans $(10,28 \%)$ (Fig. 20).

En ambos muestreos se observaron aislamientos que no presentaron estructuras reproductivas que permitieran su identificación y, por lo tanto, fueron agrupados como micelios hialinos estériles. En febrero la proporción de micelios estériles fue alta con un $44,1 \%$, y en noviembre sólo del 5,83\% (Fig. 20). 


\section{LAVADO DE PARTÍCULAS}

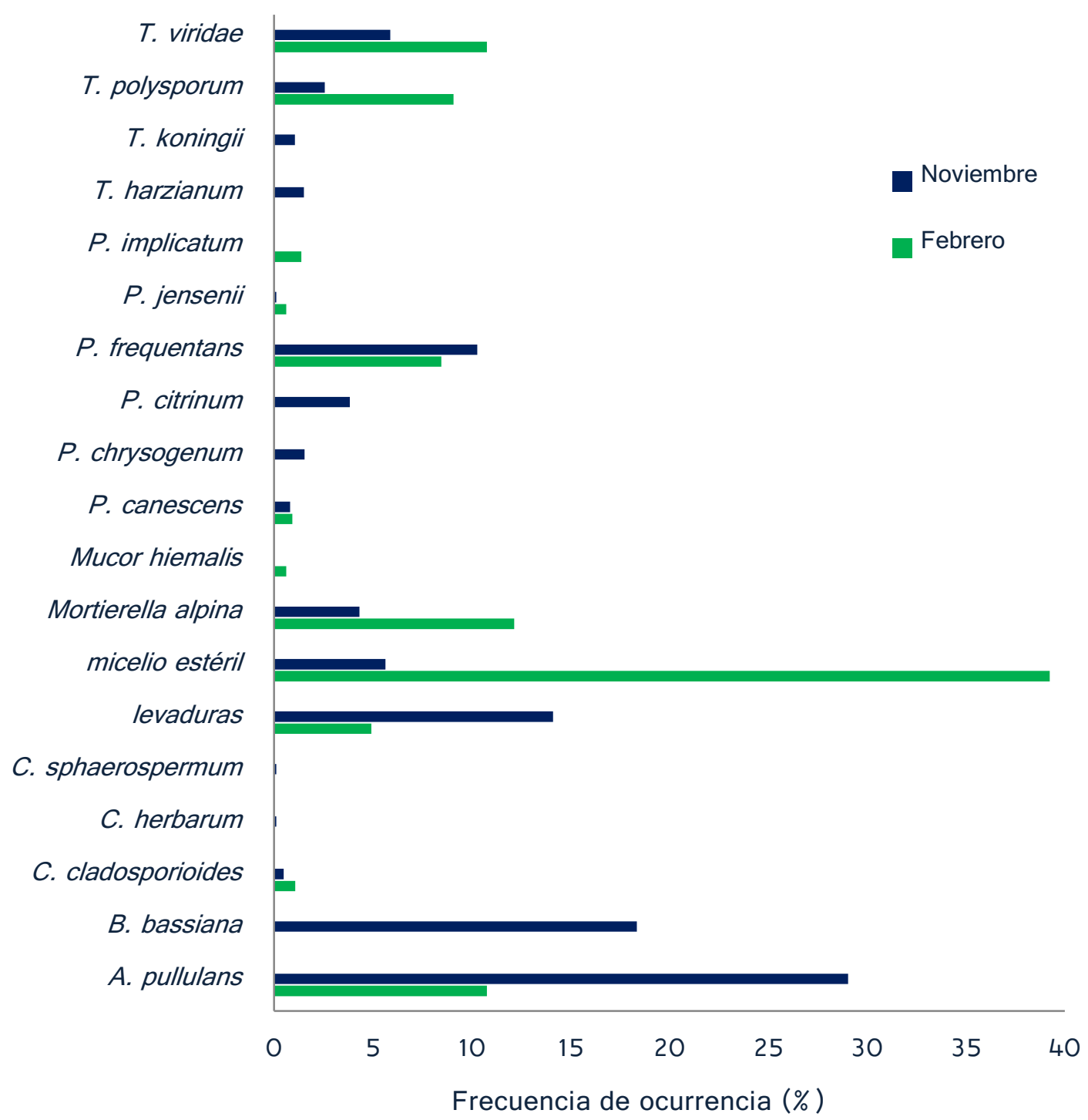

Figura 20. Frecuencia de ocurrencia de microhongos aislados por lavado de partículas, a partir de 80 muestras de turba tomadas en febrero y noviembre de 2012 en dos turberas compactas de Tierra del Fuego. 
c) Microhongos de turberas fueguinas y compactas de Astelia-Donatia

Considerando las diferentes metodologías clásicas de cultivo de hongos utilizadas en este estudio, se sembraron un total de 5.200 partículas y se obtuvieron un total de 3.225 aislamientos o colonias axénicas de hongos (Tabla 5). Estos aislamientos correspondieron a 9 géneros (Aureobasidium, Beauveria, Botryosporum, Cladosporium, Mortierella, Mucor, Parasterinella, Penicillium y Trichoderma) y 19 especies (Tabla 6). En algunos casos, las cepas no presentaron estructuras de reproducción (conidios) que permitieran su determinación y/o clasificación taxonómica, y, por lo tanto fueron registrados como micelios estériles. 
Tabla 5. Número de partículas sembradas y número de aislamientos fúngicos obtenidos de 80 muestras de turba recolectadas en dos turberas compactas de Tierra del Fuego a partir de dos muestreos (febrero y noviembre de 2.012) y utilizando diferentes metodologías clásicas de cultivo fúngico (siembra directa de suelo, lavado de partículas de suelo, cámaras húmedas).

\begin{tabular}{clcc} 
MUESTREO & METODOLOGÍA & $\mathrm{n}$ PARTICULAS & $\mathrm{n}$ AISLAMIENTOS \\
\hline \multirow{3}{*}{ feb-12 } & Siembra Directa & 200 & 87 \\
\cline { 2 - 4 } & Lavado & 800 & 658 \\
\cline { 2 - 4 } & Cámaras Húmedas & 200 & 28 \\
\hline nov-12 & Lavado & 4.000 & 2.452 \\
\hline & & & 3.225 \\
\hline
\end{tabular}


Tabla 6. Lista de microhongos aislados a partir de 80 muestras de turba, obtenidas de dos turberas compactas (Astelia-Donatia) de Tierra del Fuego durante dos temporadas de muestreo en el período febrero-noviembre 2012.

\begin{tabular}{|c|c|c|}
\hline CLASE & GÉNERO & ESPECIE FÚNGICA \\
\hline \multirow[t]{17}{*}{ Ascomycetes } & Aureobasidium & A. pullulans \\
\hline & Beauveria & B. bassiana \\
\hline & Botryosporum & Botryosporum sp. \\
\hline & Cladosporium & C. cladosporioides \\
\hline & & C. sphaerospermum \\
\hline & & C. herbarum \\
\hline & Parasterinella & Parasterinella sp. \\
\hline & Penicillium & P. canescens \\
\hline & & P. chrysogenum \\
\hline & & $P$. citrinum \\
\hline & & P. frequentans \\
\hline & & P.implicatum \\
\hline & & P. jensenii \\
\hline & Trichoderma & T. harzianum \\
\hline & & T. koningii \\
\hline & & T. polysporum \\
\hline & & T. viride \\
\hline \multirow[t]{3}{*}{ Zygomycetes } & Mucor & M. hiemalis \\
\hline & Mortierella & M. alpina \\
\hline & & levaduras \\
\hline
\end{tabular}


d) Análisis de la composición específica y abundancia según 'cobertura vegetal':

\section{Astelia vs Sphagnum}

En la tabla 7 se observan los datos de frecuencia de ocurrencia de las especies fúngicas aisladas según el tipo de cobertura vegetal (Astelia pumila y Sphagnum magellanicum) presentes en las parcelas de muestreo para cada temporada de muestreo (febrero y noviembre). La mayor parte de los microhongos aislados estuvo presente en las muestras de los dos tipos de turba; la suma total de la proporción de especies en cada cobertura fueron muy similares (aproximadamente el 50\%). El número de especies observadas para la temporada de febrero fue igual tanto para Astelia como para Sphagnum ( 8 especies), y fue muy similar que en el muestreo posterior, donde se observó el doble de especies (15 especies en Astelia y 14 en Sphagnum) debido a la siembra de un mayor número de partículas (Tabla 7 ).

Las especies que presentaron las mayores frecuencias de ocurrencia variaron en cada cobertura y temporada. En las muestras de turba de Astelia recolectadas en febrero, las especies más frecuentemente observadas fueron a M. alpina, A. pullulans y T. polysporum; mientras que en las muestras de Sphagnum se determinó la presencia de T. viride, A. pullulans y M. alpina. En noviembre, los resultados fueron diferentes ya que $A$. pullulans y Beauveria bassiana fueron las especies más frecuentemente aisladas tanto de Astelia como de Sphagnum. Sin embargo, $B$. bassiana sólo estuvo presente durante la temporada de muestreo de noviembre y, al mismo tiempo, las frecuencias de ocurrencia fueron levemente superiores en Astelia para las dos especies fúngicas (Tabla 7 ). 
Teniendo en cuenta el período de muestreo, las especies que estuvieron presentes en ambas coberturas y en ambas temporadas fueron: $A$. pullulans, C. cladosporiodes, Mortierella alpina, P. canescens, P. frequentans, Trichoderma polysporum y T. viridae. Las especies B. bassiana, C. sphaerospermum, C. herbarum, P. chrysogenum, P. citrinum, T. harzianum y $T$. koningii solo fueron aisladas a partir de muestras tomadas en noviembre de ambas coberturas, mientras que la especie $P$. implicatum fue aislada sólo en febrero. Por otro lado, la especie $P$. jensenii se encontró en las muestras de Astelia en febrero y en las de Sphagnum durante noviembre, y la especie $C$. sphaerospermum sólo se aisló a partir de parcelas cubiertas por Astelia,

Con respecto a la presencia de levaduras y micelio estéril en ambas coberturas y temporadas de muestreo, los porcentajes registrados para ambos grupos fueron muy similares en ambas coberturas (Tabla 7). 
Tabla 7. Frecuencias relativas de hongos microscópicos aislados a partir de muestras de turba recolectadas de parcelas con diferentes coberturas vegetales (Astelia pumila y Sphagnum magellanicum) durante dos campañas de muestreo ( $F$ : febrero y $\mathrm{N}$ : noviembre) en turberas compactas de Astelia-Donatia en Tierra del Fuego.

\begin{tabular}{|c|c|c|c|c|}
\hline \multirow{2}{*}{ Especie fúngica } & \multicolumn{2}{|c|}{ Febrero } & \multicolumn{2}{|c|}{ Noviembre } \\
\hline & Astelia & Sphagnum & Astelia & Sphagnum \\
\hline Aureobasidium pullulans & 6,08 & 4,86 & 15,62 & 13,42 \\
\hline Beauveria bassiana & -- & -- & 9,87 & 8,48 \\
\hline Cladosporium cladosporioides & 0,46 & 0,61 & 0,24 & 0,24 \\
\hline C. herbarum & -- & - & 0,08 & $0, \mathrm{O}_{4}$ \\
\hline C. sphaerospermum & -- & -- & 0,12 & -- \\
\hline Mortierella alpina & 7,14 & 4,86 & 1,88 & 2,45 \\
\hline Mucor hiemailis & -- & -- & 0,61 & - \\
\hline Penicillium canescens & 0,61 & 0,30 & 0,53 & 0,3 \\
\hline P. chrysogenum & -- & - & 0,53 & 1,02 \\
\hline P. citrinum & -- & -- & 2,16 & 1,67 \\
\hline P. frequentans & 5,02 & 3,34 & 4 & 6,28 \\
\hline Penicillium implicatum & 0,15 & 1,22 & - & - \\
\hline P. jensenii & 0,61 & -- & -- & 0,12 \\
\hline Trichoderma harzianum & -- & - & 0,2 & 1,31 \\
\hline T. koningii & -- & -- & 0,41 & 0,65 \\
\hline T. polysporum & 5,78 & 3,19 & 0,9 & 1,67 \\
\hline T. viride & 5,02 & 5.62 & 4,08 & 1,79 \\
\hline Levaduras & 2,74 & 2,13 & 6,73 & 7,38 \\
\hline Micelio estéril & 16,72 & 22,95 & 2 & 3,83 \\
\hline Total & 50,30 & 49,70 & 49,35 & 50,64 \\
\hline
\end{tabular}




\section{e) Análisis de la composición especifica y abundancia según sitio': Moat vs Garibaldi}

A partir de los datos presentados en la tabla 8 se analizaron las frecuencias de ocurrencia de los hongos microscópicos aislados de turberas compactas teniendo en cuenta la ubicación de las turberas (Moat: turbera ubicada en zona costera con fuerte influencia marina y Garibaldi: turbera ubicada en zona montañosa).

Ambas turberas compartieron gran parte de las especies aisladas durante este estudio. De ellas, la especie Trichoderma koningii sólo se observó en la turbera situada en Moat, mientras que las especies Cladosporium herbarum, C. sphaerospermum, $P$. implicatum y $P$. jensenii se aislaron únicamente de la turbera situada en Garibaldi. Las especies $A$. pullulans, M. alpina, $P$. frequentans, T. polysporum y T. viridae fueron aisladas a partir de muestras tomadas en ambas turberas y durante los dos períodos de muestreo (Tabla 8).

Tanto en febrero como en noviembre, fue mayor el número de especies aisladas de las muestras de la turbera situada en Garibaldi (12 especies en febrero y 14 especies en noviembre) con respecto a las muestras de Moat ( 7 especies en febreo y 9 especies en noviembre) (Tabla 8).

Por otra parte, B. bassiana, $P$. chrysogenum, $P$. citrinum y $T$. harzianum estuvieron presentes también en ambas turberas pero únicamente en noviembre; mientras que $P$. implicatum también estuvo presente en ambas turberas pero solo en febrero. Las especies $C$. herbarum y $C$. sphaerospermum fueron aisladas de la turbera situada en Garibaldi solo en noviembre. Por otro lado, T. koningii se aisló a partir de las muestras tomadas en noviembre en Moat (Tabla 8). 
Las especies más comúnmente aisladas fueron diferentes en las turberas. Es así que en

febrero, la especie más frecuente para la turbera situada en Moat fue $M$. alpina y para la turbera en Garibaldi, A. pullulans, T. polysporum y T. viridae (Tabla 8).

Por otra parte, tanto en febrero como en noviembre los mayores porcentajes de micelios estériles y los menores de levaduras, se obtuvieron a partir de las muestras tomadas en Moat (Tabla 8). 
Tabla 8. Frecuencias relativas de hongos microscópicos aislados a partir de muestras de turba recolectadas de parcelas ubicadas en dos turberas compactas de Astelia en Tierra del Fuego y en zonas geográficas disímiles (Moat: turbera con fuerte influencia marítima; Garibaldi: turbera ubicada en zona montañosa).

\begin{tabular}{|c|c|c|c|c|}
\hline \multirow{2}{*}{ Especie fúngica } & \multicolumn{2}{|c|}{ Febrero } & \multicolumn{2}{|c|}{ Noviembre } \\
\hline & Moat & Garibaldi & Moat & Garibaldi \\
\hline Aureobasidium pullulans & 0,3 & 10,64 & 19,39 & 9,8 \\
\hline Beauveria bassiana & -- & - & 2,21 & 16,23 \\
\hline Cladosporium cladosporioides & -- & 1,06 & 0,41 & 0,08 \\
\hline C. herbarum & -- & - & -- & 0,12 \\
\hline C. sphaerospermum & --- & -- & -- & 0,12 \\
\hline Mortierella alpina & 8,81 & 3,19 & 3,93 & 0,41 \\
\hline Mucor hiermalis & -- & 0,61 & -- & -- \\
\hline Penicillium canescens & 0,91 & - & 0,25 & 0,57 \\
\hline P. chrysogenum & -- & - & 0,82 & 0,74 \\
\hline P. citrinum & -- & - & 1,56 & 2,3 \\
\hline P. frequentans & 4,56 & 3,8 & 5,16 & 5,16 \\
\hline P. implicatum & 0,3 & 1,06 & -- & - \\
\hline P. jensenii & -- & 0,61 & -- & 0,12 \\
\hline Trichoderma harzianum & -- & - & 1,02 & 0,49 \\
\hline T. koningii & -- & -- & 1,07 & -- \\
\hline T. polysporum & 0,46 & 8,51 & 2,09 & 0,49 \\
\hline T. viride & 3,8 & 6,84 & 4,14 & 1,76 \\
\hline Levaduras & 0,3 & 4,56 & 5,33 & 8,85 \\
\hline Micelio estéril & 26,9 & 12,77 & 3,77 & 1,6 \\
\hline Total & 46,35 & 53,65 & 51,15 & 48,84 \\
\hline
\end{tabular}




\section{f) Análisis de la composición especifica y abundancia según 'profundidad de}

\section{muestreo': profundidad $A$ vs profundidad $B$}

Se analizó la ocurrencia de las especies fúngicas aisladas de las turberas en estudio según su distribución en profundidad (profundidad A: $3-10 \mathrm{~cm}$; profundidad $B: 10-20 \mathrm{~cm}$ ) (Tabla 9).

Todas las especies aisladas en el estudio completo estuvieron presentes en las muestras tomadas en ambas profundidades y solo difirieron en los períodos en los que fueron encontradas en las mismas. En cuanto a la cantidad de especies aisladas de cada profundidad, los resultados fueron muy similares en las dos temporadas (7-10 especies aisladas en A y 14-15 especies aisladas en B).

Las especies A. pullulans, C. cladosporium, M. alpina, P. frequentans, T. polysporum y T. viride fueron aisladas de las muestras tomadas en las dos temporadas y en las dos profundidades; mientras que $B$. bassiana, C. herbarum, $P$. chrysogenum, $P$. citrinum, $T$. harzianum y $T$. koningii fueron aisladas en las dos profundidades únicamente en noviembre. $P$. implicatum estuvo presente solo en la profundidad A y en febrero (Tabla 9).

Se detectó la presencia de levaduras y micelios estériles en las dos temporadas y profundidades de muestreo siguiendo el mismo patrón: frecuencias levemente superiores en la profundidad B en febrero y en la profundidad $A$, en noviembre. 
Tabla 9. Frecuencias relativas de hongos microscópicos aislados a partir de muestras de turba recolectadas a dos profundidades diferentes $(A: 3-10 \mathrm{~cm}$ y $B: 10-20 \mathrm{~cm}$ ) de parcelas ubicadas en dos turberas compactas de Astelia en Tierra del Fuego.

\begin{tabular}{|c|c|c|c|c|}
\hline \multirow{2}{*}{ Especie fúngica } & \multicolumn{2}{|c|}{ Febrero } & \multicolumn{2}{|c|}{ Noviembre } \\
\hline & A & B & A & B \\
\hline Aureobasidium pullulans & 4,56 & 6,38 & 11,75 & 17,29 \\
\hline Beauveria bassiana & -- & -- & 9,67 & 8,69 \\
\hline Cladosporium cladosporioides & 0,3 & 0,76 & 0,24 & 0,24 \\
\hline C. sphaerospermum & -- & -- & -- & 0,12 \\
\hline C. herbarum & -- & --- & $0, \mathrm{O}_{4}$ & 0,08 \\
\hline Mortierella alpina & 8,05 & 3,95 & 2,16 & 2,16 \\
\hline Mucor hiemalis & -- & 0,61 & - & -- \\
\hline Penicillium canescens & -- & 0,91 & 0,7 & 0,16 \\
\hline P. chrysogenum & -- & -- & 1,10 & 0,49 \\
\hline P. citrinum & -- & -- & 1,40 & 2,45 \\
\hline$P$. frequentans & 4,26 & 4,1 & 5,10 & 5,18 \\
\hline P. implicatum & 0,91 & 0,46 & - & - \\
\hline P. jensenii & -- & 0,61 & 0,10 & $0, \mathrm{O}_{4}$ \\
\hline Trichoderma harzianum & -- & -- & 1,20 & 0,29 \\
\hline T. koningii & -- & -- & 0,70 & 0,37 \\
\hline T. polysporum & 5,47 & 3,5 & 1,47 & 1,1 \\
\hline T. viride & 5,78 & 4,86 & 2,28 & 3,59 \\
\hline Levaduras & 1,98 & 2,89 & 7,38 & 6,73 \\
\hline Micelio estéril & 18,69 & 20,97 & 3,38 & 1,75 \\
\hline Total & 50 & 50 & 48,67 & 50,73 \\
\hline
\end{tabular}




\section{g) Análisis de la diversidad fúngica}

Se determinaron y compararon la riqueza de especies fúngicas $(S)$, equitatividad $(J)$ y el Índice de Shannon-Wiener $\left(\mathrm{H}^{\prime}\right)$ en las dos turberas en estudio teniendo en cuenta tanto la profundidad de muestreo $(A=3-10 \mathrm{~cm} ; B=10-20 \mathrm{~cm})$ como la cobertura vegetal presente en las parcelas muestreadas (Astelia y Sphagnum).

Febrero. En general, la diversidad $\left(H^{\prime}\right)$ presentó valores medios entre 0,25 y 0,70

(Figura 21.A) que coinciden con diversidades bajas y no mostró tendencias a diferir según la profundidad, el sitio, ni la cobertura vegetal presente en las parcelas de muestreo (ANOVA: ANEXO 9-Tablas A, B y C). La equidad ( $\mathrm{J}$ ') tomó valores medios entre 0,25 y 0,69, los cuales fueron consistentes con los valores de diversidad mencionados (Figura 21.B). Del mismo modo, el número de especies registradas $(\mathrm{S})$ no varió significativamente conforme aumentaba la profundidad de muestreo, ni según el tipo de cobertura vegetal y el sitio de muestreo (ANOVA: ANEXO 10-Tablas A, B y C); todos las situaciones de muestreo presentaron una riqueza de $2-3$ especies, excepto un caso en el que se obtuvieron 5 especies (Figura 21.C). 
A

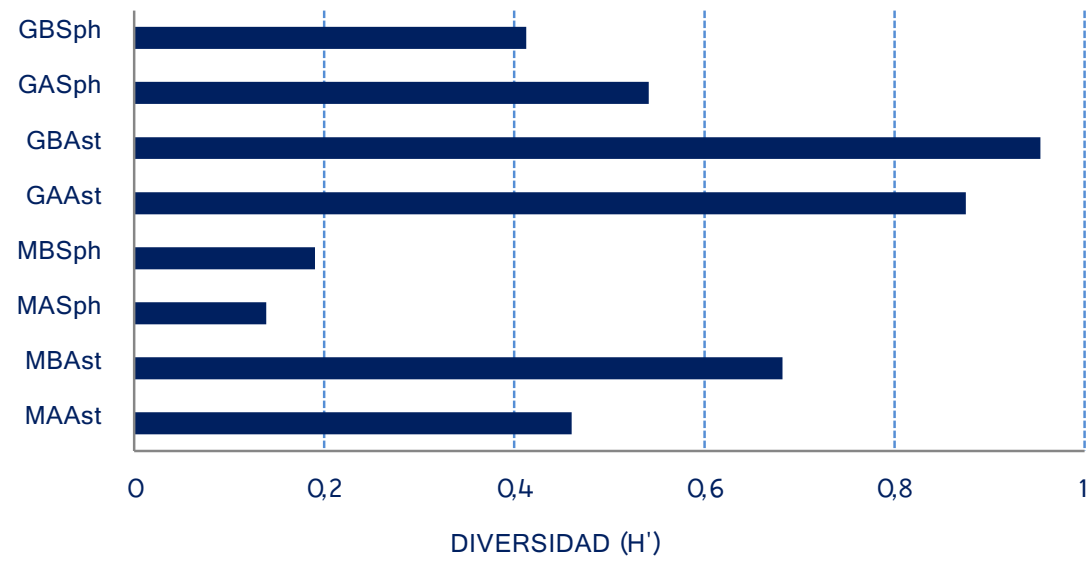

B

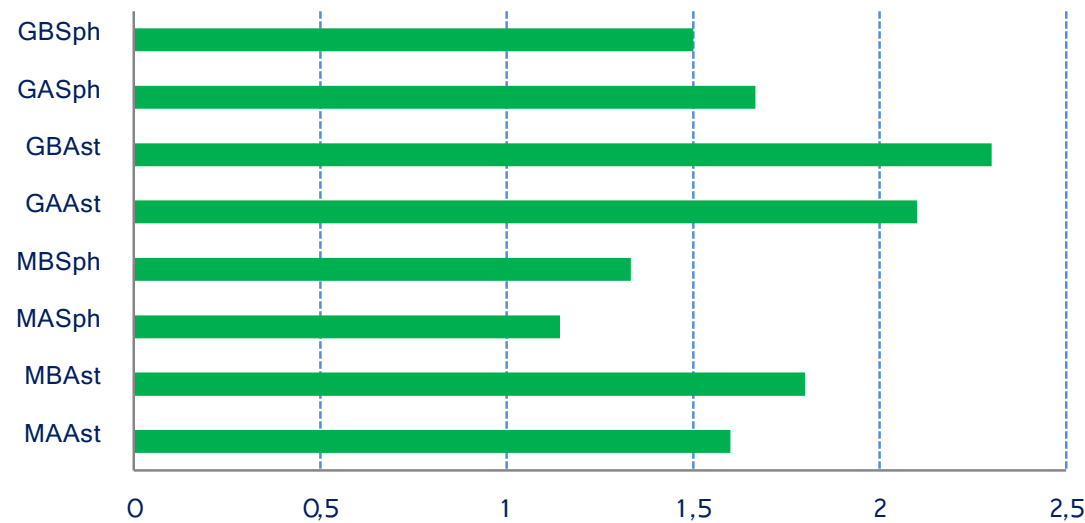

EQUIDAD (J)

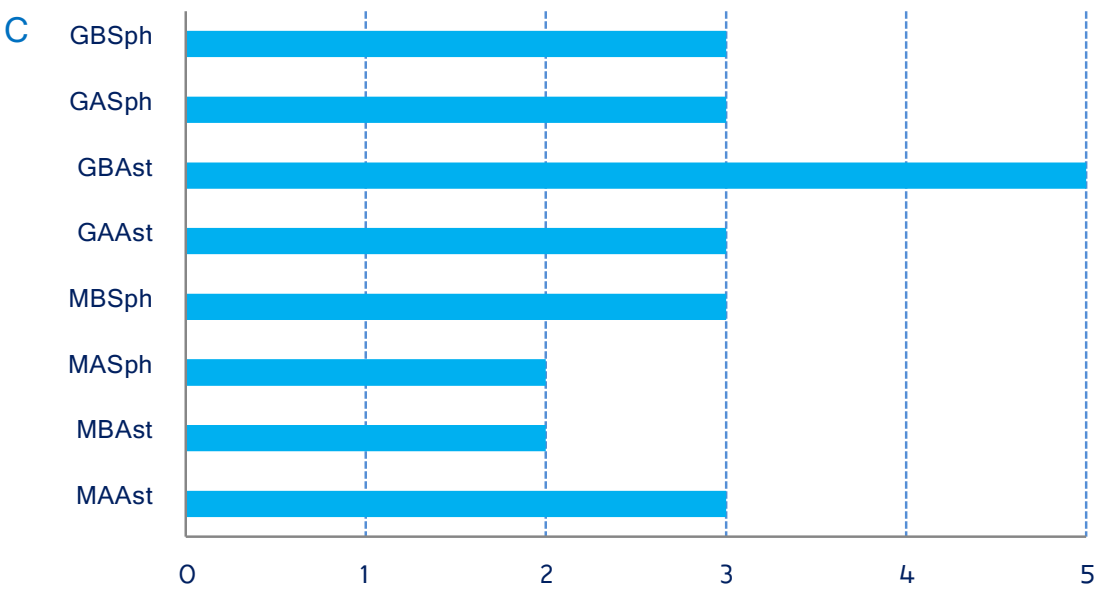

RIQUEZA ESPECÍFICA (S) 
Figura 21. Valores de índice de diversidad de Shannon-Weaner (A), equidad (B) y riqueza específica (C) calculados para muestras de turba provenientes de dos turberas compactas en Tierra del Fuego (M: Moat: G: Garibaldi), colectadas en febrero de 2012, a dos profundidades diferentes (A: 3-10 cm.; B: $10-20 \mathrm{~cm}$.) y en presencia de dos tipos de cobertura vegetal (Ast: Astelia pumila y Sph: Sphagnum magellanicum).

Noviembre. Para esta temporada de muestreo, los valores medios del índice de diversidad estuvieron en un rango de 1,45-1,68 (Figura 22.A), que coinciden con valores de diversidad media y no se encontraron diferencias significativas según el sitio muestreado, así como tampoco según la cobertura vegetal presente en la parcela ni en la profundidad de muestreo (ANOVA: ANEXO 11-Tablas A, B y C).La equidad ( $\mathrm{J}^{\prime}$ ) presentó valores medios entre 0,72 y 0,89 , los cuales son consistentes con los valores de diversidad mencionados (Figura 22.B). El número de especies registradas (S) fue de 5 a 8 (Figura 22.C) y no se registraron diferencias significativas conforme el aumento de la profundidad de muestreo, ni según el tipo de cobertura vegetal y/o según el sitio muestreado (ANOVA: ANEXO 12 - Tablas A, B y C). 
A

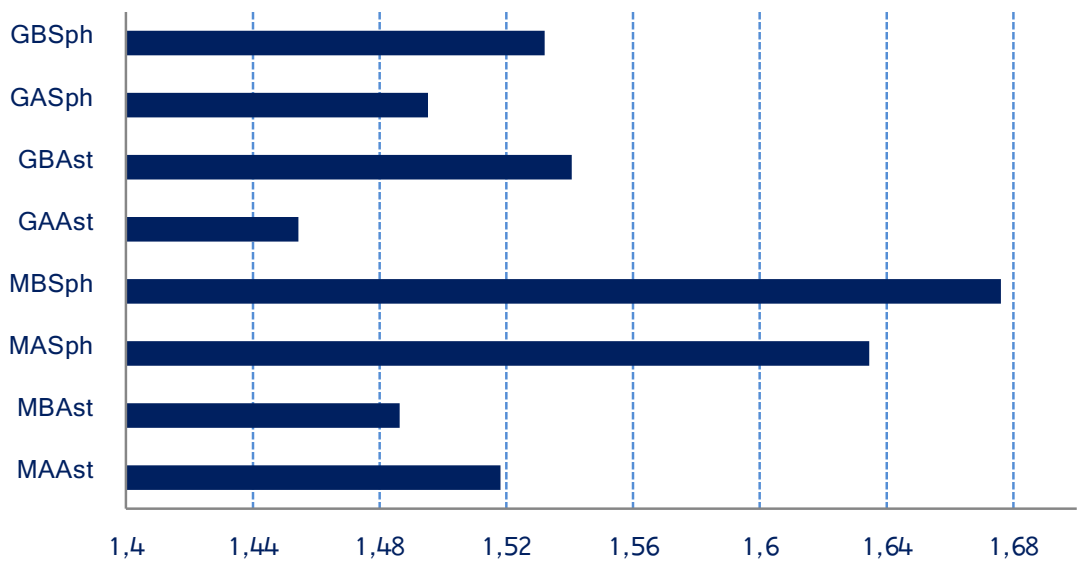

DIVERSIDAD (H')

B

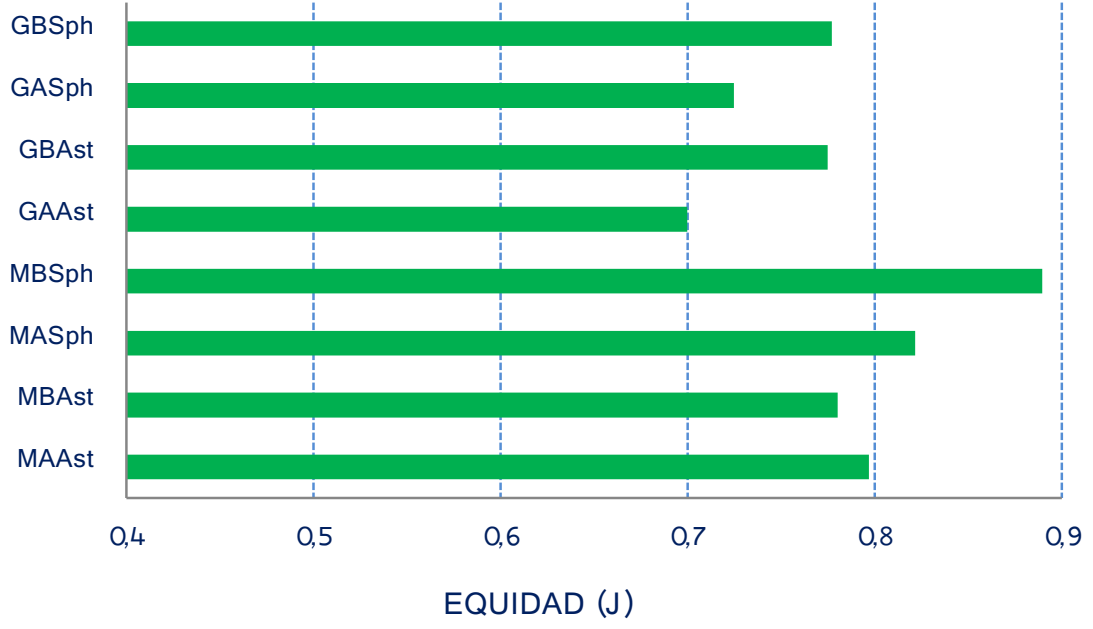

C

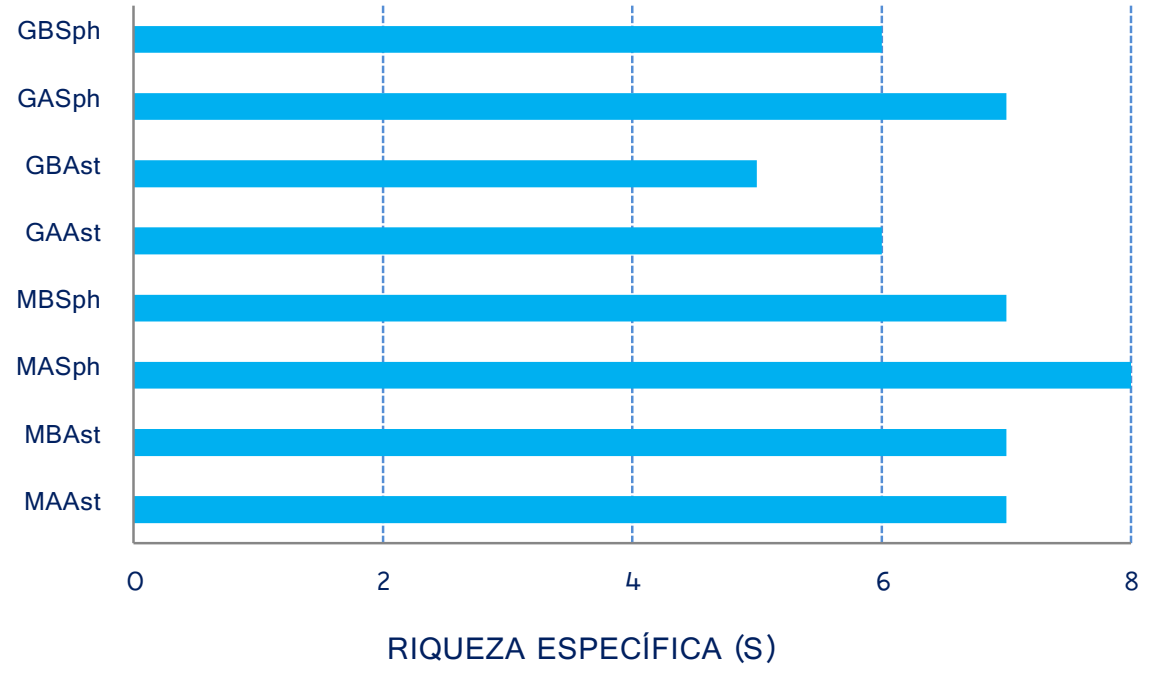


Figura 22. Valores de índice de diversidad de Shannon-Weaner (A), equidad (B) y riqueza específica (C) calculados para muestras de turba provenientes de dos turberas compactas en Tierra del Fuego (M: Moat; G: Garibaldi), colectadas en noviembre de 2012, a dos profundidades diferentes (A: 3-10 cm.; B: $10-20 \mathrm{~cm}$.) y en presencia de dos tipos de cobertura vegetal (Ast: Astelia pumila y Sph: Sphagnum magellanicum).

\section{h) Análisis de la composición fúngica y su relación con las variables abióticas}

La ordenación de las muestras en función de la composición específica se muestra por tipo de cobertura y mes de muestreo en las figuras 23 a 26.

En el mes de febrero, los dos primeros ejes del ACP explican el 51,79\% de la varianza de las muestras de Astelia. El eje $1(33,87 \%)$ muestra un gradiente de sitios con mayor frecuencia de $M$. alpina hacia el lado positivo del eje y una mayor frecuencia de $P$. frequentans hacia el lado negativo del eje. El eje $2(17,91 \%)$ presenta un gradiente de muestras asociado positivamente con la frecuencia de $A$. pullulans. No hubo una clara separación de los sitios, pero para un determinado grupo de muestras se manifestó una contribución importante de las especies M. alpina (algunas muestras de Moat) y A. pullulans (Garibaldi) (Figura 23). De acuerdo a la correlación entre los valores de la posición de las muestras sobre los ejes y las variables abióticas (Tabla 10.A) se observa que para el eje 2 las muestras se asocian tomadas más distantemente del nivel freático y una disminución de la relación $\mathrm{C} / \mathrm{N}$. Por lo tanto, la especie $A$. pullulans estaría asociada a sitios con niveles freáticos más bajos y menores relaciones $\mathrm{C} / \mathrm{N}$ con respecto a $M$. alpina que presentaría un asociación inversa. 
Por otro lado, durante el mes de noviembre, los dos primeros ejes del ACP explican el $71,78 \%$ de la variabilidad con el eje I $(53,04 \%)$ asociado positivamente con $B$. bassiana y el eje $2(18,83 \%)$ asociado, también positivamente, con $A$. pullulans (Figura 24). Las muestras del sitio Moat están asociadas con la presencia de $A$. pullulans mientras que las muestras del sitio Garibaldi lo están con B. bassiana. El análisis de correlación con las variables ambientales (Tabla 10.A) presenta al eje 1 asociado positivamente con el contenido hídrico de las muestras y negativamente tanto con el contenido de materia orgánica como con la relación $\mathrm{C} / \mathrm{N}$. Es decir que aquellas muestras asociadas a la presencia de $A$. pullulans estarían vinculadas a mayores contenidos de materia orgánica, mayor relación $\mathrm{C} / \mathrm{N}$ y bajo contenido hídrico en el ambiente con respecto a las muestras asociadas a $B$. bassiana, cuya vinculación es opuesta.

En el caso de las muestras de Sphagnum, en el diagrama de ACP realizado para febrero, el 50, $21 \%$ de la variabilidad de las mismas fue explicada por los dos primeros componentes (eje 1: $27,62 \%$ y eje 2: $22,59 \%$ ) y tal como ocurrió con las muestras de Astelia, en esta temporada no se observó una clara ubicación de las muestras de acuerdo a la composición de especies (Figura 25). Del mismo modo, en esta situación de análisis no hubo ninguna asociación significativa entre el ordenamiento de las muestras y las variables ambientales (Tabla 10.B).

En el mes de noviembre los dos primeros componentes explicaron el $54,86 \%$ de la variabilidad de las muestras. El eje $1(36,87 \%)$ presenta las muestras asociadas positivamente con $B$. bassiana; mientras que el eje $2(17,81 \%)$ mostró una mayor frecuencia de $A$. pullulans en las muestras hacia el lado negativo del eje. En este caso sí se observó una separación entre las turberas con respecto a su composición específica. Las especies T. harzianum y A. pullulans se 
asociaron con las muestras de Moat y B. bassiana se asoció con las de Garibaldi (Figura 26).

Por otro lado, el resultado de la correlación con las variables ambientales mostró que la relación

$\mathrm{C} / \mathrm{N}$ se asocia negativamente con las muestras sobre el eje 1, tal como sucedió con las muestras

de Astelia tomadas en noviembre. Por lo tanto, las muestras asociadas con las especies $A$. pullulans y $T$. harzianum estarían vinculadas a sitios con relación $\mathrm{C} / \mathrm{N}$ mayor que aquellas que se asociaron con B. bassiana (Tabla 10.B). 


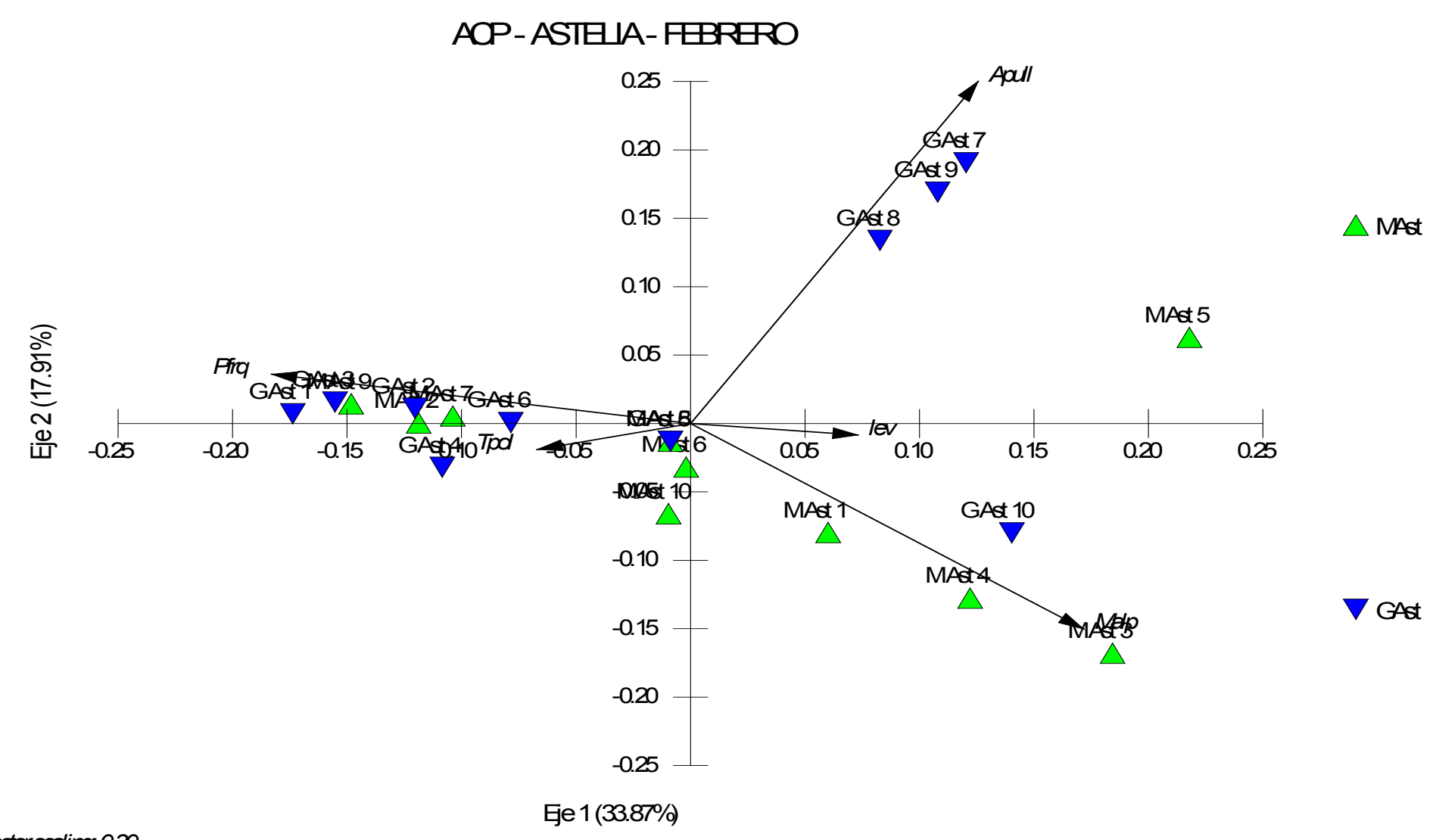

Vedorscaling 0.30

Figura 23. Análisis de componentes principales (ACP) de las muestras basado en la abundancia de las especies fúngicas de Moat y Garibaldi para febrero 2012. Las muestras corresponden a cubiertas con Astelia (Ast). Se representan los vectores de las espcies de mayor contribución a cada eje. Apull: Aureobasidium pullulans; lev: levaduras; Malp: Mortierella alpina; Pfrq: Penicillium frequentans; Tpol: Trichoderma polysporum. 


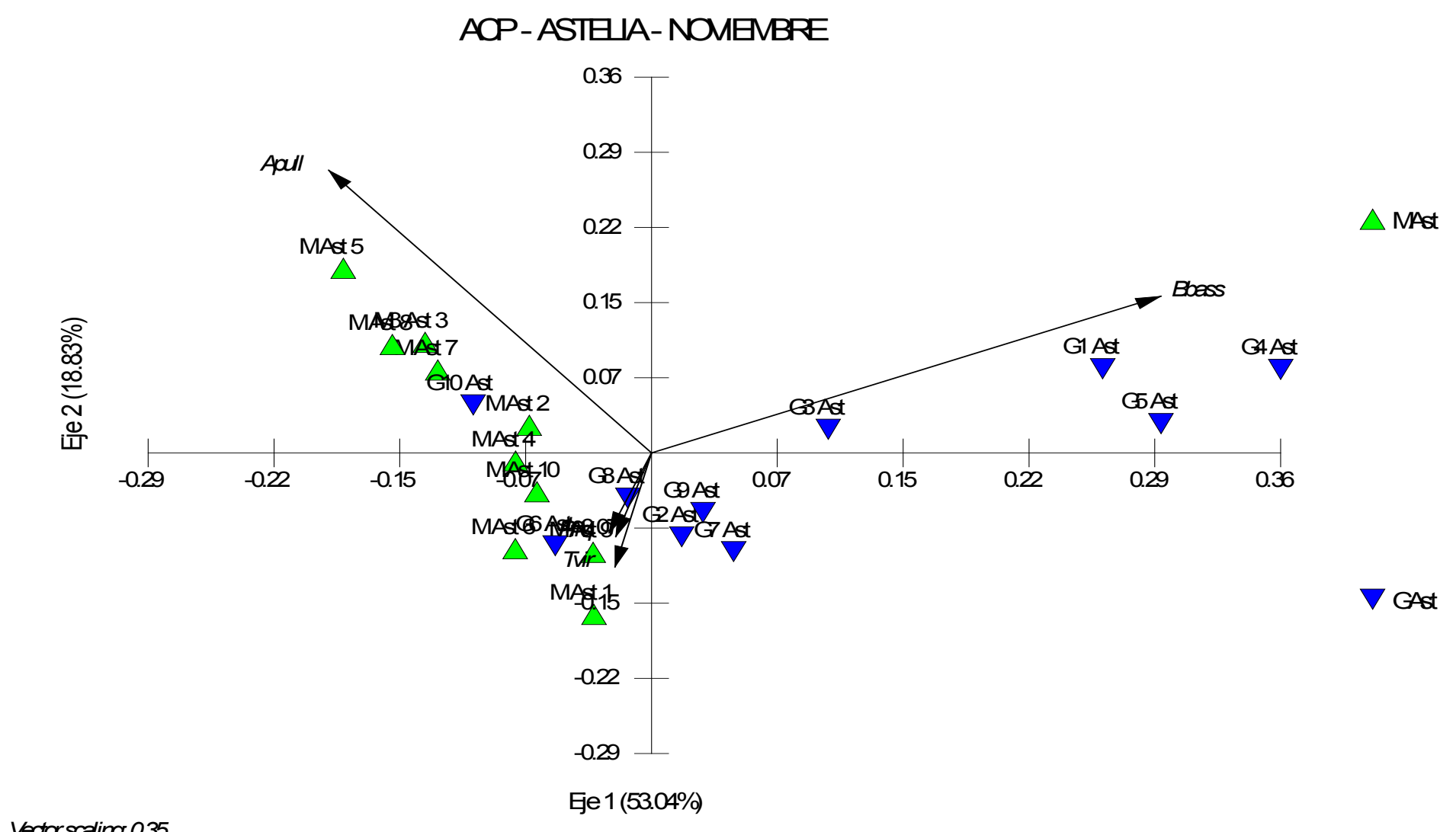

Figura 24. Análisis de componentes principales (ACP) de las muestras basado en la abundancia de las especies fúngicas de Moat y Garibaldi para noviembre 2012. Las muestras corresponden a cubiertas con Astelia (Ast). Se representan los vectores de las espcies de mayor contribución a cada eje. Apull: Aureobasidium pullulans; Bbass: Beauveria bassiana; Pfrq: Penicillium frequentans; Tvir. Trichoderma viridae. 


\section{ACP-SPHAGNM- FERERO}

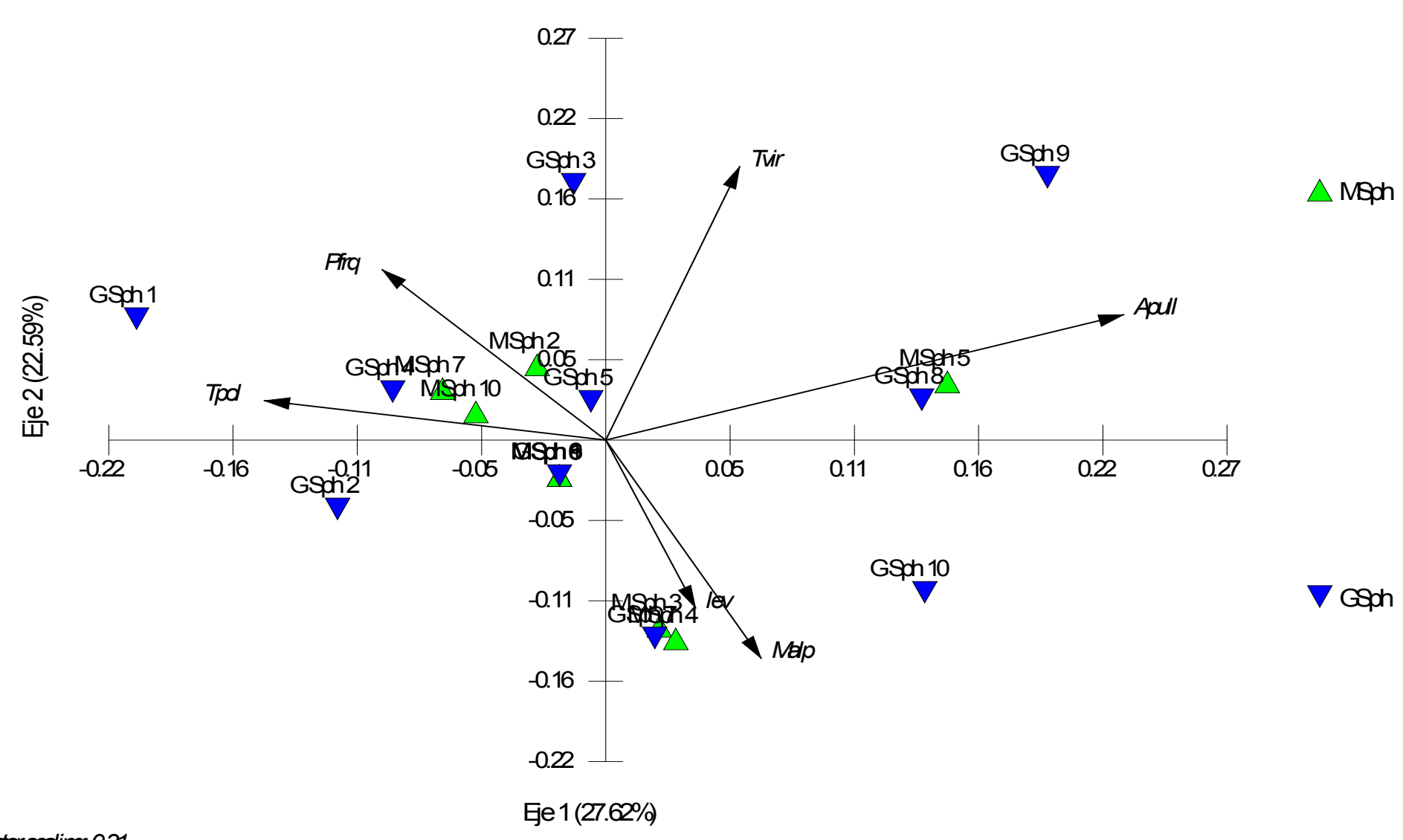

Vedorscaling 0.31

Figura 25. Análisis de componentes principales (ACP) de las muestras basado en la abundancia de las especies fúngicas de Moat y Garibaldi para febrero 2012. Las muestras corresponden a cubiertas con Sphagnum (Sph). Se representan los vectores de las espcies de mayor contribución a cada eje. Apull: Aureobasidium pullulans; lev: levaduras; Malp: Mortierella alpina; Pfrq: Penicillium frequentans; Tpol: Trichoderma polysporum. 


\section{ACP-SPHANUM-NOMEMBRE}

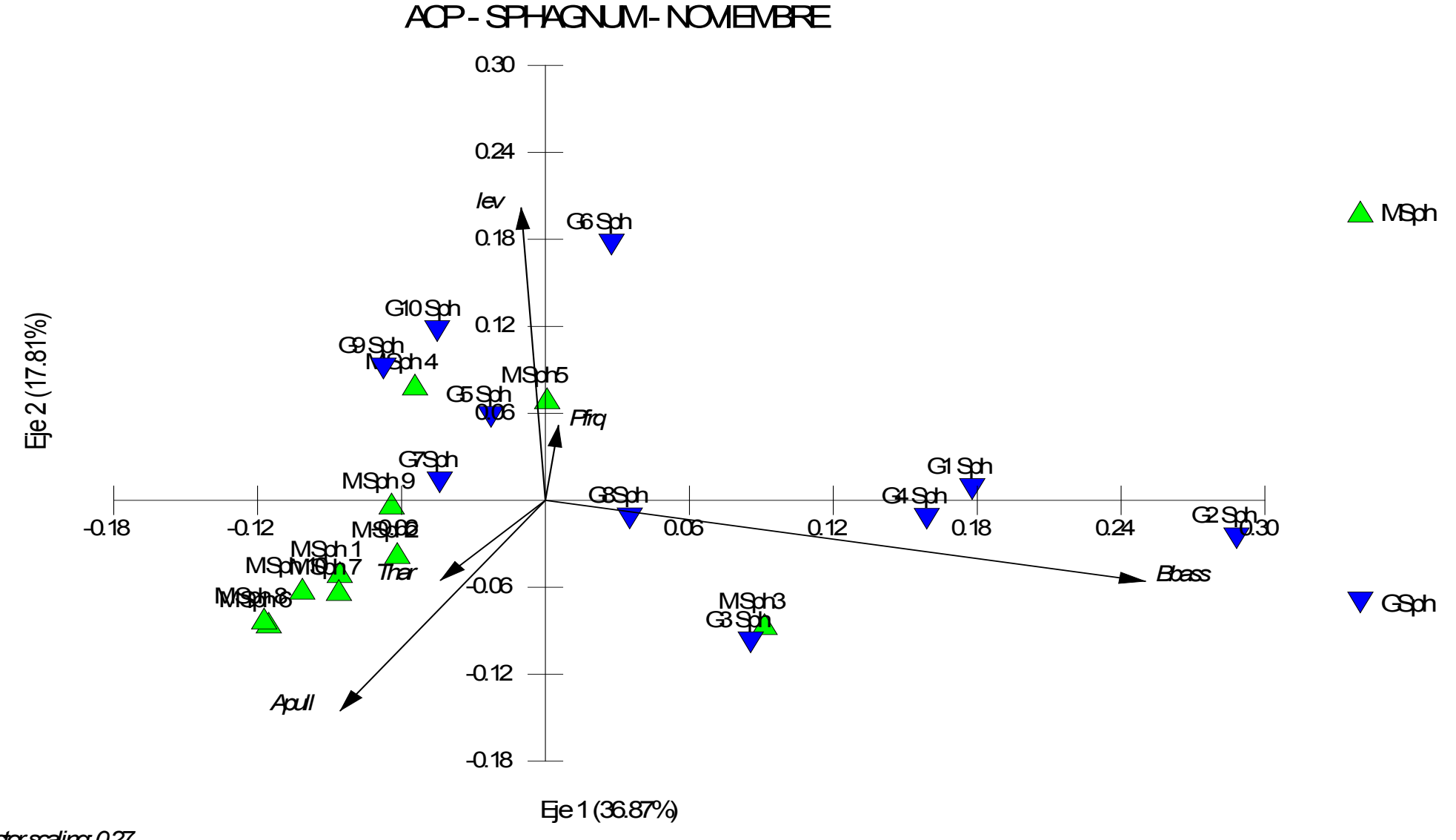

Figura 26. Análisis de componentes principales (ACP) de las muestras basado en la abundancia de las especies fúngicas de Moat y Garibaldi para noviembre 2012. Las muestras corresponden a cubiertas con Sphagnum (Sph). Se representan los vectores de las espcies de mayor contribución a cada eje. Apull: Aureobasidium pullulans; Bbass: Beauveria bassiana; lev: levaduras; Thar. Trichoderma harzianum. 
Tabla 10. Matriz de correlación entre las variables ambientales y la posición de las muestras sobre los ejes I y II para Astelia (A) y Sphagnum (B). (\%N: contenido de nitrógeno; \% MO: contenido de materia orgánica; NF: nivel freático; $\mathrm{CH}$ : contenido hídrico; $\mathrm{C} / \mathrm{N}$ : relación carbono:nitrógeno). En rojo se muestran los valores significativos.

\begin{tabular}{|c|c|c|c|c|}
\hline \multirow{2}{*}{$\begin{array}{l}\text { (A) } \\
\text { Variable }\end{array}$} & \multicolumn{2}{|c|}{ Febrero } & \multicolumn{2}{|c|}{ Noviembre } \\
\hline & Eje 1 & Eje 2 & Eje 1 & Eje 2 \\
\hline$\% \mathrm{~N}$ & -0.23 & 0.17 & 0.093 & -0.240 \\
\hline$\% \mathrm{MO}$ & 0.09 & -0.41 & -0.650 & 0.091 \\
\hline NF & -0.08 & 0.50 & 0.074 & -0.440 \\
\hline $\mathrm{CH}$ & -0.22 & 0.22 & 0.640 & -0.128 \\
\hline CN & 0.23 & -0.53 & -0.540 & 0.119 \\
\hline
\end{tabular}

\begin{tabular}{|c|c|c|c|c|}
\hline \multirow{2}{*}{$\begin{array}{l}\text { (B) } \\
\text { Variable }\end{array}$} & \multicolumn{2}{|c|}{ Febrero } & \multicolumn{2}{|c|}{ Noviembre } \\
\hline & Eje 1 & Eje 2 & Eje 1 & Eje 2 \\
\hline$\% N$ & 0.21 & -0.21 & 0.34 & 0.20 \\
\hline$\% \mathrm{MO}$ & 0.02 & -0.01 & -0.44 & -0.24 \\
\hline NF & -0.30 & -0.26 & 0.52 & 0.61 \\
\hline $\mathrm{CH}$ & -0.26 & -0.05 & 0.06 & 0.08 \\
\hline$C N$ & -0.13 & -0.01 & -0.46 & -0.25 \\
\hline
\end{tabular}

\subsubsection{AMPLIFICACIÓN Y SECUENCIACIÓN DE ADN A PARTIR DE MICELIOS ESTÉRILES}

Se utilizó ADN purificado de cada uno de los 30 micelios estériles seleccionados al azar y se amplificó la región ITS del ADNr. Para ello se siguieron las condiciones de extracción y programa de PCR para la amplificación del producto de PCR deseado, descriptas en la sección

\subsection{3}


Para la amplificación de los ADN provenientes de estos aislamientos fúngicos no fue necesario realizar ningún ajuste. El tamaño de los fragmentos obtenidos fue de aproximadamente entre 600 y 700 pb (Figura 27).

$\begin{array}{llllll}M & 1 & 2 & 3 & 4 & 5\end{array}$

$700 \mathrm{pb}$

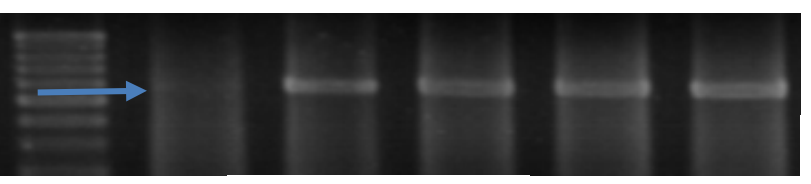

Figura 27. Productos de amplificación obtenidos utilizando cebadores ITS5 e ITS4 a partir del ADN genómico total de 30 micelios estériles, separados por electroforesis en gel de agarosa al $1 \%$ y teñidos con Gel Red (10 mg/l). Calle M: marcador de peso molecular escala de $100 \mathrm{pb}$ (Life Techonology); calles 1-5: muestras de micelio estéril. La flecha señala la posición del producto de amplificación esperado para la región ITS e las especies fúngicas.

Los 30 productos de PCR provenientes de la amplificación del ADN de los micelios estériles con los cebadores ITS5 e ITS4 fueron enviados para su secuenciación. En la tabla 11 se muestran las especies fúngicas con mayor similitud a los productos de amplificación enviados luego del análisis de la comparación de las secuencias con aquellas depositadas en las bases de datos y analizadas según la clasificación realizada mediante el análisis de BLAST (Althschul y col., 1997) de la base de datos del GenBank. 
Tabla 11. Análisis de 30 productos de PCR obtenidos a partir de la amplificación de ADN de micelios fúngicos estériles según el análisis de las secuencias nucleotídicas obtenidas según el análisis de BLAST.

\begin{tabular}{|c|c|c|c|c|c|}
\hline Grupo & $\begin{array}{c}\mathrm{N}^{\circ} \mathrm{de} \\
\text { aislamientos }\end{array}$ & $\begin{array}{l}\text { Organismo con } \\
\text { mayor similitud }\end{array}$ & $\begin{array}{l}\text { Porcentaje } \\
\text { de similitud }\end{array}$ & $\begin{array}{c}\mathrm{N}^{\circ} \text { de } \\
\text { accesión }\end{array}$ & $\begin{array}{c}\text { Tamaño de } \\
\text { productos } \\
\text { de amplificación }\end{array}$ \\
\hline 1 & 6 & Trichoderma viride & $97-99$ & $\mathrm{KF} 944470$ & $600-700$ \\
\hline 2 & 10 & $\begin{array}{l}\text { Tolypocladium } \\
\text { cylindrosporum }\end{array}$ & $98-99$ & KJ0287796 & $487-550$ \\
\hline 3 & 8 & $\begin{array}{l}\text { Tolypocladium } \\
\text { inflatum }\end{array}$ & 99 & FJ 411408 & $550-650$ \\
\hline 4 & 3 & $\begin{array}{l}\text { Uncultured } \\
\text { ectomycorrhiza }\end{array}$ & $90-95$ & FJ5544384 & $750-770$ \\
\hline 5 & 3 & $\begin{array}{l}\text { Fusarium } \\
\text { culmorum }\end{array}$ & $90-91$ & FJ210610 & $650-670$ \\
\hline
\end{tabular}

Los datos de la tabla 11 indican que a partir de la comparación de secuencias amplificadas de cada uno de los 30 micelios fúngicos clasificados como estériles en este trabajo fue posible determinar 4 especies fúngicas diferentes a las identificadas por técnicas clásicas de cultivo, las cuales pertenecen a la División Ascomycotina. 


\subsection{DISCUSIÓN}

\section{a) Métodos de aislamiento de microhongos}

La técnica de lavado de partículas de suelo mostró ser la más eficiente para aislar hongos microscópicos creciendo activamente y permitiendo la obtención de una mayor cantidad de hongos microscópicos que presentaron distintos grados de esporulación (10 especies; Tabla 8). Una de las ventajas del método fue el uso de tamices (filtros) que retuvieron los micelios en estado activo, dejando pasar las esporas de menor tamaño y evitando de este modo tanto la contaminación ambiental como la incidencia de especies de rápido crecimiento que inhibirían la expresión de una mayor diversidad fúngica (Bills y col., 2004). Sin embargo, no deben menospreciarse los restantes métodos que también aportaron un buen número de especies, y con algunas pocas ( $P$. citrinum, Botryosporum sp. y Parasterinella sp.) que no se habrían aislado con el uso exclusivo de esta metodología.

Asimismo, la mayoría de las especies aisladas por lavado también se obtuvieron por siembra directa ( 6 especies en común; Tabla 7), a pesar que esta última tiende a evaluar esporas de un modo desproporcionado (Cabello y Arambarri, 2002). La coincidencia en especies entre ambas metodologías podría deberse a que las porciones a sembrar de cada bloque de turba (muestra) fueron tomadas de la parte más interna del mismo, intentando reducir al mínimo posible el arrastre de esporas y/o propágulos provenientes del ambiente y no de la muestra en sí. 
Por otro parte, la baja abundancia y número de especies obtenidas por el método de cámaras húmedas en comparación con las otras dos metodologías empleadas, se asociaría con el hecho de que la siembra en cámaras húmedas no provee de ningún nutriente extra para los hongos más que el propio sustrato del que se requieren aislar (turba, en este caso); mientras que, tanto para las técnicas de lavado y siembra directa de partículas, se utilizan medios de cultivo (medios CMYA y APG, respectivamente) que proveen la fuente de materia orgánica de un modo más rápidamente asimilable por los hongos objetivo. Es importante resaltar que la técnica de siembra directa se lleva a cabo con la utilización del medio de cultivo más enriquecido pero a la vez menos selectivo con respecto a la técnica de lavado de suelo; no obstante, se obtuvieron mejores resultados con la aplicación de la técnica de lavado, que precisa de un medio de cultivo menos enriquecido, permitiendo el desarrollo de una mayor y más acertada diversidad de especies debido al tratamiento previo que reciben las partículas que serán sembradas. Además, la utilización de un medio menos enriquecido deriva en el lento crecimiento de los hongos sobre las partículas, permitiendo la visualización e identificación de los mismos de un modo más ordenado temporalmente.

La detección y cuantificación de los hongos microscópicos (saprobios) representan procesos complejos y laboriosos, debido a que las diferentes técnicas empleadas pueden exponer panorámicas distintas (Bills y col., 2004). Los procedimientos clásicos microbiológicos para abordar el estudio de hongos filamentosos se basan en cultivos que implican el aislamiento de propágulos microbianos o hifas activas que crecen en el suelo, y su crecimiento en un medio de cultivo axénico para su posterior identificación y cuantificación (Ludwig y Magalhães de Abreu, 
2012). Además, los métodos utilizados para el aislamiento de hongos microscópicos presente en el suelo, rizósfera y rizoplanos, han sido revisados por varios autores (Frankland y col., 1990; Gray, 1990; Gams, 1992; Singleton y col., 1992; Cannon, 1996; Davet y Rouxel, 2000; Bills y col., 2004). Por lo tanto, la mayor parte de la metodología existente para el aislamiento de hongos de suelo está relacionada o es igual que la utilizada en el estudio de hongos fitopatógenos. Sin embargo, se ha progresado considerablemente utilizando técnicas de lavado, medios de cultivo parcialmente selectivos y adictivos que reducen el crecimiento de ciertos grupos de hongos (Ludwig y Magalhães de Abreu, 2012).

Puede resultar indispensable la aplicación de una variedad de técnicas o estrategias de aislamiento, así como realizar el seguimiento en diferentes medios de cultivo para obtener un panorama completo, sin prejuicios, y una medida confiable de los parámetros que definen a las comunidades fúngicas. De esto modo, se cree que se cubrirían las diferentes peculiaridades de la diversidad taxonómica y los grupos fisiológicos de hongos presentes en el ecosistema o ambiente en estudio. Sin embargo, este tipo de acepciones representan grandes esfuerzos, la inversión de mucho tiempo y altos costos para llevarlos a cabo. Por estas razones, se decidió en la segunda etapa de trabajo, invertir esfuerzos y costos en la utilización de una sola metodología de cultivo (lavado de partículas de suelo).

Tradicionalmente, las investigaciones relacionadas con el estudio de las comunidades de microhongos han sido realizadas en base a la identificación de estructuras reproductivas. Asimismo, las metodologías mencionadas en este estudio también fueron utilizadas en diferentes investigaciones realizadas en nuestro país para identificar hongos microscópicos con objetivos 
diferentes a los planteados en esta tesis doctoral. Es así que la metodología de lavado se ha implementado para la determinación de la diversidad fúngica en suelos de bosque de Celtis tala y Scutia buxifolia (Arambarri \& Cabello, 2002), el aislamiento de hongos alcalofílicos y alcalinotolerantes (Elíades y col., 2006), y el aislamiento de especies de Fusarium en suelos cultivados (Silvestro y col., 2013), entre otros. Por otra parte, son abundantes los reportes en los que se utiliza la metodología de siembra en placa de diluciones seriadas de suelo para aislar hongos y realizar su recuento, por ejemplo, para aislar especies de Aspergillus de suelos cultivados con maní (Barros y col., 2003) y para evaluar su toxicidad alimento para aves domésticas (Astoreca y col., 2011). En Tierra del Fuego, las investigaciones más recientes sobre hongos microscópicos están vinculadas al estudio de los efectos de la radiación UV-B y con la aplicación de diferentes metodologías (Searles y col., 2001; Pancotto y col., 2003; Robson y col., 2004; Paredes y col., 2014). Es así que Pancotto y col. (2003) utilizaron el método de lavado de Parkinson y Williams (1961) al estudiar el efecto sobre la microbiota de Gunnera magellanica. Mientras que tanto Searles y col. (2001), en turberas de Sphagnum y Carex, y Robson y col. (2004) en turberas de Sphagnum, estudiaron los efectos sobre la microbiota diluyendo las muestras y sembrando una alícuota en placas con medio APG. Además, estos últimos realizaron el recuento de unidades formadoras de colonias (UFC). Recientemente, Paredes y col. (2014) reportaron un estudio acerca de la composición fúngica en la turbera de Astelia-Donatia situada en Moat, utilizando las técnicas de dilución de suelo, cámaras húmedas y siembra directa complementando la identificación de especies con herramientas moleculares. 
Los recuentos en placa de las especies proveen una medida preliminar de la diversidad de subgrupos de la población microbiana del suelo, aunque no es tan precisa $y / o$ adecuada como la implementación de otros métodos (Kennedy \& Gewin, 1997). Es sabido que esta metodología genera inconvenientes, siendo el mayor de ellos que usualmente el $90 \%$ de los aislamientos obtenidos se originan a partir de estados de latencia (Warcup, 1955) y además pueden llevar a una sobreestimación de la abundancia real. De hecho, la única alternativa para aislar especies fúngicas en estados activos es la metodología de lavado de suelo, ya que esta técnica está dirigida al aislamiento de hongos adheridos a las partículas de suelo como hifas (Gams, 1992). En un estudio realizado por Cabello y Arambarri (2002) se prueba que el método de lavado representa una técnica eficaz para obtener un mayor número de especies con respecto a la siembra en placa de las diluciones de suelo.

La mayoría de los estudios de hongos microscópicos en turberas, han sido realizados en turberas situadas en el hemisferio norte y formadas por Sphagnum y otras plantas vasculares (Küster \& Locci, 1963; Gorham, 1991; Sundh y col., 1997; Fisk y col., 2003; Freeman y col., 2005; Laiho, 2006; Thornmann y col., 2004; Thormann, 2005; Bragazza y col., 2007; Golovchenko y col., 2007; Fenner y col., 2007; Peltoniemi y col., 2009; Winsborough \& Basiliko, 2010; Hájek y col., 2011; Straková y col., 2011). Por ello, resultó necesario para iniciar el estudio de la diversidad fúngica de turberas compactas de Astelia-Donatia analizar la eficacia de los métodos de aislamiento clásicos utilizados en distintos reportes. Resulta importante destacar que una característica determinante en el método de aislamiento a emplear es la eficiencia en la reducción de contaminación ambiental. Es por ello, que la comparación de 
diferentes técnicas de aislamiento de microhongos se planteó como uno de los objetivos de esta tesis, a fin de permitir el correcto análisis de la abundancia y diversidad fúngica de las turberas en estudio y poder establecer lo más certeramente posible, las especies más frecuentes y/o dominantes en estos particulares ambientes fueguinos.

Por último y a partir del análisis de los resultados obtenidos por la implementación de tres técnicas de cultivo clásico de hongos (siembra directa, siembra en cámaras húmedas y lavado de partículas de suelo) para la realización de esta tesis doctoral, se demostró que el método de lavado de partículas fue el más adecuado y/o eficiente para el aislamiento de hongos Hyphomycetes de turberas compactas de Astelia-Donatia.

\section{b) Microhongos en turberas compactas}

A través de la implementación de las metodologías clásicas mencionadas anteriormente, y, a partir de 80 muestras de turba, colectadas en febrero y noviembre de 2.012 , en dos turberas compactas de Astelia-Donatia de Tierra del Fuego (Argentina), obteniéndose 3.225 aislamientos fúngicos. Estos correspondieron a 9 géneros (Aureobasidium, Beauveria, Botryosporum, Cladosporium, Mortierella, Mucor, Parasterinella, Penicillium, Trichoderma) y 19 especies de Hyphomycetes, representados principalmente por las Subdivisiones Ascomycotina y Zygomycotina; siendo mayor el número de Ascomycetes (Tabla 6). Estos resultados concuerdan con estudios previos sobre diversidad fúngica basados en aislamientos directos, originados por fragmentos de micelio activo o esporas capaces de germinar, en los que se comunica una 
dominancia de hongos Ascomycetes (Thornmann, 2006). Por otra parte, también coinciden con los datos publicados para otras turberas, ya que de los aproximadamente 600 taxa fúngicos conocidos para estos ambientes, los grupos dominantes son los Ascomycetes y Basidiomycetes, que comparten similitudes en términos de diversidad taxonómica (276 y 243 especies registradas, respectivamente) (Thormman \& Rice, 2007) y están involucrados principalmente en la descomposición de la materia orgánica (Thornmann 2006a, 2006b; Thornmann \& Rice, 2007; Artz y col., 2007). Asimismo, se ha reportado que los géneros de Zygomycetes que dominan estos ecosistemas son Mucor, Mortierella y Umbelopsis (Thornmann y Rice, 2007).

En las últimas décadas se ha visto un renovado interés en el estudio de la diversidad de hongos saprótrofos, debido a su rol en el ciclado de nutrientes y regulación de los tamaños poblacionales de microorganismos patógenos (Windels \& Lindow, 1985; Fokkema, 1991; Andrews, 1992; Lindow \& Leveau, 2002; Muñoz y col., 2013). Es así que se han registrado y/o estudiado diversos ensambles de hongos a partir de las turberas en todo el mundo como Ascomycetes anamórficos, Ascomycetes teleomórficos, Zygomycetes y Basidiomycetes (Thormann, 2006a). De ellos, los Ascomycetes han recibido la mayor atención, sobre todo aquellos relacionados con la descomposición en esos ambientes (Thormann y col., 2002; Rice \& col., 2006; Thornmann y col., 2007).

Thormann \& Rice (2007) realizaron una revisión basada en la información sobre hongos aislados a partir de turberas en todo el mundo $y$, entre otras cosas, generaron una lista de Ascomycetes con el fin de resumir sus roles generales. Todas las especies de Ascomycetes presentadas en esta tesis fueron documentadas en tal revisión y además estos resultados están 
en concordancia con estudios previos en los que se describe la diversidad fúngica encontrada en estudios que fueron llevados a cabo tanto en el hemisferio norte como en el sur (Thormann, 2005; Gilbert y Mitchell, 2006; Thornmann y Rice, 2007).

La caracterización a nivel de especie, y aún a nivel de género no siempre es posible debido a la ausencia de caracteres morfológicos discriminantes. Aun así la proporción de morfoespecies estériles obtenidas en este estudio ( $44 \%$ en febrero y $5.83 \%$ en noviembre; Figura 20), no afectó los resultados obtenidos, ya que para cada caso se cuantificó su abundancia y se clasificó según el tipo de micelio y morfología de las colonias, para realizar posteriormente la identificación por metodologías moleculares. La mayoría de los trabajos que involucran el estudio de hongos microscópicos obtienen una gran proporción de aislamientos que no llegan a producir esporas (Stone y col., 2004; Watrud y col., 2006), probablemente debido a que entre los micelios estériles se encuentran especies que requieren de sustratos naturales o la presencia de algún compuesto determinado para inducir los mecanismos de esporulación. Además, la producción de esporas puede presentar diferentes dinámicas en los distintos taxa y algunas especies podrían esporular escasamente o directamente no producir esporas bajo las condiciones en las que se realiza la toma de muestras. Asimismo hay que tener en cuenta que la esporulación es un fenómeno estacional que puede estar altamente relacionado con el estado fisiológico del hongo y con factores ambientales.

Hasta el presente, solo unos pocos estudios han examinado el ensamble de la comunidad fúngica en turberas de Tierra del Fuego. Sin embargo, la mayoría de las especies en este estudio coinciden con las mencionadas investigaciones previas (Searles y col., 2001; Robson y col., 
2004; Paredes y col., 2014). Es así que de las 19 especies aisladas en esta tesis doctoral, 4 de ellas fueron reportadas en el trabajo de Robson y col. (2004) en turberas de Sphagunm ( $A$. pullulans, C. herbarum, M. alpina y P. thomii); mientras el estudio de Paredes y col. (2014), realizado en una turbera compacta, presentó 8 especies en común ( $C$. Cladosporium, $P$. canescens, P. chrysogenum, P. citrinum, P. thomii, T. harzianum, T. koningii y T. polysporum). A su vez, Searles y col. (2001) reportaron también la presencia de los géneros Mortierella y Penicillium en una turbera de Sphagnum sp., y los géneros Penicillium y Cladosporium en una turbera de Carex sp. Las diferencias que se presentan entre el presente estudio y estudios previos podrían atribuirse a variaciones vinculadas con las técnicas que fueron empleadas para llevar a cabo la investigación. Es importante destacar que las metodologías de siembra en placa de dilución seriada de suelo sirve principalmente para aislar los propágulos de los hongos que están inactivos al momento del muestreo (Azaz, 2002), al igual que las técnicas de siembra directa (utilizada por Paredes y col., 2014) y siembra de suelo diluído (utilizada por Searles y col., 2001 y Robson y col., 2004). Mientras que la técnica de lavado de partículas de suelo se utiliza con el objetivo de aislar hifas de hongos que están activos al momento del muestreo (Azaz, 2002). Esto explicaría en gran parte las diferencias entre los resultados aquí presentados y los publicados por Paredes y col. (2014) (realizado en la turbera Moat, uno de los sitios de estudio de esta tesis) ya que la cantidad de especies y géneros fúngicos obtenidos en dicha publicación fueron mucho mayores (38 especies, 18 géneros). Por otra parte, Robson y col. (2004) incubaron las placas en oscuridad, y esto pudo haber derivado en la subestimación del número de especies obtenidas ( 9 especies), debido a que es ampliamente conocido que existen 
especies de Hyphomycetes que producen esporas al ser expuestas a la luz. Por ejemplo, el desarrollo de Trichoderma es fuertemente influenciado por la luz y su espectro, afectando fundamentalmente su esporulación. Las colonias de este hongo que se desarrollan bajo condiciones de luz alterna, son blancas y algodonosas al inicio y luego con zonación concéntrica, alternando una banda delgada hialina con otra ancha de color verde oscuro, mientras que bajo la luz continua son uniformemente de color verde (Wells y col., 1972). La luz influye además, en la producción de metabolitos secundarios (Purschwitz y col., 2006).

La identificación molecular de los micelios estériles permitió la determinación de 4 especies fúngicas (Tabla 11) diferentes a las identificadas por técnicas clásicas de cultivos y pertenecientes a las División Ascomycotina. Es importante destacar que los aislamientos identificados y pertenecientes al género Tolypocladium (Beauveria) existen como saprótrofos y como patógenos de insectos (Bisset 1983); y la especies $T$. cylindrosporum es un entomopatógeno representativo de este género, que ha sido investigado como un importante agente de biocontrol de diversos Ordenes de insectos (Lam y col., 1988). Por otra parte, el grupo de ectomicorrizas identificado pertenece a la Clase Leotiomycetes considerada actualmente como un taxón pequeño, con pocas especies y de distribución mundial. Estos hongos son ecológicamente diversos e incluyen fitopatógenos, saprótrofos de hojas y maderas, endófitos, micorrizas e Hyhphomycetes acuáticos (Wang y col., 2006a, b) y viven en gran cantidad de hábitats, incluyendo fondos submarinos, suelos o como parásitos de hongos o plantas vegetales hongos. Asimismo, los micelios identificados como Fusarium culmorum, al igual que otros hongos del género Fusarium, pertenecen a especies comunes aisladas desde distintos ambientes 
aunque para su identificación deben ser cultivados en medios específicos para esporular y poder ser identificados (Fisher y col., 1982; Burgess y col., 1994). El género Fusarium comprende una gran diversidad de hongos que están distribuidos por todo el mundo como oportunistas, saprofitos de restos vegetales e importantes patógenos de una gran variedad de plantas de diversas condiciones medioambientales (Doohan y col., 2003; Logrieco y col., 2003). De todas las especies del género Fusarium, F. culmorum es la única que resulta un buen competidor de las especies de los géneros Aspergillus y Penicillum (Lacey, 1989); además, es un importante patógeno de una amplia variedad de plantas, sobre todo de alto interés agrícola, provocándoles graves enfermedades (Hestberg y col., 2002; Miedaner y col., 2004).

Por último, la mayoría de los Hyphomycetes aislados en este trabajo presentan una distribución geográfica muy amplia, y la misma no se restringe al área de estudio, sino que estas especies presentan un marcado carácter cosmopolita y corresponden a la microcarga normal que se ha comunicado/publicado para otras turberas en el mundo.

c) Abundancia, composición \& diversidad de la comunidad fúngica en turberas compactas

Aurebasidium pullulans, Beauveria bassiana, Mortierella alpina, Penicillium frequentans y Trichoderma viridae representan las especies más frecuentes y/o abundantes en este estudio (Figura 20) y tal como se mencionó anteriormente su presencia ya fue comunicada en estudios realizados en otras turberas del mundo, atribuyendo la misma a que poseen amplios perfiles 
enzimáticos $\mathrm{y}$, consecuentemente, son capaces de degradar una amplia variedad de polímeros estructurales y de almacenamiento a partir de la turba y la vegetación de turberas (Thormann, 2005).

Penicillium y Trichoderma resultaron los géneros mejor representados en las dos campañas de muestreo llevadas a cabo ( 6 especies de Penicillium y 4 de Trichoderma; Tabla 7 ). Ambos son géneros muy bien conocidos y que habitualmente son encontrados en distintos tipos de ambiente y sobre todo formando parte de la microbiota edáfica. El género Penicillium es el de mayor incidencia en muestras de suelo, posiblemente debido a su capacidad de producir una amplia gama de antibiótiocs y micotoxinas en defensa de aquellos organismos que dificultan su desarrollo (Khalid y col., 2006). Asimismo, las especies de Trichoderma también son consideradas como los hongos más versátiles del suelo y esto se debe a su gran adaptabilidad a los ambientes, donde se reproducen tanto asexual como sexualmente, dependiendo de las condiciones ambientales (Farah y col., 2012). La presencia de Trichoderma en suelos agrícolas y naturales en todo el mundo es evidencia que es un excelente competidor por espacio y recursos nutricionales (Hjeljord y col., 1998) y de su plasticidad ecológica (Infante y col., 2009). La competencia por nutrientes de Trichoderma está dada principalmente por el carbono, hierro y nitratos (Sivan y col., 1989). Además, estos dos géneros junto a Cladosporium son comúnmente conocidos como los colonizadores finales o de la última etapa en la descomposición del material vegetal (Hudson, 1968; Osono y Takeda, 2007) y el dominio o gran abundancia de estos hongos saprótrofos indicaría una rápida descomposición y reciclaje de materia orgánica muerta y 
restos vegetales, manteniendo así el estado nutritivo del ambiente (Baath, 1981; Sharma y col., 2015).

Representantes del género Parasterinella fueron aislados sólo a partir de partículas sembradas en cámaras húmedas. Este grupo está conformado por hongos que presentan un micelio marrón negruzco superficial y se desarrollan abundantemente en las células del tejido epidérmico vegetal, en el que provocan la estimulación del crecimiento de células parenquimáticas, generando puntos conspicuos y elevados de la superficie. Las especies de Parasterinella están asociadas principalmente a hojas de Drymys winteri (Arambarri, 1985), especie vegetal que si bien no fue registrada en los puntos de muestreo elegidos para la realización de este estudio, es muy frecuente su presencia en turberas compactas.

El filotipo de Zygomycetes dominante en nuestras muestras de turba fue Mortierella sp., reconocido por comprender hongos que son fuertes digestores de quitina, el componente fundamental de las hifas (Young-Ju y col., 2008). Existen experimentos que demuestran que los Zygomycetes degradan quitina casi tan eficientemente como los Actinomycetes quitinolíticos (De Boer y col., 1999). Los Zygomycetes producen esporas de paredes resistentes que les permiten sobrevivir por períodos prolongados en estado de dormancia (Bartnicki-García, 1987). Adicionalmente, los miembros en la división Zygomycotina no responden tan bien como los de Dikarya (Ascomycotina y Basidiomycotina) a los productos solubles de degradación vegetal (por ej., celulosa y sacarosa) y, en su lugar, parecen estar asociados con los sustratos de carbono de origen animal y fúngico como las hifas fúngicas (Cromack y Caldwell, 1992; De Boer y col., 1999; Hobbie y col., 2003). 
En la mayoría de las investigaciones realizadas sobre hongos de turberas, incluyendo las turberas compactas de Astelia-Donatia (Paredes y col., 2014), aquellos que son ubicuos, de rápido crecimiento y esporuladores prolíficos (particularmente las especies de Penicillium, Trichoderma, Aspergillus, Cladosporium, y los Zygomycetes Mortierella y Mucor) fueron los más comúnmente aislados (Thormann y col., 2001; Rice y Currah, 2002; Thormann y col., 2004; Thormann, 2005; Thormann y col., 2006; Thormann y Rice, 2007; Artz y col., 2007). Estos hongos tendrían un papel importante en la descomposición pero probablemente también según algunos autores (Rice y Currah, 2002; Rice y col., 2006; Thormann, 2005, 2006) estarían sobrerrepresentados como resultado de las características mencionadas y de su facilidad para crecer en medios de cultivo estándar, independientemente del lugar y el sustrato natural del que fueron aislados.

El número, tipo y frecuencia de las especies de microhongos aislados en este trabajo fueron muy similares en cada una de las situaciones analizadas (influencia de la cobertura vegetal, sitio y profundidad) (Tablas 8,9 y 10). Es así que la mayor parte de los hongos aislados estuvo presente en Astelia y Sphagnum, en las profundidades A y B y tanto en la turbera de Moat como la de Garibaldi. Por lo tanto, se cree que existiría una marcada homogeneidad en la estructura de la comunidad microfúngica presente en turberas compactas y que ésta estaría sustentada por las condiciones ambientales en las que conviven y/o cohabitan las especies. Los resultados comunicados en el capítulo 2 indicaron que no existen grandes diferencias en las características físico-químicas de las turberas de estudio. Por lo tanto, como las turberas en estudio presentan características no disímiles, era esperable que las comunidades establecidas 
en ellas sean relativamente similares. A su vez, esta situación se reconfirmó con los resultados obtenidos luego de realizar los análisis de componentes principales; ya que, en general, las muestras no presentaron un ordenamiento característico acorde a su composición de especies y teniendo en cuenta los tipos de sustrato (Astelia y Sphagnum) y la temporada de muestreo (febrero y noviembre) (Figuras 23, 24, 25 y 26). Por otra parte, los resultados presentados en esta tesis concuerdan con los obtenidos por Paredes y col. (2014), en los que no se encontraron diferencias significativas entre los Hyphomycetes aislados a dos profundidades diferentes en una turbera de Astelia-Donatia. Sin embargo, al analizar la relación de las variables ambientales con la posición de las muestras sobre los ejes en los ACP (Tabla 10), se observó que esta relación fue más marcada en el período de primavera (noviembre). La relación $\mathrm{C} / \mathrm{N}$, la distancia a la napa freática y el contenido hídrico estuvieron estrechamente correlacionados con las muestras de Astelia y Sphagnum en Moat, mientras que la distancia a la napa freática y el contenido hídrico estuvieron positivamente asociados a la distribución de las muestras de Garibaldi. La importancia de las variables abióticas como humedad, $\mathrm{pH}$ y temperatura en la distribución y composición de la comunidad de hongos fueron demostradas en diversos trabajos (Bisset y Parkinson, 1979; Devi y col., 2012). La estructura de la comunidad y diversidad de hongos es sensible a cambios en su microhábitat; se ha demostrado que los mejores predictores de la composición específica y la riqueza de la comunidad fúngica son los factores climáticos seguidos por las variables edáficas, no solo a escala local sino también a escala global (Tedersoo y col., 2014). 
Los microorganismos de las turberas parecen organizarse como mosaicos repetidos que responden a la vegetación y a las características físico-químicas e hidrológicas más que a las distancias geográficas. Por lo tanto, las propiedades químicas y físicas en la turba limitan el crecimiento de los hongos filamentosos de determinadas especies. Esto podría, a su vez, reducir la competencia e influir en la interacción de las especies y la composición de la comunidad fúngica en las capas superficiales (Andersen y col., 2013). Según Thormann y col. (2001b, 2002) los hongos aislados con mayor frecuencia de las turberas tienen una capacidad limitada para degradar los polímeros más complejos, que, consecuentemente, se acumulan y aumentan en proporción con la profundidad (Turetsky y col., 2000), donde las limitaciones ambientales (acidez, anoxia y baja temperatura) dificultan aún más su degradación. Además, se trata de una reducción de la biomasa más que una alteración de la comunidad, lo que resulta característico de la estratificación vertical de hongos, con una disminución en el número de esporas, biomasa y longitud de hifas al aumentar la profundidad (Andersen y col., 2013). Una excepción a esta característica es la presencia de levaduras, cuya abundancia parece permanecer estable a lo largo de todo el perfil de turba (Golovchenko y col., 2002).

La diversidad microbiana de las turberas está caracterizada por organismos que han desarrollado adaptaciones físicas y metabólicas para hacer frente a las condiciones limitadas de estos ecosistemas, como la baja disponibilidad de oxígeno, las bajas temperaturas, acidez y oligotrofia (Andersen y col., 2013). Estas condiciones extremas hacen que la riqueza de especies sea baja comparada con los ecosistemas adyacentes, generalmente boscosos y relativamente más diversos, incluso entre ecosistemas de turbera (Roig y Roig, 2004). 
En base al análisis de los parámetros de diversidad (Figuras 21 y 22) se afirmaría que las turberas compactas de Tierra del Fuego se caracterizan por sustentar una comunidad microfúngica cuya estructura de especies (riqueza) es relativamente simple y con una diversidad de nivel medio. Estas características estructurales de la comunidad estudiada son acordes a la existencia de un ambiente estable, como lo son las turberas fueguinas, sometidas a condiciones extremas. Es así que la homogeneidad en sus características ambientales influiría directamente en la diversidad temporal y espacial de los ensambles de hongos microscópicos que sostienen. Sin embargo, aún resulta complejo definir un modelo de comunidad típica para este tipo de estos ambientes.

Las bajas temperaturas que se presentan en las turberas compactas fueguinas las convierten en propicias para la proliferación de ciertos microorganismos capaces de vivir en tales condiciones adversas, gracias a diversos mecanismos de resistencia. Según Gadre y col. (2003), algunos hongos producen enzimas que permanecen activas aún a temperaturas inferiores a los $20^{\circ} \mathrm{C}$. Asimismo, estos organismos han desarrollado varias formas de adaptación como cambios estructurales a nivel membrana, proteínas constitutivas y enzimas (Gerday y col., 2000). En general, según Gocheva y col. (2006), se pueden resumir los mecanismos de adaptación en tres: función de enzimas, transporte de nutrientes y función de la membrana celular. Por consiguiente, se afirma que los hongos aislados de las turberas compactas fueguinas son típicos de estos ecosistemas y además es común aislarlos del suelo, sin ser producto de contaminación cruzada. 


\subsection{CONCLUSIONES}

* La técnica de lavado de partículas de suelo fue el método más adecuado y/o eficiente para aislar de hongos microscópicos activos de turberas compactas de Astelia-Donatia.

* A través de la implementación de las metodologías clásicas de cultivo y aislamiento de hongos microscópicos se obtuvieron 3.255 aislamientos fúngicos que correspondieron a 9 géneros (Aureobasidium, Beauveria, Botryosporum, Cladosporium, Mortierella, Mucor, Parasterinella, Penicillium, Trichoderma) y 19 especies, representados principalmente por las Subdivisiones Ascomycotina y Zygomycotina; siendo mayor el número de Ascomycetes.

* Aurebasidium pullulans, Beauveria bassiana, Mortierella alpina, Penicillium frequentans y Trichoderma viridae representan las especies más frecuentes y/o abundantes en este estudio.

* El número, tipo y frecuencia de las especies de microhongos aislados en este trabajo no fueron influenciados significativamente por el sitio (turbera costera o turbera montañosa), el tipo de sustrato (turba de Astelia o Sphagnum) y la profundidad $(3-10 \mathrm{~cm} ; 10-20 \mathrm{~cm}$ ).

* Al ordenar las especies fúngicas teniendo en cuenta los tipos de sustrato y la temporada de muestreo y vincular dicho ordenamiento con las variables ambientales, no se pusieron de manifiesto sus requerimientos o preferencias.

* La identificación de los micelios estériles permitió determinar a las especies Tolypocladium cylindrosporum, T. inflatum, Fusarium culmorum y un hongo perteneciente a la clase Leotiomycetes (ectomicorriza no cultivable), que al presentar requerimientos de cultivo diferentes no habían sido aisladas con las metodologías clásicas.

* La mayoría de los microhongos aislados presentan un marcado carácter cosmopolita y corresponden a la microcarga normal que se ha comunicado para otras turberas en el mundo. 


\section{Capítulo 4}

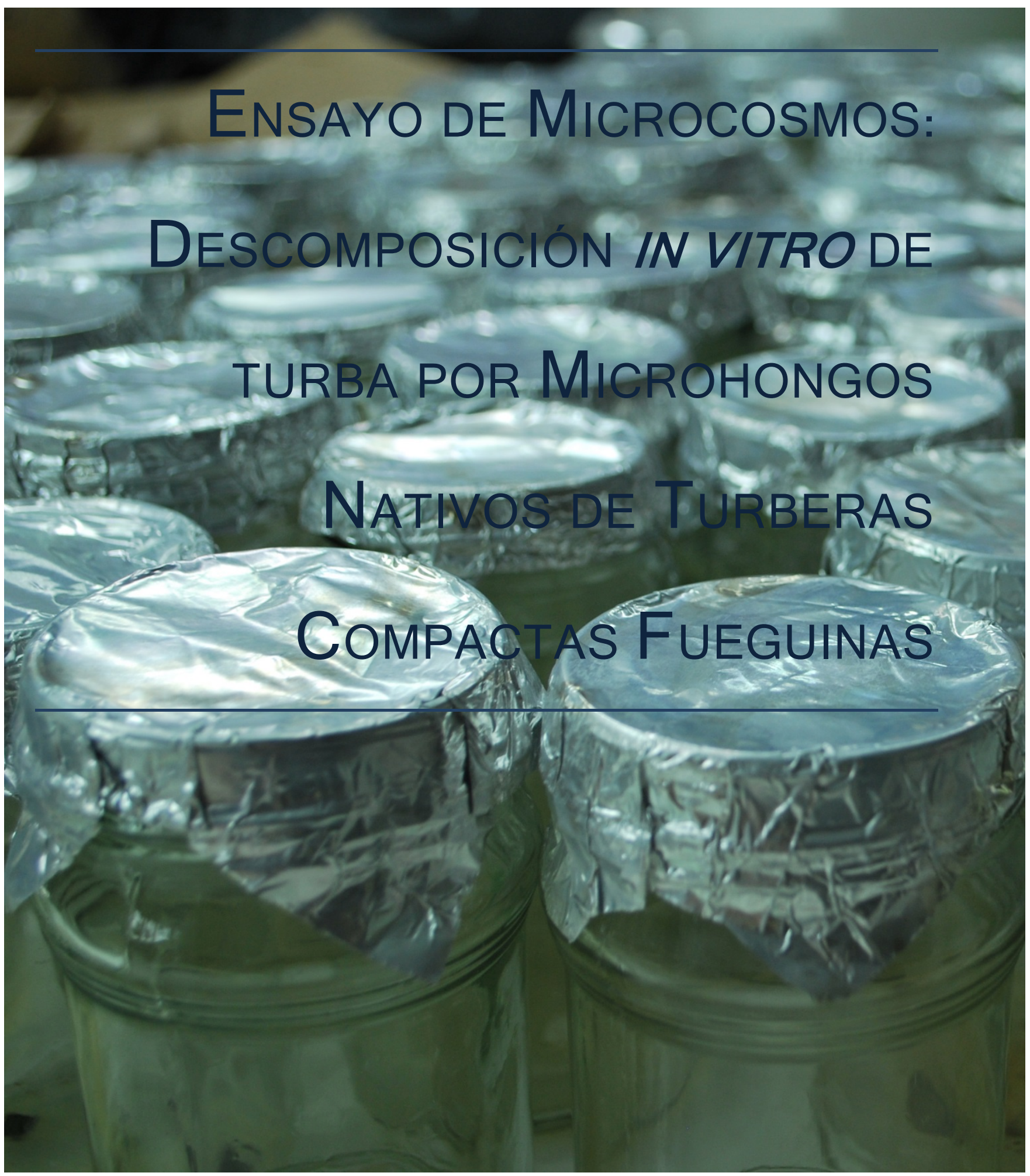




\subsection{INTRODUCCIÓN}

"From dead plant matter to nematodes to bacteria, never underestimate the cleverness of mushrooms to find new food!!"

Paul Stamets

"They live fast, they die young, they will be back". Del poema About the Dead Man and Fungi, Marvin Bell, 1937.

La descomposición de los restos vegetales es un proceso crucial que controla los flujos del carbono de los ecosistemas terrestres (Swift, 1989; Couteaux y col., 1995; Sun y col., 2004) y representa los procesos físicos y químicos involucrados en reducir los restos a sus constituyentes químicos elementales. Por lo tanto, este proceso es el principal determinante de los ciclos de nutrientes en la mayoría de los ecosistemas (Meentemeyer, 1978; Swift y Anderson, 1989; Van Vuuren y col., 1993; Aerts y De Caluwe, 1997). En este sentido, la liberación de nutrientes a partir de la descomposición del material vegetal influye sobre la productividad primaria en los ecosistemas (Blair, 1988), dado que estos nutrientes se vuelven disponibles para las plantas y no se pierden en el sistema (Santa Regina y col., 1997).

En términos generales, las tasas de descomposición vegetal son controladas por las condiciones ambientales (temperatura y humedad), la composición química del material y por los organismos del suelo. Se ha postulado que estos factores ejercen un control jerárquicamente organizado sobre la descomposición debido a la regulación de la actividad microbiana en escalas decrecientes de tiempo y espacio (Rodríguez Pleguezuelo y col., 2009). Es decir, existen tres niveles principales de control de la descomposición del material vegetal, que opera en el siguiente

orden: clima > composición química del material vegetal $>$ microorganismos del suelo (Lavelle y col., 1993). 
Una manera de estimar la tasa de descomposición de un ambiente en particular es a través de la medición de la pérdida de masa; una estimación que en la mayoría de los estudios se realiza con el uso de bolsas de descomposición (Bragazza y col., 2009). La descomposición de los restos vegetales, con la implementación de esta técnica, ha sido estudiada en muchos ecosistemas: climas tropicales y subtropicales (Powers y col., 2009; Hättenschwiller y col., 2010; Bothwell y col., 2014), semiáridos (Uma y col., 2014; Gaxiola y Arnesto, 2015), templados (Cornelissen y col., 1996; van Hyusen y col., 2013; Sheffer y col., 2015) y mediterráneos (Cotrufo y col., 2004; Sheffer y col., 2015). Es aún más extensiva la investigación que se ha realizado sobre la descomposición vegetal y la liberación de nutrientes en ecosistemas forestales (Giesselman y col., 2010; Ibarra y col., 2011; Bahamonde y col., 2012; Gao y col., 2015). Por otro lado, la descomposición en turberas se ha llevado a cabo principalmente en ecosistemas boreales (Latter y col., 1998; Bragazza y col., 2007; Moore y col., 2007; Trinder y col., 2009; Myers y col., 2012; Hageman y Moroni, 2015), siendo la temperatura y el nivel de la freática los principales factores que afectan la descomposición. Algunos de estos trabajos también exploraron la influencia de los microorganismos en la descomposición.

En Tierra del Fuego, los bosques de Nothofagus pumilio (Poeppig \& Endl.)Krasser conforman el ecosistema dominante, y por ello la mayoría de los estudios de descomposición, con el uso de bolsas de descomposición, han sido realizados en estos ambientes (Frangi y col., 1997; Barrera y col., 2000; Pancotto y col., 2003; Ulloa y col., 2012; Moretto y col., 2005; Moretto y Pastur, 2014).

Los hongos tienen un papel importante en los procesos de descomposición y mineralización de los nutrientes presentes en los restos orgánicos, incluyendo entre sus funciones la volatilización del carbono, hidrógeno y oxígeno, la reducción en volumen de los materiales orgánicos, la fragmentación de macromoléculas, el incremento de la homogeneidad del sustrato, lo que favorecería la asimilación por parte de otros microorganismos que se alimentan de detritos (Christensen, 1989). Generalmente estos microorganismos no son abordados como 
componentes importantes de los procesos de mineralización o son ignorados por completo (Gilbert y col., 1998). Sin embargo, en los ecosistemas ácidos, tales como las turberas, los hongos pueden asumir un papel más dominante que las bacterias y la mayoría de los organismos celulolíticos presentes en ellas pueden ser hongos (Latter y col., 1967; Andersen y col., 2006). Además, William y Crawford (1983) mostraron que los hongos eran más diversos en sus capacidades para utilizar una variedad de fuentes de carbono y que desempeñan un papel importante en la descomposición de la lignina y la celulosa en las turberas.

Existen solo unos pocos estudios que vinculan a los hongos como descomponedores presentes en los sitios de turberas a la descomposición de diferentes sustratos. William y Crawford (1983) han demostrado que existe una alta diversidad fisiológica entre los microorganismos de turbera, presentando algunos descomponedores un metabolismo activo aun cuando las condiciones son frías y muy ácidas. Más recientemente, Thornmann y col. (2002) observaron la variación en la capacidad que tienen 9 hongos para descomponer diferentes compuestos de carbono o azufre de Sphagnum fuscum y virutas de madera. Además, Thornmann y col. (2003) encontraron hongos que descomponen diferentes tipos de turba, concluyendo que la calidad del material a descomponer influye más en los ensamblajes fúngicos respecto de las variables físicas o la química del agua.

En general, la mayoría de especies fúngicas se consideran mesófilas y la baja temperatura y el clima seco pueden llegar a influir negativamente en su actividad (Kredics y col., 2003; Samuels, 2006). La temperatura es uno de los factores abióticos más importantes que afectan sus actividades y su distribución. Sin embargo, el estudio de este y otros factores que controlan la descomposición de los restos vegetales en turberas fueguinas con la utilización de bolsas de descomposición y su vinculación con la comunidad fúngica no ha sido abordado. Como se mencionó anteriormente, solo existen reportes acerca de la influencia de la radiación UV sobre los microhongos asociados (Searles y col., 2001; Robson y col., 2004). 
Por lo tanto, teniendo en cuenta que es importante determinar el rol de los hongos en el funcionamiento de las turberas fueguinas y principalmente en la dinámica de la descomposición, y en función de los resultados obtenidos en el capítulo 3, se seleccionaron cuatro cepas de microhongos (aquellas que fueron aisladas con mayor frecuencia) para realizar un estudio in vitro, a corto plazo, y evaluar la influencia de la temperatura sobre su capacidad para utilizar como sustrato dos tipos de turba (Astelia y Sphagnum).

\section{Objetivos particulares}

$\checkmark \quad$ Analizar en condiciones de laboratorio la descomposición de la materia orgánica de Astelia sp. y Sphagnum sp. con cuatro microhongos nativos de turberas compactas de Astelia-Donatia.

$\checkmark$ Determinar si existen diferencias en la habilidad de cuatro microhongos para descomponer dos tipos de turba (Astelia y Sphagnum) a diferentes temperaturas de incubación (temperatura óptima $20^{\circ} \mathrm{C}$ y $7^{\circ} \mathrm{C}$ ).

\subsection{MATERIALES \& MÉTODOS}

\subsubsection{DISEÑO Y MONTAJE DE MICROCOSMOS}

Se realizó un experimento de descomposición in vitro (microcosmos) con turba de diferentes orígenes vegetales (Astelia y Sphagnum) y con incubación de hongos microscópicos nativos de turberas compactas fueguinas a dos temperaturas diferentes. 
a) Recolección de muestras y conservación del material. El material utilizado para la construcción del ensayo de microcosmos se obtuvo a partir de muestras de turba de Astelia pumila y Sphagnum magellanicum tomadas entre los 3 y $20 \mathrm{~cm}$ de profundidad (Capítulo 2, sección 2.2). Las muestras se homogeneizaron con el objetivo de reducir la heterogeneidad, fueron secadas a temperatura ambiente y se almacenaron hasta su utilización.

b) Eleccción y acondicionamiento de las cepas fúngicas. El criterio de selección de las cepas fúngicas a evaluar se basó en la abundancia y/o frecuencia de ocurrencia que presentaron en la primera etapa de desarrollo del proyecto de tesis. Es así que se utilizaron en este ensayo aquellos microhongos que fueron más frecuentemente aislados. Por lo tanto, las especies seleccionadas fueron: Penicillium frequentans, Trichoderma viride, Beauveria bassiana y Aureobasidium pullulans. Se realizaron repiques de los hongos en placas de Petri conteniendo agar papa glucosado y cloranfenicol $(0.1 \mathrm{~g} / \mathrm{I})$, y se incubaron a temperatura ambiente.

c) Preparación de bolsas de descomposición. Se confeccionaron pequeñas bolsas de descomposición con tela (gasa textil) de $5.5 \times 5.5 \mathrm{~cm}$, que luego se rellenaron con $0.5 \mathrm{~g}$ de turba y fueron esterilizadas con autoclave a $121^{\circ} \mathrm{C}$ por 15 minutos.

d) Ensayos de microcosmos. Las unidades experimentales (microcosmos) estuvieron representadas por frascos de vidrio estériles conteniendo $40 \mathrm{ml}$ de medio Agar-Agua $(15 \mathrm{~g} / \mathrm{l})$ y cloranfenicol $(0.1 \mathrm{~g} / \mathrm{I})$ que fueron inoculados con 4 porciones $\left(1 \mathrm{~cm}^{3}\right.$; tomadas con ansa de cultivo) de micelio fúngico activo de cada uno de los cuatro hongos a evaluar (Figura 28). Se incubaron 12 unidades con cada una de las 4 especies fúngicas y cada uno de los 2 tipos vegetales a dos temperaturas: $7^{\circ} \mathrm{C}$ (simulando la temperatura en la turbera) y $20{ }^{\circ} \mathrm{C}$ (temperatura ambiente); resultando en un total de 16 diferentes combinaciones ( 4 cepas $\times 2$ 
temperaturas $\times 2$ coberturas) con 12 réplicas en cada caso, totalizando 240 microcosmos. También se incubaron 12 controles ( $\sin$ cepa) de cada combinación temperatura/cobertura ( 48 unidades control). Se prepararon un total de 240 unidades experimentales que fueron regadas semanalmente (bajo flujo laminar) con $5 \mathrm{ml}$ de agua estéril con el fin de mantener constante la humedad del microcosmos.

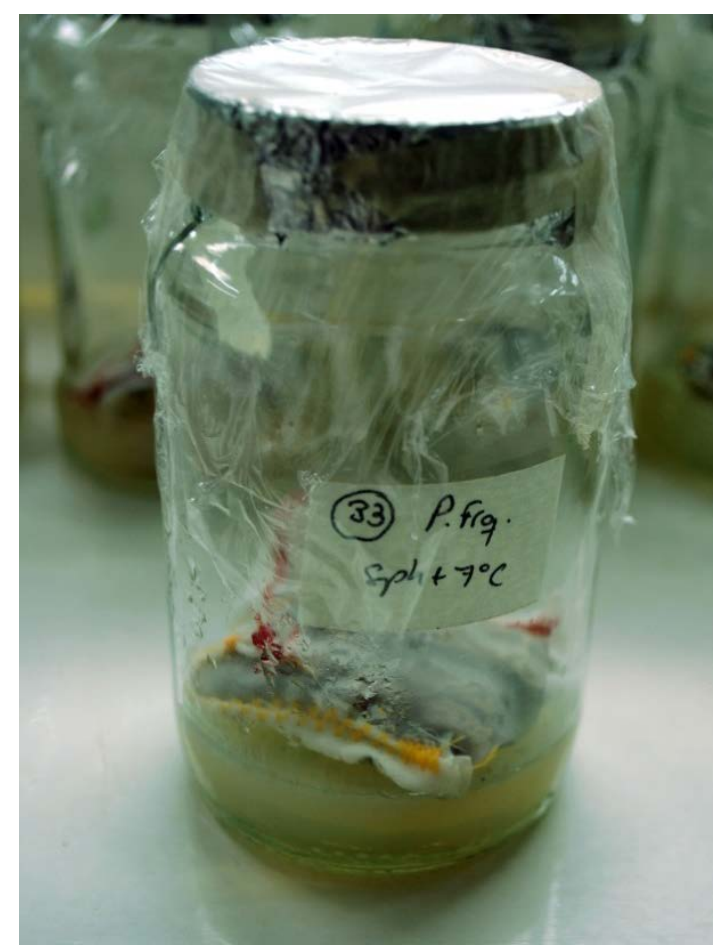

Figura 28. Unidad experimental utilizada en el ensayo de microcosmos para evaluar la descomposición de distintos tipos de turba incubada con especies de hongos nativos de turberas compactas de Tierra del Fuego.

Luego de 6 meses de incubación se tomaron las bolsas de descomposición de cada unidad y se secaron en estufa a $60^{\circ} \mathrm{C}$ (para detener el crecimiento fúngico). Una vez secas las muestras, se retiró cuidadosamente el material del interior de las bolsas, se removió (con ayuda de pinzas) el micelio fúngico visible en su superficie y, por último, se pesó el material. 
Previo al análisis estadístico, se estimaron las pérdidas de material por manipulación y tratamiento anterior a la incubación de las muestras (secado en estufa + esterilización en autoclave), y se aplicó el factor de corrección a los valores iniciales.

\subsubsection{ANÁLISIS DE DATOS}

La pérdida de masa se utilizó como indicador de la descomposición y se expresó como un porcentaje de la masa inicial. Los análisis fueron realizados en base al porcentaje de masa remanente.

Para evaluar la participación de los hongos en el proceso de descomposición, se realizó un ANOVA simple, evaluando la masa remanente (variable dependiente) con respecto a la presencia de cepas (variables independientes). La comparación entre las 4 cepas de hongos microscópicos utilizadas respecto a la pérdida de masa se realizó con un ANOVA simple. Para evaluar el efecto de la temperatura y el tipo de cobertura en la pérdida de materia orgánica con incubaciones con cepa se utilizó un ANOVA con temperatura y tipo de cobertura como factores independientes, cada uno con dos niveles de tratamiento $(2 \times 2)$. Este análisis se realizó con todas las cepas y con cada una en particular. En los casos necesarios, se aplicaron transformaciones a los datos para cumplir con los supuestos de normalidad y homocedasticidad. 


\subsection{RESULTADOS}

\subsubsection{Descomposición con cepas fúngicas vs controles}

Luego de 6 meses, la masa remanente de turba en las bolsas de descomposición incubadas con cepas fúngicas osciló entre el 88,60 y el $90,79 \%$ en los tratamientos con turba de Sphagnum y el $91,79 \%$ y el $92,23 \%$ en los de Astelia, mientras que para los controles estuvo entre 95,80 y $96,90 \%$ (Figura 29 ).

La pérdida de masa de los controles fue menor respecto de las incubaciones con cepas fúngicas. Este patrón se repitió tanto a temperatura de $20^{\circ} \mathrm{C}$ (ANOVA, $\mathrm{F}=75,67$ y $\mathrm{p}<0,01$ ) como a $7^{\circ} \mathrm{C}$ (ANOVA, $\mathrm{F}=35,23$ y $\mathrm{p}<0,01$ ).

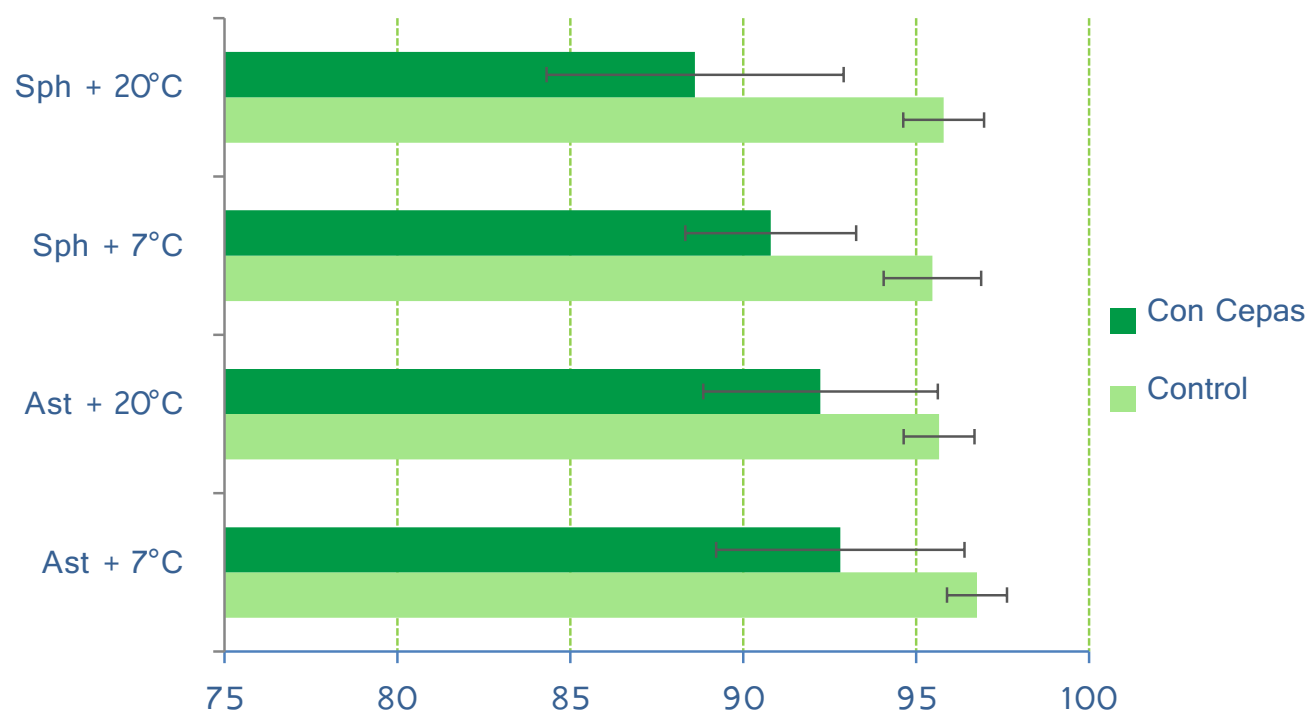

Figura 29. Masa remanente (\%) luego de 6 meses de incubación de un ensayo de descomposición en microcosmos con microhongos nativos de turberas compactas. Las unidades experimentales fueron incubadas con diferentes tratamientos: bolsa con Astelia a $7^{\circ} \mathrm{C}\left(\right.$ Ast $+7^{\circ} \mathrm{C}$ ), bolsa con Sphagnum a $7^{\circ} \mathrm{C}\left(\mathrm{Sph}+7^{\circ} \mathrm{C}\right)$, bolsa con Astelia a $20^{\circ} \mathrm{C}$ (Ast $+20^{\circ} \mathrm{C}$ ) y bolsa con Sphagnum a temperatura ambiente $\left(\mathrm{Sph}+20^{\circ} \mathrm{C}\right)$. 


\subsubsection{Influencia de la temperatura y el sustrato sobre la descomposición fúngica}

Se observó un efecto de interacción de la pérdida de masa vegetal en la respuesta a la temperatura de incubación y el tipo de turba (ANOVA, $F=3,93 ; p=0,048$ ). A baja temperatura de incubación $\left(7^{\circ} \mathrm{C}\right)$ no existió una diferencia significativa entre la descomposición de turba de Astelia y turba de Sphagnum; mientras que, a mayor temperatura de incubación $\left(20^{\circ} \mathrm{C}\right)$, se observó una mayor pérdida de turba de Sphagnum.

\subsubsection{Análisis de la descomposición entre cepas fúngicas}

Se observaron diferencias significativas entre los porcentajes de la masa remanente registrados para cada especie fúngica (ANOVA, $F=3,56 ; p=0,01$ ), siendo diferentes significativamente las masas remanentes de $A$. pullulans y $B$. bassiana, y muy similares los porcentajes de ambas especies con respecto a los porcentajes de $P$. frequentans y $T$. viride. La especie que presentó un menor porcentaje de masa remanente (mayor descompsición) fue $B$. bassiana, mientras que $A$. pullulans presentó el mayor porcentaje de masa remanente (menor descomposición) (Figura 30). 


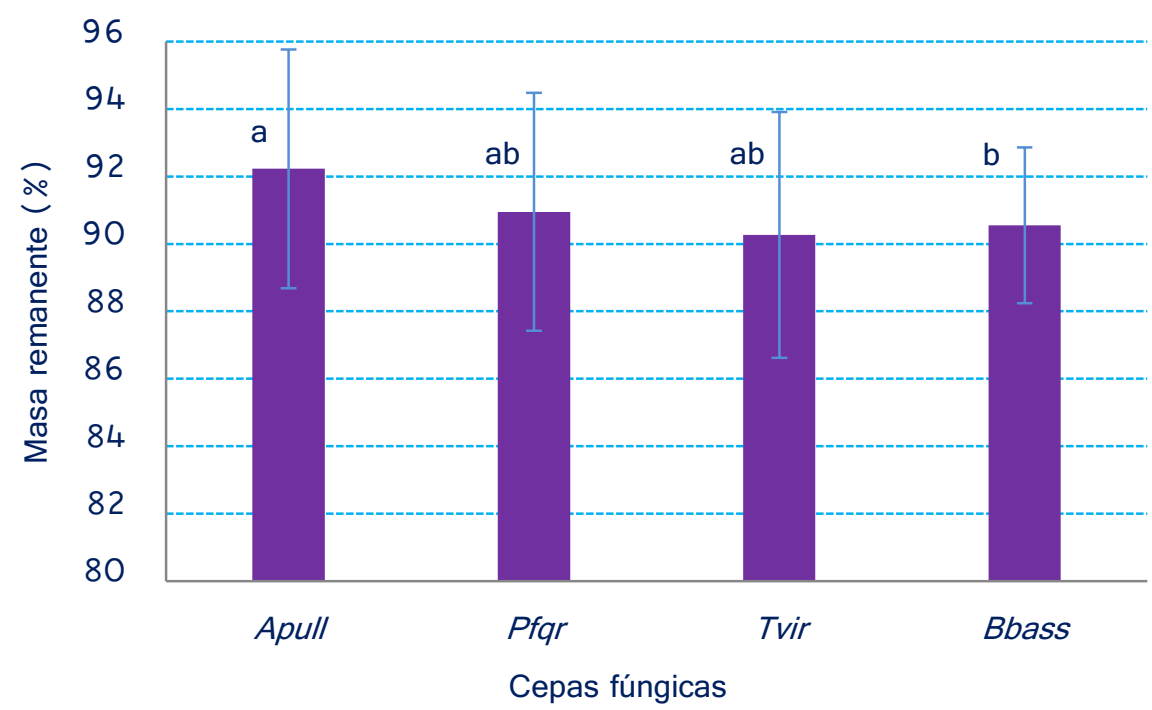

Figura 30. Masa remanente media luego de 6 meses de incubación de un ensayo de microcosmos para testear la habilidad de descomposición de 4 cepas microfúngicas aislados de turberas compactas de Astelia-Donatia. (Letras diferentes indican diferencias significtativas)

Al considerar cada una de las especies por separado, se observó que no todas respondieron con el mismo patrón. Se observó que solo $A$. pullulans presentó una respuesta diferencial y significativa de la temperatura (ANOVA, $F=33,46 ; p<0,01$ ) y al tipo de sustrato (ANOVA, $F=41,78 ; p=<0,01$ ). La descomposición (menor porcentaje de masa remanente) resultó mayor con turba de Sphagnum y a temperatura ambiente (Figura 31). En las incubaciones con $P$. frequentans y $T$. viride sólo la temperatura de incubación influyó significativamente en la descomposición, con mayor descomposición a temperatura ambiente (ANOVA P. frequentans, $F=7,27, p<0,01$; ANOVA $T$. viride, $F=8,33, p<0,01$ ) (Figura 31). La masa remanente en las incubaciones con $B$. bassiana no resultó significativamente afectada por la temperatura ni por el tipo de turba $(p>0,05)$. 
A Aureobasidium pullulans

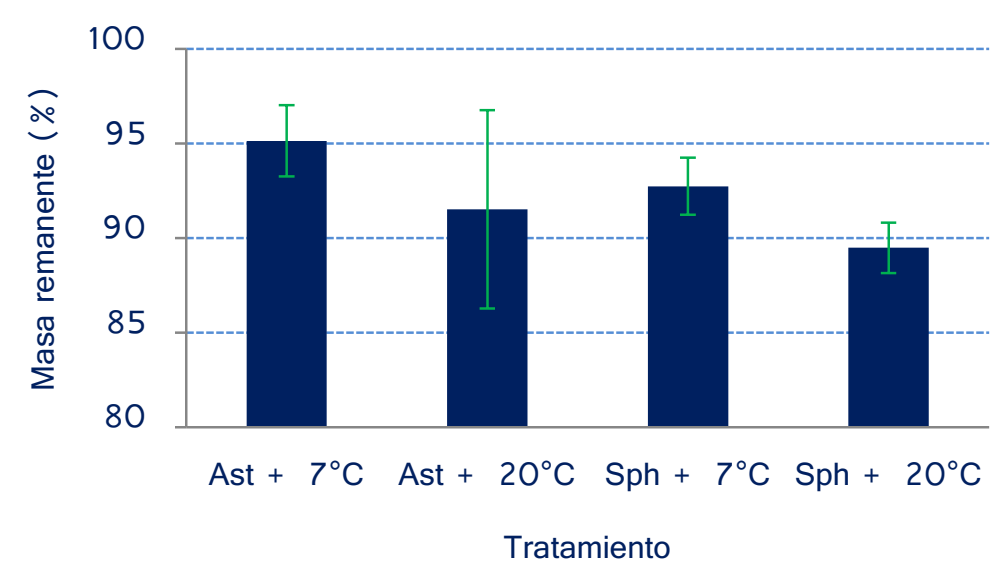

C Penicillium frequentans

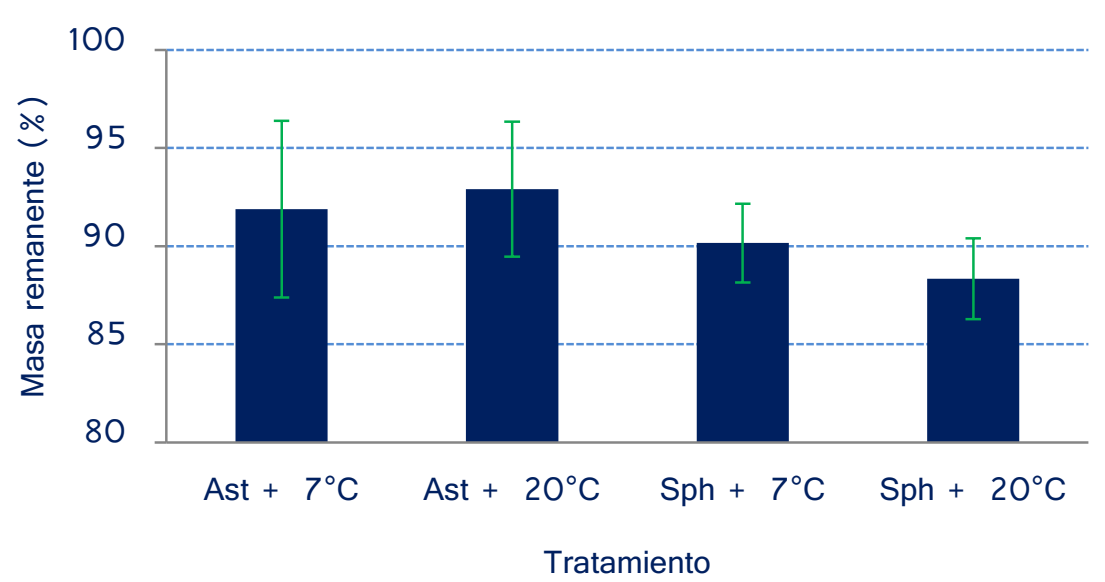

B Beauveria bassiana

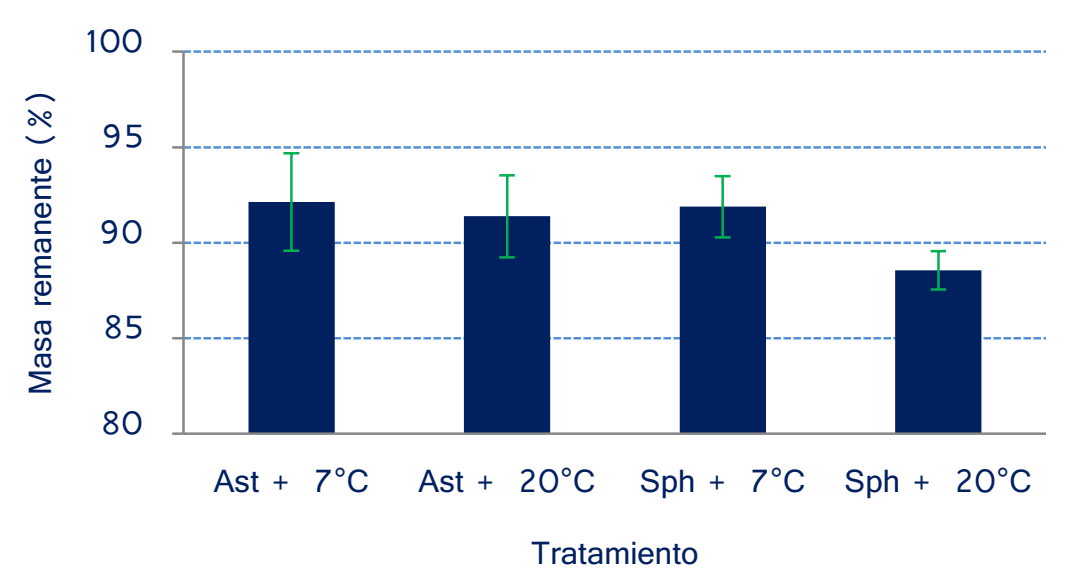

Tirchoderma viride

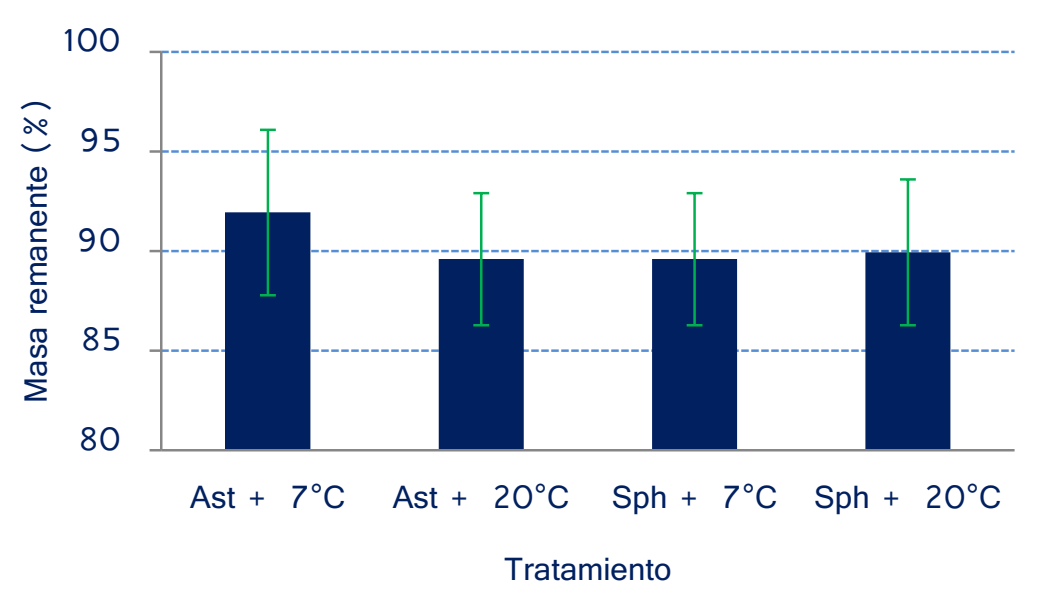


Figura 30. Masa remanente (\%) de turba luego de un ensayo de microcosmos para testear la habilidad de descomposición para cuatro microhongos nativos de turberas compactas. A. Aureobasidium pullulans. B. Beauveria bassiana. C. Penicillium frequentans. D. Trichoderma viride. Los tratamientos fueron: Astelia a $7^{\circ} \mathrm{C}\left(\right.$ Ast $\left.+7^{\circ} \mathrm{C}\right)$, Sphagnum a $7^{\circ} \mathrm{C}\left(\mathrm{Sph}+7^{\circ} \mathrm{C}\right)$, Astelia a temperatura ambiente $\left(\right.$ Ast $\left.+20^{\circ} \mathrm{C}\right)$ y Sphagnum a temperatura ambiente $\left(\mathrm{Sph}+2 \mathrm{O}^{\circ} \mathrm{C}\right)$. 


\subsection{DISCUSIÓN}

En vista de los resultados obtenidos, se puede resaltar que las cuatro cepas de microhongos (Aureobasidium pullulans, Beauveria bassiana, Penicillium frequentans y Trichoderma viride) utilizadas en este experimento colaboran y/o están directamente involucradas en la descomposición de turba tanto de Astelia como de Sphagnum en las turberas compactas de Astelia-Donatia. Además, es importante destacar que, si bien el experimento presentado fue llevado a cabo en un corto plazo ( 6 meses) con respecto a otras investigaciones sobre descomposición de la materia orgánica en turberas, se observó descomposición biomasa vegetal de importancia, considerando las características del material y las tasas de descomposición reportadas en otros estudios de microcosmos (Thormann y col., 2004; Thormann, 2011). La actividad de los microorganismos explica en gran parte estos resultados, siendo la degradación entre 5 y 10\% mayor en presencia de cepas fúngicas respecto de los controles durante los primeros 6 meses de incubación. Los microorganismos que intervienen en la descomposición de la materia vegetal, los hongos sobresalen por su alta capacidad degradadora (Griffin, 1972; Jackson y Raw, 1974) y además, desde una perspectiva funcional, son más importantes que las bacterias en los ecosistemas de humedales (Thornmann, 2006a). Asimismo, la alta capacidad degradadora de los Hyphomycetes está íntimamente vinculada con su morfología y fisiología. Su fase somática, en general, incospicua, está constituida por filamentos denominados hifas, cuya forma y modo de crecimiento, semejantes a una red, les permiten colonizar toda la superficie del sustrato y penetrarlo (Willets y Bullock, 1992).

En un experimento in vitro realizado por Thornmann (2011) se mostró que luego de 4 meses de incubación, la mayoría de los hongos pueden descomponer de manera efectiva la turba de Sphagnum derivada tanto del mesotelmo como el catotelmo, con pérdidas de masa en un rango del 2,7 al $4,3 \%$, respectivamente. En el experimento realizado con turba de Astelia y Sphagnum los valores medios de pérdida de masa oscilaron entre $7,77 \%$ y el $11,4 \%$. La mayor pérdida de masa registrada en este experimento puede deberse al mayor tiempo de incubación. 
Las hifas secretan enzimas capaces de solubilizar compuestos complejos del sustrato que, posteriormente, son incorporados por absorción a su metabolismo en forma de moléculas más simples (Kendrick, 1992). Durante este proceso una proporción de los nutrientes, queda inmovilizado en el micelio. La inmovilización es considerada un mecanismo mediante el cual es posible conservar y aprovechar los nutrientes. Con la muerte y lisis de las hifas las sustancias nutritivas son liberadas al ambiente. En la naturaleza, la actividad degradadora de los hongos saprobios está relacionada con el reciclaje de nutrientes en los ecosistemas. Mediante la mineralización de los restos vegetales y animales posibilitan la liberación de moléculas asimilables por las plantas (Carlile y col., 2001).

\section{a) Descomposición \& sustrato}

Al analizar la descomposición de los hongos microscópicos teniendo en cuenta el tipo de sustrato sobre el que fueron inoculados, se observó una tendencia general a descomponer más fácilmente la turba de Sphagnum (Figuras 28 y 29 ).

Los musgos de Sphagnum forman parte de un grupo único de plantas que perecen desde la base de su cuerpo vegetativo, manteniéndose vivos en las partes más superficiales por años, o incluso siglos. Además, como otros briofitos, carecen de lignina en su estructura (un compuesto resistente a la descomposición en las plantas superiores). Las cualidades del musgo de Sphagnum como sustrato in vitro son muy diferentes de su comportamiento in situ, esto se debe a que en su ambiente natural produce compuestos secundarios fenólicos que inhiben la actividad de aquellos organismos que normalmente facilitarían la descomposición (hongos y bacterias) (Rydin, 2006). Esta particularidad, junto a los bajos pH y las condiciones de anoxia en la naturaleza, resultan en una velocidad de descomposición más lenta que las traqueófitas (Scheffer y col., 2001). Asimismo, en un estudio realizado por Straková y col. (2011) estudiaron el efecto de la calidad del material vegetal sobre la actividad microbiana, y se observó que las actividades enzimáticas fueron generalmente más altas en los restos vegetales de plantas vasculares 
comparadas con los de Sphagnum. Sin embargo, los resultados presentados en esta tesis fueron opuestos a lo mencionado, exhibiendo in vitro una mayor pérdida de masa vegetal las bolsas de descomposición de Sphagnum con respecto a las de Astelia (Figuras 28 y 29). Uno de los procesos en este trabajo implicó el tratamiento previo de esterilización sobre el material vegetal (proceso de autoclavado) que detendría tanto la producción como las condiciones de acidez y la acción inhibitoria de cualquier compuesto secundario que haya sido producido in situ en el musgo, posibilitando así el acceso fúngico a esta fuente de materia orgánica cuya estructura vegetal es menos compleja que la de Astelia.

Existen estudios realizados en turberas del hemisferio norte en los que se han medido las tasas de descomposición de plantas vasculares y no vasculares. Algunos de los taxa más comunes incluyen especies de plantas vasculares de Carex, Salix, Typha y Betula, y de briofitas, los géneros Sphagnum, Drepanocladus y Tomenthypnum (Thornmann, 2006). Sin embargo, no incluyen trabajos de descomposición en Astelia; siendo los resultados aquí presentados la primer información obtenida de un experimento in vitro con este tipo de turba; asimismo, los experimentos de descomposición llevados a cabo para turberas fueguinas se han basado en la utilización de bolsas de descomposición armadas con turba de Carex (Zaller y col., 2009).

\section{b) Influencia de la temperatura sobre la descomposición}

La incubación a temperaturas óptimas de crecimiento para los microorganismos se tradujo en una mayor descomposición y este efecto fue aún mayor cuando el sustrato involucrado fue Sphagnum. Esta mayor pérdida de masa estaría estrechamente vinculada con la mayor actividad degradativa de los organismos a mejores condiciones de funcionamiento enzimático. Además, se observó que todas las especies fúngicas, excepto $B$. bassiana, presentaron la siguiente tendencia: 


\section{Sphagnum alta $T^{0}>$ Astelia alta $T^{0}>$ Sphagnum baja $T^{0}>$ Astelia baja}

$+$

DESCDMPOSICIÍN

Los hongos microscópicos se desarrollan fácilmente a un $\mathrm{pH}$ ácido, entre 4-6 y a una humedad relativa superior al 65\% (Florian, 2004); sin embargo, la temperatura es el factor principalmente involucrado en su crecimiento y desarrollo. La mayoría son mesofílicos y crecen a temperaturas que van de los $5^{\circ}$ a los $35^{\circ} \mathrm{C}$ con un rango óptimo de crecimiento de $20-30^{\circ} \mathrm{C}$ (Zak y Wildman, 2004). La influencia de la temperatura sobre el crecimiento fúngico tiene una gran importancia para comprender la ecología de las diferentes especies fúngicas, tanto en su comportamiento individual como en sus relaciones interespecíficas.

En las turberas de Tierra del Fuego, la temperatura media es muy baja y oscila aproximadamente entre $2-6^{\circ} \mathrm{C}$ (Capítulo 2), posicionándose en el extremo inferior del rango óptimo de crecimiento fúngico. Según Zak y Wildman (2004), se consideran condiciones ambientales estresantes o adversas cuando los microorganismos son sometidos a situaciones que difieren de las denominadas 'ideales' de crecimiento, bien sea en el laboratorio o en el campo. De este modo, podría considerarse que las temperaturas registradas para las turberas en estudio (Capítulo 2) son consideradas extremas. Esta condición fue simulada al someter las unidades a una baja temperatura, cercana a las registradas en la naturaleza $\left(7^{\circ} \mathrm{C}\right)$ y la menor pérdida de masa registrada para las mismas con respecto a aquellas que fueron incubadas en una temperatura óptima $\left(20^{\circ} \mathrm{C}\right)$ era esperable, sin embargo no se observó esta patrón para todas las especies (ver próxima sección). Si se someten a los microhongos a condiciones alejadas de su rango de desarrollo o crecimiento óptimo, sus actividades metabólicas tenderán a ser más lentas o disminuir. Porque la temperatura óptima $\left(20^{\circ} \mathrm{C}\right)$ siempre está más cerca del límite máximo del rango de temperaturas en las que puede crecer el microorganismo (Madigan y col., 1999). Además, las enzimas responsables de la degradación de los polímeros más complejos presentes en la turba, las fenoloxidasas (ligninasa, peroxidasa, lacasa y tirosinasa) 
son afectadas por la temperatura, la disponibilidad de oxígeno y el $\mathrm{pH}$ (Ruggiero \& Radogna, 1984; Pind y col., 1994; Freeeman y col., 2001, 2004; Toberman y col., 2008).

Los principales controles en la descomposición en turberas pueden ser identificados como macro y microclima, la posición dentro del perfil de turba y la química del material vegetal. La influencia del macroclima en las tasas de descomposición de la materia orgánica en bosques ha sido bien establecida, mostrando que la descomposición es lenta cuando decrece la temperatura y se vuelve más rápida cuando incrementa la precipitación (Meentemeyer, 1978; Moore y col., 1999; Trofymow y col., 2002). Sin embargo, a pesar que en turberas se han realizado algunos experimentos de transplante, este patrón no está claramente establecido para estos ambientes (Moore y Basiliko, 2006). En un estudio realizado en bosques de Canadá acerca de la descomposición de la hojarasca en bosques, un incremento de la temperatura media anual de 0 a $10^{\circ} \mathrm{C}$, durante 6 años, resultó en un aumento en la tasa de descomposición y en un descenso del 22 al 50\% de la masa original (Trofymow y col., 2002). Por otra parte, Moore y col. (2005) mostraron que en tres turberas del hemisferio norte la tasa promedio de descomposición de 12 tipos de restos vegetales decrece cuando disminuye la temperatura. La mayor parte de los estudios en los que se plantea conocer la influencia de las modificaciones de la temperatura (entre otros factores) sobre la actividad de microorganismos en turberas están vinculados principalmente a investigar los efectos del cambio climático sobre las comunidades microbianas (Freeman y col., 2001; Freeman y col., 2004; Trettin y col., 2006; Toberman y col., 2008).

El efecto destacado de la temperatura en la fisiología del crecimiento de los hongos se evidencia por la inhibición en la elongación de la hifa, la disminución en la germinación de los conidios (Santamarina y Rosello, 2006) y de la formación del tubo germinal (Kedrics y col., 2003), por ello se ha considerado este factor como limitante en el desarrollo de los microorganismos. 


\section{c) Descomposición \& cepas}

Al comparar la masa remanente con 4 microhongos inoculados, se observó que Aureobasidium pullulans fue la especie con menor actividad degradadora y que fue influenciada tanto por la temperatura como por el tipo de sustrato involucrado

El rango de temperatura óptima de $A$. pullulans es de $2-35^{\circ} \mathrm{C}$, siendo el rango de temperatura óptima de $25^{\circ} \mathrm{C}$. Además, esta especie presenta adaptaciones a bajas temperaturas (Domsch y col. 1980) y esto explicaría que aún a $7^{\circ} \mathrm{C}$ presentara una influencia de la temperatura en su actividad degradativa.

Las especies Penicillium frequentans y Trichoderma viride presentaron un mayor porcentaje de descomposición en las unidades incubadas a temperatura ambiente. Esta situación era esperable ya que sus temperatura óptimas para el crecimiento son de $23^{\circ} \mathrm{C}$ para $P$. frequentans, siendo aún mayor la temperatura para la germinación de conidios, y de $20-28^{\circ} \mathrm{C}$ para T. viride (Domsch y col., 1980).

B. bassiana fue la única especie cuya actividad degradativa fue similiar en todos los tratamientos y además presentó una mayor actividad degradativa con respecto a los demás Hyphomycetes inoculados. Este hongo crece en un amplio rango de temperaturas desde los $8^{\circ} \mathrm{C}$ a los $35^{\circ} \mathrm{C}$ (Fargues y col., 1997), por lo tanto esta capacidad de crecer en un rango tan amplio de temperaturas le permitiría presentar una gran capacidad degradativa en las temperaturas utilizadas en este experimento. A diferencia del resto de las especies que se utilizan en este ensayo, B. bassiana tiene la capacidad de alta degradación de los diversos tipos de materiales vegetales y su actividad no es afectada por la temperatura, demostrando la voracidad de materia orgánica de esta especie y la importancia de la misma en el reciclaje de los nutrientes del sistema.

Es importante destacar que en el caso de estos ensayos, las especies fúngicas fueron incubadas en forma aislada en cada uno de los sustratos por lo que las acciones de competencia 
entre especies u otros aspectos que puedan modificar su comportamiento no fueron considerados. Las respuestas observadas representan respuestas puras de cada especie sin estar inmersas en la comunidad, bajo condiciones ambientales.

\section{d) Consideraciones finales}

La descomposición es un proceso complejo que incluye casi todos los cambios en la materia orgánica que ha llegado a la senescencia. Desde una perspectiva micológica, se ha demostrado que los cambios en la calidad del sustrato (turba), el potencial de agua de la materia orgánica, la temperatura y el $\mathrm{pH}$ afectan las comunidades fúngicas de varios sustratos (Pugh, 1958; Christensen \& Whittingham, 1965; Pugh y Mulder, 1971; Dix, 1985; Nilsson y col., 1992; Lumley y col., 2001; Thormann y col., 2003). Sin embargo, reproducir en el laboratorio o in vitro las condiciones ambientales originarias (incluyendo sus variaciones) a las que están expuestas y/o sometidos los microorganismos resulta muy laborioso y hasta inalcanzable en algunas situaciones determinadas.

Frente a la realización de experimentos similares al presentado en este estudio, se recomienda tener precaución al interpretar los resultados, porque estos sólo son indicadores de las habilidades relativas de estos hongos para degradar diversos compuestos, y que, a su vez, provocan la pérdida de masa vegetal de Astelia y Sphagnum. Además, la habilidad de un hongo para utilizar un sustrato particular in vitro no implica necesariamente la misma habilidad in situ; sin embargo, indica la habilidad potencial de estos hongos para utilizar un tipo particular de sustrato. Los hongos compiten por los recursos con otros organismos in situ, es decir, en su "nicho realizado", lo que puede conducir a la supresión de algunas de las capacidades expresadas in vitro, o sea, en su "nicho fundamental". El nicho fundamental de un organismo es siempre más grande que su nicho realizado debido a la ausencia de competencia en el primero. Por lo tanto, este estudio no determina si los Hyphomycetes involucrados en este experimento tienen capacidades enzimáticas similares en presencia de otros organismos o in situ. No obstante, 
estos datos indican que tienen un potencial considerable para descomponer los restos vegetales que forman la turba de Astelia y Sphagnum en turberas compactas.

Finalmente, estas cepas fúngicas al estar comprometidas con la descomposición de los dos tipos de turba, seguramente también estén involucradas en los procesos de mineralización del carbono. Consecuentemente, es importante continuar los estudios considerando los roles de estos y otros hongos microscópicos en la descomposición de los distintos tipos de turba y sus interacciones, especialmente en las turberas fueguinas por ser depósitos de carbono tan significativos para la región.

\subsection{CONCLUSIONES}

* Las especies Aureobasidium pullulans, Beauveria bassiana, Penicillium frequentans y Trichoderma viride están directamente involucradas en la descomposición de turba en las turberas compactas de Astelia-Donatia.

* Al comparar la pérdida de masa entre las cuatro cepas se observó una tendencia general a descomponer más fácilmente la turba de Sphagnum.

* El incremento de la temperatura de incubación se tradujo en una mayor actividad degradativa y este efecto fue aún mayor cuando el sustrato fue Sphagnum.

* B. bassiana fue la especie relacionada con mayor actividad degradativa de materia orgánica, mientras que $A$. pullulans presentó una menor actividad degradativa. 


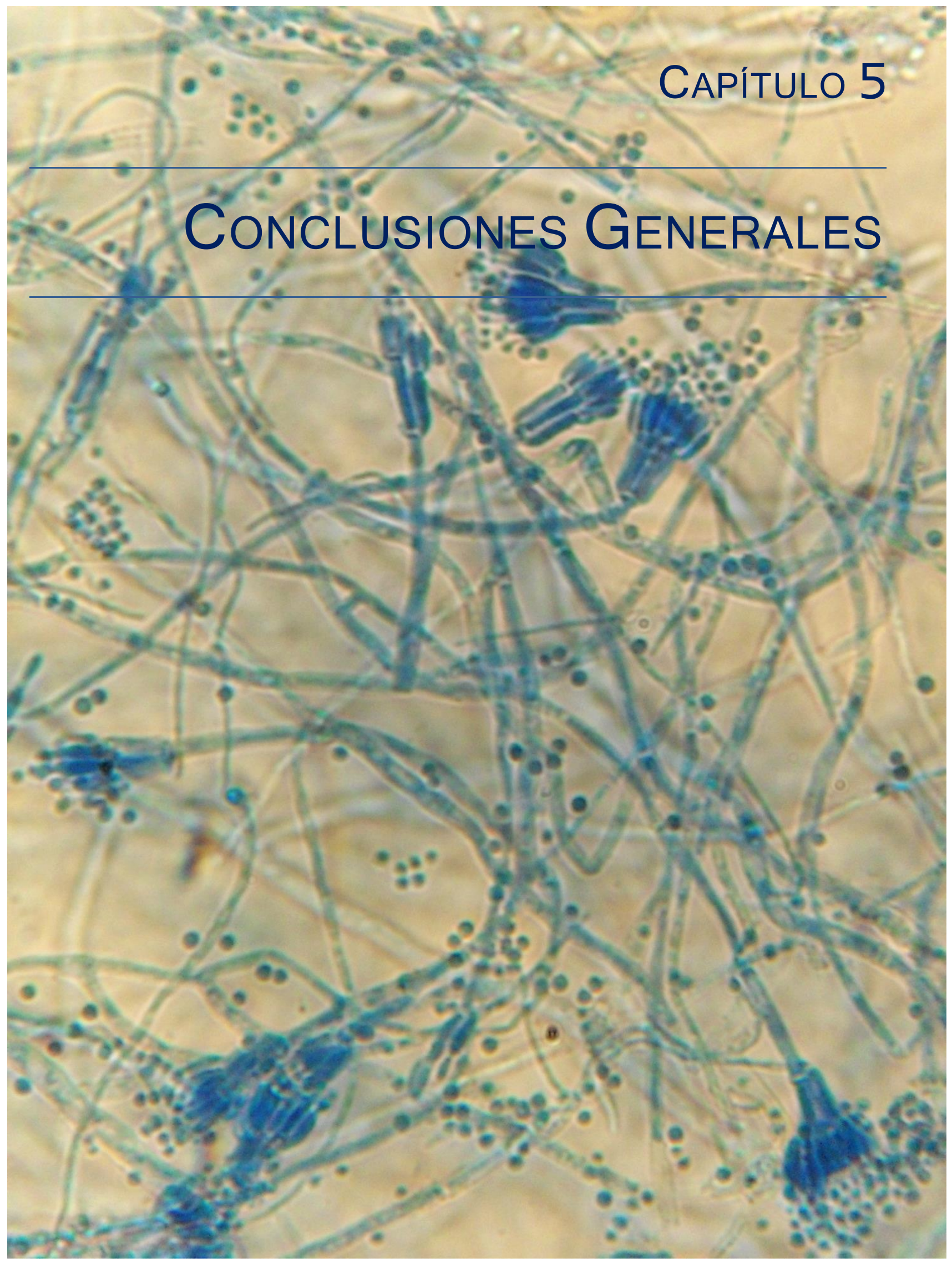


El objetivo principal de esta tesis fue el de analizar la composición, la diversidad y dinámica y el rol de la comunidad de microhongos en turberas compactas (Astelia-Donatia) de Tierra del Fuego y las variables que determinan las características de esta comunidad.

Los hongos filamentosos constituyen uno de los grupos más numerosos de hongos microscópicos, presentando una elevada diversidad en diferentes tipos de ambientes. Sin embargo, el estudio de estos microorganismos en el sur de nuestro país, y en particular en turberas, se ubica en una fase muy preliminar. Cabe destacar que en la provincia de Tierra del Fuego existen una gran variedad de turberas que ocupan $2.700 \mathrm{~km}^{2}$ de la superficie total insular, y que conforman gran parte del paisaje fueguino, especialmente al sur de la isla. Además, en comparación con la contraparte del hemisferio norte, en esta región se encuentran aún turberas que representan verdaderos ecosistemas prístinos. No obstante, la comunidad de hongos microscópicos presente en estos ambientes ha sido poco investigada.

Las turberas en las que se llevó a cabo el estudio de microhongos por sus ubicaciones geográficas contrastantes representan las distintas situaciones ambientales en que se encuentran las mismas. La turbera "Moat" se encuentra ubicada en cercanía al mar, con una gran influencia de las deposiciones de spray marino, mientras que la turbera "Garibaldi", se ubica en una zona montañosa. A pesar de ello, al realizar la caracterización físico-química de ambos sitios no se observaron diferencias entre las variables registradas y, además, compartieron estrechamente los rasgos que las definen: $\mathrm{pH}$ muy ácido (aproximadamente 4), exposición a bajas temperaturas $\left(2-5^{\circ} \mathrm{C}\right)$, similar diversidad vegetal y acumulan turba con altos contenidos hídrico y de carbono 
(más del $90 \%$ ) y bajo contenido de nitrógeno (menos del $4 \%$ ). Resulta importante destacar que en este caso la caracterización de los sitios se hizo en base al registro de datos puntuales los días que se realizaron los muestreos, a fin de determinar cuáles eran las condiciones en las que se encontraban los microhongos activos al momento de la toma de muestras. Por lo tanto, no se evaluó el efecto de la estacionalidad en los parámetros físico-químicos registrados, porque esto no formó parte de los objetivos principales de esta investigación.

En una primera etapa de trabajo, y ante la falta de una metodología y/o protocolo estándar de aislamiento de hongos microscópicos de turberas, se implementaron diferentes técnicas de cultivo clásicas (siembra directa, siembra en cámaras húmedas y lavado de partículas de suelo) y se analizó la eficacia de cada una de ellas. De este modo, se lograron establecer las bases metodológicas para abordar de la manera más adecuada el estudio de la diversidad fúngica en turberas compactas de Astelia-Donatia. Es así que se demostró que la metodología que implica el lavado de partículas de suelo resultó ser la más adecuada y/o eficiente para aislar microhongos activos presentes en estos ambientes.

A través de la implementación de las metodologías clásicas mencionadas se obtuvieron 3.255 aislamientos fúngicos que correspondieron a 9 géneros (Aureobasidium, Beauveria, Botryosporum, Cladosporium, Mortierella, Mucor, Parasterinella, Penicillium, Trichoderma) у 19 especies, representados principalmente por las Subdivisiones Ascomycotina y Zygomycotina; siendo mayor el número de Ascomycetes. La mayoría de estas especies coinciden con los resultados publicados en otros trabajos acerca de la comunidad fúngica presente no sólo en 
turberas de Tierra del Fuego sino que, al tener un marcado carácter cosmopolita, también corresponden a la microcarga normal de otras turberas del mundo. Entre las especies aisladas Aureobasidium pullulans, Beauveria bassiana, Mortierella alpina, Penicillium frequentans y Trichoderma viridae resultaron las más frecuentes y/o abundantes en estos ambientes, condición que se vincularía con la alta capacidad que presentan estos organismos para degradar una amplia variedad de compuestos presentes en la turba y la vegetación de turberas, su rápido crecimiento y su prolífica producción de esporas. Por otra parte, entre los representantes de Ascomycetes, se logró aislar el género Parasterinella cuya presencia solo ha sido asociada a hojas de Drymys winteri, una de las especies vegetales que componen la estructura vegetal de las turberas muestreadas, y no habiendo sido registrada en Astelia y Sphagnum. A estos resultados se suman los obtenidos por la identificación molecular de 30 micelios estériles que correspondieron a 4 especies fúngicas diferentes a las aisladas por metodologías clásicas de cultivo. Estas especies fueron Tolypocladium cylindrosporum, T. inflatum, Fusarium culmorum y un hongo perteneciente a la clase Leotiomycetes (ectomicorriza no cultivable), quienes presentan requerimientos de cultivo diferentes, por lo que no fueron aisladas con las metodologías clásicas. De este modo, resultó eficiente y necesario combinar y/o complementar el uso de metodologías clásicas con metodologías moleculares para identificar los aislamientos estériles obtenidos en este estudio.

El número de especies de la comunidad de microhongos que sostienen las turberas de Astelia-Donatia es relativamente simple, con una diversidad de nivel medio; ambas turberas de estudio presentaron una marcada homogeneidad, debido a que el tipo de cobertura (Astelia o 
Sphagnum), la ubicación geográfica (sitio costero o sitio montañoso) y la profundidad de muestreo no tuvieron una influencia significativa sobre el número, tipo y frecuencia de especies aisladas. Luego de analizar la relación de las mismas con las variables ambientales se observó que la misma fue más marcada en el muestreo de noviembre. La relación carbono:nitrógeno, la distancia la napa freática y el contenido hídrico estuvieron estrechamente relacionados con las muestras de Astelia y Sphagnum en Moat, mientras que la distancia a la napa freática y el contenido hídrico estuvieron positivamente asociados a la distribución de las muestras de Garibaldi. La estructura de la comunidad y la diversidad de los hongos filamentosos es muy sensible a los cambios en su microhábitat. También responden a la comunidad vegetal y las características físico-químicas que presentan las turberas que los sustentan, y si éstas se manifiestan como ambientes estables, homogéneas y sometidas a condiciones limitadas, resulta esperable que los microorganismos que conviven en ella se asocien siguiendo una tendencia similar. Sin embargo, es importante tener en cuenta que la turba representa un sustrato complejo que responde a cambios temporales y estacionales de la química ambiental, así como también a los parámetros climáticos, pudiendo esto limitar los resultados obtenidos y sobre todo el entendimiento de la diversidad fúngica en las turberas estudiadas.

Los resultados del ensayo de microcosmos mostraron que las cuatro cepas más frecuentemente aisladas de estos ambientes (Aureobasidium pullulans, Beauveria bassiana, Penicillium frequentans y Trichoderma viridae) participan activamente en la descomposición de la materia orgánica, que tienen una mayor habilidad de descomponer turba de Sphagnum que de Astelia y esta actividad degradativa se potencia con el incremento de la temperatura de 
incubación. De las 4 especies, $B$. bassiana presentó una mayor pérdida de masa vegetal independientemente de la temperatura y sustrato, mientras que $A$. pullulans tuvo la menor actividad degradativa. En las turberas de estudio, la temperatura registrada fue muy baja y osciló aproximadamente entre $2-6^{\circ} \mathrm{C}$, posicionándose en el extremo inferior del rango óptimo de crecimiento fúngico. Esta situación generaría una tendencia a disminuir o enlentecer las actividades metabólicas de las 4 cepas involucradas en este estudio, cuyas temperaturas de crecimiento óptimo son cercanos a $20^{\circ} \mathrm{C}$.

Finalmente, el ensayo de microcosmos presentado en esta tesis representa el primer estudio que vincula la actividad fúngica con la descomposición en las turberas compactas de Astelia-Donatia.

\section{LÍNEAS DE INVESTIGACIÓN FUTURAS}

Los resultados expuestos en esta tesis consolidaron una gran base de información acerca de la comunidad de hongos microscópicos de turberas compactas y a su vez generaron un amplio abanico de posibilidades de estudio que deberán ser encarados no solo desde una perspectiva micológica, sino también en pos de comprender aún más su funcionalidad en estos ambientes tan particulares. A continuación se enlistan algunas de las posibles líneas de investigación originadas a partir de la información presentada. 
* Las actividades microbianas revelan los cambios en la calidad de un ambiente debido al manejo. El monitoreo de las funciones microbianas en ambientes como las turberas y su vinculación con la transformación de nutrientes (ciclos) puede ser una herramienta eficaz para evidenciar el efecto antropogénico sobre estos ambientes. Es por ello que se propone estudiar los aspectos fisiológicos de la comunidad fúngica presente en turberas compactas de Astelia-Donatia, empleando tal vez la metodología denominada 'Perfiles fisiológicos a nivel comunidad' (en inglés, CLPP: Comunity Level Physiologic Profile). Esta técnica tiene como finalidad analizar el potencial metabólico de la comunidad, evaluando sus múltiples atributos fisiológicos, con el propósito de discriminar patrones espaciales, temporales, o bien aspectos experimentales. De esta manera, el estudio de la diversidad fúngica abordado de un modo tradicional (analizando la diversidad taxonómica) podría ser complementado y perfeccionado con el estudio de su diversidad funcional. Además, la información obtenida por esta técnica debería combinarse y vincularse con los parámetros físico-químicos que definen a las turberas compactas y agregar la determinación de aquellas variables que no fueron analizadas en este trabajo (por ejemplo: contenido de fósforo, calidad del material vegetal, entre otros).

* Con respecto a la abundancia y diversidad de hongos microscópicos presentes en turberas compactas de Astelia-Donatia resultaría de gran utilidad contar con códigos de barra para estos microorganismos para develar otros aspectos de su biología y ecología, y sobre todo facilitar su identificación. Para ello resultaría necesario armar una base de datos confiable que se conseguiría realizando la identificación molecular de las diferentes cepas obtenidas a través de la implementación de diversas técnicas moleculares. 
* El ensayo de microcosmos presentando representa el primer estudio realizado para vincular la descomposición en turberas compactas con la presencia y la actividad de hongos microscópicos. Se recomienda completar y/o complementar el estudio in vitro con datos de descomposición a campo. Así como también, se sugiere profundizar las investigaciones sobre la fisiología de los hongos aislados a fin de caracterizar su comportamiento fisiológico.

* A partir de las muestras de turba (tanto de Astelia como de Sphagnum) fue posible el aislamiento de cepas de microhongos con alto potencial antagónico para el manejo integrado de hongos fitopatógenos e insectos plaga en cultivos. Entre ellas se encuentran algunas especies del género Trichoderma y la especie Beauveria bassiana. Estas cepas, al estar adaptadas a condiciones de acidez y frío extremos, podrían presentar características genéticas que las distingan de las mismas especies aisladas en otras partes del país (sobre todo el norte argentino). Por lo tanto sería recomendable evaluar en laboratorio (in vitro) y en invernadero la efectividad antagonista de los aislamientos frente a hongos patógenos comunes.

* La amplia gama de potencialidades biotecnológicas de los hongos microscópicos, en especial de los microhongos, en los últimos años, ha despertado el interés en este grupo por parte de diversos sectores industriales. En consecuencia, y considerando el amplio rango de hongos microscópicos que ofrecen las turberas fueguinas, podrían utilizarse las diferentes cepas aisladas para diferentes aplicaciones biotecnológicas, ya que representan organismos adaptados a vivir en ambientes considerados de condiciones extremas (bajo $\mathrm{pH}$, baja temperatura, elevadas 
precipitaciones). Además, no existe información acerca de este tipo de investigaciones llevadas a cabo en la provincia de Tierra del Fuego.

* El género Trichoderma también es reconocido como un micoparásito de ciertos hongos degradadores de madera. En Tierra del Fuego, las pérdidas de árboles de lenga (Nothofagus pumilio) por infección con pudriciones pardas y blancas representan actualmente una de las problemáticas forestales más importantes. Se sugiere evaluar el potencial de las distintas cepas de Trichoderma aisladas en este estudio como posibles agentes biocontroladores de este problema fitosanitario. Para ello, como primera instancia, se recomiendan realizar diferentes ensayos de interacción (dual culture tests) en bloques de madera de lenga en presencia de ambos tipos fúngicos. 


\section{BIBLIOGRAFÍA}

- Adair E. C., Parton W. J., del Grosso S. J., Silver W. L., Harmon M. E., Hall S. A., Burke I. C. \& Hart S. C. 2008. Simple three-pool model accurately describes patterns of long-term litter decomposition in diverse climates. Global Change Biology, 14:2636-2660.

- Aguirre-Acosta E., Ulloa M., Aguilar S., Cifuentes J. \& Valenzuela R., 2014. Biodiversidad de hongos en México. Revista Mexicana de Biodiversidad, 85: S76-S81.

- Allué C., Arranz J. A., Bava J. O., Beneitez J. M., Collado L. \& García-López J. M., 2010. Caracterización y cartografía fitoclimáticas del bosque nativo subantártico en la Isla Grande de Tierra del Fuego (Patagonia, Argentina). Forest Systems, 19 (2): 189-207.

- Amon J. P., Thompson C. A., Carpenter Q. J. \& Miner J., 2002. Temperate zone fens of the glaciated Midwestern USA. Wetlands, 22: 301-317.

- Andersen R., Francez A.-J. \& Rochefor, L. 2006. The physicochemical and microbiological status of a restored bog in Quebec: Identification of relevant criteria to monitor success. Soil Biology \& Biochemistry, 38: $1375-1387$.

- Anderson I. C. \& Cairney J. W. C. 2004. Diversity and ecology of soil fungal communities: increased understanding through the application of molecular techniques. Environmental Microbiology, 6: 769-779.

- Aerts R. \& De Caluwe H., 1997. Nutritional and plant mediated controls on leaf litter decomposition of Carex species. Ecology, 78: 244-260.

- Aramabarri A. M., 1985. Mycothyriales of Tierra del Fuego I: The genus Parasterinella Spegazzini. Sydowia, Annales Mycologici Ser.ll, 38: 1-5.

- Artz R. R. E., Anderson I. C., Chapman S. J., Hagn A., Schloter M., Potts J. M. \& Campbell C. D., 2007. Changes in fungal community composition in response to vegetatioanl succession during the natural regeneration of cutover peatlands. Microbial Ecology, 54: 508-522.

- Atlas R. \& Bartha R., 2002. Ecología microbiana y Microbiología Ambiental. 4ta Edición. Editorial Addison Wesley. España. 
- Barrera M. D., Frangi J. L., Ritcher L., Perdomo M. H. \& Pinedo L. B., 2000. Structural and functional changes in Nothofagus pumilio forests along an altitudinal gradient in Tierra del Fuego, Argentina. Journal of Vegetation Science, 11: 179-188.

- Bartnicki-García S., 1987. The cell Wall: a crucial structure in fungal evolution, págs.389-403. En: A. D. M. Rayner, C. M. Brasier y D. Moore (eds.), Evolutionary biology of the fungi. Cambridge University Press, Cambridge, UK.

- Basiliko N., Yavitt J. B., P. Dees \& Merkel S. M., 2003. Methane biogeochemistry and methanogen communities in two northern peatland ecosystems, New York State. Geomicrobiology Journal, 20: 563577.

- Bava J., 1998. Los bosques de lenga en Argentina. Patagonia Forestal, 4: 5-8.

- Bedford B. L. \& Godwin K. S., 2003. Fens of the Unitated States: Distribution, characteristics, and scientific connection versus legal isolation. Wetlands, 23: 608-629.

- Begon M., Towsend C. R. \& Harper J. L., 2006. Ecology: From individuals to Ecosystems. $4^{\text {ta }}$ Edición. Blackwell Publishing Ltd. Estados Unidos.

- Belyea L. R. \& Malmer N., 2004. Carbon sequestration in peatland: patterns and mechanisms of response to climate change. Global Change Biology, 10: 1043-1052.

- Bills F. G., Christensen M., Powell M. \& Thorn G., 2004. Saprobic soil fungi. En: G. M. Mueller, G. F. Bills \& M. S. Foster (eds),Biodiversity of fungi: inventory and monitoring methods. Amsterdam; Boston; Elsevier Academic Press, pp 272-302.

- Bissett J. \& Parkinson D., 1979. Functional relationships between soil fungi and environment in alpine tundra. Canadian Journal of Botany, 57: 1642-1659.

- Bisett J., 1983. Notes on Tolypocladium and related genera. Canadian Journal of Botany, 61: 1311-1329.

- Blair J.M., 1988. Nitrogen, sulfur and phosphorous dynamics in decomposing deciduous leaf litter in the southern Appalachians. Soil Biology \& Biochemistry, 20: 693-701

- Blanco D. E. \& de la Balze V. M., 2004. Los turbales de la Patagonia: Bases para su inventario y la conservación de su biodiversidad. Publicación No. 19. Wetalnds International. Buenos Aires, Argentina. 
- Blodau C., Basiliko N. \& Moore T. R. 2004. Carbon turnover in peat-land mesocosms exposed to different water table levels. Biogeochemistry, 67: 331-351.

- Bothwell L. D., Selmants P. C., Giardina C. P. \& Litton C. M., 2014. Leaf litter decomposition rates increase with rising mean annual temperature in Hawaiian tropical montane wet forests. PeerJ 2:e685.

- Borelli P. \& Oliva G., 2001. Ganadería ovina sustentable en la Patagonia austral. Tecnología de manejo extensivo. Ed. INTA. Río Gallegos. Argentina, 270 pp.

- Bragazza L. \& Siffi C., 2007. Mass loss and nutrient reléase during litter decay in peatland: The role of microbial adaptability to litter chemistry. Soil Biology and Biochemistry, 39: (1): 257-267.

- Bragazza L., Buttler A., Siegenthaler A. \& Mitchell E. A. D., 2009. Plant litter decomposition and nutrient release in petalands. Carbon Cycling in Northern Peatlands Geophysical Monograph Series 184 . The American Geophysical Union.

- Bremmer J. M. y Mulvaney C. S., 1982. Nitrogen-total. En: A.L. Page, R.H. Miller \& D.R. Keeney (eds.), Methods of soil analysis, part 2. Chemical and microbiological properties, 2da edición. págs. 595-624. (Agronomy series no 9) ASA. SSSA. Madison.

- Brindgham S. D., Pastor J., Janssens J. A., Chapin C. \& Malterer T. J., 1996. Multiple limiting gradients in peantlands: A call for a new paradigm. Wetlands, 16: 45-65.

- Bridgham S. D., Pastor J., Dewey B., Weltzin J. F. \& Updegraff, K., 2008. Rapid Carbon Response of Peatlands to Climate Change. Ecology, 89: 3041-3048.

- Bridge, P. D. \& Spooner B. M., 2001. Soil fungi: diversity and detection. Plant Soil, 232: 147-154.

- Brodie E., Edwards S. \& Clipson N., 2003. Soil fungal community structure in a temperate upladan grassland soil. FEMS Microbiology Ecology, 45: 105-114.

- Burguess L. W., Summerell B. A., Bullock S., Gott K. P. \& Backhouse D., 1994. Laboratory manual for Fusarium research. $3^{\text {ra }}$ edición. Sydney, University of Sydney.

- Cabello M. N., Aon M. A. \& Velázquez M. S., 2003. Diverstity, structure and evolution of fungal communities in soils under different agricultural managment practices. Boletín de la Sociedad Argentina de Botánica, 38: 225-232. 
- Cabello M. N. \& Arambarri A. M., 2006. Diversity in soil fungi from undisturbed and disturbed Celtis tala and Scutia buxifola forests in the eastern Buenos Aires province (Argentine). Microbial Research, 157: 115125.

- Cannon P. F., 1996. Filamentous fungi. En: G. Hall (ed.), Methods for examination of organismal diversity in soils and sediments CAB International, Wallingford, pp. 127-145.

- Carabelli F. A., 2002. Una contribución a la planificación del uso múltiple de las áreas boscosas de Tierra del Fuego. Publicación técnica N³1. Esquel, Chubut: CIEFAP-GTZ.

- Carlile M.J., Watkinson S. \& Gooday G. W., 2001. The Fungi (2 ${ }^{\text {nd }}$ Edition). Academic Press Inc. pp 496.

- Charman D. J., 2000. Peatlands and environmental change. Wiley. Chichester.

- Chen Y., Dumont M. G., McNamra N. P., Chamberlain P. M., Bodrossy L., Strails-Pavese N. \& Murrel J. C. 2008. Diversity of the active methanotrophic community in acidic peatlands as assessed by mRNA and SIP-PLFA analyses. Environmental Microbiology, 10: 446-459.

- Christensen M. (1989). A view of fungal ecology. Mycologia, Vol. 81, No. 1, pp 1-19.

- Christensen M. \& Whittingham W.F., 1965. The soil microfungi of open bogs and conifer swamps in Wisconsin. Mycologia, 57, 882-896.

- Cornelissen J. H. C., 1996. An experimental comparison of leaf decomposition rates in a wide range of temperate plant species and types. Journal of Ecology, 84: 573-582.

- Cotrufo M. F., Raschi A., Lanini M \& Ineson P., 1999. Decomposition and nutrient dynamics of Quercus pubescens leaf litter in a naturally enriched $\mathrm{CO}_{2}$ Mediterranean ecosystem. Functional Ecology, 13: 343351.

- Cotrufo M. F., Delle Vedove G., Subke J. A., Inlgima I., Alberti G. \& Pressotti A., 2004. Litter decomposition and soil $\mathrm{CO}_{2}$ efflux on the Mediterranean island of Pianosa. Journal of Mediterranean Ecology, 5: 23-29.

- Couteaux, M.M., Bottner, P., Berg, B., 1995. Litter decomposition, climate and litter quality. Trends in Ecology \& Evolution, 10, 63-66. 
- Cromack, K. \& Caldwell, B. A., 1992. The role of fungi in litter decomposition and nutrient cycling, págs. 653-668. En: G. C. Carroll \& D. T. Wicklow (eds.), The fungal community: its organization and role in ecosystem, 2da edición. Marcel Dekker, New York.

- Cicerone R. J. \& Oremland R. S., 1988. Biogeochemical aspects of atmospheric methane. Global Biogeochemical Cycles, 2: 299-327.

- Clymo R. S., 1984. The limits to peat bog growth. Philosophical Transaction of Royal Society of London Biological Science, 303: 605-654.

- Crum H., 1988. A focus on peatlands and peat mosses. University of Michigan Press, Ann Arbor, MI, pp. 306.

- Daldourn D. M. A., Mubarak A. R. \& Elbashir A. A., 2010. Leaf litter decomposition and nutrient realease pattern of three species under semi-arid conditions. JONARES, 5: 75-88.

- Davet P. y Rouxel F., 2000. Detection and isolation of soil fungi. Science Publishers, Enfield.

- Davidson, E.A. \& Janssens, I.A., 2006. Temperature sensitivity of soil carbon decomposition and feedbacks to climate change. Nature, 440: 165-173.

- De Boer W., Gerard S., Gunnewiek P. J. A. \& Modderman R., 1999. Response of the measures of concentration and molecular size of dissolved organic carbon in humic Lake Tjeukemeer. Water Research, 21: $731-734$.

- Dedysh S. N., 2002. Methanotrophic bacteria of acidic Sphagnum peat bogs. Microbiology, 71: 639650.

- Devi L. S., Polashree K., Fenella M., Nongkhlaw W. \& Joshi S. R., 2012. Diversity of culturable soil microfungi along altitudinal gradients of eastern Himalayas. Mycobiology, 40(3): 151-158.

- Díaz M.F., Zegers G. \& Larraín J., 2005. Antecedentes sobre la importancia de las turberas y el pompón de la Isla de Chiloé. 33p. http://www.infoandina.org/sites/default/files/publication/files/Turberas.pdf

- Díaz F., Larraín J., Zegers G. \& Tapia C., 2008. Caracterización florística e hidrológica de turberas de la Isla Grande de Chiloé, Chile. Revista Chilena de Historia Natural, 81: 455-468. 
- Dohan F. M., Brennan J. \& Cooke B. M., 2003. Influence of climatic factors on Fusarium species pathogenic to cereals. European Journal of Plant Pathology, 109: 755-768.

- Domsch K. H, Gams W. \& Anderson T. H., 1980. Compendium of soil fungi. Academi Press, London, 406 págs.

- Domínguez E., 2014. Manual de buenas prácticas para el uso sostenido del musgo Sphagnum magellanicum en Magallanes, Chile. Instituto de Investigaciones Agropecuarias. Centro Regional de Investigación Kampenaike. Punta Arenas, Chile. Boletín INIA № 276.113 pp.

- Dooley M. J. \& Dickinson C. H, 1970. Microbiology of cut-away peat II. The ecology of fungi in certain habitats. Plant Soil, 32: 454-446.

- Fargues J., Goette M. S., Smits N., Ouedraogo A. \& Rougier M., 1997. Effect of temperature on vegetative growth of Beauveria bassiana isolates from different origins. Mycologia, 89(3): 383-392.

- Fenner N., Freeman C. \& Reynolds B., 2005. Observations of a seasonally shifting thermal optimum in peatland carbon-cycling processes: implications for the global carbon cycle and soil enzyme methodologies. Soil Biology \& Biochemistry, 37: 1814-1821.

- Fernández R. D. \& Aragón R., 2014. Descomposición de hojarasca de las especies leñosas nativas y exóticas más abundantes del pedemonte de las Yungas, Tucumán, Argentina. Ecología Austral, 24: 286293.

- Filippova N. V. \& Thornmann M. N, 2014. Communities of larger fungi of ombotrophic bogs in west Siberia. Mires and Peat, Vol. 14, Article 08, 1-22. International Mire Conservation Group and International Peat Society.

- Fisher N. L., Burgess L. W., Tousson T. A. \& Nelson P. E., 1982. Carnation leaves as a substrate and for preserving cultures of Fusarium species. Phytopathology, 72: 151-153.

- Fisk M. C., Ruether K. F. \& Yavitt J. B., 2003. Microbial activity and functional composition among northern peatland ecosystems. Soil Biology and Biochemistry, 35: 591-602.

- Florian M. L. E., 2004. Fungal facts. Solving fungal problems in heritage collections. Archetype Publications Ltd., London, UK, 146 págs. 
- Frangi J. L., Ritcher L. L., Barrera M. D. \& Aloggia M., 1997. Decomposition of Nothofagus fallen woody debris in forest of Tierra del Fuego, Argentina. Canadian Journal of Forest Research, 27: 1095-1102.

- Frangi J. L., Barrera M. D., Puigdefábregas J., Yapura P. F., Arambarri A. M. \& Richter L., 2004. Ecología de los bosques de Tierra del Fuego. En: M. F. Arturi, J. L. Frangi \& J. F. Goya (eds.) Ecología y manejo de los bosques de Argentina. EDULP, La Plata.

- Frankland J. C., Dighton J. \& Boody L., 1990. Methods for studying fungi in soil and forest litter. Methods in Microbiology, 22: 343-404.

- Freeman C., Ostle N. \& Kang H., 2001. An enzymic ‘latch’ on a global carbon store. Nature, 409-149.

- Freeman C., Ostle N. \& Fenner N., 2004. A regulatory role for phenol oxidase during decomposition in peatland ecosystems. Soil Biology and Biochemistry, 35: 591-602.

- Frostegård, A. \& Bååth, E., 1 996. The use of phospholipid fatty acids analysis to estimate bacterial and fungal biomass in soil. Biology and Fertility of Soils, 22: $59-65$.

- Gao J., Kang F., Li T., Song X., Zhao W., Yu X. \& Han H., 2015. Assessing the effect of leaf litter diversity on the decomposition and associated diversity of fungal assemblages. Forests, 6: 2371-2386.

- Gaxiola A. \& Arnesto J. J., 2015. Understanding litter decomposition in semiarid ecosystems: linking leaf traits, UV exposure and rainfall variability. Frontiers in Plant Science, 6: 140.

- Giesselman U. Ch., Martins K. G., Brändle M., Schädler M., Marques R. \& Brandl R., 2010. Diversity and ecosystem functioning: Litter decomposition dynamics in the Atlantic rainforest. Applied Soil Ecology, 46: $283-290$.

- Golovchenko, A.V. \& Polyanskaya, L.M., 1999. Viability of fungal mycelium and spores in peat soils. En: S. E. Vompersky (ed.) Proceedings of the Conference "Swamps and Swampy Forests in Connection with the Problems of Stable Exploitation of Natural Resources". GEOS publishers, Moscow, 106-109.

- Gams W., 1992. The analysis of communities of saprophytic microfungi with special reference to soil fungi. En: Fungi in vegetation science (ed. Winterhoff W.). Kluwer, Academic Publishers, Dordrecht, pp. 183.223. 
- Glaser P. H. \& Janssens J. A., 1986. Raised bogs in eastern North-America-Transitions in landforms and gross stratigraphy. Canadian Journal of Botany-Revue Canadienne De Botanique, 64: 395-415.

- Gaspar M. L., Cabello M. N., Pollero R. J. \& Aon M. A., 2001. Fluorescent diacetate hydrolysis as a measure of fungal biomass in soil. Current Microbiology Research, 156: 113-119.

- Gray T. R. G., 1990. Methods for studying the microbial ecology in soil. En: Methods in Microbiology (eds. Grigorova R. G. \& Norris J. R.). Vol. 22, Academic Press, London. pp. 310-342.

- Greslebin A., 2001. Sistotremateae (Corticiaceae, Aphyllophorales) from the Patagonian Andes Forests of Argentina. Mycological Research, 105(11): 1392-1396.

- Greslebin,A. G. \& Rajchenberg M., 2003. Diversity of Corticiaceae s.I. in Patagonia, Southern Argentina. New Zealand Journal of Botany, 41: 437-446.

- Golovchenko A. V., Polyanskaya L. M., Dobrovol'skaya T. G., Vasil'eva L. V., Chernov I. Y. \& Zvyagintsev D. G., 1993. Peculiarities in space distribution and structure of microbial complexes of boggyforest ecosystems. Pochvovedenie, 10, 78-89.

- Golovchenko A. V., Semenova T. A., Polyakova A. V. \& Inisheva L. I., 2002. The structure of the micromycete complexes of oligotrophic peat deposits in the southern Taiga subzone of West Siberia. Microbiology: 71, 575-581.

- Golovchenko A. V., Tikhonova E. Y. \& Zvyagintsev D. G., 2007. Abundance, biomass, structure and activity of the microbial complexes of minerotrophic and ombrotrophic peatlands. Microbiology: 76: 630637.

- Gorham E., 1991. Northern peatlands -role in the carbon-cycle and probable responses to climatic warming. Ecological Applications, 1: 182-195.

- Griffin D. M., 1972. Ecology of soil fungi. Chapman and Hall, Londres, 193 pp.

- Grum-Grzhimaylo O. A., 2013. Micromycetes of Paludifying Water Bodies on the Shore of Kandalaksha Bay. PhD Thesis, Moscow State University, 242 pp. 
- Hagemann U. \& Moroni M. T., 2015. Moss and lichen decomposition in old-growth and harvested high boreal forests estimated using the litterbag and minicontainer methods. Soil Biology \& Biochemistry, 87: $10-24$.

- Hájek M., Horsak M., Hajkova P. \& Dite D., 2006. Habitat diversity of central European fens in relation to environmental gradients and an effort to standarise fen terminology in ecological studies. Perspectives in Plant Ecology Evolution and Systematics, 8: 97-114.

- Hájek T., Balance S., Limpens J., Zijlstra M. \& Verhoeven J. T. A. Cell-wall polysaccharides play an important role in decay resistance of Sphagnum and actively depressed decomposition in vitro. Biogeochemistry, 103: 45-47.

- Hättenschwiler S., Coq S., Barantal S. \& Handa T., 2010. Leaf traits and decomposition in tropical rainforests: revisiting some commonly held views and towards a new hypothesis. New Phytologist, 189: $960-965$.

- Hawksworth D. I., 2001. The magnitude of fungal diversity: the 1.5 millon species estimate revisted. Mycological Research, 105: 1422-1432.

- Heim A. \& Frey B., 2004. Early stage litter decomposition rates for Swiss forests. Biogeochemistry, 70: $301-315$

- Herbert P. D. N., Cywinska A., Ball S. L. \& deWaard J. R., 2003. Biological identifications through DNA barcodes. Proceedings of Royal Society, 270: 313-321.

- Herstbjerg H., Felding G. \& Elmholt S., 2002. Fusarium culmorum infection of Barley Seedings: Correlation between aggressiveness and deoxynivalenol content. Journal of Phytopathology, 150: 308-312.

- Hjeljord L. \& Tronsmo A., 1998. Trichoderma and Gliocladium in biological control: an overview. Págs. 131-151. En: Harman G. \& Kubicek C. (eds.) Trichoderma \& Gliocladium. Vol. 2. Enzymes, biological control and commercial applications. Taylor \& Francies. London, Uk, 1998.

- Hobbie E. A, Watrud L. S., Maggard S., Shiroyama T. \& Rygiewicz P. T., 2003. Carbohydrate use and assimilation by litter and soil fungi assessed by carbon isotopes and BIOLOG® assays. Soil Biology and Biochemistry, 35: 303-311. 
- Hooper D., Solan M., Symstad A., Díaz S., Gessner M., Buchmann N., Degrange V., Grime P., Hulot F., Mermillod-Blondin F., Roy J., Spehn E. \& van Peer L., 2002. Species diversity, functional diversity and ecosystem functioning. En: Loreau M., Naeem S., Inchausti P. (eds.). Biodiversity and Ecosystem Functioning Synthesis and Perspectives. Oxford University Press. pp. 195-281.

- Horak, E. 1979[1980]. Fungi, Basidiomycetes, Agaricales y Gasteromycetes secotioides. En: GUARRERA, S.A., I. J. GAMUNDÍ DE AMOS \& D. RABINOVICH DE HALPERÍN (eds.), Flora Criptogámica de Tierra del Fuego, Tomo XI, fasc. 6, 524 pp. FECIC, Buenos Aires.

- Horton T. R. \& Bruns T. D., 2001. The molecular revolution in ectomycorrhizal ecology: peeking into the black-box. Molecular Ecology, 10: 1855-1871.

- Houston A. P. C., Visser S. \& Lautenschlager R. A., 1998. Microbial processes and fungal community structure in soils from clear-cut and unharvested areas of two mixed wood forests. Canadian Journal of Botany, 76: 630-640.

- Hulme P. D., Nicol A. T. \& Robertson R. A., 1980. Peat. En: C. J. Brown \& R. E. F. Helsop (eds.), The soils of the country round Stranraer and Wigtown, págs.. 170-195. Macaulay Institute, Aberdeen.

- Ibarra M., Caldentey J. \& Promis A., 2011. Descomposición de hojarasca en rodales de Nothofagus pumilio de la región de Magallanes. BOSQUE, 32(3): 227-233.

- Infante D., Martínez B., González N. \& Reyes Y., 2009. Mecanismos de acción de Trichoderma frente a hongos fitopatógenos. Revista de Protección Vegetal, 24 (1): 14-21-

- Ingram H. A. P., 1978. Soil layers in mires-Function and terminology. Journal of Soil Science, 29: 224227.

- Ingram H. A. P., 1992. Introduction to the ecohydrology of mires in the context of cultural perturbation. En: Peatland Ecosystems and Man: An impact assessment (eds. O. M. Bragg, P. D. Hulme, H. A. P. Ingram \& R. A. Robertson). British Ecological Society/ International Peat Society. Dundee. pp. 67-93.

- Iturraspe R. \& Roig C. E., 2000. Aspectos hidrológicos de turberas de Sphagnum de Tierra del FuegoArgentina. En: Conservación de ecosistemas a nivel mundial con énfasis en las turberas de Tierra del Fuego. Disertaciones y conclusiones (eds. A. Coronato \& C. Roig). Ushuaia, Argentina. Marzo 2000., pp 85-93. 
- Iturraspe R. J y A. Urciuolo, 2004. Les tourbieres de la Terre de Feu en Argentine: un patrimoine naturel très menacè. Geocarrefour, 79(4): 143-152.

- Iturraspe R. J., Urciolo A., Guerrero Borges V., Gaviño Novillo M., Collado L., Sarandón R. \& Burns S., 2007. Report on basin response for Argentina. D18 Epic Force Project-INCO-CT2004-510739. http: / / www.ceg.ncl.ac.uk/epicforce/deliverables.html

- Iturraspe R., 2010. Las turberas de Tierra del Fuego y el cambio climático global. Fundación para la Conservación y el Uso Sustentable de los Humedales. Wetlands International.

- Jaatinen K., Fritze H., Laine J. \& Laiho R., 2007. Effects of short- and long-term water level draw- down on the populations and activity of aerobic decomposers in a boreal peatland. Global Change Biology, 13: 491-510.

- Joosten $\mathrm{H} .$, 2010. The global peatland $\mathrm{CO}_{2}$ picture. Peatland status and drainage related emissions in all countries of the world. Wetlands International, Ede, August 2010.

- Joosten H. \& Clarke D., 2002. Wise use of mire and peatlands. Background and principles including a framework for decision-making. International Mire Conservation Group and International Peat Society. Saarijärven Offset Oy, Saarijärvi, Finland.

- Kachalkin, A.V., 2010. Yeast Communities of Sphagna. Ph.D. Thesis, Moscow State University, 179 pp.

- Kamal S. A. \& Varma A., 2008. Peatland Microbiology. En: P. Dion \& C. Nautiyal (eds.) Microbiology of Extreme Soils, pp. 177-203. Berlin-Heidelberg: Springer.

- Kedrics L., Antal Z., Manczinger L., Szekeres A., Kevei F. \& Nagy E., 2003. Influence of environmental parameters on Trichoderma strains with biocontrol potential. Food Technology and Biotechnology, 41(1): $37-42$.

- Kendrick W. B., 1992. The fifth kingdom. Focus Information Group, MA, 406 pp.

- Kennedy A. C. \& Gewin V. L., 1997. Soil microbial diversity: present and future considerations. Soil Science, 162: 607-617.

- Killham K., 1994. Soil Ecology. Cambridge University Press, UK. 
- Kip N. Fritz C. Langelaan E., Pan Y., Bodrossy L., Pancotto V. A., Jetten M. S. M., Smolders A. J. M. \& den Camp H. J. M. 2012. Methanotrophic activity and diversity in different Sphagnum magellanicum dominated peat bog habitats in Tierra del Fuego. Biogeosciences, 9: 47-55.

- Kurakov, A., Lavrent'ev, R., Nechitailo, T., Golyshin, P. \& Zvyagintsev, D. ,2008. Diversity of facultatively anaerobic microscopic mycelial fungi in soils. Microbiology:77, 90-98.

- Küster E. \& Locci R., 1963. Studies on peat and peat microorganisms: Taxonomic studies on thermophilic Actinomycetes isolated from peat. Archiv für Mikrobiologie, 45: 188-197.

- Lacey J., 1989. Pre- and post-harvested ecology of fungi causing spoilage of foods and other stored products. Journal of Applied Bacteriology, Simposium Supplment 11S-25S.

- Lacey J. \& Magan N., 1991. Fungi relationships in cereal grains: their occurrence and water and temperature. En: J. Chelkowski (ed.), Cereal grains. Mycotoxins, fungi and quality in drying and storage. Amsterdam, Elsevier, 77-118.

- Laiho R., 2006. Decomposition in peatlands; Reconciling seemingly contrasting results on the impacts of lowered water levels. Soil Biology and Biochemistry, 38: 2011-2014.

- Laine J. \& Vasander H., 1996. Ecology and vegetation gradients of peatlands. En: H. Vasander (ed.) Peatlands in Finland, pp. 10-19. Finnish Peatland Society.

- Lam T. N. C., Goettel M. \& Soares G. G. Jr., 1988. Host records for the entomopathogenic Hyphomycete Tolypocladium cylindrosporum. Florida Entomologist, 71: 86-89.

- Landry J., Bahamonde N., García Huidobro J., Tapia C. \& Rochefort L., 2010. Canadian peatland restoration framework: A restoration experience in Chilean peat bogs. Peatlands International, 2: 50-53.

- Lange M. \& Lange B. (1982). Agarics growing in Sphagnum: specialization and distribution in arctic and alpine zones. En: Laursen, G.A., Ammirati, J.F. (eds.) Arctic and Alpine Mycology, University of Washington Press, Seattle, WA, USA, 150-160.

- Latter P. M., Cragg J. B. \& Heal O.W., 1967. Comparative studies on the microbiology of four moorlands in the northern Pennines. Journal of Ecology, 55: 445-464. 
- Lavelle, P., Blanchart, E., Martin, A., Spain, A., Toutain, F., Barois, I., Schaefer, R., 1993. A hierarchical model for decomposition in terrestrial ecosystems: application to soil of the humid tropics. Biotropica, 25: 130-150.

- Letourneau A., Seena S., Marvanová A. \& Bärlocher, 2010. Potential use of barcoding to identify aquatic hypomycetes. Fungal Diversity, 40: 51-64.

- Limpens J., Berendse F., Blodau C., Canadell J.G., Freeman C., Holden, J., Roulet, N., Rydin, H. \& Schaepman-Strub, G., 2008. Peatlands and the carbon cycle: from local processes to global implications a synthesis. Biogeosciences, 5: 1475-1491.

- Lin X., Green S., Tfaily M. M., Prakash O., Konstantinidis K. T., Corbett J. E., Chanton J. P, Cooper W. T. \& Kostka J. E., 2012. Microbial community structure and activity linked to contrasting biogeochemical gradients in bog and fen environments of the Glacial Lake Agassiz Peatland. Applied and Environmental Microbiology, 78: 7023-7031.

- Lindahl, B.O., Taylor, A.F.S. \& Finlay, R.D. 2002. Defining nutritional constraints on carbon cycling in boreal forests - towards a less 'phytocentric' perspective. Plant and Soil, 242: 123 - 135.

- Lindahl B.O., Ihrmark K., J., B., Trumbore S.E., Stenlid, J. \& Finlay, R.D. 2007.Spatial separation of litter decomposition and mycorrhizal nitrogen uptake in a boreal forest. New Phytologist, 173: 611 - 620.

- Lindsay R. A., Ihmark K., Boberg J., Trumbore S., Hogberg P., Stenlid J. \& Finlay R. D., 2007. Spatial separation of litter decomposition and mycorrhizal nitrogen uptake in a boreal forest. New Phytologist, 173: 611-620.

-Liu W., Marsh T. L., Cheng H \& Forney L., 1997. Characterization of microbial diversity bye determining terminal restriction fragment length polymorphisms of genes encoding 16s rRNA. Applied and Environmental Microbiology, 63: 4516-4522.

- Logrieco A., Bottalico A., Mule G., Moretti A. \& Perrone G., 2003. Epidemiology of toxicogenic fungi and their associated mycotoxins for some Mediterranean crops. European Journal of Plant Pathology, 109: 645-667. 
- López Lastra C. C., Reboredo G. R. \& Spinedi H., 1991. Primer registro de Tolypocladium cylindrosporum Gams (Deuteromycotina: Hyphomycetes) para la Antártida. Consideraciones sobre su patogenicidad sobre larvas de Culex pipines L. Contribuciones del Instituto Antártico Argentino, $392: 11$.

- Ludwig H. \& Magalhães de Abreu, 2012. Hongos del suelo saprófitos y patógenos de plantas. En: Manual de biología de suelos tropicales. Muestreo y caracterización de la biodiversidad bajo suelo (eds. Moreira F. M. S., Huising J. \& Bignell D. E. ). Instituto Nacional de Ecología, México, 337 pp.

- Madigan M. T., Martnko J. M. \& Parker J., 1999. Brock. Biología de los microogranismos. Prentice Hall Iberia, Madrid, 1999.

- Malmer N., Horton D. G. \& Vitt D., 1992. Element concentration in mosses and surface waters of western Canadian mires in relation to precipitation chemistry and hydrology. Ecography, 15: 114-121.

- Malmer N. \& Wallén B., 1993. Accumulation and release of organic matter in ombotrophic bog hummocks-processes and regional variation. Ecography, 16: 193-211.

- Malosso E., Waite I. S., English L., Hopkins D. W. \& O' Donnell A. G., 2006. Fungal diversity in mairitime Antarctic soils determined using a combination of culture isolation, molecular fingerprinting and cloning thechniques. Polar Biology, 29: 552-561.

- Malvárez A. I., Kandus P. \& Carbajo A., 2004. Distribución regional de los turbales en Patagonia (Argentina y Chile). En: D. E. Blanco \& V. M. de la Balze (eds.), Los Turbales de la Patagonia. Bases para su inventario y la conservación de su biodiversidad. Wetlands International-America del Sur, Buenos Aires, Argentina. pp. 22-29.

- Martínez A. E., Chiocchio V. M. \& Godeas A. M., 2001. Hyphomycetes celulolíticos en suelos de bosques de Nothofagus, Tierra del Fuego. Gayana Botanica, 58: 123-132.

- Martínez Carretero, 2004. Capítulo 4 - Los turbales patagónicos. En: D. E. Blanco \& V. M. de la Balze (eds.), Los Turbales de la Patagonia. Bases para su inventario y la conservación de su. Wetlands International-America del Sur, Buenos Aires, Argentina. pp. 22-29.

- Martínez Cortizas A., Pontevedra Pombal X., Nóvoa Muñoz J. C., Rodríguez Fernández R. \& López-Sáez J. A., 2009. Turberas ácidas de esfagnos. En: VV.AA., Bases ecológicas preliminares para la 
conservación de los tipos de hábitat de interés comunitario en España. Madrid: Ministerio de Medio Ambiente, y Medio Rural y Marino. 64 págs.

- Meentemeyer, V., 1978. Macroclimate and lignin control of litter decomposition rates. Ecology, 59: $465-472$.

- Mitsch J. W. \& Gosselink J. G., 2000. Wetlands, 3ra edición. John Wiley \& Sons Inc., New York.

- Moore T. R., Trofymow J. A., Taylor B., Prescott C., Camiré C., Duschene L., Fyles J., Kozak L., Kranabetter M., Morrison I., Siltanen M., Smith S., Titus B., Visser S., Wein R.\& Zoltai S., 1999. Litter decomposition rates in Canadian forests. Global Change Biology, 5: 75-82.

- Moore T. R., Trofymow J. A., Siltanen M., Presscott C., CIDET Working Group, 2005. Patterns of decomposition and carbon, nitrogen and phosphorus dynamics of litter in upland forest and peatland sites, central Canada. Cannadian Journal of Forest Research, 35: 133-142.

- Moore T. R. \& Basiliko N., 2006. Decomposition in boreal peatlands. En: R. K. Wieder \& D. H. Vitt (eds. ), Boreal peatland ecosystems, pp 125-143. Berlin: Springer.

- Moore T. R., Bubier J. L. \& Bledzki L., 2007. Litter decomposition in temperate peatland ecosystems: the effect of substrate and site. Ecosystems, 10: 949-963.

- Moretto A., Lázzari A. \& Fernández O., 2005. Calidad y cantidad de nutrientes de la hojarasca y su posterior mineralización en bosques primarios y bajo manejo con distintos sistema de renegeración. Dirección de Bosques de la Secretaría de Ambiente y Desarrollo Sustentable de la Nación (SAyDS). Proyecto BIRF 4085-AR.

- Moretto A. \& Martínez Pastur G. J., 2014. Litterfall and leaf decomposition in Nothofagus pumilio forests along an altitudinal gradient in Tierra del Fuego, Argentina. Journal of Forest Science, 60(12): 500-510.

- Moro M. J. \& Domingo F., 2000. Litter decomposition in four Woody species in a mediterranean climate: weight loss, N and P dynamics. Annals of Botany, 86: 1065-1071.

- Munson R. K. \& Gherini S., 1993. Influence of organic acids on the pH and acid-neutralizing capacity of Adirondack lakes. Water Resources Research, 29(4): 891-899. 
- Muyezer G., de Waal E. C. \& Uitterlinden A. G., 1993. Profiling of complex microbial populations by denaturing gradient electrophoresis analysis of polymerase chain reaction-amplified genes coding for $16 \mathrm{~S}$ rRN. Applied and Environmental Microbiology, 59: 695-700.

- Myers B., Webster K. L., McLaughlin N. \& Basiliko N., 2012. Microbial activity across a boreal peatland nutrient gradient: the role of fungi and bacteria. Wetlands Ecology and Management, 20: 77-88.

- Nicholsocn B. J. \& Vitt D. H., 1990. The paleoecology of a peatland complex in continental western Canada. Canadian Journal of Botany, 68: 121-138.

- Page S. E., Rieley J. O. \& Banks C. J., 2011. Global and regional importance of the tropical peatland carbon pool. Global Change Biology, 17: 798-818.

- Paredes N. I., Consolo V. F., Pancotto V. A., Fritz C., Barrera M. D., Arambarri A.M. \& Salerno G., 2014. Microfungal composition in an Astelia-Donatia cushion peatland in Tierra del Fuego, Argentina. DARWINIANA, nueva serie 2(1): 112-124.

- Parish F., Sirin A., Charman D., Joosten H., Minayeva T., Silvius M. \& Stringer L, 2008. Assessment on peatlands, biodiversity and climate change: Main report. Global Environment Centre, Kuala Lumpur and Wetlands International, Wageningen. Disponible en: http://www.imcg.net/media/download gallery/books/assessment peatland.pdf

- Peltoniemi, K.; H. Fritze \& R. Laiho. 2009. Response of fungal and actinobacterial communities to waterlevel drawdown in boreal peatland sites. Soil Biology \& Biochemistry, 41: 1902- 1914.

- Pind A., Freeman C. \& Lock M. A., 1994. Enzymic degradation of phenolic materials in peatlands measurement of phenol oxidase activity. Plant and Soil, 159: 227-213.

- Pontevedra Pombal X. \& Martínez Cortizas A., 2004. Turberas de Galicia: Procesos formativos, distribución y valor medioambiental. El caso particular de las 'Serras septentrionais'. Chioglossa, 2: 103121.

- Powers J. S., Montgomery R. A., Adair C. E., Brearley F. Q., DeWalt S. J., Castanho C. T., Chave J., Deldernt E., Ganzhorn J. U., Gilbert M. E., González-Iturbe J. A., Bunyavejchewin S., Grau H. R., Harms K. E., Hiremath A., Iriarte-Vivar S., Manzane E., de Oliveira A. A., Poorter L., Ramnamanjato J. B., Salk C., Varela A., Weiblen G. D. \& Lerdau M. T., 2009. Decomposition in tropical forests: a pan-tropical study of 
the effects of litter type, litter placement and mesofaunal exclusion across a precipitation gradient. Journal of Ecology, 97: 801-811.

- Purschwitz, Müller S., Kastner C. \& Fischer R., 2006. Seeing the rainbow: light sensing in fungi. Current Opinion in Microbiology, 9: 566-571.

- Päiväen J. \& Paavilainen E., 1996. Foresrty on peatlands. En: Peatland in Finland (ed. Vasander H.). Gummerus Printing, Helsinki, pp. 72-83.

- Reichert J. M., Rodrigues M. F., Bervald C. M. P., Brunetto G., Kato O. R. \& Schumacher M. V., 2015. Fragmentation, fiber separation, decomposition, and nutrient release of secondary-forest biomass, mechanically chopped-and-mulched, and cassava production in the Amazon. Agriculture, Ecosystems \& Environment, 204: 8-16.

- Rabassa J., Coronato A. \& Roig C., 1996. The peat bogs of Tierra del Fuego, Argentina. En: Global Peat Resources (ed. Lappalainen E.). International Peat Society Publisher. pp. 261-266.

- Rabassa J., 2000. Las turberas como fuente de información paleoambiental. Disertación en Curso-Taller: Conservación de ecosistemas a nivel mundial con énfasis en las turberas de Tierra del Fuego. Ushuaia, 6$10 / 03 / 2000$

- RAMSAR, 2002. Humedales: agua, vida y cultura. 8va. Reunión de la Conferencia de las partes contrastantes en la Convención sobre los Humedales (Ramsar, Irán, 1971). Valencia, España.

- Robson T. M., Pancotto V. A., Ballaré C. L., Sala O. E., Scopel A. L. \& Caldwell M. M., 2004. Reduction of solar UV-B mediates changes in the Sphagnum capitulum microenvironment and the peatland microfungal community. Oecologia, 140: 480-490.

- Rodríguez Pleguezuelo C. R., Durán Zuazo V. H., Muriel Fernández J. L., Peinado Martín F. J. \& Franco Tarifa D., 2009. Litter decomposition and nitrogen release in a slopping Mediterranean subtropical agroecosystem on the coast of Granada (SE, Spain): Effects of floristic and topographic alteration on the slope. Agriculture, Ecosystems and Environment, 134: 79-88

- Roig C. E., Roig F. A., Collado L., Coronato A., Martínez Carretero E. \& Barrios V., 2001. Inventario de los turbales de la zona centro de la provincia de Tierra del Fuego. Informe final. CFI-Subsecretaría de Recursos Naturales, provincia de Tierra del Fuego, Antártida e Islas del Atlántico Sur. Ushuaia. 102 pp. 
- Rondon M. R., August P. R., Betterman A. D., Brady S. F., Grossman T. H., Liles M. R., Loiacono K. A., Lynch B. A., MacNeil I. A., Minor C., Tiong C. L., Gilman M., Osbourne M. S., Clardy J., Handelsman J. \& Goodman R. M., 2000. Cloning the soil metagenome: A strategy for accesing the genetic and functional diversity of uncultured microorganisms. Applied Environmental Microbiology, 66: 2541-2547.

- Ruggiero P. \& Radogna V. M., 1984. Properties of laccase in humus-enzyme complexes. Soil Science, 138: $74-87$.

- Rydin, H. y J.K. Jeglum. 2006. The biology of peatlands. Oxford University Press.

- Salo, K. (1979) Mushrooms and mushroom yield on transitional peatlands in central Finland. Annales Botanica Fennica: 16, 181-192.

- Santa Regina I., Rapp M., Martin A. \& Gallardo J.F., 1997. Nutrient release dynamics in decomposing leaf litter in two Mediterranean deciduous oak species. Annals of Forest Science, 54: 747-760.

- Santamarina M. P. \& Rosello J., 2006. Influence of the temperature and water activity on the antagonism of Trichoderma harzianum to Verticillium and Rhizoctonia. Crop Protection, 25: 1130-1134.

- Scheffer R. A., Van Logtestijn R. S. P. \& Verhoeven J. T. A., 2001. Decomposition of Carex and Sphagnum litter in two mesotrophic fens differing in dominan plant species. Oikos, 44-54.

- Sharma M. \& Sharma M., 2009. Influence of environmental factors on the growth and sporulation of Geophilic Keratinophiles from soil samples of public parks. Asian Journal of Experimental Biological Sciences, 23(1): 307-312.

- Sheffer E., Canham Ch. D., Kigel J. \& Perevolotsky A., 2015. Countervailing effects on pine and oak leaf litter decomposition in human-altered Mediterranean ecosystems. Oecologia, 177: 1039-1051.

- Singleton L. L., Mihail J. D. \& Rusch C. M., 1992. Methods for research in soilborne phytopatogenic fungi. APS Press, St Paul, MN.

- Sivan A. \& Chet I., 1989. Degradation of fungal cell walls by lytic enzymes of Trichoderma harzianum. Journal of General Microbiology., 135: 675-682. 
- Sizova M. V., Panikov N. S., Tourova T. P. \& Flanagan P. W., 2003. Isolation and characterization of oligotrophic acido-tolerant methanogenic consortia from a Sphagnum peat bog. FEMS Microbiology Ecology, 45: $301-315$.

- Solly E. F., Schöning I., Boch S., Kandeler E., Marhan S., Michalzik B., Müller J., Zscheischler J., Trumbore S. E. \& Schrumpf M., 2014. Factors controlling decomposition rates of fine litter in temperate forests and grasslands. Plant Soil, 382: 203-218.

- Stasinska, M., 2011. Macrofungi of raised and transitional bogs of Pomerania. Monographiae Botanicae, 101: $1-142$.

- Straková P., Niemi R. M., Freeman C., Peltoniemi K., Toberman H., Heiskanen I., Fritze H. y Laiho R., 2011. Litter type affects the activity of aerobic decomposers in a boreal peatland more tan site nutrient and water table regimes. Biogeosciences, 8: 2741-2755.

- Succow M. \& Joosten H., 2001. Landschaftsökologische Moorkunde. Schweizerbart, Stuttgart.

- Sundh, I., Nilsson, M. \& Borga, P., 1997. Variation in microbial community structure in two boreal peatlands as determined by analysis of phospholipid fatty Acid profiles. Applied and Environmental Microbiology, 63: 1476-1482.

- Sun O.J., Campbell J., Law B.E. \& Wolf V., 2004. Dynamics of carbon storage in soils and detritus across chronosequences of different forest types in the Pacific Northwest USA. Global Change Biology, 10: $1470-1481$.

- Swift M. J. \& Heal O. W., 1979. Decomposition in terrestrial ecosystems. Berkeley, University of California Press.

- Swift M.J. \& Anderson J.M., 1989. Decomposition. En: H. Lieth \& Werger M. J. A. (eds.), Tropical Rain Forest Ecosystems; Biogeographical and Ecological Studies, Ecosystems of the World, 14B. Elsevier, Amsterdam.

-Tarnocai, C., 2006. The effect of climate change on carbon in Canadian peatlands. Global and Planetary Change, 53: 222-232.

- Tedersoo L., Bahram M. \& Pome S. y otros, 2014. Global diversity and geography of soil fungi. Science, (346) no. 6123. 
- Thorn G., 1997. The fungi in soil, En: J. D. van Elsas, J. T. Trevors \& E. M. H. Wellington (eds.), Modern Soil Microbiology). Marcel Decker, New York, USA. pp 63-127.

- Thornmann M. N., Currah R. S. \& Bayley S. E., 2001. Microfungi isolated from Sphagnum fuscum from a Southern boreal bog in Alberta Canadá. The Bryologist, 104 (4): 548-559.

- Thornmann M.N., Currah R. S. \& Bayley S. E., 2002. The relative ability of fungi from Sphagnum fuscum to decompose selected carbon substrates. Canadian Journal of Microbiology, 48: 204-211.

- Thormann M. N., Currah R. S. \& Bayley S. E., 2003. Succession of microfungal assemblages in decomposing peatland plants. Plant Soil, 250: 323-333.

- Thormann M. N., Currah R. S. \& Bayley S. E., 2004. Patterns of distribution of microfungi in decomposing bogs and fen plants. Canadian Journal of Botany, 82: 710-720.

- Thormann M. N., 2006a. Diversity and function of fungi in peatlands: A carbon cycling perspective. Canadian Journal of Soil Science, 86: 281-293.

- Thormann M. N., 2006b. The Role of Fungi in Boreal Peatlands. En: R. K. Wieder \& D. H. Vitt (eds.), Boreal Peatland Ecosystems. Ecological Studies, Vol.188. Springer- Verlag, Berlin Heidelberg, pp. 101 123.

- Thormann M. N. \& Rice A. V. 2007. Fungi from peatlands. Fungal Diversity, 24: 241-299.

- Toberman H., Evans C. D., Freeman C., Fenner N., White M., Emmett B. A. \& Artz R. R. E. 2008. Summer drought effects upon soil and litter extracellular phenol oxidase activity and soluble carbon release in an upland Calluna heathland. Soil Biology \& Biochemistry, 40: 1519-1532.

- Trettin C. C., Laiho R., Minkkiken K. \& Laine J., 2006. Influence of climate change factors on carbon dynamics in northern forested peatlands. Canadian Journal of Soil Science, 86: 269-280.

- Trinder C. J., Johnson D. \& Artz R. E., 2009. Litter type, but not plant cover, regulates initial litter decomposition and fungal community structure in a recolonizing cutover peatland. Soil Biology \& Biochemistry, 41: 651-655. 
- Trivi de Mandri M. E., Burry L. S. \& D’Antoni h. L., 2005. Fechados radiocarbónicos en una turbera holocénica del centro de Tierra del Fuego. Relaciones de la Sociedad Argentina de Antropología, 30: 219224.

- Tsao P. H., Erwin D. C. \& Bartnicki-Garcia S., 1983. Phytophtora, its Biology, Taxonomy, Ecology and Pathology. APS Press, St Paul, MN.

- Turunen J., Tomppo E., Tolonen K. \& Reinikainen A., 2002. Estimating carbon accumulation rates of undrained mires in Finland-application to boreal and subartic regions. Holocene, 12: 69-80.

- Ulloa E., Anderson Ch. B., Ardón M., Murcia S. \& Valenzuela A. E. J., 2012. Organic matter characterization and decomposition dynamics in sub-Antarctic streams impacted by invasive beavers. Latin American Journal of Aquatic Research, 40 (4): 881-892.

- Uma M., Saravanan T. S. \& Rajendran K., 2014. Growth, litterfall and litter decomposition of Casuarina equisetofolia in a semiarid zone. Journal of Tropical Forest Science, 26(1): 125-133.

- van Huysen T., Harmon M. E., Perakis S. S. \& Chen H., 2013. Decomposition and nitrogen dynamics of $15 \mathrm{~N}$-labeled leaf, root, and twig litter in temperate coniferous forests. USDA Forest Service / UNL Faculty Publications. Paper 253. http://digitalcommons.unl.edu/usdafsfacpub/253

- Van Vuuren, M.M.I., Berendse, F., De Visser, W., 1993. Species and site differences in the decomposition of litters and roots from wet heathlands. Canadian Journal of Botany, 71: 167-173.

- Vasander H. \& Kettunen A., 2006. Carbon in boreal peatlands. En: (eds. K. Wieder \& D. H. Vitt) Boreal peatland ecosystems, Ecological Studies 188, Springer-Verlag, Heiderlberg, Germany, pp. 165-199.

- Verry E. S., Boelter D. H., Päivänen J., Nichols D. S., Malterer T. \& Gafni A., 2011. Physical properties of organic soils. Chapter 5. En: R. K. Kolka, S. D Sebestyen, E. S. Verry \& K. N. Brooks (eds.), Peatland biogeochemistry and watershed hydrology at the marcel experiment forest. CRC Press. Taylos \& Francis Group. Boca Raton, FL, USA.

- Vitt D. H., 2000. Peatlands: Ecosistems dominated by bryophytes. En: J. Shaw \& B. Goffinet (eds.), Bryophyte Biology. Cap. 10. pp. 312-343. Cambridge University Press. 
- Waddington J. M., Rochefort L. \& Campeau S., 2003. Sphagnum production and decomposition in a restored cutover peatland. Wetlands Ecology and Management, 11: 85-95.

- Wang Z., Binder M., Schoch C. L., Johnston P. R., Spatagora J. W. \& Hibbett D. S., 2006a. Evolution of helotialean fungi (Leotiomycetes, Pezizomycotina): A nuclear rDNA phylogeny. Molecular Phylogeny and Evolution, 41: 295-312.

- Wang Z., Johnston P. R., Takamatsu S., Spatafora J. W. \& Hibbet D. S., 2006b. Toward phylogenetic classification of the Leotiomycetes based on rDNA data. Mycologia, 98: 1065-1075.

- Warcup J. H., 1955. On the origin of fungi developing on soil dilution plates. Transactions of the British Mycological Society, 38, 298-301.

- Warcup J. H.,1960. Methods for isolation and estimation of activity of fungi in soil. En: D. Parkinson \& J. S. Waid (eds.), The Ecology of Soil Fungi. An International Symposium. Liverpool University Press, pp. 321.

-Waksman, S.A. \& Purvis, E.R., 1932. The microbiological population of peat. Soil Science, 34: 95-113.

- Wells H., Bell D. \& Jaworski C., 1972. Efficacy of Trichoderma harzianum as a biocontrol for Sclerotium rolfsii. Phytopathology, 62: 442-447.

- Weyers S. L. \& Spokas K. A., 2014. Crop residue decomposition in Minnesota biochar-amended plots. Solid Earth, 5: 499-597.

- Wheeler B. D. \& Proctor M. C. F., 2000. Ecological gradients, subdivisions and terminology of northwest European mires. Journal of Ecology, 88: 187-203.

- Whitmore T. C., 1984. Tropical rain forests of the far east. Oxford University Press.

- Whitten A. J., Damanik S. J., Jazanul A. \& Nazaruddin H., 1987. The ecology of Sumatra. Gadjah Mada University Press, Yogyakarta, Indonesia.

- Widden P. \& Parkinson D., 1973. Fungi from Canadian coniferous forest soils. Canadian Journal of Botany, 51: 2275-2290. 
- Wieder R. K. \& Vitt H. D., 2006. Boreal peatland ecosystems. Springer-Verlag Berlin Heidelberg Ecological Studies 188.

- Willetts H. J. \& Bullock S., 1992. Developmental biology of sclerotia. Mycological Research, 96:801-816.

- Williams, R.T. \& Crawford, R.L. 1 983. Effects of various physiochemical factors on microbial activity in peatlands: aerobic biodegradation processes. Canadian Journal of Microbiology, 29: 1430-1437.

- World Energy Council 2007. Survey of Energy Resources. London: World Energy Council. Disponible en: http://www.worldenergy.org/documents/ser2007_final_online_version_1.pdf

- Wurtzburger, N., Hartshorn, A.S. \& Hendrick, R.L., 2004. Ectomycorrhizal fungal community structure across a bog-forest ecotone in southeastern Alaska. Mycorrhiza: 14, 383-389.

- Young-Ju, K., Zhao, Y., Oh, K. T., Nguyen, V. N. \& Park, R. D., 2008. Enzymatic deacetylation of chitin by extracellular chitin deacetylase form a newly screened Mortierella sp DY-52. Journal of Microbial Biotechnology, 18: 759-766.

- Yu, Z.C., Loisel, J., Brosseau, D.P., Beilman, D.W., Hunt, S.J., 2010. Global peatland dynamics since the Last Glacial Maximum. Geophysical Research Letters 37.

- Zak J. C. \& Wildman H. G., 2004. Fungi in stressful environments. En: G. Mueller \& G. Bills (eds.) Measuring and Monitoring Biological Diversity: Standard Methods for Fungi. Washington DC, Smithsonian Institution Press, págs. 59-75.

- Zaguralskaya L. M., 1967. Microbial populations of peat-bog soils of Tomsk district. En: N. I. Pyavchenko (ed.) Interrelation of Forest and Bog. On the Results of Stationary Investigations. Nauka, Moscow, 56-81.

- Zaller J. G., Caldwell M. M., Flint S. D., Ballaré C. L., Scopel A. L. \& Salas O. E., 2009. Solar UVB and warming affect decomposition and earthworms in a fen ecosystem in Tierra del Fuego, Argentina. Global Change Biology, 15: 2493-2502.

- Zhang K., Cheng X., Dang H., Ye Ch., Zhang Y. \& Zhang Q., 2012. Linking litter production, quality and decomposition to vegetation succession following agricultural abandonment. Soil Biology and Biochemistry, 57: 803-813. 


\section{ANEXOS}

ANEXO 1. Tablas con valores de $\mathrm{F}$ y $\mathrm{p}$ para los análisis de varianza (ANOVA) realizados para testear la influencia de los factores 'profundidad' (tabla A), 'cobertura' (tabla B) y 'sitio' (tabla C) en los valores medios de NIVEL DE AGUA (medido como distancia al agua) calculados para las muestras tomadas en febrero 2012 y en 4 tipos diferentes de parcelas (M Ast: parcela ubicada en Moat y cubierta por Astelia; M Sph: ubicada en Moat y cubierta por Sphagnum; G Ast: en Garibaldi y con Astelia; G Sph: en Garibaldi y con Sphagnum). (En rojo: valores signifcativos de p)

\section{A. ANOVA- Factor: PROFUNDIDAD; Variable: NIVEL AGUA}

\begin{tabular}{ccc} 
FEB'12 & $F$ & $p$-level \\
\hline M Ast & 27,093 & $<0,01$ \\
\hline M Sph & 38,521 & $<0,01$ \\
\hline G Ast & 4,698 & 0,043 \\
\hline G Sph & 6,522 & 0,019 \\
\hline
\end{tabular}

B. ANOVA-Factor: COBERTURA; Variable: NIVEL AGUA

\begin{tabular}{ccc} 
FEB'12 & $F$ & p-level \\
\hline M A & 9,317 & 0,006 \\
\hline M B & 9,317 & 0,006 \\
\hline G A & 0,472 & 0,501 \\
\hline G B & 0,472 & 0.501 \\
\hline
\end{tabular}

\section{ANOVA-Factor: SITIO; Variable: NIVEL AGUA}

\begin{tabular}{ccc} 
FEB'12 & $F$ & p-level \\
\hline Ast A & 0,110 & 0,743 \\
\hline Ast B & 0,110 & 0,743 \\
\hline Sph A & 10,130 & 0,005 \\
\hline Sph B & 10,130 & 0,005 \\
\hline
\end{tabular}




\section{ANEXOS}

ANEXO 2. Tablas con valores de $\mathrm{F}$ y $\mathrm{p}$ para los análisis de varianza (ANOVA) realizados para testear la influencia de los factores 'profundidad' (tabla A), ‘cobertura' (tabla B) y 'sitio' (tabla C) en los valores medios de NIVEL DE AGUA (medido como distancia al agua) calculados para las muestras tomadas en noviembre 2012 y en 4 tipos diferentes de parcelas ( $M$ Ast: parcela ubicada en Moat y cubierta por Astelia; M Sph: ubicada en Moat y cubierta por Sphagnum; G Ast: en Garibaldi y con Astelia; G Sph: en Garibaldi y con Sphagnum). (En rojo: valores signifcativos de p)

\section{A. ANOVA-Factor: PROFUNDIDAD; Variable: NIVEL AGUA}

\begin{tabular}{ccc} 
NOV'12 & $F$ & p-level \\
\hline M Ast & 98,822 & $<0,01$ \\
\hline M Sph & 8,226 & 0,0102 \\
\hline G Ast & 13,569 & 0,0016 \\
\hline G Sph & 36,571 & $<0,01$ \\
\hline
\end{tabular}

B. ANOVA- Factor: COBERTURA; Variable: NIVEL AGUA

\begin{tabular}{ccc} 
NOV'12 & $F$ & p-level \\
\hline M A & 0,0261 & 0,873 \\
\hline M B & 2,916 & 0,104 \\
\hline G A & 2,632 & 0,122 \\
\hline G B & 2,632 & 0,122 \\
\hline
\end{tabular}

\section{ANOVA-Factor: SITIO; Variable: NIVEL AGUA}

\begin{tabular}{ccc} 
NOV'12 & $F$ & p-level \\
\hline Ast A & 7,929 & 0,011 \\
\hline Ast B & 7,929 & 0,011 \\
\hline Sph A & 3,804 & 0,066 \\
\hline Sph B & 61,439 & $<0,01$ \\
\hline
\end{tabular}




\section{ANEXOS}

ANEXO 3. Tablas con valores de $\mathrm{F}$ y $\mathrm{p}$ para los análisis de varianza (ANOVA) realizados para testear la influencia de los factores 'profundidad' (tabla A), 'cobertura' (tabla B) y 'sitio' (tabla C) en los valores medios del CONTENIDO HÍDRICO presente en las muestras de turba tomadas en febrero 2012 y en 4 tipos diferentes de parcelas (M Ast: parcela ubicada en Moat y cubierta por Astelia; M Sph: ubicada en Moat y cubierta por Sphagnum; G Ast: en Garibaldi y con Astelia; G Sph: en Garibaldi y con Sphagnum). (En rojo: valores signifcativos de p)

\section{Factor: PROFUNDIDAD; Variable: CONT HIDRICO}

\begin{tabular}{ccc}
\hline FEB'12 & F & p-level \\
\hline M Ast & 0,756 & 0,387 \\
\hline M Sph & 0,333 & 0,570 \\
\hline G Ast & 0,542 & 0,480 \\
\hline G Sph & 2,953 & 0,113 \\
\hline
\end{tabular}

\section{Factor: COBERTURA; Variable: CONT HIDRICO}

\begin{tabular}{ccc}
\hline FEB'12 & $F$ & p-level \\
\hline M A & 101,961 & $<0,01$ \\
\hline M B & 59,195 & $<0,01$ \\
\hline G A & 18,572 & 0,002 \\
\hline G B & 3,947 & 0,072 \\
\hline
\end{tabular}

\section{Factor: SITIO; Variable: CONT HIDRICO}

\begin{tabular}{c|cc}
\hline FEB'12 & $F$ & p-level \\
\hline Ast A & 5,130 & 0,042 \\
\hline Ast B & 2,223 & 0,158 \\
\hline Sph A & 1,089 & 0,314 \\
\hline Sph B & 1,609 & 0,223 \\
\hline
\end{tabular}




\section{ANEXOS}

ANEXO 4. Tablas con valores de $\mathrm{F}$ y $\mathrm{p}$ para los análisis de varianza (ANOVA) realizados para testear la influencia de los factores 'profundidad' (tabla A), 'cobertura' (tabla B) y 'sitio' (tabla C) en los valores medios del CONTENIDO HÍDRICO presente en las muestras de turba tomadas en febrero 2012 y en 4 tipos diferentes de parcelas (M Ast: parcela ubicada en Moat y cubierta por Astelia; M Sph: ubicada en Moat y cubierta por Sphagnum; G Ast: en Garibaldi y con Astelia; G Sph: en Garibaldi y con Sphagnum). (En rojo: valores signifcativos de p)

\section{Factor: PROFUNDIDAD; Variable: CONT HIDRICO}

\begin{tabular}{ccc} 
NOV'12 & F & p-level \\
\hline M Ast & 0,15611579 & 0.697401226 \\
\hline M Sph & 2.77625799 & 0.112977929 \\
\hline G Ast & 2.02725625 & 0.171603844 \\
\hline G Sph & 0,2568267 & 0,618460417 \\
\hline
\end{tabular}

Factor: COBERTURA; Variable: CONT HIDRICO

\begin{tabular}{ccc} 
NOV'12 & $F$ & p-level \\
\hline M A & 41,9263229 & $<0,01$ \\
\hline M B & 10,5744801 & 0,004 \\
\hline G A & 7,64373493 & 0,012 \\
\hline G B & 0,19020149 & 0,667 \\
\hline
\end{tabular}

\section{Factor: SITIO; Variable: CONT HIDRICO}

\begin{tabular}{c|cc} 
NOV'12 & F & p-level \\
\hline Ast A & 17,075 & 0,0006 \\
\hline Ast B & 19,153 & 0,0003 \\
\hline Sph A & 1,337 & 0,262 \\
\hline Sph B & 3,711 & 0,069 \\
\hline
\end{tabular}




\section{ANEXOS}

ANEXO 5. Tablas con valores de F y p para los análisis de varianza (ANOVA) realizados para testear la influencia de los factores 'cobertura' (tabla A) y 'sitio' (tabla B) en los valores medios de CONTENIDO DE CARBONO calculados para las muestras tomadas en febrero 2012 y en 4 tipos diferentes de parcelas ( $\mathrm{M}$ Ast: parcela ubicada en Moat y cubierta por Astelia; M Sph: ubicada en Moat y cubierta por Sphagnum; G Ast: en Garibaldi y con Astelia; G Sph: en Garibaldi y con Sphagnum). (En rojo: valores signifcativos de p)

\section{A. Factor: COBERTURA; Variable: CARBONO}

\begin{tabular}{|c|c|c|}
\hline FEB'12 & F & p-tevel \\
\hline Moat & 0,85 & 0,454 \\
\hline Garibaldi & 1,001 & 0,330 \\
\hline
\end{tabular}

\section{B. Factor: SITIO; Variable: CARBONO}

\begin{tabular}{c|c|c} 
FEB'12 & F & p-level \\
\hline Ast & 212,374 & $<0,01$ \\
\hline Sph & 86,146 & $<0,01$ \\
\hline
\end{tabular}

ANEXO 6. Tablas con valores de F y p para los análisis de varianza (ANOVA) realizados para testear la influencia de los factores 'cobertura' (tabla A) y 'sitio' (tabla B) en los valores medios de CONTENIDO DE CARBONO calculados para las muestras tomadas en noviembre 2012 y en 4 tipos diferentes de parcelas ( $\mathrm{M}$ Ast: parcela ubicada en Moat y cubierta por Astelia; M Sph: ubicada en Moat y cubierta por Sphagnum; G Ast: en Garibaldi y con Astelia; G Sph: en Garibaldi y con Sphagnum). (En rojo: valores signifcativos de p)

Factor: COBERTURA; Variable: CARBONO

\begin{tabular}{c|cc}
\hline FEB'12 & $F$ & p-level \\
\hline Moat & 0,4854 & 0,4949 \\
\hline Garibaldi & 0,1508 & 0,7023 \\
\hline
\end{tabular}




\section{Factor: SITIO; Variable: CARBONO}

\begin{tabular}{|c|c|c|}
\hline FEB'12 & $F$ & p-level \\
\hline Ast & 79,289 & $<0,01$ \\
\hline Sph & 77,363 & $<0,01$ \\
\hline
\end{tabular}

ANEXO 7. Tablas con valores de F y p para los análisis de varianza (ANOVA) realizados para testear la influencia de los factores 'profundidad' (tabla A), 'cobertura' (tabla B) y 'sitio' (tabla C) en los valores medios de CONTENIDO DE NITRÓGENO calculados para las muestras tomadas en febrero 2012 y en 4 tipos diferentes de parcelas ( $\mathrm{M}$ Ast: parcela ubicada en Moat y cubierta por Astelia; M Sph: ubicada en Moat y cubierta por Sphagnum; G Ast: en Garibaldi y con Astelia; G Sph: en Garibaldi y con Sphagnum). (En rojo: valores signifcativos de $\mathrm{p}$ )

\section{A. ANOVA - Factor: PROFUNDIDAD; Variable: NITRÓGENO}

\begin{tabular}{ccc} 
FEB'12 & F & p-level \\
\hline M Ast & 0,822 & 0,376 \\
\hline M Spha & 0,532 & 0,475 \\
\hline G Ast & 1,733 & 0,205 \\
\hline G Sph & 9,951 & 0,005 \\
\hline
\end{tabular}


B. ANOVA - Factor: COBERTURA; Variable: NITRÓGENO

\begin{tabular}{ccc}
\hline FEB'12 & F & p-level \\
\hline M A & 2,162 & 0,159 \\
\hline M B & 6,829 & 0,018 \\
\hline G A & 18,184 & $<0,01$ \\
\hline G B & 1,050 & 0,319 \\
\hline
\end{tabular}

\section{ANOVA - Factor: SITIO; Variable: NITRÓGENO}

\begin{tabular}{ccc} 
FEB'12 & F & p-level \\
\hline Ast A & 7,783 & 0,012 \\
\hline Ast B & 10,017 & 0,005 \\
\hline Sph A & 0,181 & 0,675 \\
\hline Sph B & 11,457 & 0,003 \\
\hline
\end{tabular}

ANEXO 8. Tablas con valores de $\mathrm{F}$ y $\mathrm{p}$ para los análisis de varianza (ANOVA) realizados para testear la influencia de los factores 'profundidad' (tabla A), 'cobertura' (tabla B) y 'sitio' (tabla C) en los valores de CONTENIDO DE NITRÓGENO calculados para las muestras tomadas en noviembre 2012 y en 4 tipos diferentes de parcelas (M Ast: parcela ubicada en Moat y cubierta por Astelia; M Sph: ubicada en Moat y cubierta por Sphagnum; G Ast: en Garibaldi y con Astelia; G Sph: en Garibaldi y con Sphagnum). (En rojo: valores signifcativos de $\mathrm{p}$ )

\section{A. ANOVA - Factor: PROFUNDIDAD; Variable: NITRÓGENO}

\begin{tabular}{|c|ll}
\hline NOV'12 & \multicolumn{1}{c}{ F } & p-level \\
\hline M Ast & 2,166 & 0,158 \\
\hline M Spha & 1,134 & 0,301 \\
\hline G Ast & 2,388 & 0,140 \\
\hline
\end{tabular}




\section{B. ANOVA - Factor: COBERTURA; Variable: NITRÓGENO}

\begin{tabular}{c|cl}
\hline NOV'12 & F & p-level \\
\hline M A & 2,678 & 0,119 \\
\hline M B & 1,320 & 0,266 \\
\hline G A & 6,594 & 0,019 \\
\hline G B & 1,080 & 0,312 \\
\hline
\end{tabular}

\section{ANOVA - Factor: SITIO; Variable: NITRÓGENO}

\begin{tabular}{c|cl} 
NOV'12 & F & p-level \\
\hline Ast A & 21,242 & 0,0002 \\
\hline Ast B & 2,678 & 0,119 \\
\hline Sph A & 7,105 & 0,016 \\
\hline Sph B & 43,406 & $<0,01$ \\
\hline
\end{tabular}

ANEXO 9. Tablas con valores de $\mathrm{F}$ y $\mathrm{p}$ para los análisis de varianza (ANOVA) realizados para testear la influencia de los factores 'profundidad' (tabla A), 'sitio' (tabla B) y 'cobertura' (tabla C) en los valores del ÍNDICE DE DIVERSIDAD DE SHANNON-WIENER ( $\left.\mathrm{H}^{\prime}\right)$ calculados para las muestras tomadas en febrero 2012 y en 4 tipos diferentes de parcelas (M Ast: parcela ubicada en Moat y cubierta por Astelia; M Sph: ubicada en Moat y cubierta por Sphagnum; G Ast: en Garibaldi y con Astelia; G Sph: en Garibaldi y con Sphagnum). 


\section{ANOVA - Factor: PROFUNDIDAD; Variable: ÍNDICE DE S-W}

\begin{tabular}{c|cl}
\hline FEB'12 & F & p-level \\
\hline M Ast & 0,75 & 0,420 \\
\hline M Spha & 0,063 & 0,806 \\
\hline G Ast & 0,084 & 0,775 \\
\hline G Sph & 0,142 & 0,711 \\
\hline
\end{tabular}

\section{ANOVA - Factor: SITIO; Variable: ÍNDICE DE S-W}

\begin{tabular}{c|cc}
\hline FEB'12 & F & p-level \\
\hline Ast A & 3,048 & 0,098 \\
\hline Ast B & 0,708 & 0,415 \\
\hline Sph A & 1,291 & 0,275 \\
\hline Sph B & 2,346 & 0,148 \\
\hline
\end{tabular}

\section{ANOVA - Factor: COBERTURA; Variable: ÍNDICE DE S-W}

\begin{tabular}{c|cl}
\hline FEB'12 & F & p-level \\
\hline M A & 0,775 & 0.393 \\
\hline M B & 3,146 & 0,110 \\
\hline G A & 1,724 & 0,207 \\
\hline G B & 1,206 & 0,287 \\
\hline \hline
\end{tabular}

ANEXO 10. Tablas con valores de $\mathrm{F}$ y $\mathrm{p}$ para los análisis de varianza (ANOVA) realizados para testear la influencia de los factores 'profundidad' (tabla A), 'sitio' (tabla B) y 'cobertura' (tabla C) en los valores de RIQUEZA ESPECÍFICA (S) calculados para las muestras tomadas en febrero 2012 y en 4 tipos diferentes de parcelas (M Ast: parcela ubicada en Moat y cubierta por Astelia; M Sph: ubicada en Moat y cubierta por Sphagnum; G Ast: en Garibaldi y con Astelia; G Sph: en Garibaldi y con Sphagnum). 


\section{ANOVA - Factor: PROFUNDIDAD; Variable: RIQUEZA ESPECÍFICA}

\begin{tabular}{c|cc}
\hline FEB'12 & F & p-level \\
\hline M Ast & 0,310 & 0,587 \\
\hline M Spha & 2,031 & 0,182 \\
\hline G Ast & 3,082 & 0,096 \\
\hline G Sph & 3,757 & 0,069 \\
\hline
\end{tabular}

\section{ANOVA - Factor: SITIO; Variable: RIQUEZA ESPECÍFICA}

\begin{tabular}{c|cc}
\hline FEB'12 & F & p-level \\
\hline Ast A & 0,529 & 0,476 \\
\hline Ast B & 1,776 & 0,206 \\
\hline Sph A & 0,074 & 0,789 \\
\hline Sph B & 6,000 & 0,028 \\
\hline
\end{tabular}

ANOVA - Factor: COBERTURA; Variable: RIQUEZA ESPECÍFICA

\begin{tabular}{c|cl}
\hline FEB'12 & F & p-level \\
\hline M A & 1,047 & 0,322 \\
\hline M B & 3,273 & 0,104 \\
\hline G A & 0,643 & 0,434 \\
\hline G B & 0,086 & 0,773 \\
\hline
\end{tabular}

ANEXO 11. Tablas con valores de $F$ y $p$ para los análisis de varianza (ANOVA) realizados para testear la influencia de los factores 'profundidad' (tabla A), 'sitio' (tabla B) y 'cobertura' (tabla C) en los valores del ÍNDICE DE DIVERSIDAD DE SHANNON-WIENER ( $\left.\mathrm{H}^{\prime}\right)$ calculados para las muestras tomadas en noviembre 2012 y en 4 tipos diferentes de parcelas ( $M$ Ast: parcela ubicada en Moat y 
cubierta por Astelia; M Sph: ubicada en Moat y cubierta por Sphagnum; G Ast: en Garibaldi y con Astelia; G Sph: en Garibaldi y con Sphagnum).

\section{A. ANOVA - Factor: PROFUNDIDAD; Variable: ÍNDICE DE S-W}

\begin{tabular}{ccc}
\hline NOV'12 & F & p-level \\
\hline M Ast & 0,019 & 0,892 \\
\hline M Spha & 0,032 & 0,861 \\
\hline G Ast & 0,095 & 0,761 \\
\hline G Sph & 0,048 & 0,829 \\
\hline
\end{tabular}

\section{B. ANOVA - Factor: SITIO; Variable: ÍNDICE DE S-W}

\begin{tabular}{c|cc}
\hline NOV'12 & F & p-level \\
\hline M Ast & 0,060 & 0,809 \\
\hline M Spha & 0,047 & 0,830 \\
\hline G Ast & 0,309 & 0,586 \\
\hline G Sph & 0,868 & 0,365 \\
\hline
\end{tabular}

\section{ANOVA - Factor: COBERTURA; Variable: ÍNDICE DE S-W}

\begin{tabular}{c|cl}
\hline NOV'12 & F & p-level \\
\hline M Ast & 0,273 & 0,608 \\
\hline M Spha & 0,616 & 0,443 \\
\hline G Ast & 0,020 & 0,891 \\
\hline G Sph & 0,002 & 0,962 \\
\hline
\end{tabular}

ANEXO 12. Tablas con valores de $F$ y $p$ para los análisis de varianza (ANOVA) realizados para testear la influencia de los factores 'profundidad' (tabla A), 'sitio' (tabla B) y 'cobertura' (tabla C) en los valores de RIQUEZA ESPECÍFICA (S) calculados para las muestras tomadas en noviembre 
2012 y en 4 tipos diferentes de parcelas (M Ast: parcela ubicada en Moat y cubierta por Astelia; M Sph: ubicada en Moat y cubierta por Sphagnum; G Ast: en Garibaldi y con Astelia; G Sph: en Garibaldi y con Sphagnum).

\begin{tabular}{|ccc}
$\begin{array}{c}\text { A. ANOVA - Factor: PROFUNDIDAD; Variable: RIQUEZA } \\
\text { ESPECÍFICA }\end{array}$ & p-level \\
\hline NOV'12 & F & 1,000 \\
\hline M Ast & 0,000 & 0,755 \\
\hline M Spha & 0,100 & 0,821 \\
\hline G Ast & 0,053 & 0,783 \\
\hline G Sph & 0,078 & \\
\hline
\end{tabular}

\section{B. ANOVA - Factor: SITIO; Variable: RIQUEZA ESPECÍFICA}

\begin{tabular}{|c|c|c|}
\hline NOV'12 & $\mathrm{F}$ & p-level \\
\hline M Ast & 0,0004 & 0,985 \\
\hline M Spha & 0,036 & 0,851 \\
\hline G Ast & 0,049 & 0,827 \\
\hline G Sph & 0,151 & 0,703 \\
\hline
\end{tabular}

C. ANOVA - Factor: COBERTURA; Variable: RIQUEZA ESPECÍFICA

\begin{tabular}{ccc}
\hline NOV'12 & F & p-level \\
\hline M Ast & 0,101 & 0,755 \\
\hline M Spha & 0,0003 & 0,987 \\
\hline G Ast & 0,340 & 0,569 \\
\hline G Sph & 0,060 & 0,809 \\
\hline
\end{tabular}

